\title{
Self-regulation in English language learning: Case studies of six Malaysian undergraduates
}

\author{
By
}

Azizah Binti Mohd Zahidi

A thesis

submitted to the Victoria University of Wellington in fulfilment of the requirements for the degree of Doctor of Philosophy

in Education

Victoria University of Wellington

2012 


\begin{abstract}
This study employed a qualitative design involving multiple case studies to explore how six English Language learners used self-regulated learning (SRL) strategies to complete language learning tasks and cope with the challenges of learning and using English as a second language. The case studies of the English language learners provided a detailed description of self-regulation among tertiary level students in Malaysia. This study explored the personal and contextual factors that might act as facilitators and constraints of the participants' self-regulation. This study is underpinned by a social cognitive theory of self-regulation as a conceptual and theoretical framework. The primary data sources of this study were multiple interviews with the learners over a semester and interviews with three language instructors. Course documents and assignments, students' reflective diaries, and notes on observations were additional data sources. Thematic analysis of the data indicated that the six English language learners used SRL strategies in unique and varying degrees, within their Academic Communication course and in the university context. Findings from the study suggest that personal and environmental factors influence the self-regulated learning strategies used in language learning. Implications for language teachers at the tertiary level were identified and discussed.
\end{abstract}




\section{Acknowledgements}

\section{Ehara taku toa, he taki tahi, he toa taki tini}

(My success should not be bestowed onto me alone, as it was not individual success but success of a collective)

I dedicate this dissertation to my mother, late father, husband, children, sisters, brothers, nieces and nephews. Their belief in my ability, support, and understanding have given me the persistence and endurance necessary to achieve my goal. This research experience has made me grow intellectually and become stronger emotionally and mentally.

To my husband, Azam and two children, Alya and Alif who have stood by me and given me full support throughout the three years in Wellington, I really am in your debt. To my son, Iman who is independent, courageous and looks after himself well and keeps on reassuring mama to focus on her thesis, you give me the strength to keep on being motivated and persistent.

I am greatly indebted to my primary supervisor, Dr Stephanie Doyle, whose critical comments, guidelines and encouragement have given me the motivation and strength throughout this PhD journey. Equally, and no less important in any means, is my secondary supervisor, Dr Carolyn Tait, whose care, understanding, assistance and constructive feedback have helped me through the phases of this dissertation.

I would like to thank the Malaysian Ministry of Higher Education and National University of Malaysia for awarding me the scholarship and study leave necessary to do my PhD studies. Their trust is greatly appreciated.

I am particularly grateful to the research grant committee of the Faculty of Education, Victoria University of Wellington, for awarding me the grant for conducting the fieldwork in Malaysia and the travel grant to present my research at two international conferences. I learnt a lot from other presenters. I also managed to form relationships with other researchers and academics from other 
universities. I am also indebted to PGSA and Malay Chair Studies, VUW for awarding me travel grants to present my research findings at national and international conferences.

I must express my gratitude to the staff at Student Learning Support and WJS library for the assistance; especially to Nicola and Matthew for being patient in solving my Endnote glitches.

I am also thankful to the participants and other people who have helped in this research, who gave me their time and provided me with a rich and varied data, which has made the research findings all the more interesting.

To dear friends in New Zealand, thanks for the laughter, worries, food and fun trips shared. These people made this journey more bearable and provided the motivation and strength to keep on writing and revising. Thank you too to the members of the Language Education Cohort, especially to Margaret and Carolyn. It was encouraging to share with those who have similar concerns about issues related to language teaching and learning in our specific context. To my dear friends at the postgraduate house at 31 Campbell Street, Karori, thanks a lot for the encouragement, worries, laughter, and lunches shared.

I also would like to thank my trusted friends, Mas, Kak Liza and Siti for being true friends. True friends are not those who tell us what we 'want' to hear but rather what we 'need' to hear.

Finally, thanks to myself, who kept on being persistent no matter how hard the journey was, even though there were times when the journey was not smooth and I was searching for a light to show me the way forward.

\section{Kaua e mate wheke mate ururoa}

(Success can be measured not only in achievements, but in lessons learned, lives touched and moments shared along the way) 


\section{Table of Contents}

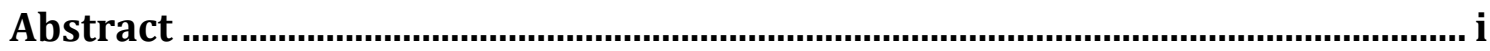

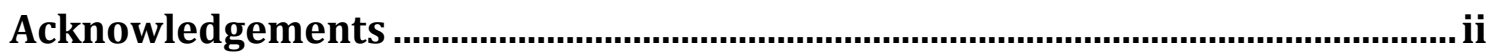

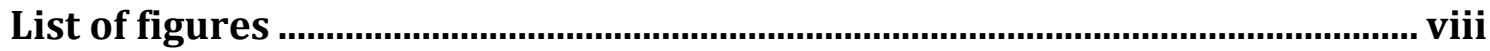

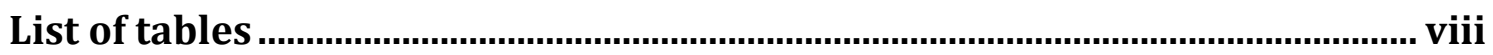

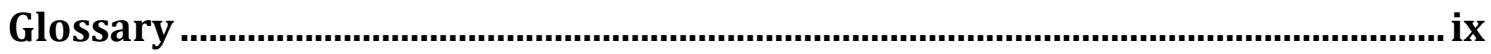

CHAPTER ONE: Introduction ............................................................................. - 1 -

Background to the language context in Malaysia.............................................................. - 4 -

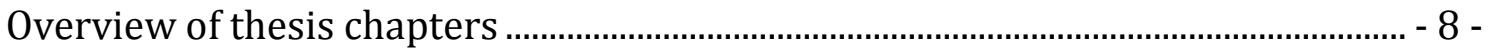

CHAPTER TWO: Review of Literature ………................................................... - 9 -

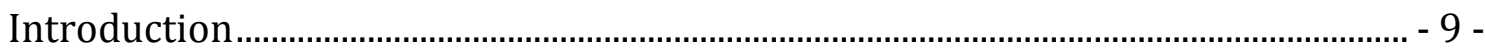

English language teaching and learning in Malaysia ....................................................... - 9 -

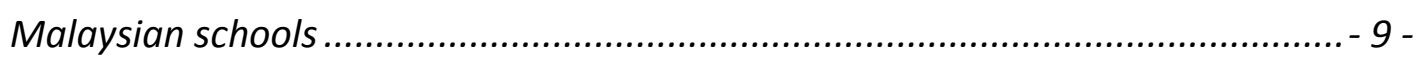

Malaysian universities................................................................................... 12 -

Self-regulated learning ..................................................................................................... 14

Definitions .............................................................................................. 14

Relationship between self-regulated learning with autonomy ............................ 16 -

Components ................................................................................................ 17 -

Learning strategies...................................................................................... 31 -

Self-regulated learning and academic achievement at university.............................. - 34 -

Self-regulation in language learning .............................................................................- 38 -

Cultural influences on self-regulation .......................................................................- 43 -

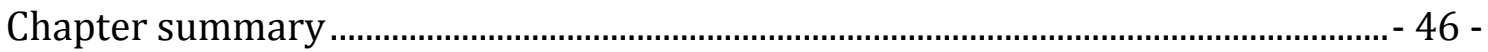

CHAPTER THREE: Theoretical Framework

Introduction................................................................................................................ 48 -

A social cognitive theory of self-regulation .................................................................- 48 -

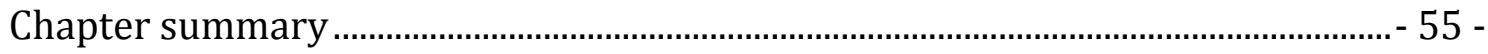

CHAPTER FOUR: Methodology ........................................................................... 57 -

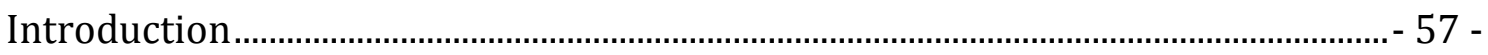

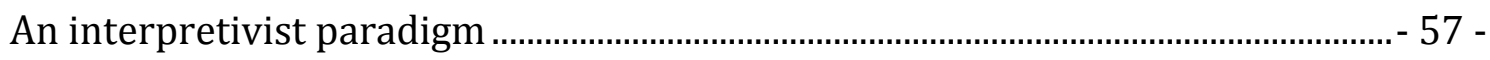

Qualitative research........................................................................................................ 58 -

Case study research design..........................................................................................- 60 -

Interpretive case study ................................................................................ 61 -

Research questions ............................................................................................................- 62 -

The research context ....................................................................................................... 63 -

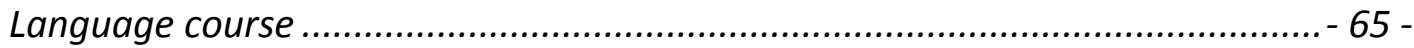




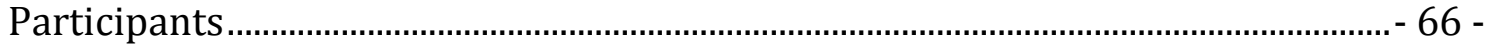

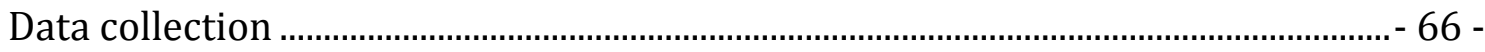

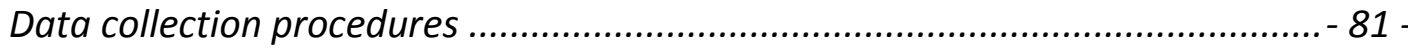

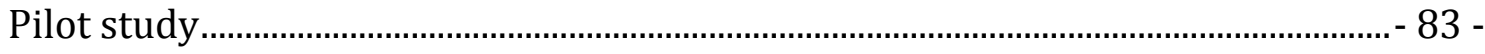

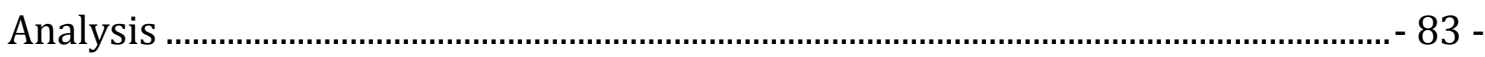

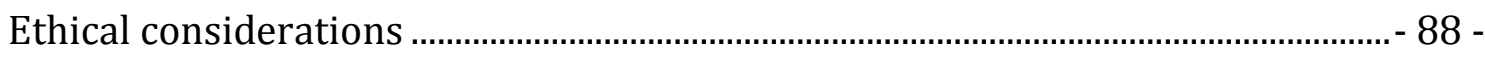

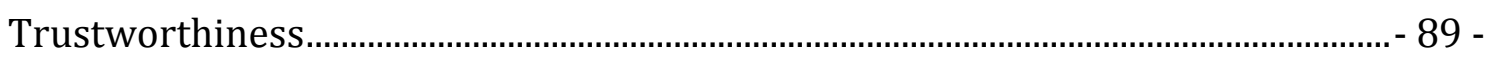

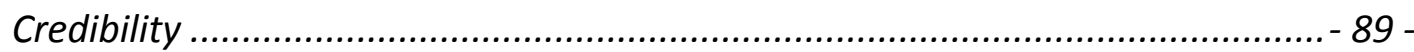

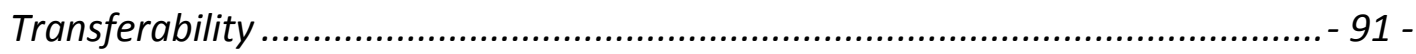

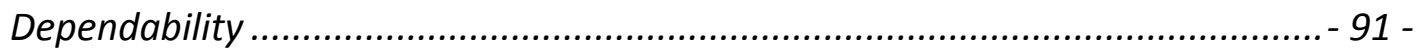

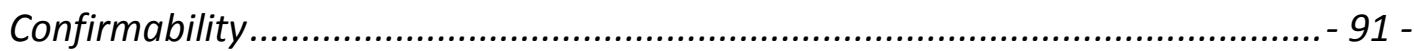

The researcher's role …............................................................................................. 92 -

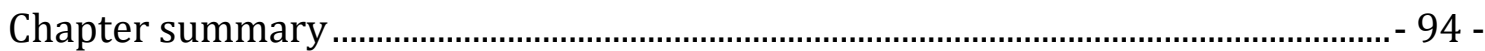

CHAPTER FIVE: Case Studies of Six Learners .................................................... 96 -

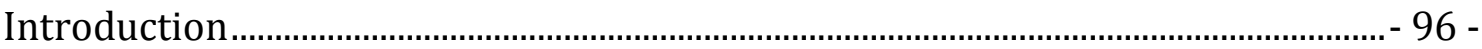

Learner one-Sepatu Chenta ........................................................................................... 96

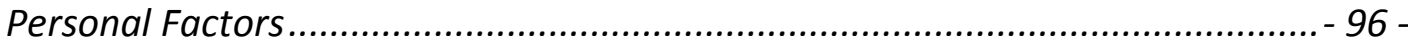

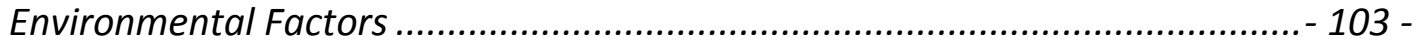

Behaviour - Self-regulated learning strategies ............................................. 106 -

Learner two-Rae ........................................................................................................... 118

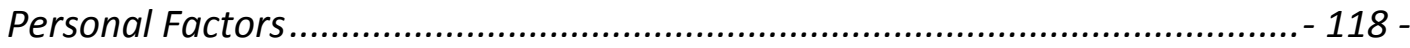

Environmental Factors .......................................................................... 124 -

Behaviour - Self-regulated learning strategies ............................................. 129 -

Learner three-Stanza Nurmalam................................................................................. - 144 -

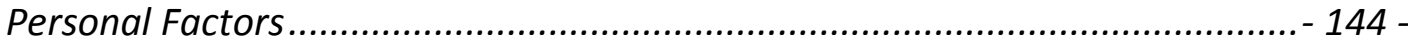

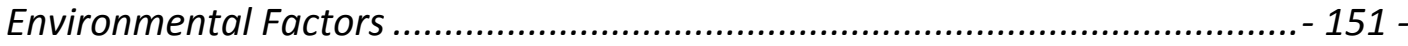

Behaviour - Self-regulated learning strategies ............................................ 153 -

Learner four-Ares Mark 111 ........................................................................................ 166 -

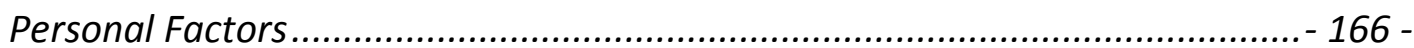

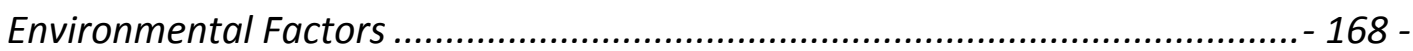

Behaviour - regulated learning strategies .................................................... 170 -

Learner five-Confidence Hero .................................................................................. - 176 -

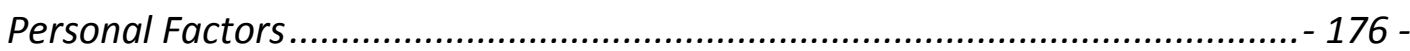

Environmental Factors ........................................................................ 178

Behaviour - Self-regulated learning strategies ............................................. 184 -

Learner six-Unblocker ..................................................................................................... - 188 -

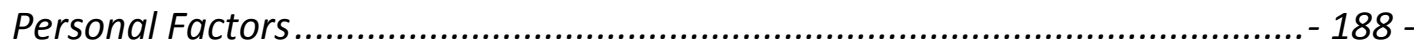


Behaviour - Self-regulated learning strategies ............................................ 195 -

Chapter summary ..................................................................................................... 200 -

CHAPTER SIX: Cross-Case Analysis …….......................................................... - 201 -

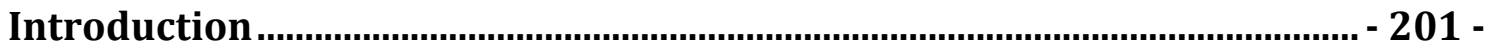

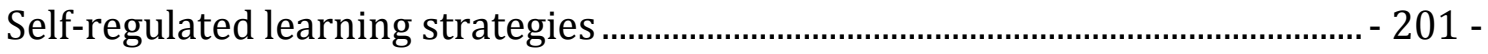

Cognitive and metacognitive ..................................................................... 202 -

Resource management .......................................................................... 210 -

Managing emotion..................................................................................... 214 -

Motivational influences................................................................................................... 216 -

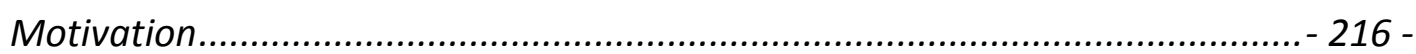

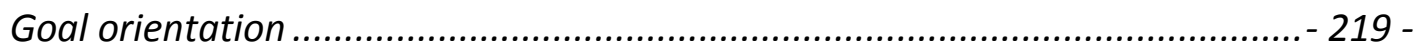

Language learning beliefs ........................................................................ 221 -

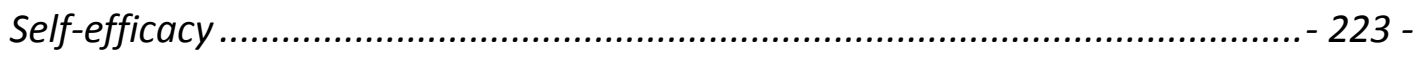

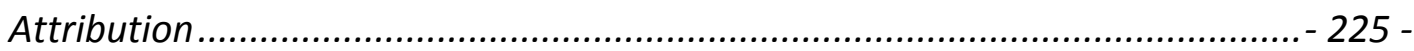

Environmental influences ..................................................................................... - 226 -

The university environment..................................................................... 226 -

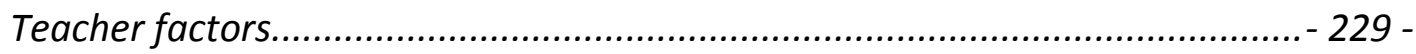

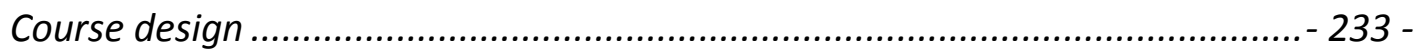

The nature of self -regulation ................................................................................... - 236 -

The reciprocal relationship of the interdependent factors in self-regulation ....- 236 -

Categorisation of the participants' self-regulation ......................................... 237 -

Self-regulation and course grades ............................................................................ - 238 -

Differences in SRL strategy use............................................................................ - 240 -

Chapter summary ......................................................................................................... 241 -

CHAPTER SEVEN: Conclusion ............................................................................ 242 -

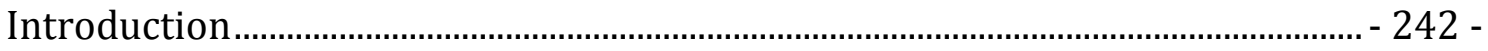

Summary of the research.......................................................................................... 242

Summary of research findings..................................................................................... - $243-$

Contributions to the self-regulation field ................................................................ - 250 -

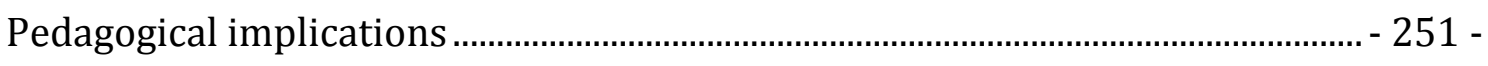

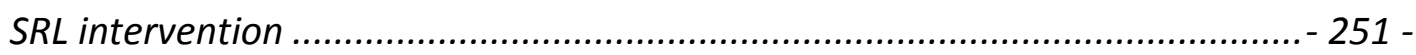

ESL learners' self-efficacy strengthening ..................................................... 252 -

Motivating the learners ....................................................................... 252 -

Attribution retraining ............................................................................... 254 -

Library orientation programme ................................................................ 254 -

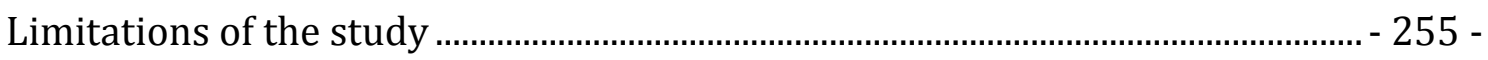


Implications for future research - 256 -

Concluding statement $-258-$

References $260-$

Appendices 279

Appendix A: MUET results 279 -

Appendix B (1): Categories of SRL strategies $-283-$ Appendix B (2): Categories of SRL strategies of Malaysian tertiary level ESL learners. $284-$

Appendix C: Approval letter from the Educational Planning and Research Division (EPRD) of Malaysia to carry out this research $-285-$ Appendix D: Research information sheets and consent forms. - 287 Appendix E: Description of language course - 299 Appendix F: Description of research instruments - 303 Appendix G: Summary of Participants' Personal Background $-308-$ 


\section{List of figures}

Figure 2.1: Summary of the components in self-regulation $-31-$

Figure 3.1: Model of triadic reciprocality. Adapted from Schunk, et al. (2008, p. 127)

Figure 3.2: Phases and sub-processes of self-regulation. Adapted from Zimmerman and Campillo (2003, p. 239) $50-$

Figure 4.1: Process of cross-language interpretation. Adapted from Esposito (2001, p. 571)

Figure 5.1: An illustration of Sepatu's mind-map of his article presentation .. - 111 -

Figure 5.2: Summary of the SRL strategies and factors influencing Sepatu Chenta's self-regulation in language learning

Figure 5.3: A page of Rae's vocabulary book $121-$

Figure 5.4: Rae's notes for her preparation of the information-sharing assessment.

Figure 5.5: Summary of the SRL strategies and factors influencing Rae's selfregulation in language learning $-143-$

Figure 5.6: An example of Stanza's grammatical notes. $-150-$

Figure 5.7: A page of Stanza's vocabulary book $-156-$

Figure 5.8: Summary of the SRL strategies and factors influencing Stanza's self-regulation in language learning.

Figure 5.9: Summary of SRL strategies and factors influencing Ares' selfregulation in language learning.

Figure 5.10: Summary of SRL strategies and factors influencing Confidence Hero's self-regulation in language learning.

Figure 5.11: Summary of SRL strategies and factors influencing Unblocker's self-regulation in language learning.

Figure 6.1: Self and group regulation in socially shared learning. Adapted from Järvelä, et al. (2008, p. 123)

Figure 6.2: Categorisation of the participants' self-regulation. Adapted from Che Musa, et al. (2012, p. 46)

Figure 7.1: The participants' SRL strategies, and motivational and environmental influences on the SRL strategies use. $-245-$

Figure 7.2: Conceptualization of self-regulation that mediate the relations between the person, context, and eventual achievement in language learning.

Figure 7.3: Contribution of both effort and self-efficacy in academic success in Malaysian educational context.

\section{List of tables}

Table 4.1: Number of interviews with the participants............................................. 68 -

Table 4.2: Number of classroom observations and the stimulated recalls conducted 
Table 4.3: Log of activities during the data collection and analysis processes..

\section{Glossary}

Bumiputera are Indigenous people of Malaysia like the Malays and people in Sabah and Sarawak like the Kadazans and Bidayuh.

KBSM (Kurikulum Baru Sekolah Menengah) is a new curriculum for Malaysian secondary schools.

MUET (Malaysian University Entrance Test) is a test of English language proficiency, used for Malaysian public university and college admissions.

PMR (Penilaian Menengah Rendah) is a standardized examination for all lower secondary school students taken at the age of 15 years old or in Form 3.

\section{Sijil Pelajaran Malaysia (SPM) Examination/Malaysian Certificate of} Examination (MCE) is a national standardized examination for all high school students taken at the end of their high school years at the age of 17 years old or in Form 5/fifth-year secondary school students. 


\section{CHAPTER ONE: Introduction}

This thesis provides a rich description of the self-regulatory behaviours of six tertiary level learners studying English at a public university in Malaysia. In addition, this thesis considers contextual factors that influence their use of selfregulatory strategies, such as the learners' motivational beliefs and social support from peers and language teachers.

I am aware of individual language learning differences from my experience of being a learner and teacher of English as a Second Language (ESL). I have observed that some of my students seem to learn English easily and others face difficulties, and understanding the way in which learners differ from one another is of major concern to me as a teacher. In an effort to make the language learning experience as successful as possible, language teachers have to look for concrete ways to assist their students by empowering them to take responsibility and to manage their own learning. Much of the accomplishment in language learning rests with individual students and their capability to take advantage of every opportunity to learn. Rubin and Thompson (1982, p. 3) emphasize the role of the language learner in the success of their learning: "You, the language learner are the most important factor in the language learning process". My belief that language learners' active participation plays a key role in their learning is what motivates me to conduct this research.

A common learning problem among Malaysian ESL learners is that they do not know "how" to learn to improve their command of the English language. It seems that the 'how' question of learning English still poses a problem to these learners, despite them being at a tertiary level and having been taught English for at least 11 years of their schooling experience (Mohd Noor, 2006). Montalvo and Torres (2004) stated that research on self-regulation enables a better understanding of factors involved in the teaching-learning process. From this, educators can develop ways to reduce students' difficulties in learning that arise from their lack of awareness and control over learning. This may be especially useful for many Malaysian undergraduates who come directly from high school, where a 'spoon feeding' mentality is still very much ingrained in them. 
Previous studies support the importance of self-regulated learning by linking it to positive educational outcomes and desirable characteristics (Lai \& Gu, 2011; Nota, Soresi, \& Zimmerman, 2004; Whipp \& Chiarelli, 2004). These studies suggest that self-regulated students have the following characteristics: they are familiar with and know how to use a series of cognitive strategies that help them to attend to, transform, organize, elaborate and recover information; they know how to plan, control and direct their mental processes towards the achievement of personal goals; they show motivational beliefs and adaptive emotions, and the capacity to control and modify these to the requirements of the task and specific learning situation; they plan and control the time and effort for task completion; they create favourable learning environments; they practise help-seeking; they show efforts to participate in the control and regulation of academic tasks, and the classroom climate and structure; and they are able to use volitional strategies to avoid external and internal distractions in maintaining effort for task completion. These characteristics have been linked to success in and beyond school. However, there is scarcity of research in this area in the context of English language learning by Malaysian students. There is an increasing need for developing students' self-regulatory strategies and self-regulatory systems (Zimmerman, Bonner, \& Kovach, 2006), and also for researching self-regulated learning (SRL) among Malaysian tertiary level students (Mohd Kosnin, 2007).

There is potential to improve teaching by focusing on how learners conduct learning tasks as they learn a second language (Noels, 2005). One of the ways to empower students in managing their language learning is through equipping them with SRL strategies. However, before this can happen, teachers have to gain an understanding of students' learning processes. This need to gain a better understanding was what motivated me to begin this research. In the university where I undertook my research, the English language classes are held twice a week for twelve weeks. This is not sufficient to equip the undergraduates with the English language skills they will need for employment or postgraduate education. Thus, it is important that English language courses develop the skills, knowledge and attitudes learners need if they are to take greater responsibility for their own learning. Learning and using English in the Malaysian context, where English can be either ESL (English as a Second Language) or EFL (English 
as a Foreign Language), requires learners to be proactive in their own learning process (Embi \& Mohd Amin, 2010).

Reflecting on my own experiences as an English language learner, I am aware of the contextual influences on an individual learner's ability to manage their language learning. Breen (2001, p. 1) suggests that an adequate explanation of how a learner learns another language must take into account four important variables:

what the learners contribute to the process; the language data made available to the learners in the communicative environment in which the learning occurs; the interaction between learners and environment in terms of situated learning process; and the actual outcomes from the learning.

The learner contribution to the language learning process includes learner aptitude, beliefs, motivation, learner strategies, and personality (Cohen \& Macaro, 2007; Dörnyei, 2005, 2009; Ellis, 2008). In addition, studies have provided evidence of the role of language learners' self-regulation in tertiary level language learning (Bown, 2009; Gan, Humphreys, \& Hamp-Lyons, 2004; Gao, 2010; Rivers, 2001). Two of these studies investigated how mainland Chinese learners of English as a foreign language carried out their out-of-class English learning (Gan, et al., 2004) and explored mainland Chinese students' language learning experiences with a focus on their shifting strategy use prior to and after their arrival in an English-medium university in Hong Kong (Gao, 2010). Bown's (2009) and Rivers' (2001) studies investigated learners in a university in the United States of America; however, Bown looked at how students managed their learning of Russian in individualized instruction, whereas Rivers conducted classroom-based research on self-directed language learning behaviours of adults learning Georgian and Kazakh as a third language. The applicability of the results obtained to Malaysian language learners is questionable, as the learning context differs. Little is known about how Malaysian ESL learners at the tertiary level self-regulate their language learning. The current study seeks to contribute to self-regulation research by investigating the self-regulated learning of students in the area of postsecondary education. 
A considerable amount of literature has been published on the complex and dynamic interplay of individual learners' cognition, emotion, social context, and external enablements and constraints on the success in learning a second or foreign language. These studies (Bown, 2009; Gan, et al., 2004; Gao, 2010; Nakata, 2006) suggest that besides individual factors like motivation, influential factors from one's social context like peers, teachers and society play a very important role in the learning process. This finding is what prompted my decision to undertake in-depth case studies to explore the personal and contextual factors that might act as facilitators of or constraints on the participants' self-regulation in this study. A social cognitive perspective of selfregulation is drawn upon in this study.

The qualitative approach adopted for this study makes a methodological contribution to self-regulated learning research in the context of Malaysia. In Malaysia, self-regulatory research is in its infancy; mostly questionnaire-based studies, modelled after the Motivated Strategies for Learning Questionnaire (MSLQ), have been done (see Mohd Kosnin, 2007; Rahman \& Phillips, 2006), and classroom-based qualitative studies are lacking, with the exception of Lee's (2002).

\section{Background to the language context in Malaysia}

The context of English language learning in Malaysia is unique. To understand the present status and setting of the teaching and learning of English in Malaysia, it is necessary to look briefly at the country's historical background, especially in terms of how this has shaped the country's language education policies.

English played an important role as the medium of instruction in the Malaysian education system during British colonisation. After independence in 1957, Bahasa Melayu replaced English and became the official national language. Since then, Bahasa Melayu has been the language of administration used in government offices, and also the medium of instruction at national schools and public universities. English is recognized as the second language and is taught as a compulsory subject in national schools (Pandian, 2002). In addition, English use is common in the business and corporate sectors. 
The population of Malaysia includes three main ethnic groups: Malays, Chinese, and Indians. This is evident in the three types of schools in the Malaysian education system: the Malay medium schools (mainstream schools), the Chinese medium schools, and the Tamil medium schools. In the mainstream schools or national schools (as they are normally called), the language of instruction is Bahasa Melayu, while English is learnt as a second language subject. In the Chinese and Tamil schools, Mandarin and Tamil are the mediums of instruction, with Bahasa Melayu and English as required subjects that students must learn.

English language policy in Malaysia has undergone a series of shifts. Malaysia tried, through its educational system, to impose a national identity by mandating the use of Bahasa Melayu in the national curriculum, only to later reintroduce English as the medium of instruction in the schools and at the tertiary level for maths and science subjects due to economic and political necessity (Hashim, 2009; Ridge, 2004). In 2012, the decline in Malaysian school students' performance in mathematics and science led the government to repeal the requirement for English to be the medium of instruction for the two subjects (Hashim, 2009).

Most Malaysian children study at national schools that use the national language, Bahasa Melayu, as the medium of instruction. The National Language (Bahasa Melayu) policy might be one of the reasons for the decline in the use and standard of English at all levels within the Malaysian education system (Kaur \& Peng, 2000). Students have to learn English from year one (seven years old) to form five (seventeen years old). However, when students enter university, a number of them still lack the English language proficiency required to meet the demands of academic reading, writing and oral communication (Kaur \& Peng, 2000).

As a result of these historical and educational developments in Malaysia, English language learning and its use in Malaysia can be regarded as a mixed situation, where English can be either a second language or a foreign language. A proportion of the society is bilingual or multilingual, maintaining their first language (L1) for use in the home and other domains (Ridge, 2004). English is used for communicating with speakers of other languages and for official 
purposes in various institutions and education. However, there are geographical influences, with vast differences between urban and rural learners' language proficiency (Darus, 2010). Currently, English is taught as a second language in Malaysia but it is regarded by some students as a foreign language (Choy \& Troudi, 2006). Unlike an ESL context, where English is used as a means of communication and is learnt through communication in social situations, in an English as a Foreign Language (EFL) context, English has no vital function in people's everyday life and communication, and is only learnt through classroom instruction (Azman, (2009). In such a situation, the learners do not have any immediate need to use English for communication. Hence, the role of English in Malaysia is neither uniformly ESL nor EFL. It is somewhere in-between. The setting of English in Malaysia may be defined as an institutional L2 setting (Siegel, 2003), where English is commonly used in a number of domains and institutions, but is just an additional language for most of the population. Thus, Malaysian students from different life backgrounds differ in the levels of knowledge and English proficiency.

Nakata (2006) suggests that motivation in language learning occurs when learners find that society provides a value and a purpose for language learning. Thus in an EFL situation like in the rural areas of Malaysia, where there is lack of a conducive environment for language acquisition and learners are separated "logistically and psychologically from the target language" (Nakata, 2006, p. 19), learners may be less motivated. This scenario of a lack of opportunity for real life communication in English may be one of the factors that contribute to the lack of proficiency among Malaysian tertiary level learners, even though they have learnt English since their primary years.

Admission to tertiary education in Malaysia is selective, based on academic merit including passing a test in English. However, the English language ability of entrants varies (Refer to Graph 1 and 2 in Appendix A). Most of the students scored below the satisfactory level in English competency. Even though they have been learning English since their primary years, a majority of these students are still not competent in English, especially in spoken ability (Shakir, 2009). This affects undergraduates in two ways. Firstly, Malaysian universities require students to successfully pass English as a second language (ESL) courses before 
graduation. ESL grades are included in the students' cumulative grade point average (CGPA). Thus, a low English grade will affect the end of semester result. Secondly, as the teaching of scientific and mathematical courses is in English, undergraduates with limited proficiency in English struggle to comprehend lectures, read English texts and to write assignments. This affects their academic achievement and later employment. Poor command of English has been found to be an impediment to Malaysian graduates' employment (Quek, 2005). It is imperative to upgrade the level of mastery of the language among undergraduates if they are to secure employment and compete in a globalised world (Shankar, 2003).

The importance of the English language for tertiary level learners in Malaysia at present and in the future is clearly evident. In this regard, studies designed to investigate the self-regulated learning strategies employed by tertiary level learners learning English in the Malaysian context can play an important part in understanding the language learning process. The understanding of what these learners do in the language learning process and how the strategies they use affect language success is paramount in the effort to assist these learners in learning the English language. 


\section{Overview of thesis chapters}

The remainder of this thesis is comprised of chapters focusing in turn on the literature review, theoretical framework, methodology, findings, cross case analysis, and conclusions.

In Chapter two I present the review of the relevant literature. This chapter provides the justification for the research questions and the methodology adopted for this research. To set up the context of this study, I discuss the issues related to language teaching and learning in the Malaysian context. Relevant literature on self-regulated learning and academic achievement and selfregulation in language learning that contribute to this study are reviewed. This chapter concludes with a justification for research on self-regulation in language learning in other educational and cultural contexts.

Chapter Three presents the social cognitive theory of self-regulation, the theoretical framework of this study.

Chapter Four details the methodology of the research. I argue why a qualitative inquiry is appropriate to address the research questions and I describe the instruments used. The analysis of the data is explained, and ethical issues are addressed. I examine my own position within this study, and the trustworthiness of the research is evaluated.

Chapter Five presents the findings in the form of a case study of each participant. It describes the participants' self-regulation, use of self-regulated learning strategies and the factors that influence their use of the strategies.

Chapter Six discusses the findings by answering the research questions. The findings are compared using a cross-case analysis. This chapter explores the SRL strategies used by the participants and what appears within each learner's data that may have had an effect on self-regulation in language learning.

Chapter Seven summarizes the findings and forms the conclusion of the research findings. Its contributions to the fields of self-regulation study and tertiary level ESL classroom teaching are discussed. The limitations of the study are explained and areas for further research that expand and build upon the findings of this study are suggested. The chapter ends with a concluding statement. 


\section{CHAPTER TWO: Review of Literature}

\section{Introduction}

This research explores learners' self-regulation in learning English as a second language in a Malaysian tertiary institution and focuses on the personal, behavioural and environmental factors that might influence the learner's use of self-regulated learning strategies. This literature review is divided into two parts. Firstly, to set up the context of this study, I will discuss the issues related to language teaching and learning in the context of Malaysia. Secondly, relevant studies on self-regulated learning and academic achievement and self-regulation in language learning are reviewed. This places this study within a wider field of literature on self-regulation and academic achievement. This chapter concludes with a justification for this research on self-regulation, in that it is undertaken in a specific educational and cultural context.

\section{English language teaching and learning in Malaysia}

In order to understand the issues surrounding English language proficiency among Malaysian students, recent studies on English language learning in Malaysian schools and studies on undergraduates' language learning will be reviewed. Studies conducted at schools are pertinent as English language proficiency in Malaysia is generally acquired through schools (Azman, 2009). Students go through a formal, structured process of learning English throughout their eleven years of schooling. Teachers follow the syllabus and curriculum prepared by the Ministry of Education. Standardised textbooks are used and students are assessed in standardized public assessments.

\section{Malaysian schools}

Studies of English language learning indicate a declining ESL proficiency in Malaysia and show dissatisfaction among learners, teachers, policy makers and society regarding the teaching and learning of the language (Hassan \& Fauzee, 2002; Ismail, 2008; Mohamed, Morad, Mohamed Ismail, Omar, \& Abdul Rahman, 2006). There is a growing consensus that the emphasis on national examinations combined with ineffective teaching practices has resulted in low levels of English 
language proficiency among Malaysian English language learners (Pandian, 2002).

The English Language Teaching (ELT) syllabus in Malaysia frequently emphasizes reading and writing skills and neglects oracy skills (listening and speaking) (Ali, 2008). Lessons are taught without considering learners' individual needs (Koo, 2008). Students have little say in or sense of responsibility for their own learning. Classroom teaching is characterized by teacher-centred approaches and the chalk-and-talk drill method (Koo, 2008). A common teaching practice is discussing past national examination questions and rote learning to equip students with examination strategies (Koo, 2008).

Hassan and Fauzee (2002) investigated secondary teachers' perceptions of their classroom practices, the KBSM (New Curriculum for Secondary School), the PMR (standardized examination for all lower secondary school students) examination and their students' language proficiency. Using a mixed-method approach, data were collected from 58 KBSM teachers from the central region of Malaysia. The findings revealed that the KBSM syllabus and the national examination for lower secondary students focused on writing and reading skills with correct grammar required for examinations. Listening and speaking skills were neglected. While this might result in good English grades in the national examination, where reading and writing were emphasised, it limited learners' ability to communicate as speaking skills were not important in the teaching and testing (Ali, Hamid, \& Moni, 2011). The teaching and learning of English is viewed as a school subject, focusing on reading, writing and grammar, without creating connections to language use in real-life situations.

Other studies have confirmed the priority placed on preparing students for national examinations. Koo (2008, p. 56) argues that the discourse of "reproduction of information and privileging examination" dominates Malaysian education levels. She concluded that the importance placed on national examinations in Malaysian schools forced teachers to concentrate on teaching those language skills that were tested, such as writing, reading and grammar, and to neglect the communicative aspects of language teaching and learning. The examination orientation of the Malaysian education system has generally 
produced students who are unable to operate autonomously, presuming that teachers will teach them all they need to know. This does not encourage independent language learning. This dependence on teachers is exacerbated by the importance placed on scoring good grades in examinations (Pandian, 2006). The focus on language structures and the lack of focus on communicative aspects of language has contributed to low levels of ability to use English to communicate and to learn other subjects through English.

There are other factors such as context, motivation and the language learners' attitude towards learning English that could influence English language proficiency and achievement in the Malaysian multicultural and multilingual context. Azman (2009) examines the influence of sociolinguistic factors in why ESL learners in Malaysia are not competent in English. She discusses the significance of understanding sociolinguistics in the diverse, multicultural setting of Malaysia to enhance ESL teachers' awareness of learners' differences. Learners are from communities with diverse language behaviours, cultures, socioeconomic standing and backgrounds. Those from isolated and rural areas might not realize the value of learning English; thus, they do not show high levels of motivation and also find it hard to master this foreign language.

In addition to the influence of environmental factors in language learning and use, learners' attitudes also affect language proficiency (Adnan, 2005). Tiang (2003) found out that the factors responsible for the lack of proficiency among Malaysian ESL learners included the students' family background and their views or attitudes towards the language. English may be a learner's second or third language compared to their mother tongue, be it Bahasa Melayu, Chinese or Tamil.

In a mixed methods study using surveys and interviews in three elite boarding schools for Bumiputera (Indigenous people of Malaysia), Adnan (2005) found that generally Bumiputera Malay students did not use as much English as their teachers wanted them to, and many students within the sample believed that English was both difficult and uninteresting. The students reported that they constantly mixed English and Bahasa Melayu together in single sentences, with a higher percentage of the latter language. Adnan concludes that this might be the 
result of negative attitudes towards English, the people who use English, and the culture connected to the language. A lack of motivation and a poor attitude beginning at secondary school may influence some learners as they continue their study of English at a tertiary level.

Considering the teaching and learning of English of Malaysian language learners in primary and secondary education, their academic literacy in English may not be sufficient for study at university, where most of the reading materials are in English. They may be ill-equipped to meet the challenges they will experience as undergraduates.

\section{Malaysian universities}

Studies on Malaysian undergraduates' attitude to and motivation in learning English show similar results to studies situated in secondary schools. In her paper, Thang (2004) discusses the applicability to Malaysia of Kember's (2000) proposal that all Asian students would be motivated to improve their English language proficiency for the attainment of highly rewarding careers. She concluded that motivating Malaysian English language learners is not a simple task and consideration needs to be paid to other factors that might influence it. Thang concludes that generalising the research findings from Hong Kong's homogenous society to Malaysia's multicultural society may not be valid because there are other dynamics involved which affect the students' language learning motivation. Her interviews with 13 undergraduates at Universiti Kebangsaan Malaysia showed that these Malaysian undergraduates had an awareness of the importance of learning English for future career goals. However, out of the 13 students interviewed, only two reported that they were intrinsically motivated to improve their English. Thang concluded that this might be the result of the context in which their language learning takes place.

Mohd Shah's (2002) study on low achievers at Universiti Kebangsaan Malaysia supports the findings in Thang's (2004) study. The low achievers in her study recognized the need to master English, especially to improve their job prospects. However, they did not display a positive attitude towards learning English and seemed to be uninterested in its cultural aspects. Mohd Shah concludes that this might be the effect of a lack of exposure to English and few chances to use it in 
their current environment. Both studies indicate that although the undergraduates realised the need for fluency in English, they made little effort to improve their proficiency.

A lack of acceptance of the use of English may be one of the factors influencing Malaysian learners' oral proficiency. There still exists a dislike of using English in interpersonal contexts, mainly among Malays who are not competent in English (Lee, 2003). In a study of undergraduates at the National University of Malaysia, Lee found that participants who attempted to use English were labelled as showoffs trying to be like 'the whites'. Hostility towards the use of English exists because it is seen as a remnant of colonialism. English is connected to Christianity, which means that Malays will be seen as not being good Muslims when they use English. Chinese students may also face difficulties. Lee reported that one Chinese interviewee stated that she was labelled as too westernised because she speaks mostly English. Recent findings from Ali et al.'s (2011) case study conducted on a sample of students, educators, and administrators in a public university resonate with Lee's (2003) finding that using English could result in undesirable experiences for some students and dampen their enthusiasm to communicate in English. These findings point to the necessity of considering many factors in learning English in a multicultural society.

The studies reviewed above suggest there are multiple factors that influence Malaysian learners' language learning and use. Thus, qualitative research provides knowledge about the learning process of the ESL learners at Malaysian universities because it enables individual and contextual aspects of learning to be explored. Findings from the above studies show that factors like teaching practices, a focus on national examinations, learners' negative attitude, a nonconducive environment with little English language use in daily communication, low levels of motivation and peer acceptance have caused low achievement among certain students. Further investigation and exploration of the personal and contextual factors of Malaysian language learners' self-regulation provides insight into how tertiary level learners self-regulate their English language learning in a challenging language-learning environment. Self-regulated learning in language learning research has been conducted with learners learning the second language in the target language setting (for example, Wang, 2004) and in 
a foreign language context (for example, Gan et al., 2004). However, very little has been investigated so far in a mixed English language setting such as Malaysia where English is both a second and a foreign language.

The literature on issues surrounding English language teaching and learning in Malaysian schools and universities illustrates the challenges and the complexities of improving English proficiency among Malaysian learners. One common suggestion that emerges from these studies is to deliberate on the social and cultural influences on English language learning (Lee, 2003; Rajadurai, 2010). Mustaffa (2006) calls for better understanding of Malaysian learners' learning styles and processes in order to promote better English language learning. In learning a second or a foreign language, research suggests that it is important that learners receive maximum support from a conducive learning environment as well as adequate, meaningful language experience (Ali, et al., 2011; Hang, 2009; Mohamed, et al., 2006; Segalowitz \& Freed, 2004). As shown in the review of related studies, these elements are currently lacking in the Malaysian education system.

A review of studies on the limited English language proficiency of Malaysian English learners shows multiple individual and contextual factors contributing to low proficiency. Though these findings cannot be generalized to all Malaysian ESL learners, they do characterize many of the learners. This suggests the need for higher levels of self-regulation among Malaysian tertiary level language learners. The next part of the literature review discusses self-regulated learning.

\section{Self-regulated learning}

In the next section, the related fields of research on self-regulated learning and academic achievement and language learning are reviewed. Before examining the literature on self-regulated learning and academic achievement, and selfregulation in language learning, it is essential to first present a definition of selfregulated learning and self-regulated learning strategies.

\section{Definitions}

There are multiple definitions of self-regulation and self-regulated learning. These are multidimensional constructs which are not easy to describe (Dornyei, 
2005). Even the terms and related derivatives investigators employ to label the notion vary (Boeakaerts, Pintrich, \& Zeidner, 2000), ranging from autonomous learning, to self-planned learning or self-education, and self-efficacy (Hiemstra, 2004). Definitions situate self-regulation as an ability or capacity (Lemos, 1999), or as a process (Pintrich, 2000b). Other interpretations incorporate selfregulation as strategies (Pintrich, 1999), or "self-generated thoughts, feelings and actions that are planned and cyclically adapted to the attainment of personal goals" (Zimmerman, 2000a, p. 14). Most SRL theorists agree that these thoughts, feelings and actions have interconnected cognitive, affective, motivational, and behavioural dimensions (Montalvo \& Torres, 2004). Nevertheless, theorists and models depict opposing views on which dimensions they put emphasis on and, thus, what strategies and processes they promote to support academic achievement.

Zimmerman and Schunk (2001a) identified a common conceptualization of selfregulated learning as a psychological construct that describes how learners metacognitively, motivationally, and behaviourally improve their learning and performance. They indicate that self-regulated learners constantly prepare to learn by regulating their own thinking and motivational beliefs as well as managing their resources and the learning environment effectively. In other words, they take ownership of their own learning and do not depend on teachers to provide them with information and constant guidance. For such proactive and independent learning to take place, both willpower and learning skills are required. In general, students who engage in self-regulated learning are familiar with the use of cognitive strategies. For instance, they know how to organise and elaborate on information from reading materials. Such students plan and control their mental processes to ascertain that their actions do not divert them from their academic goals. Positive motivational beliefs, such as a high sense of selfefficacy, contribute towards their persistence when addressing difficult tasks, and their willingness to seek help when needed. Moreover, if the learning environment is less favourable to them, they seek a more conducive learning setting or restructure the existing one in order to optimize their learning outcomes. 
Dörnyei (2005) defined self-regulation in second language learning as "the degree to which individuals are active participants in their own learning" (p. 191). Pintrich's (2000b, p. 453) definition of SRL in academic achievement, on the other hand, is more multifaceted, describing several of the construct's characteristics and building blocks (i.e., phases):

... a general working definition of self-regulated learning is that it is an active, constructive process whereby learners set goals for their learning and then attempt to monitor, regulate, and control their cognition, motivation, and behaviour, guided and constrained by their goals and their contextual features in the environment. These self-regulatory activities can mediate the relationships between individuals and the context, and their overall achievement.

The definition of self-regulation in this study is drawn from the literature of selfregulation in general academic achievement and second language learning. Selfregulated learning for second language learners refers to the process during which L2 learners proactively use strategies to improve a specific English language skill by managing their language learning activities in order to achieve language learning goals (Oxford \& Shchramm, 2007; Zimmerman, 2002b). For example, second language learners apply cognitive strategies (methods for utilizing mental resources) to acquire vocabulary and metacognitive strategies (knowledge which allows learners to control their cognition) to manage their learning environment (Oxford \& Shchramm, 2007).

Thus, the operational definition of self-regulation in language learning in this study refers to the degree to which individuals are dynamic participants in their own learning and includes factors such as cognition, metacognition, motivation, behavioural and environmental variables used by learners to promote their own language learning.

\section{Relationship between self-regulated learning with autonomy}

Zimmerman (1998, p. 1) indicates that self-regulated learners "are distinguished by their view of academic learning as something they do for themselves rather than as something that is done to or for them". Little $(2007$, p. 14) states that "learner 
autonomy now seemed to be a matter of learners doing things not necessarily on their own but for themselves". Little further argues that the essence of learner autonomy is the ability to take charge of one's own learning. Similarly, selfregulated learning is viewed as an activity that students do for themselves in a proactive way rather than as a covert event that happens to them resulted from teaching (Zimmerman, 2002b). Thus, learners' ability to perform actions for themselves and their proactive learning are what link the two fields. According to Leaver (2009) SRL is an umbrella concept which might result in a person who autonomously learns at different levels. In this sense it would be logical to argue that SRL is connected to learner autonomy where learner autonomy depends on effective self-regulation.

\section{Components}

Self-regulation has been described as a triadic reciprocality in which there are three interdependent components: behavior, environment and self (Zimmerman, 1989b). The three components are not weighted equally, and one or more of the components may function as the main factor at any given time. Schunk (2009) contends that students' self-regulation is not determined only by personal factors. These factors are influenced by environmental and behavioural events in an interdependent interaction. Bandura (1986) saw this interdependence as important. For instance, he saw personal factors (e.g., motivation) being shaped by the environment, and coming into play to shape the environment.

\section{Behavioural components of self-regulation}

To be self-regulated, individuals need to use three important processes: selfobservation, self-judgement, and self-reaction (Bandura, 1986), which enable individuals to monitor and adjust their behaviours accordingly. These processes are not mutually exclusive, but they interact with each other (Zimmerman, 2001). Self-observation leads to self-evaluation, and the cognitive judgments resulting from self-evaluation lead to personal and behavioural self-reactions (Schunk, 2009). Self-observation refers to the deliberate intention to observe one's own behaviour. Bandura (1986) suggested that behaviours are more likely to be affected by self-observation when the time of the observation is close to the behaviour and when there is evident progress. Self-observation can increase motivation, as when individual realizes what he or she does, he or she may react 
and alter his or her behaviour.

Though self-observation is important for self-regulation, an evaluation of the observation also plays an important role. Self-judgement refers to the comparison between one's own performance with that of a standard or goal (Zimmerman, 1989b). Personal standards, valuation of the activity, and attributions are the main components of the self-judgement process (Bandura, 1986). Personal standards are mostly based on social comparisons. Valuation of the activity is when people value the relevance of activities to them. Attributions occur when people perceive success or failure to be the result of ability or effort.

Self-reaction is the evaluative response to self-judgement (Zimmerman \& Schunk, 2004). Thus, following personal observations, individuals make a judgement of their progress toward their self-set goals. Based on these judgements, they alter their behaviours accordingly to attain these goals (Bandura, 1986). Personal standards may be revised and rewards are used to encourage performance.

\section{Environmental components of self-regulation}

Students can acquire information from their learning environment, for example from peer models, and assistance from peers and teachers (Schunk, Pintrich, \& Meece, 2008). Through enactive outcomes and vicarious experience, students attain information regarding self-regulation (Schunk, et al., 2008).

In addition to receiving information from the environment, one's control over the environment has been shown to be essential for self-regulation. Seeking social assistance from others and structuring the learning environment are examples of the environmental component of self-regulation. Besides that, the classroom social environment can influence self-regulated learning (Schunk, 2009; Zimmerman, 2008b).

A review of the research shows that students' perceptions of the social environment of their classroom can contribute to explaining the differences in students' learning and achievement (Pintrich \& Schunk, 2010; Patrick, Kaplan, \& Ryan, 2011; Pintrich \& Schunk, 2002). Second language learning research has shown there is interaction between learner characteristics and the language learning environment (Dörnyei, 2009). Turner and Waugh (2007, p. 128) 
highlight the contextual influences on students' learning:

Within academic settings and events, each student may be thought of as a selforganizing system that acts and reacts to both external and internal informational signals. These processes may explain the unique, individual facets of students' learning-related cognitions, emotions, motivations, and behaviours.

Social cognitive researchers consider social interaction among students and teachers play an important role in self-regulated learning (Pintrich, 2004). This interaction generally happens during the teaching and learning processes.

Perry, et al. (2002) used a qualitative approach to investigate student-teacher interactions that foster or hinder self-regulated learning, with classroom observations and interviews. The focus was on reading and writing activities. The observation focused on student-teacher interactions that support self-regulated learning, such as whether the students were given choices and opportunities to make decisions regarding their academic tasks. The findings established that these young learners were able to engage in self-regulated learning if they are allowed to make choices, control challenge, and evaluate themselves. This finding also implies that student-centred learning may support self-regulated learning. Perry's research contributes to research on the social cognitive aspects of selfregulation as both the individual and social contexts are the focus in data collection and analysis.

In a survey study, Young (2005) investigated how instructor-created classroom environments influence undergraduates' motivation to learn, which in turn facilitated or reduced the use of self-regulated learning strategies in a marketing course. The results of this study offer empirical support for the theoretical relationships among cognitive evaluation theory, achievement goal theory, and self-regulated learning strategies in the context of the classroom. Rehearsal strategies using rote memorization were associated with extrinsic motivation, whereas intrinsic motivation was linked to deep cognitive and metacognitive strategy use. Moreover, perceived autonomy and competence, and task mastery orientation facilitated a classroom environment that promoted intrinsic motivation. These findings showed that an active, application-oriented classroom experience with high levels of interaction, supportive feedback, and an emphasis 
on clear learning goals rather than grades will enhance intrinsic motivation and the use of self-regulated learning strategies among undergraduates.

Feedback provided by teachers may also influence students' self-regulated learning (Nicol \& Macfarlane-Dick, 2006). Some researchers believe that feedback given by teachers is a major determiner in a student developing or using self-regulation strategies (Zimmerman \& Schunk, 2001b). Teachers' feedback can be classified into two categories: general and specific (Schunk, 2003; Shute, 2008). General feedback includes general praise (e.g., "well done!”, "good try!", "great!") in reacting to students' performance, general comments immediately after a performance, like students' presentation, and general written comments on course assignments. On the other hand, specific feedback includes specific information about academic performance, and constructive comments or suggestions about not satisfying performance or work submitted. For selfregulated learning, specific feedback is more important and helpful to students (Nicol \& Macfarlane-Dick, 2006). This is because specific feedback serves a corrective function (Lee, 2008). It not only confirms or reinforces appropriate responses, but also disconfirms and provides the basis for correcting inappropriate responses (Nicol \& Macfarlane-Dick, 2006). For instance, if a student is told that his poor performance is due to misunderstanding a grammatical rule and he needs to ask for an explanation from a teacher, such specific feedback may help him to refine his regulating strategies, particularly help-seeking strategies. In order to produce better performance in the future, he may be more inclined to seek clarification if he has difficulties in completing his course assignments.

Whipp and Chiarelli's (2004) study reported that the positive and constructive feedback from the course instructor had contributed to the students' selfregulated learning. The findings show that by providing positive interpersonal support and appropriate feedback, the teacher can support learners' efforts to reflect constructively on their learning experience and to redirect their efforts in productive ways.

However, Inpornvijit's (2008) study did not find significant differences among the participants on the effects of feedback on self-regulated learning strategy use 
and academic performance. The use of feedback did not lead to greater academic performance or substantial improvement in SRL skills among the undergraduates. Other influences such as achieving a high course grade, teacher's teaching skills and styles, interest in the course, and course relevancy were more influential in determining students' motivation to learn.

\section{Personal components of self-regulation}

Various motivational beliefs underlie each phase of the self-regulatory process (Zimmerman, 2000a). The roles of students' self-efficacy, intrinsic motivation, goal orientation and attribution are discussed in the following paragraphs.

\section{Self-efficacy}

Bandura (2001) identifies self-efficacy as the most important construct related to one's personal components of self-regulation. Self-efficacy refers to beliefs about one's capability to organize and implement actions necessary to attain a designated performance of skill for specific tasks (Bandura, 1986). Self-efficacy beliefs influence an individual's behaviours and the courses of action he or she pursues (Bandura, 1986). Bandura $(1997 ; 2006)$ concludes that self-efficacy is an appraisal of the ability to succeed at a particular task. Therefore, self-efficacy is situation-specific. A second language learner may have high self-efficacy for writing essays but low self-efficacy for presenting in public. Social cognitive theorists (Bandura, 1997; Baumeister \& Vohs, 2004; McCombs, 2001; Pajares \& Urdan, 2005) propose that high levels of self-efficacy in a specific domain is associated with high achievement in that domain.

Self-efficacy has received increasing attention in educational research, primarily in studies of academic motivation and self-regulated learning (Gahungu, 2007; Joo, et al., 2000; Wang \& Pape, 2004). Studies indicated that highly efficacious students tend to engage in more difficult tasks, expend greater efforts, persist longer, and are less anxious about their learning tasks than low efficacious students (Bandura, 1995; Bandura, 1997; Wang, 2004). According to Bandura (1986), an individual's self-efficacy mediates between knowledge and action, and accordingly self-efficacy is related to self-regulated learning (Schunk \& Pajares, 2001). Students who have high self-efficacy use more effective self-regulatory strategies (Schunk \& Zimmerman, 2008). 
Studies to investigate the link between self-efficacy and academic achievement among Asian students such as that of Chong, Smith, and Lim (2001) also showed that there was a significant positive relationship between self-efficacy and selfregulation. They examined the relationship between academic self-efficacy and academic self-regulation among Singaporean secondary school students. Academic self-efficacy was measured by the Self-efficacy Subscale taken from the Motivated Strategies Learning Questionnaire (MSLQ). The participants were asked to judge their capability to organize or exercise control over their performance, which is efficacy in schoolwork. Chong et al. (2001) found that academic self-regulation was substantially correlated to academic self-efficacy.

Other studies on learners' self-regulation in language learning have found a positive link between self-efficacy and language ability. Wang and Pape (2004) investigated the relationship among the ESL learners' self-efficacy, self-regulated learning strategies, and their success in learning English. ESL learners with high self-efficacy reported the use of more SRL strategies and experienced more success in learning English than the learners with comparatively lower selfefficacy. The ESL learners' behaviours such as raising one's hand in the classroom, willingness to engage in language activities, and persistence in performing language tasks are identified as possible evidence of their selfefficacy beliefs. The researchers point out that students with high levels of selfefficacy are more likely to participate while less efficacious students are more likely to withdraw when confronted with difficulties. In a similar vein, Gahungu (2007) reported that there were positive and significant relationships among strategy use, self-efficacy, and language ability among the foreign language learners in his study. Both studies were conducted in an American context of language learning but had different methods of investigation and participants' academic levels. Wang and Pape explored the elementary school ESL learners' self-efficacy beliefs and their use of self-regulated learning (SRL) strategies through qualitative case studies. On the other hand, Gahungu examined the relationship between language learning strategy use, self-efficacy, and language performance of college students learning French through a mixed-method data collection approach. Data from the Strategy Inventory for Language Learning (SILL) questionnaire were triangulated with qualitative data from interviews and 
class observations. Both studies highlight the fact that language learners' selfefficacy is open to change depending on the specific language task, and efficacious students are more self-regulated.

In the Malaysian context, Idrus and Salleh's (2008) study examined the selfefficacy of Malaysian ESL students from a private university in their ability to speak in English. A questionnaire, designed by Idrus and Sivapalan (2007), adapted from Bandura (1990) and Mikulecky, Lloyd, and Huang (1996), was used to assess the perceived self-efficacy of the students in the three dimensions of ability, aspiration and activity perception. The findings indicate that the students had high self-efficacy beliefs in their speaking ability in all the dimensions. This study compares the level of self-efficacy of pre-university students and final year students. This is to see whether the length of exposure to English as a medium of instruction has an influence on the students' speaking confidence. Both had high self-efficacy levels in speaking English even though their length of exposure to English as a medium of instruction was different. This may be due to different success criteria for the two groups. The pre-university students had recently graduated from high school with good results and received distinctions for English language. During the university entrance process, they were interviewed in English: thus, they had high confidence in their ability. The final year students had high self-efficacy in their speaking ability due to longer exposure to the language. All their courses were in English and they had taken part in numerous discussions and presentations in English for at least 4 years. Hence, they had confidence in their speaking ability. The students' high self-efficacy in their oral ability might be due to the use of English as the medium of instruction at this private university and the opportunities to communicate in English with international students that attended the university.

A study which showed the role of self-efficacy in language learners' use of language learning strategies was conducted by Wong (2005) at a teachers' training college in East Malaysia. The researcher explored 74 pre-service ESL teachers' use of language learning strategies and language self-efficacy and the relationship between these two constructs. The pre-service teachers were completing a one-year diploma course before they were sent to schools to teach English. Wong identified six categories of language learning strategies from the 
teachers' responses to seven hypothetical learning contexts. Quantitative analysis identified a positive association between language learning strategies and language self-efficacy. The qualitative data (from interviews) supported this finding. Wong commented that pre-service teachers with high self-efficacy reported more frequent use of a greater number of strategies than teachers with low self-efficacy.

The review of research on ESL learners' self-efficacy and its relationship to English language achievement above suggests that the participants' achievements are linked to their perceptions of their own ability. A review of past research on self-efficacy and self-regulated learning consistently showed that these two variables are significantly and positively related (Gahungu, 2007; Wang, 2004). These reviews lend further support to the notion that self-efficacy is the key personal variable affecting self-regulated learning (Bandura, 1986). Therefore, it may be a significant predictor of self-regulated learning.

Zimmerman (2002a) points out that self-efficacy is not the only influence on selfregulation, but other motivational beliefs are also associated with self-regulation, such as intrinsic motivation, goal orientation and attributions.

\section{Intrinsic motivation}

Motivation is another important dimension of self-regulated learning (Schunk \& Zimmerman, 2008). Students motivated to accomplish a goal engage in selfregulatory activities they believe will assist them in learning (Schunk, et al., 2008). In turn, self-regulation supports learning, and progress and increased competence sustains motivation and self-regulation to reach new goals (Zimmerman \& Schunk, 2004).

Students' reports of their beliefs, strategies and behaviours such as choice of activities, level and quality of task engagement, persistence, and performance indicate levels of motivation and self-regulation. Motivation is not seen as a dispositional trait, with some students being "more" or "less" motivated. Rather, student motivation is anticipated to be situated and changeable as a function of instructions, tasks, and activities that take place in a classroom (Bonney, Kempler, Zusho, Coppola, \& Pintrich, 2005). 
Intrinsic motivation is an important precursor of self-regulated learning. Intrinsic motivation is defined as learners' motivation to engage in an activity for its own sake and without coercion (Schunk, et al., 2008). Vansteenkiste, Simons, Lens, Sheldon, and Deci (2004) reported that students who were oriented toward an intrinsic motivation showed deeper learning, better performance, and greater persistence in learning tasks compared to students who were oriented toward an extrinsic motivation.

\section{Goal orientation}

SRL models of regulation assume that learners can set standards or goals to strive for in their learning, monitor their progress toward these goals, and then adapt and regulate their cognition, motivation, and behaviour in order to reach them (Zeidner, Boekaerts, \& Pintrich, 2000; Zimmerman, 2001). Goal setting is defined as identifying "the object or aim of an action, for example, to attain a specific standard of proficiency, usually within a specified time limit" (Locke \& Latham, 2002, p. 705). This standard is a basis of personal feedback about one's effectiveness and self-regulatory control (Zimmerman, 2008a).

Self-regulated learning from a social cognitive theoretical perspective refers to learning that results from students' self-generated thoughts and behaviours that are systematically oriented toward the attainment of their learning goals (Schunk, 2001). Rather than being passive recipients of information, selfregulated learners contribute actively to their learning goals and exercise control over goal attainment. In the social cognitive model of self-regulation used by Zimmerman \& Campillo ( 2003), goal setting is influenced by an individual's goal orientations and beliefs about self-efficacy. Students with specific and proximal goals displayed superior achievement and perceptions of personal efficacy (Zimmerman, 2002b). The performance control phase details processes such as attentional focusing and self-monitoring that are activated during the achievement situation. Once performance is completed, the goals a learner has set for the task can be evaluated during the self-reflection phase, and the judgements made during this evaluation influence the goal setting process in subsequent forethought phases. All of the phases and processes of the social cognitive model are intertwined (Zimmerman \& Campillo, 2003). 
There are three properties of goals that help in enhancing students' learning (Schunk, 2001). The first important property of goals is specificity. Specific goals are more effective than general or vague goals, as specific goals make progress easier to measure. Specific performance standards are more likely to heighten self-regulation and motivate self-evaluations than general goals, because specific goals identify the extent of effort needed for success and increase self-efficacy by offering a clear standard to define progress. Proximity is another property of goals, as proximal goals afford more immediate feedback of one's progress. Proximal goals can be achieved more quickly than distal goals, and result in higher motivation and better self-regulation. Moreover, proximal goals reinforce self-efficacy as they provide clear and regular self-evaluations of progress. However, distal or long-term goals may prompt self-regulated learners to set proximal or short-term goals (Zimmerman, 2008a). Zimmerman (2000a) stresses that when distal goals are integrated with proximal goals in a hierarchy, there might be self-regulatory benefits. Hence, hierarchical integration is the third advantageous property of goals. Another important property of goals is their degree of difficulty. Moderately difficult goals seem to result in better motivation and self-regulated performance compared to goals that are either too easy or too difficult.

Zimmerman (2008a) highlights that the goals students set could affect their motivation to learn in four ways. Firstly, goals motivate students' choice of and attention to goal-relevant tasks. Secondly, goals influence students to put in extra effort. Thirdly, goals stimulate greater persistence over time; and fourthly, higher quality goals influence students' learning by generating affective reactions like greater self-satisfaction.

This literature shows the role of goals in students' efforts to self-regulate their learning. These studies show the qualities of goals and the properties of goals that influence their usefulness. They also provide evidence of the relationship between goals and other self-regulatory processes and beliefs. The two key goalorientations in the literature will be addressed next.

Mastery and performance goals are the two main goal-orientations described in achievement contexts (Kaplan \& Lichtinger, 2009). Each goal-orientation creates 
different patterns of motivation that are relevant to regulatory processes (Kaplan \& Lichtinger, 2009). Studies have shown that students oriented toward mastery goals have demonstrated high-levels of self-regulated learning (Schunk, 2001; Zimmerman \& Campillo, 2003). Schunk (2001) contended that mastery goal orientation is positively related to self-regulated learning and self-efficacy.

With a mastery goal, individuals strive to improve their competence. They are interested in learning as an end in itself. Students with mastery goals focus on developing their ability over time and acquiring the skills required to master a specific task (Mattern, 2005). Mastery goals have been linked to a number of adaptive behaviours, comprising higher level self-efficacy, task value, interest, positive affect, effort and persistence, use of more cognitive and metacognitive strategies, and better performance (Harackiewicz, Barron, Tauer, Carter, \& Elliot, 2000; Mattern, 2005; Wolters, 2004). Individuals with a performance goal orientation seek to demonstrate high ability in an attempt to obtain favourable recognition or to avoid negative judgements of their competence. They set standards of success grounded in external judgements such as examination results, and performance relative to their classmates. Research evidence suggests that performance goals are connected to surface-level learning strategies, which do not necessarily support conceptual understanding (Kaplan, Middleton, Urdan, \& Midgley, 2002). Performance goals have been linked to lower grades for college students (Mattern, 2005). However, these patterns are not consistent across studies, and researchers have stressed the need to make a distinction between approach and avoidance forms of performance goals (Harackiewicz, Barron, Pintrich, Elliot, \& Thrash, 2002; Murayama, Elliot, \& Yamagata, 2011). Evidence suggests that performance-approach goals are positively connected to perseverance and academic success, particularly for university undergraduates (Harackiewicz, et al., 2002).

Research suggests that students hold multiple goals. Diverse combinations of goals might lead to different motivation and achievement outcomes (Barron \& Harackiewicz, 2001; Linnenbrink, 2005; Pintrich, 2000a). Linnenbrink (2005) investigated the effects of a quasi-experimental classroom goal condition (mastery, performance-approach, combined mastery/performance-approach) and personal goal orientations on motivation, emotional well-being, help- 
seeking, cognitive engagement, and achievement. The participants were 237 upper elementary students in a 5-week mathematics course with group work. The findings suggest that a student's personal goal orientations and the classroom goal context might relate in many ways to significant educational outcomes. The findings for the classroom goal context indicate that the combined mastery-performance goal contexts are the most constructive for academic outcomes where there was focus on group work. The findings suggest that competitive group practices would be more constructive when the competition was organised around improvement between groups rather than performance. There were some implications for classroom teaching such as an emphasis on mastery goals focusing on understanding and learning by teachers. To promote mastery, the findings suggest that teachers provide varied and meaningful learning tasks, afford opportunities for students to make choices and practise agency in their own learning, and acknowledge students' initiative to learn and any improvement shown.

In the context of second language learning, it has been suggested that students who hold mastery goals focus their attention on increasing their ability and their endorsement of the belief that effort leads to success ( $\mathrm{Wu}, 2006)$. Thus, L2 students with mastery goals may take more risks and see making mistakes as a natural part of language learning (Oxford and Shchramm, 2007). Research has shown evidence that links a mastery goal orientation to a belief that effort results in success (Wolters, 2004). Students who pursued mastery goals reported use of effective learning strategies, including metacognitive strategies. On the other hand, performance goals direct students to demonstrate their ability in order to earn public recognition and to outperform their peers (Wu, 2006). Therefore, L2 students with performance goals value learning outcomes (e.g., good grades), and determine their progress by comparing themselves with norms, not to their prior learning experiences. Moreover, students who adopt a performance goal tend to attribute study results to ability (Moeller, Theiler, \& Wu, 2011).

Research has investigated how students manage multiple achievement goals, or balance achievement goals with other goals such as social ones (Wentzel, 2000). Harackiewicz, Barron, Tauer, Carter and Elliot (2000) called for the separation of a performance goal orientation into two types of goals: performance-approach 
and performance-avoidance. They argued that a performance-approach goal combined with a mastery goal will enhance both achievement and on-going interest in a topic. By contrast, performance-avoidance goals motivate students to withdraw from challenging tasks because they view failure as evidence of their incompetence or low self-worth (Wu, 2006). Hence, L2 learners with avoidance goals choose easier tasks and invest only limited mental effort on language tasks.

Mattern (2005) compared the achievement patterns of undergraduates of a Western public university who had mastery and performance goals simultaneously, to students at the institution who had either mastery or performance goals only. The objective of the quantitative study was to determine whether adopting a multiple goal orientation or a single goal orientation is more beneficial to undergraduates' achievement. In total, 143 undergraduates rated their motivational orientations in the Motivation Strategies for Learning Questionnaire (MSLQ), which measures mastery and performance goals. The undergraduates' achievement was determined by their final course grades. The findings suggested that undergraduates with multiple goals (high mastery and high performance) did not achieve significantly better than those with only high mastery or high performance goals. However, findings revealed students who adopted a mastery single goal orientation scored higher grades than those with a performance single goal orientation. Moreover, mastery goals were found to be associated with understanding, interest, and the use of effective learning strategies. The researcher concluded that mastery goals were more constructive than performance-approach goals for college students' success. However, the researcher suggested further research, including interviews to explore the findings. Interviews might allow for more contextual data and further probes of the students' explanations for engaging in a specific academic task.

\section{Attributions}

Another key motivational construct significant for self-regulation is the students' attributions (Schunk, et al., 2008; Schunk \& Zimmerman, 2008). Attributions are student perceptions about the causes of their academic outcomes (Schunk, et al., 2008). The beliefs one has about the cause of success and failure may vary according to age, cultural influences, gender, and the type of task. Proponents of attribution theory such as Weiner (1986) begin their analysis of motivation with 
the assumption that people seek to understand why they succeed or fail. In doing so, they attribute their accomplishments or failures to different causes: good or bad luck, difficult or easy tasks, their own hard work or lack of it, or the degree to which they possess certain abilities. Attribution theory emphasizes that learners should believe that their efforts to learn and master new tasks will succeed. However, this depends to a large extent on whether their learning goals are realistic. Failure to meet goals that are unrealistic may cause learners to doubt their abilities and to be less committed to their learning task. Teaching learners how to set realistic goals is an important aspect of any instructional program (Alderman, 2008).

Attribution theory assists in understanding learners' motivations for achievement. Mohd Shah's (2002) study on less successful L2 learners at a Malaysian university showed that the students attribute their low achievement to their lack of language learning strategies. Embi and Mohd Amin (2010) suggest that learning strategy training in a language classroom may have significant effects on students' language achievement. Attribution theory suggests that the most direct way to enhance learners' intrinsic motivation is to teach in ways that convince learners that success is largely due to factors under their control, such as effort and strategy use. In an intervention study on the trainability of reflection and constructive attribution as basic components of self-regulated learning and its effect on academic performance, Masui and De Corte (2005) reported that undergraduates in the intervention group showed a higher degree of reflective behaviour, improved attribution skills, and better study results than the undergraduates in the control group. Students in the experimental group also showed a stronger sense of feeling in control of success and failure compared to those in the control group. The participants were 141 first year students of business economics and the intervention was embedded in the natural context of the teaching of the course. Attribution and reflection behaviour was measured through specific course assignments, and study results during and after the intervention were taken to determine academic performance. 
Motivational processes (self-efficacy, motivation, goal orientation, and attribution) play a vital role in initiating, managing, and sustaining student efforts to self-regulate their learning.

Figure 2.1 below summarises the components of self-regulation. The three processes in the behavioural components of SRL are self-observation, selfjudgement, and self-reaction. Students' motivational beliefs are the factors in the personal components of self-regulated learning. Peers and teachers, and classroom social environment are the factors in the environmental component of self-regulation.

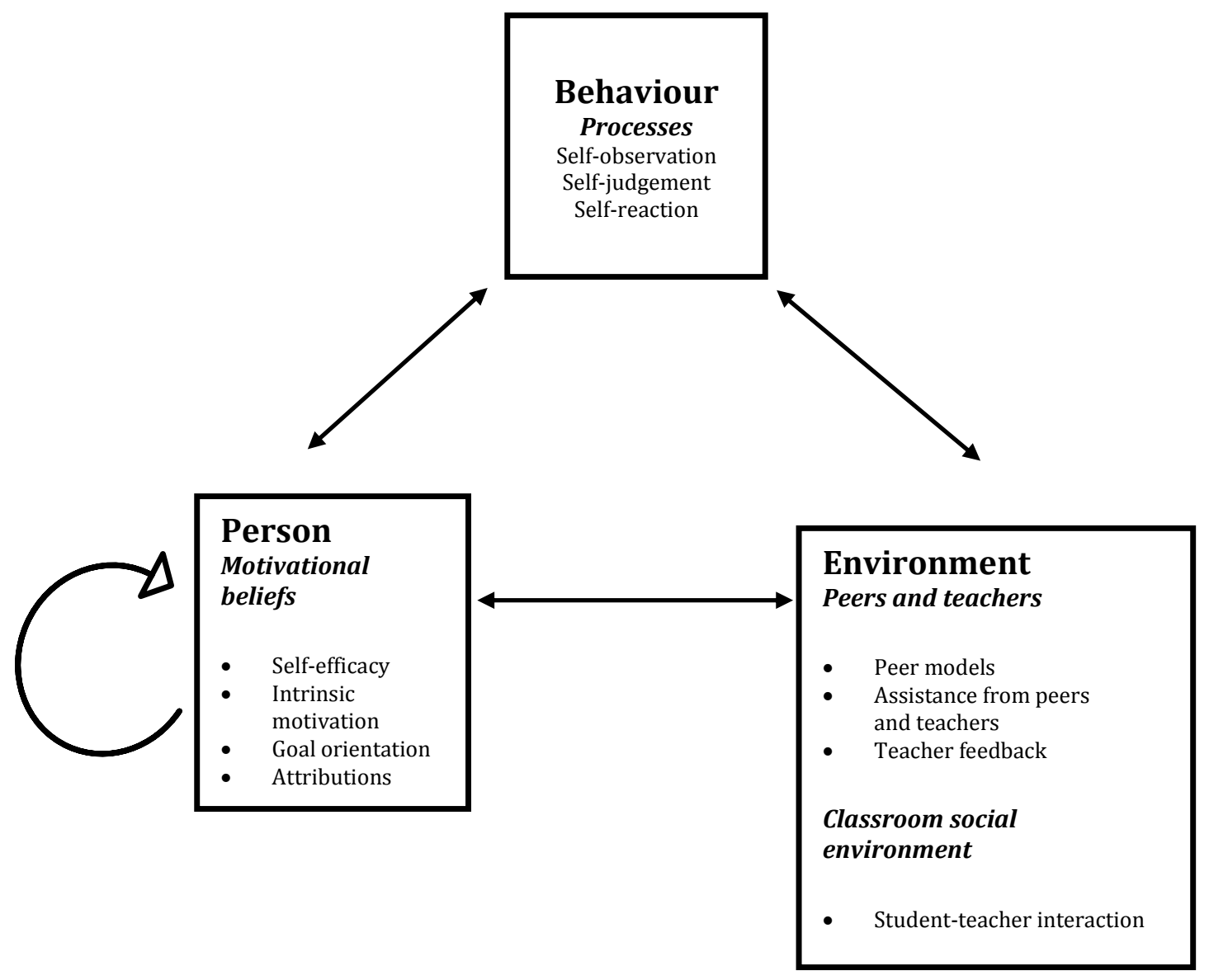

Figure 2.1: Summary of the components in self-regulation.

\section{Learning strategies}

Self-regulated learning strategies refer to self-initiated strategies that are used to manage and improve learning and achievement in and out of school. Selfregulated learning strategies, as part of self-regulated learning, are defined by Zimmerman (1990, p. 5) as "actions and processes directed at acquisition of 
information or skills that involve agency, purpose, and instrumentality perceptions by learners". Weinstein, Husman, and Dierking (2000) stated that learning strategies are comprised of any thoughts, behaviours, viewpoints, or emotions that assist the learning, understanding, or later transfer of new knowledge and skills.

Even though definitions of learning strategies often vary, based on investigators' theoretical orientations, a universal conceptualisation of learning strategies in general includes both cognitive and metacognitive strategies. Paris, Byrnes, and Paris (2001) indicate that there is no common list of self-regulated strategies that all students will follow. Social norms in the culture denote which aspects of selfregulated learning are important.

Commenting on language learning strategies and students' self-regulation, Dornyei (2005) concludes that "learning strategies constitute a useful kit for active and conscious learning [and] these strategies pave the way toward greater proficiency, learner autonomy, and self-regulation" (p. 195). Learning strategies are useful tools for dynamic and conscious learning, and they lead to better proficiency, learner autonomy and self-regulation (Hsiao \& Oxford, 2002). Cleary (2006, p. 309) states that a learning strategy that involves a series of "purposeful actions and processes directed at acquiring skill or information" is an important construct in language learners' self-regulated learning. Effective self-regulators engage in skilful strategy use during learning (Dornyei, 2005).

Self-regulated learning behaviour is often defined as students' use of learning strategies for the self-regulation of cognition and actions (Zimmerman, 2008b), and is an important aspect of students' learning and academic performance (Zimmerman, 2002b; Zimmerman \& Schunk, 2001a). There is research evidence that consistently documents the role of learning strategies in achieving optimal academic performance (Zeidner, et al., 2000; Zimmerman \& Pons, 1986; Zimmerman \& Schunk, 2001a). Higher achievers seemed to use more strategies than lower achievers.

SRL strategies can be summarized into cognitive and metacognitive strategies and resource management strategies (Pintrich, 2004). Cognitive and metacognitive strategies include rehearsal (repeating words over and over to 
assist in the recall of information), elaboration (giving meaning to new material by linking it with prior knowledge), organization (categorizing or grouping material), and critical thinking. Metacognitive strategies include planning a course of study, monitoring progress, making changes if necessary, and using past experience when approaching a new task. Effective students use metacognitive strategies by consciously planning, monitoring, and evaluating their work (Archer, 2001). Time and study environment management, effort regulation, peer learning, and seeking help are categorised as resource management strategies.

In this study, I used the categories of self-regulated learning strategies from Wang's (2004) study to analyse the behavioural SRL strategies of the second language learners in Malaysian context. The categories evolved from Pape and Wang's (2003) SRL categories which were regrouped from Zimmerman and Pons' (1986) classification of self-regulated learning strategies. In a study of high school students' learning strategies for general academic learning, Zimmerman and Pons (1986) used a structured interview to investigate 80 students' strategy use. Students reported the strategies used and the frequency of their use for six learning contexts (such as in classroom situations and when preparing for and taking tests). There were 14 specific types of self-regulated learning strategies proposed; self-evaluation, organizing and transforming, goal setting and planning, seeking information, keeping records and monitoring, environmental structuring, self-consequences, rehearsing and memorizing, seeking peer assistance, seeking teacher assistance, seeking adult assistance, reviewing tests, reviewing notes, and reviewing texts. In a later study with 80 sixth and seventhgrade students, investigating the relationship between SRL and academic achievement and mathematical problem solving, Pape and Wang (2003) divided environmental structuring category into physical environmental structuring (students' efforts to select or arrange the physical setting) and attentional control (students' efforts to structure one's internal environment). The definitions and examples of Wang (2004) categories of self-regulated learning strategies for language learning are in Appendix B (1). 


\section{Self-regulated learning and academic achievement at university}

The purpose of this section is to examine research on self-regulated learning among undergraduates. The literature review highlights developments in selfregulated learning research in the context of Malaysia.

There is an extensive body of research on the role of self-regulated learning in academic success across education levels and subjects (Van Den Hurk, 2006; Zimmerman, Bonner \& Kovach, 2006; Zimmerman \& Campillo, 2003). In this section, only research conducted on students at the tertiary or college level is reviewed.

Using a quantitative approach, Chen (2002) investigated effective self-regulated learning strategies in a lecture and in a hands-on computer lab learning environment. This study examined the influence of students' prior computer experience and software use in these two learning environments. The participants were 197 undergraduates from a business information system course at a U.S Midwestern university. The findings showed that effort regulation led to achievement in a lecture-style learning environment. Use of strategies to handle distractions and maintain concentration when studying computer and information system concepts led to higher test scores. Thus, the implications for instructors would be to encourage students to control their effort and attention when facing distractions and completing uninteresting tasks. Conflicting with teachers' perceptions, prior computer experience did not assist students to achieve better test scores.

Whipp and Chiarelli (2004) investigated how successful students in Web-based courses self-regulate their learning. Their descriptive case study used a social cognitive model of self-regulated learning (SRL) to examine how six graduate students used and adapted traditional SRL strategies to complete tasks and manage the challenges in a Web-based technology course. The study also explored motivational and environmental influences on strategy use. Primary data sources were interviews with each of the students over the course of the semester, an interview with the course instructor, and the students' reflective journals. Secondary data sources were course documents, comprising transcripts of threaded discussions and student Web pages. Findings indicated that these 
students employed numerous traditional SRL strategies; however, they also adjusted planning, organisation, environmental structuring, help seeking, monitoring, record keeping, and self-reflection strategies to self-regulate their learning in the Web-based learning environment. Findings showed that there were significant motivational influences (self-efficacy, goal orientation, interest, and attributions) on SRL strategy use. Significant environmental influences on SRL strategy use involved instructor and peer support, and course design.

Self-regulation was found to be contributing to success in a hypermedia (audiovisual aid) learning environment (Azevedo, Guthrie, and Seibert, (2004). They found that students who regulated their learning with SRL strategies like goal setting and planning showed an increase in knowledge.

Online and computer-mediated learning environments have been fruitful areas for the study of self-regulated learning and academic achievement. These studies show support for the view that self-regulated learning is significantly related to academic achievement among university undergraduates. In the next section, I will review the empirical studies of SRL and general academic achievement in the context of Malaysian universities.

In the Malaysian context, some empirical research has investigated the relationship between self-regulated learning and general academic achievement (Mohd Kosnin, 2007; Roslan, 2000). Mohd Kosnin (2007) conducted a quantitative study using the Motivated Strategies for Learning Questionnaire (MSLQ) to investigate the relationship between self-regulated learning and academic achievement among 460 second-year engineering students in a public university. The students' grade point average was used to determine their academic achievement. The results showed that self-regulated learning can be associated with academic achievement for these Malaysian undergraduates. This study of the ability of self-regulated learning (SRL) among Malaysian undergraduates found that high achievers used self-regulated learning strategies more effectively than low achievers. The undergraduates' achievement was strongly influenced by their use of managing resources strategies such as time, their study environment, effort regulation, peer learning, and seeking help. One important finding from this study was metacognitive strategies were found to 
have a significant relationship in improving low achievers' achievement. The use of metacognitive strategies is likely to have played a significant role in achieving academic performance, because metacognitive skills facilitate students' ability to plan, observe and assess their performance. Mohd Kosnin (2007) concluded that a lack of metacognitive skills may impinge on students' ability to evaluate their potential and performance, thus preventing them from making effective planning decisions and taking actions. The findings suggest that educators need to assist students, especially low achieving students to develop and improve their use of metacognitive strategies. This research supported earlier findings that highachievers utilise cognitive and metacognitive strategies more effectively to comprehend learning materials in contrast to low achievers (see Corno \& Mandinach, 1983; Rahman \& Philips, 2006; Zimmerman \& Pons, 1986).

Roslan's (2000) study found a positive relationship between self-regulated learning and academic achievement for Malaysian tertiary level students. Similarly to Mohd Kosnin's study, self-regulated learning was measured by a Motivated Strategies for Learning Questionnaire. Both Mohd Kosnin's (2007) and Roslan's (2000) quantitative survey studies informed the formation of my research in that self-regulated learning was found to have a significant effect on Malaysian university students' academic achievement and high achievers were better users of self-regulated learning strategies than low achievers.

Lee's (2002) qualitative study focussed on SRL strategy training for ESL learners who took an English for Specific Purposes (ESP) course to assist students in essay writing. Findings suggested that the strategy and self-regulation instruction had equipped the ESL learners with the knowledge to plan and improve their essays. This positive change was primarily due to the employment of four self-regulation strategies: self-evaluation, organizing and transforming, seeking information and seeking social assistance. Lee also contended that if language learners are taught the correct tools, like strategies and self-regulation, this could result in positive self-efficacy, attribution, and self-determination. With proper training and intervention in self-regulatory skills, all students can improve their degree of control over learning (Zimmerman, 2002b). 
Research on learners' self-regulation in a Malaysian tertiary environment lends additional support to the role of SRL in academic achievement. The findings show the significance of conducting a study of Malaysian undergraduates' use of selfregulated learning strategies in the process of learning English as a second language. Mohd Kosnin's (2007) and Roslan's (2000) study focused on general academic achievement and Lee's (2002) study is on implementation of strategy and self-regulation instruction. The above studies signify that researchers in Malaysia have turned their attention to research on self-regulation in general academic achievement and to interventions to equip students with selfregulation. However, research on self-regulation of language learning that focuses on how individual language learners manage their learning process and the factors influencing them complements and updates the existing studies.

A review of the research literature suggests that most studies of self-regulation would be classified as quantitative, with the most common method of data collection being questionnaires or surveys. Research using survey methods (Mohd Kosnin, 2007; Roslan, 2000) has shown significant advances in the understanding of self-regulated learning. Survey methods are efficient, costeffective in terms of work, relatively quick to administer and score, and the research has produced consistent results among constructs (Dornyei, 2007). However, survey methods may not capture what learners actually do versus what they report they did, and they cannot shed light on links between contextual factors (like teaching-learning contexts) and students' engagement in self-regulated learning (Patrick \& Middleton, 2002). Thus, survey methods may not provide detailed descriptions of SRL as an event where self-regulated learning unfolds in actual contexts and time (De Groot, 2002; Perry, 2002; Perry, et al., 2002). Therefore, there is a need for more qualitative research on language-learning and self-regulation to balance the quantitative tradition of research in this particular field, "to capture the dynamic and transactional process of self-regulation optimally" (Zeidner, et al., 2000, p. 759). As Pintrich (2000b) puts it: "There is a clear need for more descriptive ... and observational research on how different features of the context can shape, facilitate, and constrain self-regulated learning" (p. 493). Patrick and Middleton (2002) highlight the use of observations and interviews in self-regulated learning 
research to provide rich, contextualized description to answer what, how, why, and when questions. This is in line with recent thinking in the area of selfregulation, which emphasizes the importance of taking contextual variables into consideration in models of self-regulation (Perry, 2002; Zeidner, et al., 2000; Zimmerman, 2008b). Perry (2002) argues for self-regulated learning research to be conducted in real contexts and in real time, and in events rather than as aptitudes as research from an event perspective focuses on individuals' engagement in specific activities, rather than it being averaged across multiple occasions. Examining self-regulated learning with a qualitative lens in Malaysian tertiary level language teaching and learning context enables new insights and practical implications. Because the culture and educational context is important in SRL, a qualitative study complements the quantitative studies in the Malaysian context. In the following two chapters (Theoretical Framework and Methodology) I will introduce my research design. In brief, my study is positioned as adding to SRL research through a qualitative approach in a Malaysian context. From observations and interviews, I gained in-depth data about students' self-regulated learning from rich descriptions of their behaviour and their surroundings, like the teaching-learning contexts. Using observations and interviews in my research design illuminates the localised and contextualised language learning process.

\section{Self-regulation in language learning}

In recent years, the field of language teaching and learning seems to be heading away from a focus on the teacher to that of the learner and their language learning processes (Dörnyei, 2005). Parallel to this, the focus of language learning research in the last two decades has similarly shifted from investigating the 'what' or product to the 'how' or process of language learning. Dornyei and Skehan (2003) suggest that researchers have shifted the emphasis from the product to the process of language learning when they investigated language learners' self-regulation.

Drawing on work done in educational psychology, Tseng, et al. (2006) proposed a new approach to generating a psychometrically-based measure of second language learners' strategic learning. Language learners' strategic learning was 
defined as their self-regulatory capacity. The self-regulation instrument was developed as an alternative to the scales conventionally employed to measure language learning strategy use. The results demonstrate that the proposed tool has satisfactory psychometric characteristics and that the hypothesized theoretical model had a good fit with the data. They stress that the results give support for the soundness of transferring the theoretical construct of selfregulation from educational psychology to the area of second language acquisition.

The next section reviews studies on self-regulation in language learning.

A number of studies on self-regulation in language learning have been carried out in Western contexts (Bown, 2009; Mezei, 2008). Drawing upon the social cognitive and sociocultural perspectives of self-regulation, Wang, Quach, and Rolston (2009) investigated the development of four male Chinese English language learners' use of self-regulated learning strategies. Their case study participants were students at an elementary school in the United States. The focus of this qualitative study was on how SRL strategies were learned and used across home-based and school-based contexts by the learners. Findings from multiple sources of data showed that these young English language learners employed more strategies in reading activities compared to writing activities. The most commonly reported and observed strategies employed by the four young participants were seeking social assistance, seeking information, and environmental structuring. Although this study looked at young learners, the findings supported other studies of students' use of language-learning strategies that effective learners are more flexible with their repertoire of strategies and are more successful at monitoring and adapting their strategies. The data from the study also indicated that the incorporation of SRL strategies into the teaching of English helped in students' construction of their own strategies.

Using a qualitative approach, Bown (2009) investigated adult learners' selfregulatory strategies and agency when learning Russian in the context of individualized instruction at a Midwestern U.S. university. The findings showed that contextual factors such as learners' self-beliefs and social support had an influence on the self-regulatory strategies they used. Bown highlighted that in the 
context of individualized instruction, the most important self-regulatory strategy the learners must employ is structuring the learning environment to meet their language learning needs. Due to the isolation felt by the learners in this selfinstructed language learning context, they needed to deal with negative emotions like avoidance with positive self-talk.

Self-regulation and motivation of adult language learners of different proficiency levels in English language learning was investigated in Mezei's (2008) classroombased study. The case study findings showed that a learner within the upper intermediate level is more conscious of her language learning processes and more competent in regulating her language learning than the pre-intermediate learner. She self-initiated her learning process by using effective learning strategies to achieve her intrinsic language learning goal. The learner with a higher proficiency level practised self-reflection, and thus was more aware of her language strengths and specific areas to improve. However, this qualitative case study had only one learner from each proficiency level (upper and pre intermediate). Nevertheless, this study provided insight into understanding how language learners regulate their language learning in a company English language course in Hungary.

Hirata (2010) examined the motivational factors affecting self-regulated learning (SRL) in the context of second language acquisition. The focus was on a particular task, the learning of kanji ( adopted Chinese characters which are used in modern Japanese writing system) in Japanese, to provide a clearer picture of the complex relationship between motivation and SRL. Through quantitative methods, the fundamental structure of motivation and SRL was explored and the relationships among the extracted factors were studied. The participants were 381 tertiary students studying Japanese at different tertiary level institutions in New Zealand. Principal components analyses identified three motivational orientations (intrinsic, instrumental mastery, and performance orientation), four sources of motivation (self-efficacy, self-concept, extrinsic value, and intrinsic value), and four categories of self-regulation (behavioural, environmental, cognitive, and metacognitive regulation) each played a role in kanji learning. The results of correlational analyses showed a number of important relationships signifying the interdependence of the recognized constructs. Nevertheless, instrumental 
mastery, performance orientation, and extrinsic value did not predict students' use of SRL. Further examination of individual and situational factors showed that learning opportunities outside the classroom probably confounded the substantial relationships between these non-predictors and SRL. Students who had chances to use kanji outside the Japanese class reported intrinsic and instrumental mastery orientations, higher self-efficacy beliefs and intrinsic and extrinsic values, and showed more positive self-concepts. Intrinsic orientation, self-concept, self-efficacy, and intrinsic value were recognized as important predictors of SRL in general. These significant predictors showed a distinctive contribution to diverse types of SRL. The findings indicated that intrinsic interest in kanji learning is essential for cognitive and metacognitive regulation, while a sense of positive self-concept, influenced environmental regulation and selfefficacy beliefs enabled behavioural regulation. Generally, self-concept was found to be the paramount predictor of the use of SRL. Nevertheless, self-efficacy is another significant factor as students who reported behavioural regulation inclined to use a broader variety of strategies to self-regulate their own learning.

There are consistencies in the findings of previous studies in the Western contexts that self-regulated learning (SRL) skills contribute to success in language learning (Bown, 2009; Mezei, 2008; Wang, Quach, Rolston, 2009). The literature seems to suggest that much of what is understood about the relationships between self-regulation, academic achievement, and learning is grounded in Western contexts that may possibly be inconsistent with the internalization process that is developed in non-Western contexts. Investigating how learners in different cultural and educational contexts regulate their own learning processes will provide a better understanding of different aspects of learning processes.

In an Asian context, Gan, et al. (2004) looked at how university students go about their out-of-class (self-directed) English learning and sought to explore and understand the variables in their English language learning process and outcomes. This study was a follow up of a previous study by Gan (2003) which investigated the relationships between self-directedness for language learning and English language learning success among undergraduates in China and Hong Kong. The findings from the subsequent qualitative study suggest that different 
levels of success need to be explained by "a complex and dynamic interplay of internal cognition and emotion, external incentives and social context" (p. 229).

In the Malaysian context, Thang $(2001,2003,2005)$ found that undergraduates of the National University of Malaysia (both distance and on campus learners) were not autonomous learners. Thang $(2001,2005)$ studied Malaysian distance learners' conceptions of their learning in English. The participants were first and second year students who had just finished their first English proficiency course. The instruments used were a questionnaire and semi-structured interviews. The findings showed that the students were not autonomous learners and they showed a lack of awareness of the language learning process. Moreover, they still preferred a teacher-centred approach to learning. Similar findings were also shown in a study with on-campus undergraduates (Thang, 2003). In a later study, Thang \& Alias (2007) compared the learning characteristics of students from three public universities in Malaysia, to verify the degree of autonomy among undergraduates in Malaysian public universities. The results showed that generally the learners were conscious of the value of reading widely and acquiring the correct learning strategies. However, the majority of learners were teacher-centred, even if they were not entirely teacher dependent. Thang and Alias (2007, p. 14) believe that this might be "a wash back effect of the 'spoonfed' system operating" in Malaysian primary and secondary schools. Nevertheless, there were a small number of autonomous learners who wanted the freedom and responsibility to decide 'what, where, when and how to learn' (Thang \& Alias, 2007 ). The results of this study suggest that it may be inaccurate to conclude that Malaysian learners cannot be autonomous learners just because they show a preference for teacher-centred teaching and learning approach. Hence, literature on autonomy has reference to self-regulated learning.

The possibility that teacher-centeredness may be influenced by the cultural values and mentality of Asian people was pointed out by Thang and Alias (2007). They further suggested that emphasis on teacher centeredness among Asian students does not mean a lack of ability to be autonomous learners. Studies on Hong Kong Chinese learners produced findings where the learners were reported as being passive, reluctant to openly challenge authority, and lacking in 
intellectual initiative and creative learning (Ho \& Crookal, 1995; Nelson, 1995; Pierson, 1996). From a cultural viewpoint, Malaysian students show some similarities with these Hong Kong students. Chinese students in Malaysia may possibly be "indoctrinated with the Confucian ethic of piety from young" (ibid, 2007, p. 15). The Malay and the Indian students in Malaysia are also taught by their parents to show respect to their teachers. Abdul Majid et al. (1999) gave the example of Malay parents giving a cane to the teachers when they sent their children to religious classes in the past. Such a practice symbolizes power, trust and respect granted to the teachers in teaching their children. The children were trained to respect and accept the knowledge of the teachers. However, in relation to learners being responsible in managing their learning, findings from recent research on autonomy among Asian students in China (Huang, 2006), Hong Kong (Braine, 2003) and Japan (Smith, 2003) indicate that many Asian students want to take charge of their own language learning. This has implications for selfregulation among Malaysian language learners.

This research on self-regulation in language learning continues the trend in general academic learning, showing that self-regulation is a vital skill for students.

\section{Cultural influences on self-regulation}

In the area of teaching and learning English as a second language in Malaysia, there is lack of research on self-regulation. Montalvo \& Torres (2004) argued that although considerable research has been conducted on self-regulation in educational settings, most is situated in Western contexts and they questioned the generalisability of the findings to subjects from other cultures. Several studies have found evidence that educational and cultural differences could contribute to differences in the self-regulated learning behaviour of students. The concept of self in self-regulated learning is a construct influenced by others and the learners' cultural environments (Pillay, Purdie, \& Boulton-Lewis, 2000). Findings from Pillay, et al.'s (2000) study on the role of cultural influences and educational context provided evidence for the role of culture in affecting both Australian and Malaysian students' self-regulated use of learning strategies. There were differences in how the two groups of students acknowledged their 
individual responsibility to learn. The Malaysian students showed a higher sense of obligation to learn (Pillay, et al., 2000). This finding was related to the collectivist nature of Malaysian society where, for Malaysian students, obligation to learn is a responsibility to themselves and those around them. Moreover, the Malaysian students showed more persistence compared to the Australian sample. The findings show that the Malaysian students had significantly higher scores for most of the motivational beliefs and learning strategies. Pillay and colleagues concluded that their findings provide evidence contrary to the conception of Asian students being passive in their learning.

Finkbeiner (2008) stressed that individual and cultural diversity influence language learning decisions and choices. They affect the construct of learning success, which needs to be defined according to the learners' sociocultural backgrounds, their values, their attitudes to learning, the specific goals set and the methods applied. Thus, my study to understand the self-regulation of ESL learners at a Malaysian university provides a localized perspective on learners' use of self-regulation strategies in the context of language learning. McInerney (2008) believed that the use of Western principles of strategy training to facilitate students to develop into more self-regulated learners may not be successful in non-Western countries. Countries vary in educational contexts, as well as in ideals and viewpoints about education. McInerney (2008) considered how cultural differences influence the importance put on education, the relative importance of ability and effort in achievement, and the importance of social support in academic achievement. Each of these three factors has been associated with effective self-regulated learning (McInerney, 2008). Malaysian tertiary level ESL students, who live in a multi-ethnic and multicultural society and who have undergone an exam-oriented education system, might exhibit a different form of self-regulation from other language learners in different contexts. In the case of learners in diverse settings, there could be tension between what is expected of them educationally, socially and culturally (McInerney, 2008). Research shows that cultural group differences are important precursors of students' use of SRL processes (McInerney, 2008; Park, 2000; Salili, Fu, Tong, \& Tabatabai, 2001). The two studies by Purdie, Hattie, and Douglas (1996) and Purdie and Hattie (1996), studied the role of cultural influences and 
educational context on Western and Asian students' use of learning strategies. The results of these two studies suggest that culture plays a role in influencing both Australian and Japanese students' self-regulated use of learning strategies.

Members of societies share a characteristic pattern of behaviours, responsibilities, beliefs, and values that vary in a number of ways from other cultures (Salili \& Hoosain, 2007). For example, individuals from individualistic and collectivistic cultures have different perceptions on self-representations, and their role in the family, community and society, and there is evidence that such perceptions have an influence on psychological processes of cognition and selfregulation (Chiu, Salili, \& Hong, 2001). In an individualistic society that is typical of Western cultures, individuals are motivated to undertake actions that allow for the expression of one's important self-defining, inner attributes (Salili, et al., 2001). Hence, academic success and goals are expressions of individual aspirations and strivings for one's own endeavours. Personal agency beliefs of self-efficacy and self-concept may possibly play a role in academic achievement.

However, Asian behaviours may be better understood within the context of collective and interdependent societies, where individuals behave in ways that would develop their relatedness to other individuals in the community (Chiu, et al., 2001; Chong, 2007). In such societies, there is stress on academic achievement and competition, and students are driven to strive to fulfil expectations of parents and society. Rather than personal accomplishments, making one's family proud, saving face and eluding shame may be a greater reason for achieving success (Salili, Chiu, \& Lai, 2001).

While a self-regulatory theory that is conceptualized in a Western individualistic frameworks suggests that self-efficacy is the fundamental factor in academic success (Bandura, 1986, 2001), findings from Hardie (2009) imply that selfefficacy for learning was not the significant factor for the Mainland Chinese students' academic success; instead effort regulation appeared to be the factor that distinguished the successful students from the less successful. However, Chong (2007) suggests that East Asian students in collectivistic and achievementoriented societies may self-regulate and be motivated more by their self-efficacy beliefs than by the fear of failure. 
Because of the inconsistent findings of previous research in the area of selfregulation in academic achievement among Asian students, this study makes a significant contribution to this area. Many East Asian societies like Malaysia are exposed to and embrace certain aspects of Western ideologies, particularly those concerning Western beliefs about education, signifying a picture of contradictory social forces at work in influencing sought after educational outcomes. Thus, it would be of interest to examine the relevance and usefulness of self-regulation in these Asian contexts. With these questions in mind, the present study aimed to examine the self-regulatory learning of tertiary students learning English in Malaysian context where the students are exposed to Western individualistic philosophies but are at the same time rooted in Asian values. This present study contributes to the literature by extending research on self-regulation among language learners by investigating language learners in Malaysia's multicultural and multilingual context.

\section{Chapter summary}

This review of literature indicates that self-regulation research carried out internationally and in Malaysia specifically, shows that self-regulated learning is linked to positive educational outcomes and desirable characteristics of students. Research on self-regulation in language learning has mostly been carried out in Western educational contexts. However, there is little published literature on SRL in the Malaysian language learning context. The applicability of findings from Western educational contexts to Malaysian ESL learners is questionable as the language learning context differs. Malaysian ESL learners learn and use English in a multicultural and multilingual context. The context of my research is at a public university where English is one of the compulsory courses. English is the medium of instruction for certain courses; however, the university medium of communication is mainly Bahasa Melayu. My study considers how individual ESL learners in this context manage their language learning through self- regulation.

Many of the findings of international studies are based on the Motivated Strategies for Learning Questionnaire (MSLQ). The use of this questionnaire to investigate SRL may not completely portray SRL behaviours, and may not be able to fully capture contextual factors influencing students' self-regulation. A 
qualitative approach to researching self-regulation among tertiary level learners extends knowledge of SRL and allows the complexities of the Malaysian context to be considered. 


\section{CHAPTER THREE: Theoretical Framework}

\section{Introduction}

In this chapter, I present the social cognitive theory of self-regulation that is drawn upon in this thesis.

\section{A social cognitive theory of self-regulation}

Bandura's (1986) social cognitive theory emphasizes the separate yet interdependent contributions of personal, behavioural, and environmental influences in human functioning. These three influences interact through a process that Bandura (1986) termed reciprocal interaction, in which each component affects the other two.

Bandura's triadic reciprocality (as shown in Figure 3.1 ) in the social cognitive theory sees a person's performance as a series of mutual interactions involving behavioural, environmental, and personal variables.

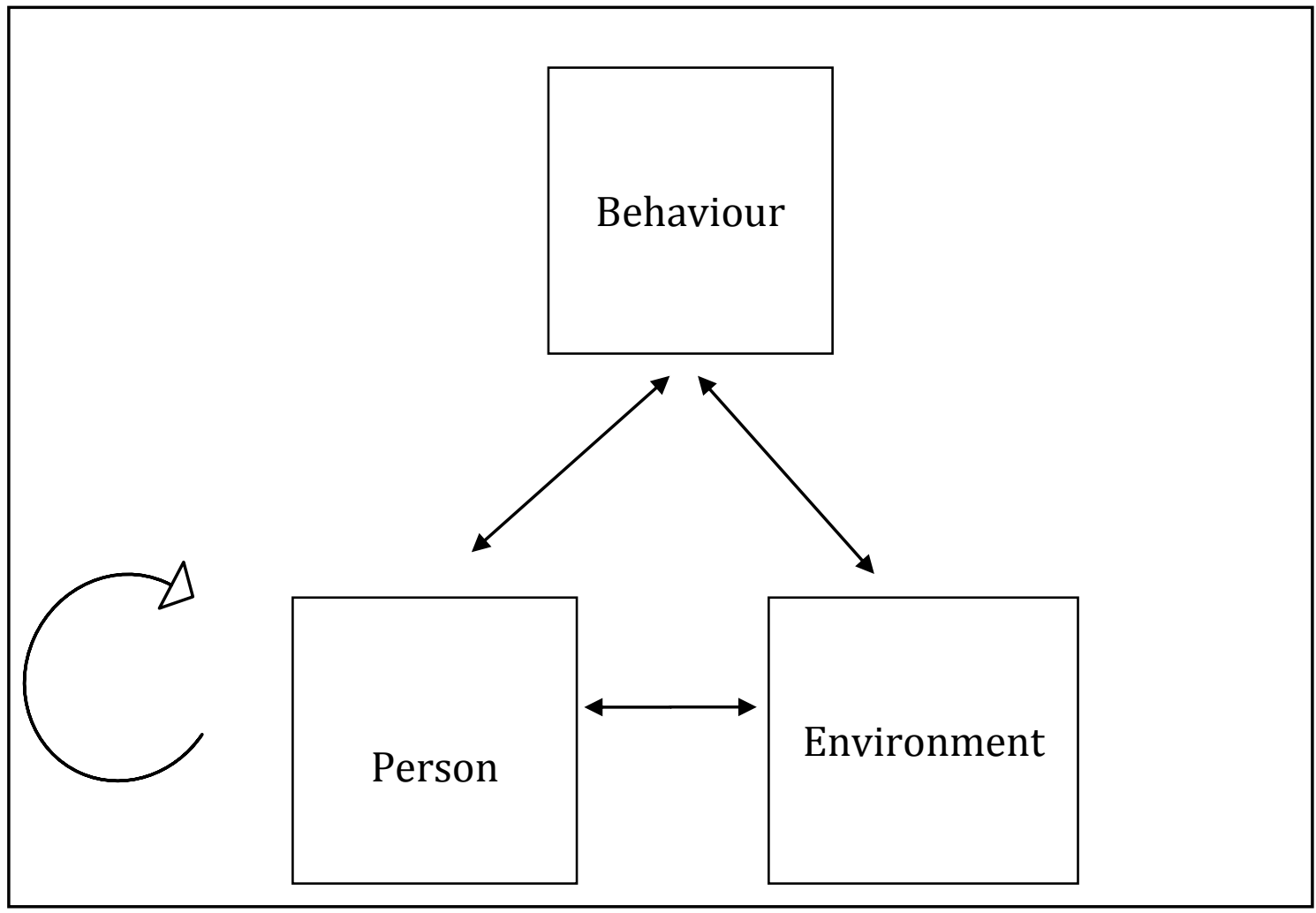

Figure 3.1: Model of triadic reciprocality. Adapted from Schunk, et al. (2008, p. 127) 
This framework of triadic reciprocality is described as follows:

In the social cognitive view people are neither driven by inner forces nor automatically shaped and controlled by external stimuli. Rather, human functioning is explained in terms of a model of triadic reciprocality in which behaviour, cognitive and other personal factors, and environmental events all operate as interacting determinants of each other.

(Bandura, 1986, p. 18)

This behavioural-environmental link can be illustrated by students' behaviours and classroom environments. For instance, classroom environmental influences on students' behaviour occur when a teacher presents information and directs students' attention to the teaching by instructing them to focus on the teaching. Thus, the teacher instruction (environmental influence) on behaviour happens when students focus their attention (behaviour) on the teacher's teaching. Conversely, students' behaviour can change the instructional environment when students do not manage to answer a teacher's questions correctly. Thus, the teacher has to explain the material again before moving on to new material.

The behavioural-personal link is shown when self-efficacy (a personal factor) influences effort (achievement behaviours). Students' behaviours also can change efficacy beliefs. As students work on academic tasks, they can see their progress toward their goals. As a result, students believe that they are capable of progressing and achieving success, which increases their self-efficacy.

Personal and environmental factors influence one another. For example, students with high self-efficacy for learning may view a learning task as a challenge and put effort into mastering it. This may result in a dynamic classroom environment. On the other hand, students with low efficacy may try to evade the task, which can upset the classroom environment. The influence of environment on students' personal factors may be exemplified when teachers give students positive and constructive feedback, which promotes self-efficacy and sustains enthusiasm for learning. Other factors in the environment such as society and culture may also influence individuals' beliefs and behavior. Their beliefs and behaviour may cause their environment to develop and improve (Bandura, 1986). 
The small loop originating from the person factor in Figure 3.1 above indicates that personal factors have an effect on one another. This can be illustrated by the use of an effective learning strategy, which promotes acquisition of skills. Thus, students have more confidence, as they are able to complete the learning task through the use of the effective strategy. Equally, students with higher selfefficacy may choose better strategies than those with lower self-efficacy.

Self-regulation is a cyclical process as the personal, behavioral, and environmental factors typically change in the course of learning and have to be monitored. The monitoring leads to changes in students' strategies, cognitions, affects, and behaviours (Schunk, et al., 2008). Working within a social cognitive framework, Zimmerman and Campillo (2003, p. 239) suggested three cyclical phases for the processes of self-regulation: forethought, performance or volitional control, and self-reflection, as shown in Figure 3.2 below:

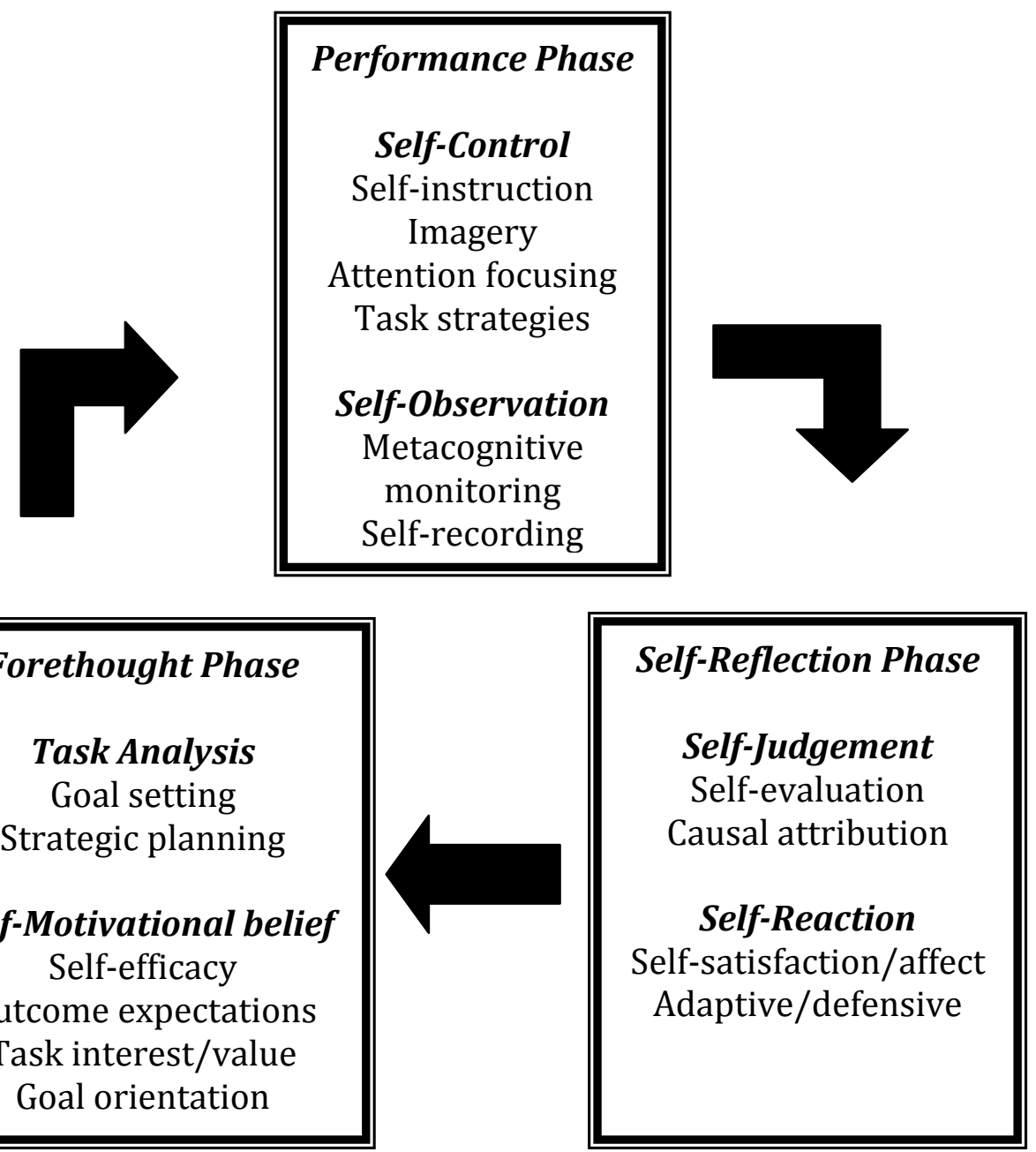

Figure 3.2: Phases and sub-processes of self-regulation. Adapted from Zimmerman and Campillo (2003, p. 239) 
The forethought phase refers to processes and beliefs that precede efforts to learn. Examples of these processes include students' motivation, self-efficacy, goal-setting, and planning. The performance or volitional control phase refers to processes that students use to focus on the task and optimize their performance. Examples of these processes include attentional control, keeping records, and monitoring. The self-reflection phase refers to processes associated with selfobservation. One example of these processes is self-evaluation. During this phase, students compare information about their performance with a standard or goal and they make a judgement about whether an unsatisfactory result is due to their limited capability or insufficient effort.

This three-phase cyclical model of self-regulation shows the interrelationship among self-generated learning strategies, beliefs (such as efficacy and goal orientation), feelings (performance anxiety, fears), and the social and physical environment. In each of these phases a self-regulated learner combines cognitive strategy use with key motivational beliefs that can, in turn, be influenced by social and environmental factors. For example, in the forethought stage, the successful self-regulated learner combines strategic goal setting and planning with strong self-efficacy beliefs to set realistic goals that, when achieved, lead to greater self-efficacy and willingness to strive for higher goals. In the performance phase, learners employ various self-control strategies (attention focusing, selfinstruction) and self-observation strategies (self-monitoring and record keeping), along with cognitive strategies (rehearsing, reviewing). Corno (2001) expanded this phase to include control of the task environment (e.g., organizing instructional materials, information seeking, structuring the study environment) and control of others in the task environment (e.g., seeking help from peers and teacher). Finally, in the self-reflection phase, learners use self-evaluation strategies to judge performance. These judgments depend greatly on assessment of what caused the results, such as whether poor performance is due to limited ability or insufficient effort. Such judgments, in turn, influence future forethought and performance. 
In the following section, justification for social cognitive theory as the main theoretical framework is provided.

Social cognitive theory was chosen as the theory for this research for four reasons. Firstly, this current research aims to examine the personal, behavioural and environmental factors influencing the individual language learners' ability to self-regulate their learning. Therefore, the reciprocal interaction of social cognitive theory may assist in exploring the possible interactions (Bandura, 1986). Secondly, in the social cognitive perspective, self-regulation is seen as situation specific (Hadwin \& Oshige, 2011; Schunk, 2009) and students vary in their self-regulation and strategies use from task to task. Students are not generally self-regulated or non-self-regulated and they do not engage in selfregulation equally in all areas of their studies (Schunk, 2009). This process definition of self-regulation in social cognitive theory may help to explain why a student may self-regulate one type of academic performance but not another (Zimmerman, 2000a). I believe that every language learner endeavours to selfregulate his or her language learning in some way. With this perspective, what distinguishes effective from ineffective forms of self-regulation is the quality and quantity of a learner's self-regulatory processes (Zimmerman, 2000a).

Thirdly, in social cognitive theory, social context and the effect of the environment are important. Social cognitive theory highlights the significance of the environment in the development and use of self-regulation. The environment impacts self-regulation in three ways: "a) the development of self-regulatory functions; b) the provision of supports for self-regulation; and c) the selective activation and disengagement of self-regulatory processes" (Zimmerman, 1990, p. 183). Current thinking in the area of self-regulation stresses the significance of considering contextual variables in models of self- regulation (Azevedo, 2009; Zimmerman, 2008b). For example, Pintrich (2004) developed a conceptual framework for self-regulated learning in the college classroom based on Bandura's social cognitive theory of SRL. One of the innovations in this conceptual framework compared to others is that the contextual factors are included as an area subject to self-regulation. This conceptual framework acknowledges that students can change and modify their context, which is an important self-regulatory skill in learning. This builds on Bandura's (1986) 
triadic theory of social cognition where self-regulated learners recognize the effect of the environment on them and can work out how to regulate the environment by utilizing a variety of strategies. In the context of English language learning in Malaysia, where the exposure and use of English is relatively low, ESL language learners have to regulate their environment to maximize their language use to achieve success in language learning.

Zimmerman (1990) divided environmental factors into two categories; the physical situation of a learning setting and the social experiences that learners undergo throughout the learning processes. A social cognitive theory of selfregulation emphasizes the social aspects of a learning environment. Within this theory, social resources, such as instructor modelling or feedback, are viewed as interdependent with self-sources of motivation. One of the main contributions of social cognitive theory is its illumination of modelling processes (Schunk, et al., 2008). Modelling refers to behavioural, cognitive, and affective changes that result from observing other models (Schunk, 2009). The development of selfregulation results from the interactions among individuals and the social context. From a social cognitive perspective, a student's acquisition and development of strategy progresses initially from social sources and develops to self-sources. In social cognitive theory, there are four levels of self-regulatory development: observation, emulative, self-control, and self-regulation (Schunk, 2009). Beginner learners attain self-regulated learning skills primarily through observing models and receiving appropriate feedback. When the learner's performance approximates the model, the learner is not merely copying the model's actions but is self-motivated to follow the model's example. The third stage is attained when the learner becomes competent with employing the strategies on his or her own. The learner's application of self-regulated learning strategies is internalized at this stage, but is still not fully autonomous. The fourth stage is not achieved until the learner is able to adapt the learning strategies to changing personal and contextual situations. As self-regulation is seen as a process in this study, the modelling processes and levels of self-regulatory development are significant in analysing the participants' self-regulation. 
Interaction between students and teachers, particularly feedback provided by teachers during the teaching and learning processes, is deemed to be an important factor that can influence self-regulated learning. This is because feedback helps to refine and improve students' self-regulated learning skills (Inpornvijit, 2008). Positive interactions and features of the classroom environment can support students' individual efforts to engage cognitively, metacognitively, and motivationally in classroom tasks (Paris, et al., 2001). Teachers can facilitate co-regulated learning by building social supports within classrooms such as through creating opportunities for collaboration among students on tasks like pair and project group work or discussion (Perry, 2002). In the literature review of Malaysian language learners, I have illustrated that these social forms are important in a Malaysian language learning context.

Fourthly, the individual-in-context perspective (Pintrich, 2000b) in the social cognitive theory of self-regulation allows for the understanding of person-social dynamics in group work (Volet \& Mansfield, 2006). The individual-in-context perspective allows me to understand the participants' self-regulation when working in a small group. One of the assessment tasks in the participants' language course is a group project. In achieving personal goals, efforts to regulate group members' behaviours, motivation and emotions may take place in collaborative tasks (Randi \& Corno, 2000).

The emphasis on the interaction between social context and individual attributes in the social cognitive theory of SRL is in line with the perspective that language learning is a social practice. Studies on language learning in a Malaysian context have provided evidence that language learning is a social practice (Che Musa, Koo Yew, \& Azman, 2012; Lee, 2003; Rajadurai, 2010). The significance of this social dimension has encouraged researchers to look at language learning from a social psychological perspective instead of a traditional linguistic perspective (Dornyei, 2006).

According to Zimmerman (1989a), a social cognitive approach to self-regulated learning has two advantages. Firstly, this theory is able to distinguish personal factors from environmental factors and can explain the relative influence of each factor. This is unlike other theories such as phenomenological theory, which 
places less emphasis on environmental factors in relation to self-regulated learning. In addition, the social cognitive approach relates learners' selfregulated learning processes to particular social experiences like communications involving learners and teachers, and can explain reciprocal impacts. Secondly, the social cognitive theory has also identified two key processes in self-regulated learning, which are self-efficacy and the use of selfregulated learning strategies (Zimmerman, 1990). Self-efficacy is defined as motivational thinking regarding one's abilities to systematize and execute actions essential to achieving a designated performance level (Bandura, 1986). Selfregulated learning strategies, as part of self-regulated learning, are defined by Zimmerman (1990, p. 5) as "actions and processes directed at acquisition of information or skills that involve agency, purpose, and instrumentality perceptions by learners". Social cognitive theory relates these two processes to motivation and achievement, thus offering a more holistic view on learning strategies, motivational beliefs, and academic performance. The social cognitive theory offers a more complete explanation of the influences of self-regulated learning than other theories, as it emphasizes the role of environmental, personal, and behavioural factors. It views SRL as not solely an individual skill or knowledge, but also an event that includes social aspects of interactions. For this reason, Bandura's $(1986,2001)$ social cognitive theory serves as the theoretical framework in this study to investigate the participants' self-regulation in language learning, as findings from previous studies on self-regulation in language learning show that personal, environmental, and behavioural processes are seen as interdependent when language learners are completing language learning tasks (Bown, 2009; Gao, 2010; Mezei, 2008).

\section{Chapter summary}

Self-regulation is viewed as a triadic reciprocality, and there are three interdependent elements of this construct: behavior, environment, and self. In the social cognitive theory of SRL, every individual attempts to self-regulate in some way, and there is no individual who is not self-regulated to some extent. Social cognitive theory of self-regulation highlights the influence of environment in the development and use of self-regulation. Social context and social interactions play a significant role in the execution of self-regulation. Thus, in the 
social cognitive theory of SRL, self-regulation is seen as a relationship, instead of an individual attribute. Individuals' self-regulation depends on the opportunities available to them and supportive contexts. Social cognitive theory sees selfregulation of learning as developing from social modelling experiences and progressing through increasing levels of self-directed functioning. The choice of social cognitive theory as the theoretical framework for this study indicates that a qualitative case study approach to this research is appropriate to explore the self-regulation of ESL learners and to understand how self-regulatory mechanisms shape their language learning behavior, and to examine the personal and contextual factors that might act as facilitators or constraints on the participants' self-regulation. 


\section{CHAPTER FOUR: \\ Methodology}

\section{Introduction}

Having reviewed research literature that is pertinent to this thesis, the discussion now turns to methodological matters. The purpose of this chapter is to present the process of investigation used in this study. This chapter starts by situating my study within a philosophical context. This draws on educational research literature to provide a rationale for the choice of a qualitative case study approach to this research. The next part elaborates on the research context, data collection, tools and procedures, data analysis processes, ethical considerations, trustworthiness of the research and findings, and the researcher's role pertinent to this study.

\section{An interpretivist paradigm}

Research is guided by research paradigms, which are views of how the world can be understood (Denzin \& Lincoln, 2005). The research paradigm not only determines how a study should be conducted, but also raises issues about the focus of a study and approaches employed to interpret the data (Hammersley, 2002).

In seeking an understanding of tertiary level learners' self-regulation in English language learning, I have situated this study in an interpretivist framework. The rationale for positioning this study within an interpretivist paradigm is outlined as follows. The emphasis within an interpretive paradigm is on exploring, describing and clarifying human experience and considering the effect of context on understanding that experience. Denzin and Lincoln $(2005$, p. 3) state that "qualitative researchers study things in their natural setting, attempting to make sense of or interpret phenomena in terms of the meanings people bring to them". Qualitative researchers within the interpretive paradigm consider knowledge to be constructed within participants' minds and to be subjective and personal by nature (Cohen, Manion, \& Morrison, 2007). Each learner is likely to have a different interpretation based on his or her perspectives and learning experiences. Each learner's interpretation will collectively create multiple 
realities that enhance the researcher's understanding of their learning process in a specific context. Thus, the interpretive paradigm is appropriate for this study to understand individual tertiary level English language learners' self-regulation and the factors influencing their use of self-regulatory strategies.

\section{Qualitative research}

This research employed a qualitative methodology within an interpretivist paradigm (Denzin \& Lincoln, 2005; Guba, 1990). A qualitative research approach is consistent with inquiry situated within an interpretivist paradigm. Cohen, et al. (2007) outline six features of a qualitative study which are relevant to my chosen approach to the research. These include the naturalistic and interpretive nature of inquiry, the researcher as the means by which data is gathered, the voice of the participants, attention to the particular, and credibility of the research processes and outcomes. Creswell (2009) also includes characteristics such as emergent design, purposive sampling, and early and on-going inductive data analysis. A qualitative researcher is concerned about "understanding the meaning people have constructed, that is how they make sense of their world and the experiences they have in the world" (Merriam, 2001, p. 6). Merriam positions the emphasis of qualitative inquiry on participants' insights and experiences and the approach they take to make sense of their lives.

This study sought to complement the existing literature on self-regulation in second language learning, and utilised less commonly used methods, that of semi-structured interviews and classroom observations as the primary means of data collection. With this approach, the emphasis in collection and analysis of data was on understanding and interpreting the participants' own perspectives on self-regulating their English language learning. This approach was seen to be the most appropriate for gaining an in-depth understanding of the learners' selfregulation in this context.

In this study, self-regulation is seen as a process which includes "cognitive, ... motivational, emotional and social factors" (Puustinen \& Pulkkinen, 2001, p. 280) that the participants apply to achieve their language learning goals. Selfregulation is perceived as a process through which the individual learners apply their agency (Bandura, 2001). In my study, the participants' SRL is seen as a 
“developing [and dynamic] process" (Boekaerts, 2005, p. 208), and accordingly this study was carried out over an extended period of time (three months - the duration of the course taken by the students). Hence, qualitative inquiry suits the purpose of this study to explore and understand the self-regulated learning of Malaysian English language learners as they embark on a language course at a public university and to examine the personal, motivational, and environmental factors that may have influenced their use of self-regulatory strategies.

Qualitative methods are appropriate for capturing the dynamic and diversified nature of the SRL phenomenon and also to produce rich description of SRL in real contexts and in real time (Winne \& Perry, 2000). Zeidner, et al. (2000, p. 759) comment that the use of experimental designs or correlational methods may not "capture the dynamic and transactional process of self-regulation optimally". A methodology that captures the complexities of students' self-regulation over a period of time provides new insight into this area in that it allows researchers to gain a nuanced understanding of what these conceptions mean for individuals in a specific context (Butler, 2002). My study extends the work in this area by providing learners' perspectives on the patterns of self-regulatory strategy in a Malaysian university context.

Self-reporting questionnaires such as the Motivated Strategies for Learning Questionnaire (MSLQ) have been the most-utilized instruments to study the different processes in self-regulated learning. Pintrich (2004) comments that one of the weaknesses of the MSLQ is that it cannot measure student affect, which is interconnected to self-regulatory behaviour. Different motivational beliefs may promote and sustain different aspects of self-regulated learning (Pintrich, 1999). Methods like observations and interviews explore self-regulation as a process rather than capturing questionnaire responses at a single point in time (Butler, 2002).

Multiple methods may provide more insight into exploring self-regulation as a process. Data can be collected by observing participants completing academic tasks, and from questioning them about their understandings and reasoning for behaviours observed (Perry, 2002). From observations and interviews, I gained in-depth data of the participants' self-regulated learning, including knowledge of 
their environment.

All research methods have weaknesses. One concern with interviews which rely on self-reporting is the probability that participants will purposefully self-report in a manner which allows them to look good in front of the interviewer, or selfreport inaccurately because of a lack of self-knowledge (Cohen, Manion, \& Morrison, 2007). During observations, the learners might behave differently when the researcher is observing them. The use of a number of diverse methods or sources of data (triangulation) serves to minimise the risk of these issues (Denzin, 2001).

Case study was used to guide the research process within a qualitative research paradigm. The rationale for the choice of case study method is described in the next section.

\section{Case study research design}

A case study design was used in this study to understand student learning experiences (Stake, 2000). A case study allows researchers to examine cases or phenomena in a real-life context. Merriam (2001, p. 19) states that case study design focuses a researcher on "the process rather than outcomes, in context rather than a specific variable, in discovery rather than confirmation". A case study allows participants to be observed and their actions to be analysed in detail within a real-life context. Case study endeavours to do justice to the "embeddedness of social truths" regarding actions within a highly contextualised frame, compared to the uncontextualised generalisations made from large scale quantitative research studies (Johnson, 2005, p. 24). This research design provides rich and vivid, subtle and complex accounts in comparison to crosssectional quantitative approaches (Cohen, Manion, \& Morrison, 2000). The investigation of a specific, bounded case allows researchers to investigate contextual factors that may have an influence on the phenomenon being studied. Understanding contextual influences may lead to a better understanding of language learning issues and the complexity of self-regulation (Wang \& Pape, 2004). 
Case study data may be drawn from multiple sources like interviews, observations, and document analysis (Merriam, 2001). Thick description is used to explain the events, phenomena, settings, and participants in detail (Geertz, 2001). This allows readers to compare and consider the findings to their own situations and contexts.

Despite its advantages, the use of a case study approach may have some disadvantages. The findings of a case study cannot be generalised to a population because a case study involves only a small number of participants. Researchers also have to be aware of the possibility of bias in reporting findings because only researchers know the criteria used for selecting the information to be reported (Cohen, et al., 2007).

When conducting a case study, researchers need to distinguish between a case and a case study. Merriam considers a case as "a thing, a single entity, a unit around which there are boundaries" (1998, p. 27). Merriam (2001) suggests that by investigating more than one case, researchers can gain variation across the cases and strengthen the interpretation of the findings.

\section{Interpretive case study}

The purpose of the research study determines the type of case study chosen. Interpretive case study researchers analyse the data to "develop conceptual categories or to illustrate, support, or challenge theoretical assumptions held prior to the data gathering" (Merriam, 1998, p. 38). The interpretive aspect of this type of case study draws on existing theory and contributes to theory building through the explanation of the influence of contextual factors on the phenomenon being studied. This type of case study is pertinent for language learning research that seeks to understand language learners' experiences. Theoretical explanations are developed based on the interpretations of the data collected. The openness of interpretivism allows a researcher to approach the complexity of the phenomenon studied. This present study and its analysis is positioned partly through the lens of Bandura's (1986) theory of the reciprocal causation of self-regulation. As an interpretivist, a researcher presents an explanation of why and how something is taking place and provides an interpretation of what is seen, heard, and understood. The focus is on identifying 
and interpreting patterns of learners' responses as a result of their own knowledge and experiences (Creswell, 2009). The researcher functions as the main research instrument, and he or she focuses on in-depth interaction with the participants to gain access to their multiple perspectives with regard to their learning process. From the in-depth interactions with the participants, the researcher forms the interpretations by "exercising subjective judgment, analyzing and synthesizing, and all the while realizing his own consciousness" (Stake, 1995, p. 41). Moreover, a researcher's interpretation might be influenced by his or her own background, context, experiences, and prior understandings. Creswell (2003, p. 182) states that a qualitative researcher filters the data through a "personal lens that is situated in a specific socio-political and historic moment". Denzin and Lincoln (2008) argue that all research is value-bound because of influences from the researcher's own personal values, the paradigm adopted to guide the inquiry, the theory through which the research is carried out, its interpretation, and the values in the research context. They further stress that all the four factors must reinforce each other to achieve meaningful results.

\section{Research questions}

This study was carried out to address the gap identified from the literature review (Chapter Two). The research questions in this study provide the investigative purpose. This case study explores the self-regulation of six learners at a public university in Peninsular Malaysia in order to understand how selfregulatory mechanisms shaped their language learning behaviour. This study also aimed to examine contextual factors that might act as facilitators or constraints on the participants' self-regulation. It was hoped that the case studies of the English language learners would provide detailed description of selfregulatory mechanisms among a group of tertiary level students in the context of Malaysia. 
Thus, the case study was intended to investigate the following research questions:

1. How do the English language learners in a Malaysian university use SRL strategies?

2. What motivational influences on SRL strategy use are reported by the participants?

3. What environmental influences on the SRL strategy use are evident among the participants?

To answer the research questions, I used qualitative data collection methods and utilised the concept of reciprocal causation developed by Bandura (1986) to analyse the data.

\section{The research context}

This section introduces the context in which the research study occurred. The research site, language course, and research participants are presented.

Research site

The setting of this study was a public university in Malaysia. The selection of the university was purposive to find ways to help English language learners at this particular public university manage their language learning better and improve their standard of English. The university uses Bahasa Melayu as its medium of instruction. Even though the national language is the main language, the university has developed policies to inspire students to improve their proficiency in English as well as other important foreign languages like French, Mandarin, and Japanese. As English is the language of academic publications, medicine, science and technology and other fields, it is important that the undergraduates and graduates of the university master the English language in order to have access to the world's 'storehouse of knowledge'. All undergraduates have to take two semesters of English to equip them with necessary language skills (reading, writing, listening and speaking) so that they can cope with their studies, as the science and technology courses are in English, as are the majority of the study materials. 


\section{Getting access at the research site}

I obtained formal approval from the Educational Planning and Research Division (EPRD) to carry out this research. The approval letter is in Appendix C. Upon receiving permission from the EPRD, I obtained approval to conduct research at the research site from the Director of Centre of General Studies and the Head of Language Department (Refer to Appendix D 3- Head of Department consent).

I worked through the Director of Centre of General Studies and the Head of the Language Department to gain access to the research site for data collection. Once consent was granted, I emailed the English language teachers inviting them to take part in the study. While some teachers were interested, their students were not. Finally, there were nine volunteers from three classes (seven from class A, one from class B and another one from class C). However, the teacher of class A did not recommend two of the students who volunteered, citing their attitude. These two students were not recruited as participants as I was worried they would not be fully committed to the research. Choosing purposive samples is crucial to the quality of data gathered. The participants had to be committed to being part of the study for the complete duration of three months. This involved a willingness to be observed and interviewed, and to share their weekly learning diary, relevant documents such as their writing drafts, concept-mapping, drafts of their project paper, and notes on preparation for class assignments and assessments.

In purposive sampling, researchers "deliberately seek certain types of elements because those cases are judged to be typical of some case of interest to the researcher" (Davidson \& Tolich, 2003, p. 118). The participants chosen were prepared to share their knowledge and experiences. Although all the participants voluntarily participated for the study and showed enthusiasm, less data were generated by three participants, Ares, Unblocker and Confidence Hero. They produced less data, such as diary entries, and fewer documents related to language course work, such as drafts for writing. This resulted in less extensive description of these three cases' self-regulation, use of self-regulated learning strategies and the factors that influence their use of these strategies. 
I began the data collection with the seven students. Midway through the data collection period, a participant dropped out of the study. She did not respond to my requests for further interviews, observation, and submission of diary and relevant course documents. As a result, I stopped contacting her, as I felt that she was no longer interested in the study. The transcriptions from her initial interview, diaries and notes on class observation were removed from the data.

\section{Language course}

The language course that provided the context for this study was Academic Communication 1 course offered in semester 2 of the 2009/2010 academic year. This first level of the language course is offered to undergraduates who have passed the Malaysian University Entrance Test (MUET) with either Band 3 or 4 as well as those students who have taken the Foundation English course. Students take this language course in their first year. Academic Communication 1 course is the first English course taken by the majority of the undergraduates before they proceed to higher level English proficiency courses. Those undergraduates who scored Band 1 or 2 in their MUET examination, had to take the Foundation English course before registering for this Academic Communication 1 course.

This course focuses on equipping the undergraduates with reading and speaking skills to ensure they can function effectively in a tertiary academic setting. Writing is incorporated into the group report and grammar input is provided throughout the course when needed, such as in the revision of a project report. Grammar is taught usually in relation to certain features that arise from the exploitation of the reading passages. Students spend 4 hours (divided into two 2hour session) each week for a period of 12 weeks. Students have a minimum of 56 hours of class instruction. To assess students' performance in the course, summative assessment and a final exam are used. The summative assessment components are information sharing (individual assessment) and a group project. Students are expected to work in groups outside of the classroom to complete the project. Marks are awarded based on students' performance in both individual and group tasks. The course description is available in Appendix E. The grades are incorporated in the calculation of the Cumulative Grade Point Average (CGPA). 


\section{Participants}

Each of the six language learners selected for participation in the study was a case. Participants ranged in age from 19 to 25 and there were two females and four males. Four of them were from rural areas and two were from urban areas. All of them were in their first year of study. The participants stayed at the residential colleges at the university. One participant took the Academic Communication 1 course after completing the Foundation English course but for other participants it was their first language course.

I chose university undergraduates as the participants as they must gain a high level of proficiency in English; a low level of English can impede students' acquisition of knowledge as most of the course materials are in English. The increasing use of English in academic contexts has made English language skills essential for academic achievement in Malaysia, especially in the fields of science and technology.

Because data collection took three months, selection of participants was based on their willingness to participate, to keep in contact, and their ability to communicate effectively with me. Dornyei $(2007$, p. 126) highlights that in a qualitative inquiry, the main goal of sampling is to find individuals who can provide "rich and varied insights into the phenomenon under investigation" to maximise what can be learnt.

The next section describes the methods used to collect data for analysis in this study.

\section{Data collection}

This section introduces the qualitative data collection tools, data collection procedure, and the pilot study.

\section{Qualitative data collection tools}

Using a range of methods enabled me to explore the complexity of the participants' self-regulation and to provide a rich, contextualised description. Multiple methods of data collection were employed to ensure internal validity and reliability of the collected data and also to triangulate the findings (Creswell, 
2008). Data were collected through semi-structured interviews, language learner diaries, observation, stimulated recall, document analysis (such as students' writing and project drafts, and course documentation such as course description and textbooks) and researcher's field notes.

\section{Semi-structured interviews}

Semi structured interviews with the learners and language instructors functioned as the main means of exploring the learners' self-regulation in managing their language learning. Interviews enabled me to gather rich and personalised information (Mason, 2002). Interviewing methodology can contribute to both theoretical understanding of self-regulation processes and strategies, and to the understanding of the development of the participant in context (De Groot, 2002). Semi-structured interviews contribute to comparability across cases whilst allowing for sensitivity to the uniqueness of each participant's experience (Huberman \& Miles, 2002). Each learner was interviewed three or four times. The interviews allowed participants to explain events in their own words and from their own perspectives (Hancock \& Algozzine, 2006). Of particular interest was the identification of the selfregulation strategies most extensively used by the language learners that helped them in their process of language learning. Through interviews, I hoped to discover and to be able to portray the "multiple views of the learners" (Stake, 1995, p. 64) towards self-regulation processes.

Semi-structured interviews suited my case study research design because I could ask predetermined but flexibly worded questions. The interview questions were open-ended and recursive where further questions were asked based on findings in the previous round of data collection. This allowed me to probe more deeply into issues highlighted by the participants in order to get more clarification and explanation; in the follow-up interview, certain interview topics resulted from questions or confusion from the previous interview. Archer (2001, p. 100) argues that "relatively open-ended questioning may avoid dictating some areas of investigation while ignoring others that may be more salient to students". The participants were encouraged to elaborate and provide examples. For example, when a participant wrote in her diary that she wanted "to speak with correct pronunciation, able to understand English in different slang and speak with correct 
tone", I enquired "Why do you think it is important to do so?". From her elaboration, I understand that conveying and getting the correct meaning in a conversation is important to her. In the interviews, I also made notes on each participant's answers, interactions, and behavioural reactions to the questions asked.

The interview questions were shaped around the constructs which underlie Pintrich and De Groot's (1990) Motivated Strategies for Learning Questionnaire (MSLQ). These constructs include three motivational dimensions (expectancy, value, and affective) and two learning strategies dimensions (cognitive and metacognitive strategies and resource management strategies). Examples of interview questions were "What is/are your goal(s) in language learning?" to explore the learners' intrinsic or extrinsic goal orientation; "Do you believe that you will be able to learn the materials in the course?" to explore the learners' beliefs that their efforts to learn will result in positive outcomes; and "What were the strategies that you used to facilitate your language learning?" The interview enabled me to elicit individual elaborations of how these constructs were manifested in the participants' accounts of their thoughts and actions. Each interview lasted between 45 minutes and one hour. Interview questions are found in Appendix F (2).

There were three to four interviews with each participant as shown in Table 4.1 below.

Table 4.1: Number of interviews with the participants

\begin{tabular}{lllllll}
\hline Participants & Sepatu & Rae & Stanza & $\begin{array}{l}\text { Confidence } \\
\text { Hero }\end{array}$ & Ares & Unblocker \\
\hline $\begin{array}{l}\text { Number of } \\
\text { interviews }\end{array}$ & 4 & 4 & 4 & 3 & 3 & 3 \\
\hline
\end{tabular}

All of the interviews were conducted in English or Bahasa Melayu. Before the start of the interview, I told participants that they could use Bahasa Melayu, or code switch when answering the questions, which gave students the choice to decide on what language would provide the richest explanation, Mostly, the participants code-switched during the interview; however two participants insisted on using English, as they welcomed the opportunity to practise it with me. I respected their decision, although at times I had to wait and ask further 
questions in order for their meaning to be conveyed. This was because these participants occasionally struggled to find the correct words and phrases; also, due to mispronunciation and grammatical mistakes, their message was not always clear.

I digitally recorded and later transcribed the interviews in Bahasa Melayu before translating them into English. Each interview was transcribed, and the transcription was given to the interviewees to check for accuracy. There were a number of issues in translation like quality and validity which depend on my ability as the translator (Birbili, 2000). Birbili (2000) states that it is essential that the translator be attentive of the cross-cultural differences in words, concepts, and the context when making the translation. Simon (1996, p. 137) contends that:

The solutions to many of the translator's dilemmas are not to be found in dictionaries, but rather in an understanding of the way language is tied to local realities, ... Translators must constantly make decisions about the cultural meanings which language carries, ...

I played an active role in the research process and was aware of my responsibility to portray the intended meaning of the participants' words and actions. For my researcher as translator role, I adapted the process of crosslanguage interpretation suggested by Esposito (2001, p. 571) as shown in Figure 4.1 below to develop a reliable translation and minimise potential threats to validity. 


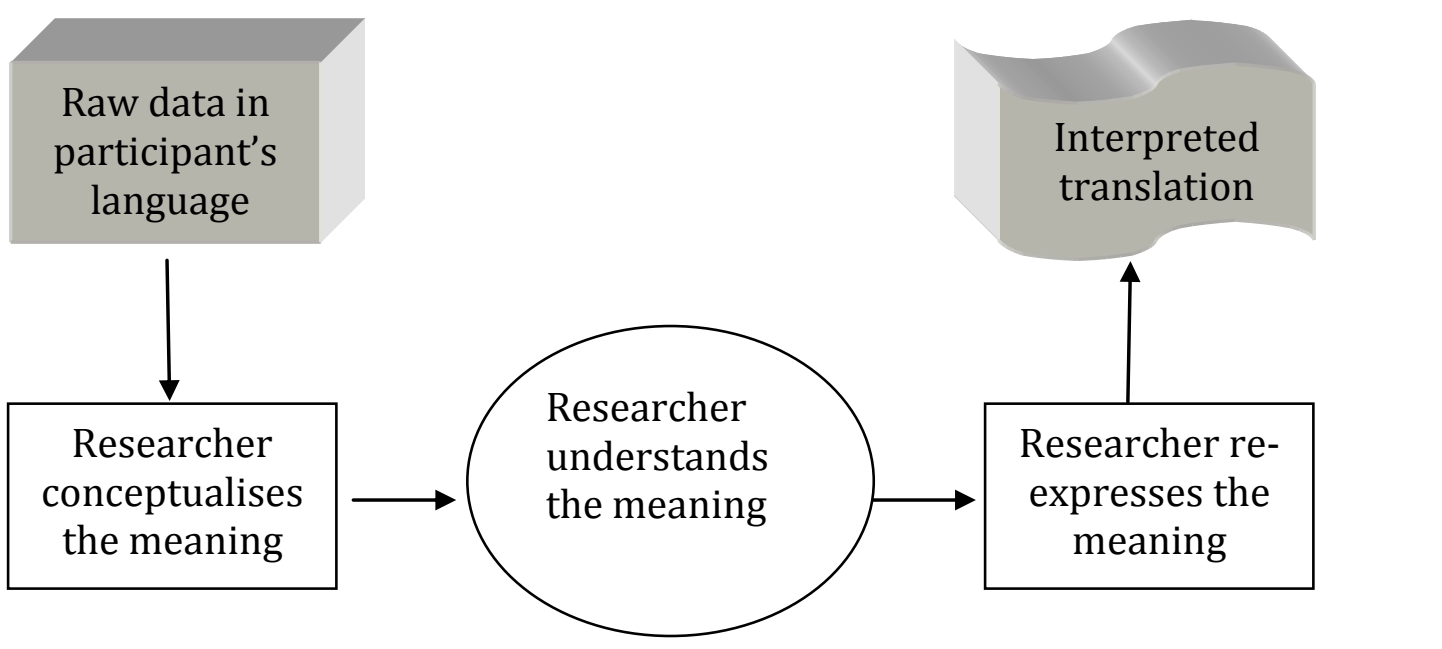

Figure 4.1: Process of cross-language interpretation. Adapted from Esposito (2001, p. 571)

Besides focusing on the vocabulary and grammatical structure of the participants' words, I also considered the participant's situation and the overall cultural context of the source language. For the interviews, I translated incidents or responses that were pertinent to my study instead of translating the entire interview. Translations were prepared for the whole interview only when it was necessary. The example below of the translation that I made from Unblocker's interview data represented the interpretation process.

The following quote was Unblocker's response to the question on his motivation to learn English for the current language course:

Bahasa Inggeris bukan satu kepentingan sebab dah belajar lama. Benda yang sama ulang-ulang. Belajar pun sama je. Result pun tak naik-naik. Sama je. Benda baru tu lebih diutamakan macam subject FEP walaupun resultnya masuk PNGK. Buat macam tu masih boleh survive, tapi tak score sangatlah (in Bahasa Melayu).

The translation is shown below.

Learning English is not a priority. Even if I put effort, my results are the same. I can still pass my English courses, though I cannot score. It is more worthwhile for me to focus on other new faculty courses. 
This response showed his helplessness in achieving better English proficiency due to past language learning experiences. I tried to relate his feeling of hopelessness to his past language learning experiences, where although he has learnt English for nearly twelve years, he has not improved much. Thus, he decided to put emphasis on new subjects at the university. However, it did not mean that he did not realize the importance of English.

I did not translate his response word for word but instead tried to conceptualize the meaning that the participant tried to convey. His further explanation to probe questions on this response clarified my understanding of the issues and challenges faced by him related to English language learning. I saw the technique of producing meaning-based translations rather than word-for-word translations (Esposito, 2001) suited my research as data collection and analysis in qualitative research were dynamic processes and occurred simultaneously (Creswell, 2009). During the data collection process, I interpreted the meaning of my participants' responses and adjusted questions and remarks in response to their answers. This enabled me to ensure meaningful representations of the participants' responses.

\section{Initial interview}

The interviews were carried out at the participants' convenience. The interviews were either carried out at a university office, the participants' faculty, in a small discussion room at the university library, or at the participants' residential colleges. I made sure that the room was free from any internal or external disruptions such as noise. Appointments were made so that the participants were free from other commitments at the agreed time. The initial interview was conducted before the formal observations in order to obtain the participants' background information, past language learning experiences, language learning goals, perceived usefulness of English, their perceived strengths and weaknesses in English language learning, their insights of themselves as language learners, and their views of their responsibilities in the learning process (see Appendix $F$ (2) for questions in initial interview). The initial interview took about 45-60 minutes for each participant. The research objectives, data collection methods and activities were described clearly to each participant before the initial interviews (see student information sheet in Appendix D 1). The participants were given the chance to ask questions about the research project and their 
participation in it. Then the participants were given the consent form to sign and a copy to keep. I asked the participants for a schedule of their language class hours to enable me to schedule the classroom observations. I also gained permission to observe them in their daily activities (such as study group discussion and sports activity).

\section{Follow- up interview (stimulated recall)}

The participants were observed in class or when they were completing out-ofclass language learning tasks such as during group discussion for the group work. In addition to the semi-structured interviews, short stimulated recall interviews took place after the observation. The stimulated recall was conducted soon after observation so that there was a greater likelihood that the reporting would be accurate. The length of the stimulated recall took about five to eight minutes. It was held at convenient places such as the library and cafe. It was used to explore learners' thought processes (or strategies) at the time of an observed language activity or task. As observation cannot capture mental processes, this stimulated recall technique helped in eliciting relevant information on mental processes related to SRL.

The stimulated recall methodology was in the form of a "prompted interview" (Gass \& Mackey, 2000, p. 13). Within the prompted interview, I asked questions regarding observed behaviours (for example: Why did you do that? What were you thinking about then? How does that help you learn?). I also asked questions to gain insight into other aspects of participants' SRL strategies that were unobservable (for example, monitoring and decision making). I used stimuli for the recall, such as giving the participants their written product or reading passages or asking the participants to refer to notes or drafts made for class activities. The purpose of the stimulus is to reactivate or refresh recollection of cognitive processes so that they can be recalled and verbalized. These interviews were to gain the participants' perspectives on the behaviours observed in the classroom and to verify my interpretation of these. Table 4.2 below shows the number of classroom observations and the stimulated recalls conducted. 
Table 4.2: Number of classroom observations and the stimulated recalls conducted

\begin{tabular}{lcc}
\hline Participants & $\begin{array}{l}\text { Number of classroom } \\
\text { observations }\end{array}$ & $\begin{array}{l}\text { Number of stimulated recall } \\
\text { interviews }\end{array}$ \\
\hline Sepatu & 6 & 5 \\
Rae & 6 & 6 \\
Stanza & 6 & 6 \\
Confidence Hero & 5 & 5 \\
Ares & 6 & 6 \\
Unblocker & 6 & 5 \\
\hline
\end{tabular}

There are potential limitations in the use of stimulated recall. Firstly, although every effort was made to ensure the recall was carried out as close as possible in time to the actual event, in some cases the memory structures being recalled may not always relate directly to the event that just occurred. Second, participants may have experienced some interference during the period between the event itself and the recollection (Gass \& Mackey, 2000). However, by careful elicitation and interpretation of data with other reliable data from other methodologies, a stimulated recall methodology can be used for triangulation of data and provided valuable information about some of the complex processes involved in learning a second language (Gass \& Mackey, 2000).

Follow-up interviews were also used to elicit further explanation from the participants about the themes that emerged in the initial data analysis. In the initial data analysis, themes such as challenges in using English, negative emotions related to past and current language learning experiences, and teacher and course factors emerged as important concerns for the learners. Therefore, in subsequent interviews, I focused on the strategies used by the learners to manage their language learning within this challenging context and on learners' use of effective strategies to achieve their language learning goals.

\section{Final interview}

An interview was conducted after the final class observation in week thirteen to elicit the participants' SRL strategies in a more general context. This interview was intended to confirm and elaborate on learners' previously reported and observed SRL strategies. In this final interview, the participants were encouraged 
to reflect on the SRL strategies they had used, their feelings and motivation, as well as on their awareness of environmental factors that support or inhibit their self-regulation in language learning. The participants were also asked to comment on their performance throughout the semester, especially in the ongoing class assessments. The final interview with each participant took about 45 minutes to one hour. Details of the interviews conducted are shown in Appendix F (2).

\section{Observation}

The findings from the interviews were triangulated by observation of participants in and outside the classroom to complement the interviews in providing rich and contextualised descriptions of students' SRL (Patrick \& Middleton, 2002). Language learning comprises both conscious and unconscious aspects and expresses itself in observable and unobservable learning behaviour (Naiman, Frohlich, Stern, \& Todesco, 1978). Thus, classroom observation could only contribute to the recording of overt learning behaviour, of which the learner may or may not be conscious. Information from the observations enriched the depth of each participant's case through capturing classroom behaviours connected to their reactions, struggles, and accomplishments in relation to SRL strategies used while learning English. It also provided the context, like classroom activities, language learning tasks, and teacher teaching techniques that affected the students' self-regulation and their choice of SRL strategies.

Data from classroom observation were additional to the main sources of data, which were interviews and learner diaries. Stimulated recall and on-going interviews were carried out after the observation in order to elicit more data from the participants in this study. From the observation, I was able to identify some of the observable strategies used by the students. These were coded as SRL strategies if they were self-regulated (based on the categories of SRL strategies by Wang (2004) - Refer to Appendix B 1) and if they were planned in order to achieve the participants' language learning personal goals. Data on the participants' language learning goals were collected during the initial interview, which was conducted before the observations. By observing carefully and using field notes, I hoped to remain open to noticing other strategies that might have a self-regulatory purpose but which were not part of the SRL categories of 
previous studies. The observational protocol is in Appendix F (3) - Description of research instruments.

\section{The classroom observation process}

After explaining the research purpose and procedure, permission was gained from the classroom teachers to conduct the classroom observations. I observed all six participants weekly. There were two meetings per week for each class. I employed the "tool of complete observer" (Creswell, 2009, p. 179) to minimise intrusion during the observations. During the observation, I positioned myself so I could clearly see and hear the teacher and student without being intrusive. I did not get too close to the participants. In order not to miss any important data, I had permission from the participants to record their conversation or discussion in class by means of a digital recorder. For class A, four digital recorders were used.

When the teacher had individual conferencing sessions with the students during the class for the information sharing assessment, I observed those sessions that involved the research participants. I observed these events for ten to fifteen minutes based on the length of session for each individual. Since the main purpose of this study was to identify SRL strategies used by each participant, the primary focus of classroom observation was on individual students. I was aware of the possibility of not being able to observe four participants equally at one time (this was the case for the four participants from class A). However, as there are two meetings per week for each class, I overcame this by focusing on just two participants per class meeting. Furthermore, as normally there were different activities within the two hours of class, I focused on a participant for each language learning activity. I did not need to divide attention for participants 5 and 6 , as each was the sole participant in their classes.

Direct observations of events were noted (e.g. Rae refers to a dictionary while answering the past year exam papers; Stanza asks for clarification from the language teacher regarding the final group project presentation and requests teacher feedback on the group project report). Combined throughout the direct observations were researcher's notes. These notes were identified as "Observation Comment" in the field notes and included thoughts and comments 
that arose during field observations. These notes normally related to the behaviours observed, overall classroom environment, and language learning activities and tasks. In order to collect data on the environmental influences on the participants' SRL strategy use, observation notes also included teacher instructions, teacher-student interactions, and student-student interactions.

I also looked for the "emergence of meaning" (Stake, 1995, p. 76) in any single instance during the observations. For example, Rae's attempt to get clarification of the facilities prepared for her final group presentation suggested that she planned for her assessments and the information of the facilities would affect her plan for the presentation. In a post observation interview, when asked about her persistence of knowing the venue and the availability of LCD (Liquid Crystal Display) projector, she answered that she wanted to plan and prepare well for the presentation. She also said that if there was no LCD projector, she had discussed plan B with her group members. From her previous experiences, during the last weeks of semester, it was difficult to get a room with LCD as other lecturers were also having their class assessment and presentation.

... Before the class ended, the class teacher reminded the students of the coming project presentation. Rae raised her hand and asked about the venue of the evaluation and also the availability of $L C D$ for the group presentation.

(Classroom observation, 23 March, 10)

Any questions resulting from observations were made clear after the observation in the follow-up interviews. For example, from his facial expression, I realised that Sepatu Chenta was disturbed when his teacher interrupted his presentation. However, he persisted with the presentation and corrected his mistakes. Right after the assessment session, I treated him to lunch and asked him about his presentation and the incident.

R: How did you feel when you were stopped during your presentation just now?

SC: I felt bad as I had really practised this morning and last night, I had prepared well for this assessment. But ... uh ... when Mr ... gave his comments, I told myself to relax ... not give up ... and ... and continue with the presentation. I must 
continue ... correct the mistakes and explain to him. But ... I'm worried that it will affect my marks.

R: Why did he stop you while you were presenting?

SC: He want me to highlight on the article first ... then only share my personal opinion of the issue

(Interview, 4 February, 2010)

\section{Learner diary}

Diary studies are a significant introspective instrument in language research as they can make available an emic or insider's perspective on participants' learning experiences and processes which may possibly be "hidden" or "inaccessible" through observation and interviews from researchers (Bailey \& Ochsner, 1983, p. 189). Learner diaries give extra insights into the SRL strategies of the learners and enable probing of affective concerns about language learning (Bown, 2009). Diary studies have revealed affective and environmental factors not highlighted by other studies on foreign and second language learning (Bailey \& Nunan, 1996; Mackay \& Gass, 2008). In this research, diary studies were used for the above reasons and for triangulation. The information collected from the learner diary complemented and informed the data from interview and observation. Instructions for the narrative language learning diary can be found in Appendix F (1).

Learner diaries are both research tools and aides to self-regulation. While diary studies can provide valuable insights on aspects of language learning and students may be more open in diaries than in other media (Boekaerts, 2005), the use of diary studies to investigate L2 teaching and learning can provide language learners with metacognitive awareness (Mckay, 2006). This may allow them to take control of future learning, to "own the learning process" they are involved in and to be more self-regulated and autonomous (Murphey, Jin, \& Li-Chi, 2005, p. 85). A factor in becoming a proficient language learner is the ability to reflect on one's own learning and assess the steps to be taken to regulate it (Graham, 1997). As has been reported in Eekelen, Boshuizen, and Vermunt's (2005) study, all the participants in my study reported that the study itself had influenced their learning; the participants reported that they were more conscious of their 
learning than normal. The impact of this research on the participants' use of SRL was further discussed in the researcher's role section in this chapter.

A language learner's diary study uses introspection and/or retrospection (Bailey, 1991). In this study, each participant was asked to write a weekly diary for three months. Writing a language learning diary was not an additional burden to the participants as two of the participants have made writing a diary in English as part of their own strategy for improving their English. As participants in the study, they just added their detailed record and reflection on their language learning experiences and sent that to me. As for the other four participants, sending a diary (electronically or hard copy) once a week was manageable for them. The diary was printed and read on a weekly basis. I responded to the diary by asking for clarification of the diary content in relation to self-regulation via email with the individual participant or during on-going interviews (for example. "So, what do you plan to do?, What are the actions that you are going to take?, Are there any effects to your performance/grade?"). For example, participant four wrote in his diary:

This week assignment, we were supposed to meet sir ... to do a conferencing about the article that we are going to present, however only three students went to see him. As for me, it does mean that I do not want to see him but I have not printed the article. I am also busy participating in the university sports events, planning for a visit for the student bureau and being in charge of the dinner for final year students. So what I've done is, I search for old newspaper and find an interesting article to show to sir, on that day also. What I've learned through this is to adjust my timetable wisely, give room to do assignments rather than fulfilling the times with other stuff.

(Unedited Diary - Ares Mark 111, 22 January, 10)

Three of the participants requested that I correct mistakes in their writing like spelling, grammar, word choice, and sentence structure. I complied with the requests to show my appreciation of the participants' commitment as research participants. Data from diary were analysed similar to other qualitative data, by means of coding techniques and thematic grouping. 


\section{Document analysis}

The analysis of documents can provide a rich source of information with which to complement data collected through interviews, stimulated recall, observation, and diary entries (Hancock \& Algozzine, 2006). In this study, students' notes, course work, assignments (writing and project drafts), and notes and drafts for assessments were collected and analyzed for any evidence of self-regulatory strategies. The students' work provided data on the way the students regulated their learning process (like notes in the margin of a text can be an indicator of ongoing regulation processes). The students' work also gave me the chance to confirm the self-reported data from the interviews and learner diary. Documents also included the course description, textbook, samples of class exercises, and samples of final exam papers discussed in class as a preparation for the final exam. The documents provided essential contextual information that assisted me to analyse the data and contextualise the interviews. The course files and textbooks were examined in order to better understand the course. 


\section{Other data collected}

I also asked the participants to fill in the demographic sheet, which requested information on the learners' age, faculty, major of studies, and past language results (for Malaysian Certificate Examination and Malaysian University Entrance Test). Final course grades were requested from the language instructors with marks for each course assessment after permission from the student participants had been received.

\section{Researcher's field notes}

To enhance the validity and reliability of the study, I kept a field diary during the study. I recorded in the field diary my own thoughts, feelings, experiences, and perspectives during the investigation process. I also noted my reaction and reflections to the interview and stimulated recall sessions and content analysis of the diary and students' documents. The reflective notes included my thoughts, such as my "speculation, feelings, problems, ideas, hunches, impressions, and prejudices" (Bogdan \& Biklen, 1992, p. 121). The notes helped me to reflect constantly on how the data were gathered and interpreted and the part that I played in the process. I was aware of my reflexivity throughout the research process, such as the data collection and data analysis (Richards, 2009). I reflected how my experience as an English language teacher and also as an English language learner might affect the study; I was aware that there might be biases, interests and areas of ignorance. I followed Richardson's (2000) suggestions on note organisation into four categories: Observation notes (ON); Methodological notes (MN); Theoretical notes (TN); and Personal notes (PN). In the log trail, I wrote my reflections on my part in the data making process, as well as any account of changes and discoveries. Writing those reflections was crucial to dealing with the challenges of validity and reliability in this qualitative research (Richards, 2009). To avoid misinterpretation of learners' behaviours, I reminded myself not to make judgements based on my experience as a language teacher. Accordingly, I clarified with the participants any interpretations that I had made about their behaviours. Denzin and Lincoln (2005) argue that the qualitative researcher and the participants interact to influence one another. 


\section{Data collection procedures}

The data collection started in December, 2009 and ended in March, 2010.

Table 4.3: Log of activities during the data collection and analysis processes.

\begin{tabular}{|c|c|c|}
\hline Date & $\begin{array}{l}\text { Data Collection } \\
\text { Activities }\end{array}$ & Analysis of data \\
\hline December, 2009 & $\begin{array}{l}\text { Informal trialling of } \\
\text { interview questions with } \\
\text { 2-3 Malaysian } \\
\text { undergraduates at VUW }\end{array}$ & \\
\hline January, 2010 & $\begin{array}{l}\text { (i) Contact } \\
\text { teacher, identification of } \\
\text { participants, and get } \\
\text { permission for } \\
\text { class observation. } \\
\text { (ii) Seek permission } \\
\text { from participants, } \\
\text { explanation of research } \\
\text { aim, focus, process, and } \\
\text { task required. } \\
\text { (iii) Initial interview } \\
\text { (iv) Observations } \\
\text { (v) Stimulated Recall } \\
\text { (vi) On-going } \\
\text { follow-up interviews } \\
\text { (vii) Collection of } \\
\text { document }\end{array}$ & $\begin{array}{l}\text { (i)Transcription and } \\
\text { preliminary analysis of } \\
\text { the initial interview } \\
\text { (ii) Preliminary analysis } \\
\text { of the fields notes of } \\
\text { observations, } \\
\text { stimulated recall, follow } \\
\text {-up interviews, } \\
\text { document } \\
\text { and diary content. }\end{array}$ \\
\hline February, 2010 & $\begin{array}{l}\text { (i) On-going classroom } \\
\text { Observations } \\
\text { (ii) Stimulated Recall } \\
\text { (iii) On-going } \\
\text { follow-up interviews }\end{array}$ & $\begin{array}{l}\text { (i) Transcription and } \\
\text { further analysis of } \\
\text { the initial interview } \\
\text { (ii) Further analysis of } \\
\text { the fields notes of } \\
\text { observations, follow up } \\
\text { interviews, stimulated }\end{array}$ \\
\hline
\end{tabular}




\begin{tabular}{|c|c|c|}
\hline & $\begin{array}{l}\text { (iv) On-going collection } \\
\text { of document } \\
\text { (v) Weekly reading of } \\
\text { diary entry and } \\
\text { responding to diary } \\
\text { content. }\end{array}$ & $\begin{array}{l}\text { recall, document and } \\
\text { diary content. }\end{array}$ \\
\hline March, 2010 & $\begin{array}{l}\text { (i) Final interview } \\
\text { - Middle of March, } 2010 \\
\text { End of March, } 2010 \\
\text { (i)Member checks for } \\
\text { clarifications and } \\
\text { checking of } \\
\text { interview transcriptions } \\
\text { and data interpretations } \\
\text { (ii) Individual case } \\
\text { analysis } \\
\text { (iii) Cross case analysis }\end{array}$ & $\begin{array}{l}\text { (i) Re-examination of } \\
\text { analysis for initial } \\
\text { interview, observations, } \\
\text { follow-up } \\
\text { interviews, } \\
\text { document, stimulated } \\
\text { recall, and diary content } \\
\text { (ii) Preliminary analysis } \\
\text { of the final interview }\end{array}$ \\
\hline
\end{tabular}

I tried to be open and to respond flexibly to new details or opportunities that emerged during the process of data collection. For example, when one of the participants reported that she had prepared grammatical notes and had them on her hostel wall, I asked for permission to have a picture of the notes be taken as part of the data collection. I also made use of chances to observe and record informal out-of-class activities like group discussions when invited by the participants, and to observe the participants' daily communication when spending time with them, such as during lunches and private study at the university library. 


\section{Pilot study}

The interview questions were informally trialled with two male and one female Malaysian undergraduates who were studying at Victoria University of Wellington. This was to check whether the questions could capture the participants' self-regulation and to make sure the questions in the interview protocol built on one another in order to flow naturally in the actual interview. The questions in a qualitative interview should encourage a positive interaction, ensure the flow of the conversation keeps going, and stimulate the participants to share their experiences and feelings (Kvale, 1996). Amendments (such as simpler wordings or more probing questions) were made to the questions based on feedback given by the students in the pilot study.

Trialling the questions gave me practice as a novice researcher. I sent the transcriptions of the trial interviews to my supervisors for comments. Listening to the interviews and reading the transcriptions made me realise there were times where I could have waited and allowed the interviewee to follow through on certain questions. I was aware that I could make use of more signals (nodding, making responses like "really", "mm") to encourage the interviewee to elaborate more. The use of phrases like "May I know more about your ...", "Why is it so?", "Can you give me some details...?" also helped in probing more comments and input from the interviewees. I also learned that the technique of selecting significant words from the interviewees' answers and repeating them in a questioning tone was also effective in getting the interviewees to contribute more.

This section presented the data collection tools, procedure and pilot study. The following section elaborates the analysis of data, coding technique, ethical considerations and trustworthiness of the research and findings. After this, the researcher's role and summary of the chapter are presented.

\section{Analysis}

This study used an inductive data analysis technique. Data were analysed in the process of collection as, according to Hancock and Algozzine (2006), in a case study research, making sense of information from multiple sources is a recursive 
process where "the researcher interacts with the information throughout the investigative process" (p. 56). I used analytic induction where I repeatedly examined the data gathered in order to discover reoccurring patterns (Mackay \& Gass, 2008). My "theoretical sensitivity" (Dornyei, 2007, p. 39) also guided me to see and decipher details, and subtleties, as well as to make decisions about the questions to ask during the interviews and which behaviours to attend closely to for observations.

In order to combine a "thick description" (Cohen, Manion \& Morrison, 2000) of the participants' use of self-regulated learning strategies with my own thoughts and reflection, I approached the matter with an interpretive and flexible perception. Merriam (2001) suggests that data collection and data analysis are a concurrent process in qualitative research. In this study, data analysis and interpretation was a continuing process involving my recurrent reflecting about the data, asking analytical questions, and making notes all through the research. Moreover, emic analysis, cross checking by asking the same questions in different contexts, and member checks contributed to this thick description. Nvivo (Bazeley \& Richards, 2000) codes and the related data were also discussed with my supervisors to make sure my interpretation and representation of the data was correct.

Bandura's social cognitive theory (Bandura, 1986; 1997; Pajares, 2002) which views environmental, personal, and behavioural factors acting reciprocally on each other, guided the analysis of the case study data. 
The SRL research literature assisted in determining the codes that emerged from the data. The starting point for coding the behavioural SRL strategies of the tertiary level English as a second language learners in Malaysian context were categories in Wang's (2004) study. The categories evolved from Pape and Wang's (2003) self-regulated learning categories. The language learning experiences handled, challenges encountered and SRL strategies used by the learners in this study were exclusive to learning and using English language as an undergraduate at a public university in Malaysia. Although English is considered as the second language in Malaysia, the medium of instruction and the language use for most of the daily communication at the research site is Bahasa Melayu. The categories from Wang (2004) were added to if they were inadequate for the description of the learning strategies used by the participants in this study. This working framework appears in Appendix F (2). Preliminary categories of SRL strategies were modified or extended, and different aspects were added to allow a more detailed and refined coding of self-regulation behaviours of Malaysian tertiary level English language learners.

Qualitative research analysis software QSR Nvivo 8 was used to manage and analyse the data. I started with organising and preparing data for analysis. This involved transcribing interviews, typing up field notes, scanning documents from learners, and sorting the data based on sources of information. Next, I read through the data to get an overall sense of the information from participants and to think of its general meaning. Questions like "what general ideas are the learners saying?" were asked, notes were made, and general thoughts were recorded. After comprehensively immersing myself in the data, I started generating codes.

For these analyses, responses from participants, records and field notes from observations, diary content, and information from documents were given codes. Codes mirrored the key meaning of a participant's answer to a question or an occurrence in the classroom or out-of-class language learning record and their language learning experiences. For example, when a participant shared the challenges that she faced in using English in her daily communication, paragraphs were coded "Challenges in using and practising English". Sections from interview transcripts, field notes, and diary entries were frequently coded 
more than once (for example, paragraphs coded "Challenges in using and practising English" would also have descriptors such as "Environmental regulation" or "persistence/volitional control" that described the participant's SRL strategies). Data were coded using the terms in the actual language of the learners. For example, Rae wrote in her second diary:

It is fun to online, but it is even fun when you discovered something new to help you learn English through online.

Thus, the code learning English online was formed. The list of codes was reduced by combining subject matter that related to each other into themes. These themes were developed into general patterns, theories, or generalisations that were then linked with existing literature and theory on the topic. The interactive steps suggested by Creswell (2009) were followed in analysing the data. As part of this data analysis process, the interpretations were revised by two research supervisors.

Individual case and cross-case analytic techniques (Patton, 1990) were used to examine the transcribed student and language instructor interviews, diary entries, and observation notes. Each case was first examined in-depth, and then the different cases were compared in a cross-case analysis to identify similarities as well as differences.

In this qualitative inquiry, I treated the uniqueness of individual cases and contexts as central to understanding the participants' self-regulation (Stake, 1995). Case analysis was employed where I analysed the data for each participant separately. This was in order to highlight the individuals involved in the study and the manner in which they differed from or resembled each other. Themes were derived inductively as patterns emerged. The qualitative data were written up as the English language learners' case studies which were compared by means of a comparative or cross-case method of analysis (Bogdan \& Biklen, 2007). Cross-case analysis of the individuals' profiles was done by looking for commonalities or differences in patterns in order to answer the research questions (Yin, 2009). The focus of the cross-case analysis was to determine significant areas or themes from a number of the learners. 
Through data collection, analysis, and report writing, I used validity strategies, such as the different types of data triangulation to help increase the validity or trustworthiness of the case study findings. As data was compared, areas of agreement and conflict within the diverse areas of data were given emphasis. I started with an exploration of the patterns within the data for each of the participants separately, and then across all participants, by means of a constant comparative method. After the first round of interviews and diary collection, I read the set of student interview transcripts and diary entries numerous times and discretely marked the texts to capture central ideas or domains. Using Bandura's (1986) 'reciprocal causation', I prepared a list of codes. Then, the codes were tried on one interview transcript, diary entry, and set of observation notes, and refinement of the coding categories was then made. When all the interviews, diary entries, observation notes, and information from documents had been coded, I organized the data by both individual learner and across learners through coding category. From these data, tables were prepared for each learner specifying frequencies for strategies used, important strategy adaptations, motivational beliefs, social supports, and other environmental support evident from the interviews, language learning diaries, and observations.

Using similar codes for the student interviews and diaries, I coded the transcribed interviews of the language instructors and used this coded information to improve the tables prepared for each learner. I then looked for confirming and disconfirming evidence (Stake, 1995) in the instructor interview to triangulate data from the student interviews, diaries, observations, and documents. Based on this analysis, I amended and extended the tables on individual learners and across learners on the variations of self-regulation strategies used and the adaptations. This data was then examined and analysed using the conceptual framework of Bandura's (1986) 'reciprocal causation' which organises data into the areas of environmental, personal, and behavioural factors within, or affecting, each learner as positioned in social cognitive theory.

Then, case reports on strategy use, adaptations, motivational beliefs, and environmental influences for each of the participants were written. The overall pattern of understanding emerged after beginning with the preliminary codes, developing into broad themes, and finally into a comprehensive interpretation. I 
also wrote cross-case reports on use and adaptations for each of the strategies and motivational beliefs and environmental influences that were revealed to be important for the success in the language learning process of the participants.

\section{Ethical considerations}

Any qualitative researcher who is not asleep ponders moral and ethical questions. (Miles \& Huberman, 1994)

I applied for ethical approval from Victoria University of Wellington's Faculty of Education Ethics Committee and conformed to the University's Human Ethics Policy. After this approval was received, an application to conduct research in Malaysia was made to the Economic Planning Unit, Prime Minister's Department in Malaysia (see Appendix C for the Approval letter from Economic Planning Unit, Prime Minister's Department in Malaysia).

I was aware of my responsibility to respect the rights, needs, and values of the participants in the study (Merriam, 2001). Although I am a language teacher at the research site, I was on study leave and was not teaching the participants. In this study, the following actions were taken to safeguard the participants' rights: 1) the research aims and the details of how the data would be collected and used were explained orally and in writing to make them clearly comprehended by the participants, and the consent form was written in both languages (English and Bahasa Melayu); 2) written permission to participate in the study was collected from the participants (Refer to Appendix D 1 - Student's consent to participate in research); and 3) verbatim transcriptions and reports were made available to the participants. Member checking was conducted to enhance credibility of the findings.

Physical data were stored in a locked filing cabinet in a secured office. An initial meeting with each participant was held to discuss the research processes and address any questions the participants might have about the study before it commenced. I worked on developing the participants' trust; in order to ensure their anonymity to those outside the study, they chose their own pseudonyms and these were used to represent the participants throughout the thesis. The use of pseudonyms was to protect the participants' identities. The name of the university where the research was conducted was also not revealed. I guaranteed 
that the information given by the participants would be kept confidential and it would not in any way affect the students' final English course results. Participation was voluntary and the participants were assured that they could withdraw and refuse to participate at any time.

\section{Trustworthiness}

The concerns for validity and reliability in qualitative inquiry is parallel to the principles of truthfulness - credibility to internal validity, transferability to external validity, dependability to reliability, and confirmability to objectivity (Denzin \& Lincoln, 2000). Each of these is explained below.

\section{Credibility}

To achieve credibility or internal validity, I endeavoured to carefully record all of the data accurately through the process of verbatim recording and transcription (Conrad, Haworth, \& Lattuca, 2001). I transcribed all the interviews myself. Creswell (2009) highlights the importance for a follow-up interview with participants to provide them the opportunity to comment on the transcriptions. I asked the participants to check my transcriptions of interviews. This was done either during the follow-up interview or through email: three of the participants changed words, phrases, and even sentences during this process. For example, one participant added new information as he felt that he had not mentioned some relevant points in the previous interviews. Sepatu elaborated more on his comment about teachers' influence on learners' learning and motivation to learn English:

Learning English is fun but some teachers tidak memahami situasi [do not understand their students], jadi dia tidak dapat [thus they cannot] cope with the problem.

(Interview 13 January, 2010)

About this ... I had experiences with past English teacher. Some teacher expect us to do well in this language, but we need guide on it. Teacher keep teaching and give exercises without really know if we understand the lesson he/she taught. Lecturer at Matriculation where I studied before entering university, she taught us like her own children. What I mean is, she tend to know what problem we faced 
and help us when we have problem. She also doing some activities to burst up our spirit in learning English.

\section{(Unedited additional comments following the member checking)}

I prepared a form for the participants to record the type of changes made (minor or major correction) and to sign as proof that member checking had been conducted. I was aware that only the participants could reveal the meaning and interpretation of their experiences and actions. Thus, I viewed the data from the participants' perspectives to achieve interpretive validity and report the findings accurately to convince readers (Cohen, et al., 2007).

The principle of triangulation, which is the means of validating aspects of a qualitative research, helped to compensate for the limitations of the individual data collection methods and to reduce the effects of researcher's bias in analysing and interpreting qualitative data (Creswell, 2009). Denzin and Lincoln (2000) propose three key types of triangulation: data triangulation, investigator triangulation, and methodological triangulation. If diverse sources of data, different researchers, and different methods all produce comparatively similar results, there are grounds for a greater degree of credibility. Data for this study came from case studies (data triangulation), and was collected using a variety of methods such as observation, interviews, stimulated recall, learner diary entries, document analysis, and the researcher's notes (method triangulation). Data triangulation and the use of various sources of data helped in achieving credibility in this study. In order to achieve this, I reviewed all the data, made sense of it, and organised it into codes, and then categories with themes that cut across all of the data sources. This helped me in building a clear justification for themes (Creswell, 2003).

The technique of peer debriefing, which involved discussing with my supervisors some of the data in order to evaluate whether the findings were credible, was also applied in this research as an additional means of justifying its credibility. Moreover, for reliability checks of the various sub-processes within this qualitative inquiry, the research supervisors checked the coding of samples of data (e.g., interview transcripts, observation notes) and commented on the interpretations made. 


\section{Transferability}

As this was a qualitative study of a small number of individuals, it is not appropriate to use statistical measures to achieve generalisability. However, qualitative researchers can achieve generalisability by relating their findings to theoretical propositions (Conrad, et al., 2001). Therefore, I related the findings to theoretical statements in related previous studies (Mohd Kosnin, 2007; Roslan, 2000). Moreover, according to Creswell (2009), the significance of qualitative research is in the specific description and themes developed in context of a definite research site. Thus, "particularity rather than generalisability is the hallmark of qualitative research" (Creswell, 2009, p. 193). My emphasis was on the particularity of the learners and not on generalisability. However, I achieved analytic generalisation by relating my findings to theoretical propositions arising from literature. I also aimed to highlight the contribution of my findings to the theoretical framework chosen; that is, social cognitive theory.

\section{Dependability}

Dependability is the degree to which the data and interpretation are reliable and consistent (Cohen, Manion \& Morrison, 2000). It relates to the significance of being open through reflexivity and accounting for the modifications to the study that arise during the research process. To ensure dependability, I provided a rich account of the participants in the study, the context of the study, and also the steps that were taken to carry out the study. This was to ensure that readers could retrieve and review the evidence provided in the research.

\section{Confirmability}

Confirmability denotes the degree to which inquiry results can be confirmed or verified by others (Cohen, et al., 2000). This matter was dealt with by making available a clear audit trail, which described carefully how data were gathered, how categories were derived, and how decisions were arrived at throughout the research. This audit trail enabled the reader to determine how acceptable they found the data and the constructs derived from it. Illustrations of data analysis and coding were included in the text and interpretations were supported by extensive quotations from the data. 
Steps were taken to ensure as far as possible that the findings of this study were the result of the experiences and ideas of the participants. My beliefs underpinning decisions made and research methods adopted are acknowledged within the description of the research design. The reasons for adopting a qualitative method to enrich understanding of self-regulated learning are explained. All of the raw data, data reduction, analysis products, process notes, materials relating to intentions and dispositions, and instrument development information have been saved for any examination to ensure confirmability.

\section{The researcher's role}

A qualitative researcher needs to systematically reflect on who he or she is in the study and how this shapes the study (Creswell, 2009). I was aware of my role in ensuring the quality and scope of the data and the interpretation of the results. Thus, acknowledging my own identity, background, power, familiarity with the context, and biases was part of the research process (Mason, 2002). Throughout this research, I tried to be aware of the personal and professional biases I bring to the study. I am a second language learner, and a language teacher at the research site. These experiences might influence my worldview of the second language learning process. Glesne and Peshkin (1992) term the study of the researcher's own organisation as "backyard" research and highlights the researcher's ability to reveal insider information. In this study, I employed strategies of validity to ensure the credibility of and confidence in the accuracy of the findings. My biases are minimised by the acknowledgement of each participant's influence, and the completion of written transcripts to retain the participants' words. I have also addressed reliability in this study by using "lowinference descriptors" (Silverman, 2006, p. 283), by making verbatim records of the interviews, and also by recording the observations in as much detail as possible. Seale (1999, p. 148) maintains that:

Recording observations in terms that are as concrete as possible, including verbatim accounts of what people say, for example, rather than researchers' reconstructions of the general sense of what a person said, which would allow researchers' personal perspectives to influence the reporting. 
Smith (2008, p. 18) comments that "when one is researching one's own context, it is important to acknowledge the perspective one brings; however the goal is not to overcome or change this perspective, but later make known how it has affected the research". Thus, in reporting the findings of the research, I examined my role as a language teacher at the research site, and reflected on how this might affect the relationships with the participants, their perceptions of the research, and the outcomes of the research. When I began the research, I was aware that I might experience some conflict in reconciling the demands of being a teacher and researcher - what Hornberger (1994, p. 689) calls "the insider/outsider dilemma". I realise that my teacher role gave me an emic, or insider's perspective during the research process. Peshkin (1993, p. 28) observes that qualitative research is "a type of research that gets to the bottom of things, that dwells on complexity, and that brings us very close to the phenomena we seek to illuminate." Thus, I believe that my insider's perspective actually sharpened my researcher's perspective: my contribution to the research setting was worthwhile and positive (Creswell, 2003). My perceptions of second language learning have been shaped by my personal experiences as a language learner, instructor, and course developer. Therefore, my understanding of the research setting and the role enriches my attentiveness, knowledge, and sensitivity to various challenges and issues faced by language learners at the university. I understood and depicted the participants' self-regulation in all its complexity while "being self-analytical, politically aware, and reflexive in consciousness" (Johnson \& Christensen, 2008, p. 393). Moreover, any possible controversial findings were handled with sensitivity (Cohen, et al., 2000). For example, no comments made by the participants about their language teachers were shared with the teachers.

Throughout the research process, I continued to develop rapport with the participants while maintaining credibility as a researcher. I realised that my role evolved from researcher to friend, to the point where the participants were no longer apprehensive about sharing information and also asked for help from me. When they were grappling for words during interviews, they would ask me for words or to correct their pronunciation. I attribute this to the rapport that was built between us, but it could also be attributed to their perception of me as a 
teacher. From my perspective, being able to assist them in this way ensured that the participants also benefited from the research, as they had done me the favour of spending time for interviews despite their hectic schedules, and of sharing their course documents. This was confirmed by a participant who shared that he also benefited by being involved in the research, through my input in teaching him correct pronunciation:

Today I have my Academic Communication class. As usual, our class becomes happening and I learn how to pronounce "reservoir". Teacher asks everyone to pronounce it and all of us pronounce it wrongly. So, to redeem my fault, with full of speed I find out how to pronounce it in Oxford Dictionary like you teach me how to pronounce word pronunciation. And I got the correct pronunciation of reservoir.

(Unedited Diary, 24 February, 2010-Confidence Hero)

Another participant indicated that she had made a good decision to volunteer for this study, as it had made her more motivated to improve her English proficiency:

When in this study, I now use English more, I more interest, motivate ... I want to improve.

(Final interview-Stanza Nurmalam)

Besides being more motivated and communicating more in English, she observed that the study itself had influenced her learning. She was more conscious of her learning than normally.

\section{Chapter summary}

The purpose of these multiple case studies was to explore the self-regulation of six ESL learners at a public university in Peninsular Malaysia and to understand how self-regulatory mechanisms shaped their language learning behaviour. This study also aimed to examine contextual factors that might act as facilitators or constraints on the participants' self-regulation. Situating this research within an interpretivist framework reflects my commitment to making sense of the selfregulatory mechanisms that shaped the participants' language learning behaviour. The qualitative case study design of this study is a suitable research 
approach as it provides rich, contextualized description of the participants' selfregulated learning and the factors influencing it. The methodological triangulation ensures the credibility of the research findings. Descriptions of coding and analysis processes were provided to strengthen trustworthiness. Qualitative inquiry and analysis is practically relevant in investigating selfregulation as a process. The elaboration on my reflexivity as a qualitative inquiry researcher shows that I have examined how my role as the main research instrument in this study, my own background, context, and experiences may have impacted on the study. This leads to the findings, which are presented in the next chapter. 


\section{CHAPTER FIVE: Case Studies of Six Learners}

\section{Introduction}

Stake (1995) states that the aim of a case study is not generalisation but particularisation. Qualitative researchers treat the "uniqueness of individual cases and contexts" as important to understanding (Stake, 1995, p. 39). In this chapter I will introduce and describe the personal, environmental and behavioural factors of each of the six participants to understand "the behaviour, issues, and contexts" of each case (Stake, 1995, p. 78). The participants' selfregulatory activities are seen as "mediators between personal and contextual characteristics and actual achievement or performance" (Pintrich, 2004, p. 388). The data was derived from the participants' interviews, observation, diary and related documents. The focus of each case was on the participants' selfregulation, use of self-regulated learning strategies and the factors that influence their use of the strategies. Each participant is introduced by quotes that exemplified the participant as a learner of English as a second language. Findings for each student will be summarised using the "reciprocal causation" triangle from Bandura (1986). All of the supporting data is from the student interviews, unless stated (such as a teacher interview, unedited diary or observation). A less extensive description of three cases, that of Ares', Unblocker's, and Confidence Hero's was a consequence of less data being generated by these three individuals.

\section{Learner one-Sepatu Chenta}

The following quote was indicative of this learner's goal-setting strategy to learning the English language.

When we have set a goal, we have something to achieve...

\section{Personal Factors}

Sepatu Chenta is a nineteen-year-old Malay male, and a first year student majoring in International Business Studies. He had an upper intermediate level of language proficiency. His scores on the English language examinations prior to enrolling in tertiary study were high enough to exempt him from his first English 
paper at university. Sepatu came from a rural area where there was limited use of English, but had made an effort to learn English. He had learnt through selfstudy and other personal efforts, such as using English in his communication with other English users.

His life at university was busy. Besides attending lectures, tutorials and being involved in students' activities at the university and university hostel, he surfed the internet and played football.

He felt that his personal strength was spoken English. This came from his confidence with communicating in English. He believes that extensive practice of English is important to its mastery.

Sepatu was more confident using English in an informal situation compared to a formal situation, like during an assessment. In formal presentations, which were being assessed, he worried about making mistakes and the effects on his marks. He became nervous and that affected his confidence and fluency:

I am not afraid to talk spontaneously but when it is a formal presentation, I will become nervous. Things that I remembered before will be gone. For example, in information sharing, I'll be nervous and I will forget. When not being assessed, I feel more comfortable.

(3 February, 2010)

These statements indicated that he felt less tense using English as a means of communication, rather than as an academic subject, which was formally assessed. His concern for accuracy during assessment might be the result of a strong emphasis on grammar during his primary and secondary language learning experiences. Although the marking criteria for the presentation put more weight on content and delivery of the presentation compared to language, Sepatu still felt anxious about making language mistakes. This indicated that perhaps the teacher did not make the marking criteria clear to the students.

\section{Goal orientation}

His espoused goal was consistent with a mastery orientation, where he wanted to increase his competence in the language. However, he was also concerned about 
scoring well in the language course. His grade for the course would affect his Cumulative Grade Point Average (CGPA). A high grade in this course was extremely important for him. This performance goal might be related to his anxiety about doing well in his assessment. Although he primarily aimed to get good grades in his individual learning tasks, he also reported a socially oriented goal, which was to associate with the group members and enjoy the experience of group work. As his group members cooperated well, he enjoyed the socially shared group learning task.

Sepatu stressed that he wanted to improve his writing skills when he described his perception of his weaknesses in communicating in English. His lack of grammatical competence constrained his ideas when writing:

Sometimes I have the ideas, but I can't manage it [them] into proper sentences because of grammatical problem.

(3 February, 2010)

Sepatu further commented that this problem occurred due to a lack of emphasis on writing in the current language course:

At the secondary school, there were lots of exercises given by our teacher, but at the university, our language teacher does not give many writing practices. ... lack of exercises.

(3 February, 2010)

Although there was a group project report to be submitted at the end of the semester, it was not sufficient for the students to improve their writing skills. He complained about the lack of input provided to students so they could carry out their projects. He suggested that students should be taught how to write a research report, how to go about it, and what to include in each heading of the report. He needed practice with the language required for writing a report. Due to a lack of input and opportunities to improve his written language skills, he was just cutting and pasting, instead of summarizing and synthesizing ideas from different articles for the report. He emphasized students needed instructions and guidelines on how to go about writing report. Even though samples of reports were given as models, these were not sufficient for him. 
He considered that his writing had been influenced by the use of short forms when sending SMS (short messages) via mobile phones. This had caused him to be unsure of the correct spelling when he wanted to write in formal English:

[the] habit of always sending messages in short forms [have affected] my writing and I also have become not sure of correct spelling.

(3 February, 2010)

Sepatu suggested that more writing activities and exercises in the Academic Communication 1 course would enable him to improve his writing, especially academic writing. Despite his perception that that he lacked grammatical and writing skills, he felt that he was able to do well in his language course.

\section{Self-efficacy}

Sepatu was self-efficacious in learning and improving his language proficiency. His self-efficacy in this area was linked to his knowledge of strategies to improve his learning. He was aware of when and how to use specific types of learning strategies:

If I do not understand the words I read or hear, I use clues from the context or situation

(25 February, 2010)

He was aware that language use was essential for proficiency:

When I learn something new, I then try to use it ... when I write, ... communicate, so I know whether I have used it correctly. I can also remember them

(25 February, 2010)

\section{Highly motivated}

Sepatu was motivated to learn and improve his English language proficiency as he realised the importance of English as a student in the Economics Faculty. Most of the course readings, for example, in his Management and Accounting classes, and the questions set by the lecturers were in English. He needed to translate the information in English books, as the assignments were to be written in Bahasa Melayu. 
We write our group assignments in Bahasa Melayu, but for management we refer to English book, I refer to this book to get the content to produce report. I got question in English, answer in Bahasa Melayu.

(25 February, 2010)

He highlighted the difficulties of translating business terms correctly:

Last semester, for accounting the resource [reading materials] are in English, when it comes to assignments, I find it difficult when it comes to the terms [business vocabularies], I don't understand the terms [business vocabularies].

(25 February, 2010)

Sepatu recognised the importance of English for an Economics graduate, as English was widely used in the workplace, especially in the private sector. He stressed the need to develop his confidence in communicating with other people at his future workplace. He saw that learning English at a tertiary level gave him the chance to be more confident in his communication:

Learning English is very important for our future when we work ... learning English enable[s] us to communicate with other people like foreigners. English language is currently being the world language. So, problem will occur if people does [do] not make their best in English. We need to communicate with lots of people when we work. We need to be confident in using English. Learning English language during our undergraduate years is an advantage.

(13 January, 2010)

He discussed how skill in English could contribute to his country, because proficiency in English as an international language would enable transfer of knowledge and technology, which would strengthen Malaysia's economic progress:

When we learn English language and we are proficient in English we can help in our country's economic progress. When we communicate with foreigners in English, it can help in the transfer of technology.

(13 January, 2010) 
His language teacher commented on Sepatu's motivation to improve his English proficiency. His teacher suggested that Sepatu's motivation and self-efficacy made him strive to achieve his goals. He made more effort in comparison to his friends, and he learned from his teachers' feedback:

He has got intrinsic motivation ... he knows the importance of English language as a student of the Economics faculty. He is not the best student in terms of proficiency but he has always been motivated and confident that he can be better. Thus, he puts extra effort to reach his goal. He shows that he evaluates his progress and he reflects on his actions. From the information sharing assessment, when he received feedback from me, he did an evaluation of what to be corrected for future evaluation and assessment.

(Teacher Interview, 29 March, 2010)

Because of Sepatu's global outlook, his interest in languages extended beyond English. He loved learning languages and he was taking Mandarin classes in addition to English. He learned Mandarin with a good friend as well as in the Mandarin class:

just got a class today, which is Chinese lesson, which is I'm taking this class by myself ... it's nothing to do with marks ... just for fun.

(Unedited diary, 14 January, 2010)

\section{Effort attribution}

Sepatu Chenta put considerable effort into completing the course assignments and in preparing for and presenting the on-going class assessments. He organised his time for the completion of course assignments. He suggested that giving up showed someone's weakness and could lead to failure. He did not see English as just another course to study at university, and thus he persisted in his language learning:

I see someone who gives up easily or does not continue his work, as someone who is weak. When we give up, we lose already. In terms of learning English, we know how important English is, and that's why I continue studying English. (25 February, 2010)

The researcher observed that despite Sepatu's presentation being interrupted by 
the teacher, he maintained his composure and kept going. The teacher commented that he should focus on the ideas from the article presented before sharing his own opinion of the issue. In the post observation interview, he revealed that he felt disturbed when he was stopped. This was because he felt he had prepared well and had practised for the assessment. He controlled his emotions by telling himself to relax and continue the presentation confidently and presented the main idea of the article as instructed by his language teacher. However, he was worried about the effect on his marks:

I felt bad as I had really practised this morning and last night, I had prepared well for this assessment. But when $\mathrm{Mr}$ A gave his comments, I told myself to relax ... not give up ... and ... and continue with the presentation. I must continue ... correct the mistakes and explain to him. But ... I'm worried that it will affect my marks.

(4 February, 2010)

This showed his use of effective strategies to persist in his language tasks.

His language teacher commented on his willingness to work hard in learning English. He was seen as a student who always showed interest. Sepatu asked for clarification and assistance when he was not clear of his language learning tasks.

\section{Summary of Sepatu's personal factors that influence language learning and use}

Sepatu was highly motivated to learn and use English. He saw language as more than just a classroom exercise. For him language was a tool for communication. His personal drive to use English for communication was associated with getting the message across, with less emphasis on getting feedback about grammatical accuracy. He was aware of the need to master English for his studies in the Economics faculty and for use in a future workplace. He regarded his confidence in spoken English as his strength. However, he was aware of his weakness in his written English. He believed that effort could lead to the improvement of his language skills. 
Besides the personal factors above, there were some contextual factors that influenced his language learning process. These will be described below.

\section{Environmental Factors}

\section{Opportunities for language use prior to university and at university}

Sepatu used less English when he was at secondary school and a matriculation centre. This was because the teaching and learning of English at his secondary school was exam oriented with a focus on reading and writing. At his secondary school all the students were Malays, so there was less chance for him to use English outside of class. When he went to university, he realized he could use English more because there were many Chinese, Indians and foreign students there.

The increasing numbers of foreign students at the university encouraged him to improve his language proficiency, especially spoken English. Realizing that he would have to make an effort to use English to improve his spoken skills, Sepatu Chenta tried to communicate with foreign students at the university. Friendships with foreign students gave him opportunities to use English in daily communication. He rarely used English with his Malay friends, as they favoured Bahasa Melayu as the language of daily interaction. However, he used English with his close friends as they did not ridicule him when he communicated in English.

Sepatu Chenta also tried to use English when communicating with other Malaysian ethnic groups, such as the Indians and Chinese. For example, he offered to assist an Indian man who seemed to have difficulty withdrawing his money at the auto-teller machine in English. He worked part time at the Nescafe kiosk on campus, increasing his chances to use English with international students and the university community:

When there are many international students, this encourages me to learn English as we need English to communicate with them. It provides the environment for us to use English. That makes us more confidence [confident]. ... we don't use English when we communicate with our Malay friends as we can survive by using Bahasa Melayu ...

(13 January, 2010) 
Sepatu used English when he communicated online with his friends and sent messages in English via mobile phone.

\section{Classroom influences on self-regulation}

At times Sepatu felt bored, as his language teacher just discussed the content in the course textbook. He found that classes based on the textbook were too predictable:

If we just do the exercises in the textbook, it is not interesting. Kind of routine ... Can expect what to be learnt today. Know teacher will continue from last lesson ... just look at the page ... not motivating. Monotonous. Teacher must plan challenging activities to ensure students' attentiveness

(3 February, 2010)

When Sepatu became bored, he would attempt to make the classroom situation livelier by asking questions to his language teacher and friends. He wanted interesting and challenging language activities so students would be motivated to attend the classes. He suggested more integration of technology in the class, like movies, computer mediated communication and online learning. He wanted more group activities to promote interaction among students. He also suggested that language teachers use more out of class activities to motivate students, as the rest of their university courses were normally held inside the tutorial rooms. He commented that the hours allocated for language classes at the university (normally held very early in the morning, during lunch time or late in the evening) could also affect students' mood and involvement in the class activities.

Sepatu emphasized the importance of a variety of well-managed class activities, as students were easily bored. He could only focus on the lessons taught for a short period. As the normal length of English classes at the university was two hours, he felt that having a break between activities would enable the students to remain attentive throughout the lesson:

Learning environment and class activities can affect students' mood and concentration in the class ... to remain attentive, give attention and focused. I can't concentrate for a long time, like English class, two hours, my focus will just 
be for one hour... So, if I want to continue my concentration, I will have to go outside, have to take a break, go to the toilet.

(3 February, 2010)

In addition to a variety of well-managed class activities, Sepatu regarded positive student teacher interaction as important. He emphasized teachers must guide students, and he thought that there were teachers who were not sensitive to students' needs and problems. They were only concerned about delivering the lessons without showing concern for students' understanding and learning. However, he felt fortunate to have a very motivating and caring teacher when he was doing his university preparatory programme who encouraged him to learn English. He maintained that teachers should be approachable, concerned and alert to students' feelings and expectations:

... I had not so good experiences with past English teacher. Some teacher expects us to do well in this language, but we need guide on it. Teacher keep teaching and give exercises without really know if we understand the lesson she taught ... but a lecturer at Matriculation where I studied before ..., she taught us like her own children. What I mean is, she tend to know what problem we faced and help us when we have problem. She also does some activities to [boost] up our spirit in learning English.

(3 February, 2010)

\section{Language course design}

Sepatu suggested that the undergraduates who scored band 3 and above should have a language course prepared for them when they first joined the university. The current regulation at the university exempted such undergraduates from English courses in their first semester. Sepatu Chenta felt that studying for one semester without taking any English course contributed to a decrease in students' language proficiency.

\section{Summary of environmental factors that influenced Sepatu's language learning and use}

Although his family background and past language learning experiences at secondary school did not seem to provide opportunities to achieve a high level of 
proficiency, at university he took the opportunities to use English with students of other races, international students and the university community. This social strategy provided practice for his spoken English. He wanted his language teachers to have more interesting activities in class to increase students' motivation and interest. Besides that, he felt teachers should be sensitive to students' problems and provide guidance to them.

Realising there were challenges that might affect his language learning and acquisition, Sepatu used strategies that contributed to getting input and practice in English, as described in the behavioural section below.

\section{Behaviour - Self-regulated learning strategies}

\section{Seeking information}

Sepatu used study strategies to improve his language proficiency and communicative ability. Although Sepatu was confident in speaking English, he wanted to improve his pronunciation in order to communicate effectively and to convey his intended message. He had developed some personal strategies to enable him to do this. Sepatu listened to English songs and printed the lyrics from the MINILYRICS website. The use of the MINILYRICS website helped him to listen effectively to the words and phrases in the song as he could read them while listening. This aided him to understand the meaning of the song and learn pronunciation. Listening to the pronunciation of better English speakers also improved his pronunciation:

I also see English movies, ... listen to the actors' pronunciation ... where they stress the words. I learn British and American pronunciation.

I'll try to listen to others' conversation ... listen to others who are better, how they pronounced words and phrases.

(3 February, 2010)

Sepatu simplified, used shorter phrases, or paraphrased as communication strategies. If the person communicating with him could not understand him, he would use gestures, facial expression, and even draw to get the message across. He asked for clarification or repetition when he himself faced difficulty during the communication. These strategies prevented communication breakdown so 
that the conversation kept going and he had further opportunities for input in English:

... when I am using English and I am not sure how to say it, I try to simplify, use shorter phrases or paraphrase.

... or when the person I talk with do not understand me, I find ways to solve the communication problems. I will use gestures, facial expression, even I will draw. I will also ask for clarification. How do you spell that? Can you say it again?

(3 February, 2010)

Sepatu Chenta was aware that he needed to improve his grammatical competence, as he was still not quite sure of the basic grammatical rules, like parts of speech. He lacked confidence in editing his work, as he was not sure of the mistakes and the corrections to make:

When someone who is better than me correct[s] my mistakes, I tend to do the same mistakes again. In the previous class, $M r$... told us about the usage of pronoun [and], verb, I can understand in the class but when I try to use it, I was not sure which one is noun, which is verb

For example when I want to edit my writing, I know there will be many errors but I don't know which ones are the errors and how to correct them.

(3 February, 2010)

He believed that grammatical competence and a wider range of vocabulary could help him in communicating with others, as he would not be hesitant. His hesitancy came from grappling for words or worrying about making grammatical mistakes that could cause a misunderstanding:

When we lack of grammar and vocabulary, then it is hard for us to talk to other person. We are hesitant ... pause a lot ... We'll make mistakes [and], use wrong words. Problems ... miscommunication might occur.

(3 February, 2010)

Sepatu reported using more language learning strategies to improve his grammatical and vocabulary knowledge at university compared with when he 
was at secondary school. For example, at the university, he used the dictionary more to look for the meaning of words and increase his vocabulary size:

I feel the differences. Now I am a friend of dictionary, I use dictionary more. Before this, during secondary school, the thickness of the dictionary makes me not interested to use it. Thus, I use lack of dictionary.

(3 March, 2010)

Sepatu's vocabulary increased as he used the dictionary, and his language proficiency also improved. His self-efficacy increased and he believed that he could improve further. His past success in his language paper for his Malaysian Certificate of Education Examination and being selected as a participant on a student-exchange program with the United Kingdom (UK), contributed to his confidence. The prospect of going to the UK made him more persistent in his efforts to improve his spoken skills. This exchange gave him a global outlook: Now, due to the interview for the selection as research assistant in the student mobility programme, I'll become a representative of university $X$ and my country, I want to improve myself. I converse in English more.

(Unedited diary, 10 March, 2010)

His strategies were focused on oral communication and even his need for more grammar was motivated by a wish to improve his oral proficiency. These strategies contributed to his getting increased input in English and were linked to his view of language as a tool for communication.

\section{Goal setting and planning}

Sepatu's language learning goal determined his decisions and actions in his language learning process. His goal determined his selection of language learning content and materials. He also pointed out that his goal led to his motivation and persistence:

When I am trying to do something, I have a goal to achieve ... When I want to keep focused, I relate to my goal.

(3 February, 2010) 
He set short-term goals for the course assessments:

... when I have to make information sharing presentation, I rehearse and my goal for the information sharing ... is I want to present clearly and make it interesting to the listeners. I want to give clear presentation because I want my teacher and everyone to know what I am talking about. I also want them to understand the issue that I present...

(25 February, 2010)

His goal for this assessment was to deliver the presentation effectively with clear pronunciation and appropriate gestures. He wanted the listeners to get the message he was attempting to convey. He practised and listened to the recorded practices to correct his pronunciation. He asked his friend to comment on the suitability of his gestures in conveying the message.

Sepatu had selected an article on the Malaysian examination-oriented education system for his presentation, as he felt learning should be meaningful and fun for students. He thought the Malaysian education system should change. Being interested in a topic motivated him to do extra work:

... if you're interested, you're more likely to read, to find out more information ... you are more motivated in what you do.

(25 February, 2010)

Sepatu recognized that his topic interested most students; he hoped to get a good response from his friends. He collected information on his topic from various sources. This showed his information literacy skills, as he knew how to access materials for his assignments and evaluate the relevance of the information for a specific assignment.

He had long-term goals of being fluent in his oral skills for his future workplace. He realized that the ability to use English was highly sought after when securing jobs in the private sector. Moreover, he wanted to be confident in communicating in English when dealing with foreign partners in the business world. He had a vision of securing a job in a big international company. 


\section{Organizing and transforming}

He synthesized the information from various sources in the form of a mind map.

This showed that he was information literate, as he could effectively use information to prepare for his individual presentation. Figure 5.1 below shows the mind-map of his article presentation. 


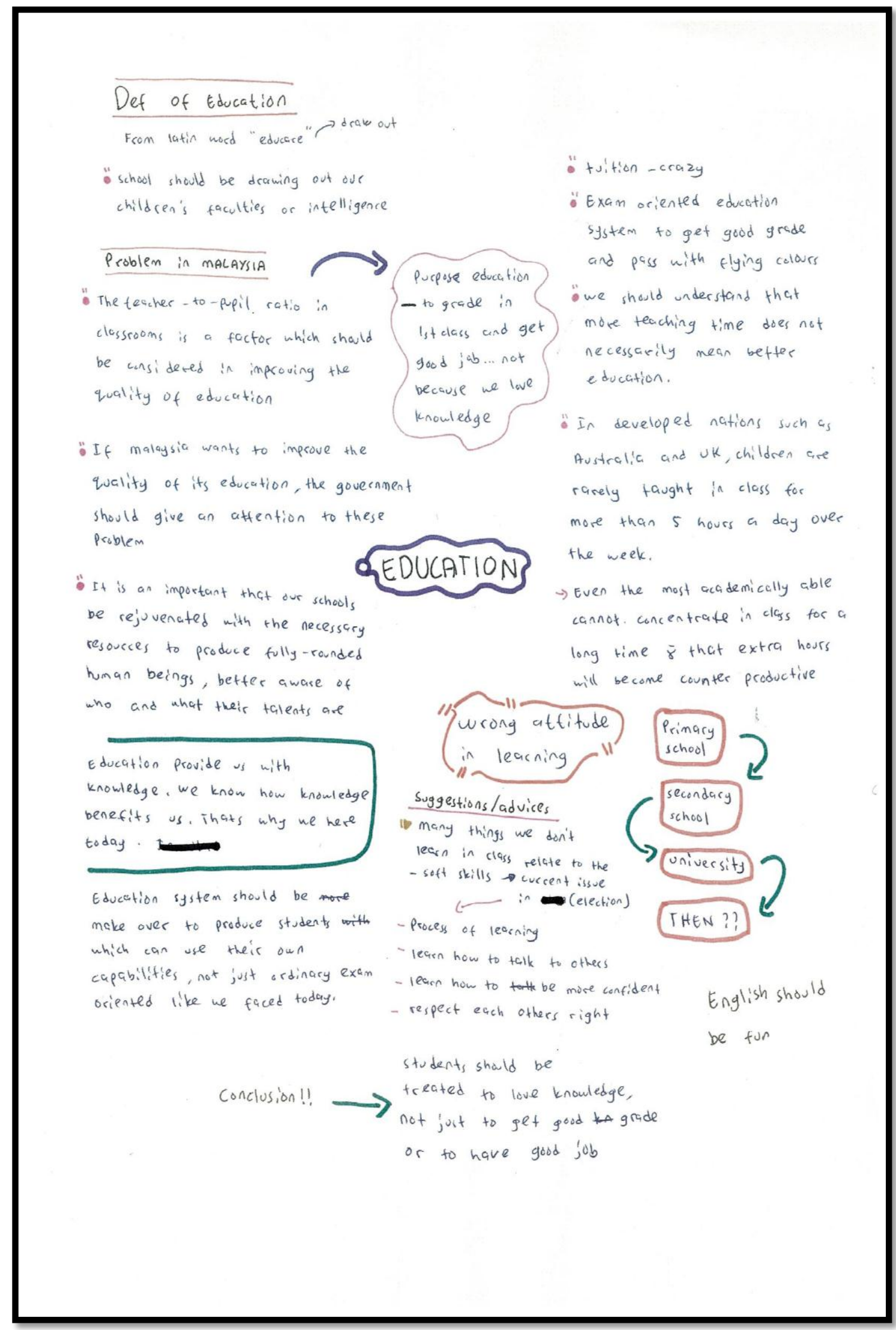

Figure 5.1:An illustration of Sepatu's mind-map of his article presentation 
Sepatu's preparation for his information-sharing assessment, which involved writing out a plan and rehearsing, made him feel confident:

I take note of what I want to do, in the morning on the evaluation day, I rehearse on my own outside of class. Indirectly, it makes me more comfortable and confident.

(4 February, 2010)

\section{Managing emotions}

Although Sepatu Chenta explained that he would not give up easily, he admitted that at times his confidence wavered. He attributed this to the fact that despite the long process of learning English from his primary school years up to the tertiary level, he still had not reached the level of proficiency that he aimed for:

... learning language is not really tough, but it's such a problem when you noticed that you have [learnt] learn English for a long period, but you still can't make it.

We have been learning English since young but the improvement is slow and little. I love learning English but at times I have doubt of my ability and progress because of the long duration.

(13 January, 2010)

When asked how he maintained his interest, he stressed on taking action and ignoring the negative influences of his friends. Sepatu emphasized students must find an interest in English to motivate themselves to learn. He said that it was not enough just to say that someone was interested, but the most important thing was to take action to improve language proficiency. He urged students who faced challenges from their peers to ignore negative comments and keep on being persistent to achieve their goals. Sepatu emphasized that students must have the confidence that they can improve their language proficiency and they must get rid of the negative perception that English is difficult to master:

We have to always have interest and motivate ourselves. It does not exist on its own. We cannot say that we are interested but we do not take any actions to improve ... negative thinking of our friends, we should neglect it ... bad influences

(3 February, 2010) 
To alleviate his negative feeling and disappointment of not achieving the level of proficiency that he had set, he kept on motivating himself to maintain interest in learning English. Sepatu stated that he practised positive self-talk while reflecting on his past actions in order to motivate himself. He kept on repeating that he would be able to achieve his language learning goals. He talked about the importance of positive thinking and belief in his own ability, and this process restored his self-efficacy. Sepatu rewarded himself for any achievement like going on outings with close friends after completion of learning tasks. By doing this, he hoped to be more motivated and energetic about future language learning tasks.

Sepatu was critical of students who did not make an effort to improve their language proficiency due to the belief English was a difficult language. He disagreed with some Malay students who felt that English language was not important as they had their first language, Bahasa Melayu. He urged those students to get rid of such a negative perception and not feel discouraged in their English language learning. Sepatu expressed his admiration for some Chinese and Indians in Malaysia who used English in their daily communication:

Some of my friends say that English is not important because we have our mother language, Bahasa Melayu but other people, like Indian or Chinese when I heard their conversation between parents and children ... they talk in English. They stress on English language. But ... we Malays keep on saying that English is difficult and from my experience, my friends who do not get A in PMR or SPM (two of the national examinations during secondary years), they feel frustrated and [do] not have the motivation to learn English more.

(3 February, 2010)

He disagreed with other students who regarded English as of little importance because they have been learning it since primary school years. He voiced his concern for the lack of English proficiency among his fellow Malays, as this would affect their employability later.

Sepatu indicated that being an undergraduate required self-discipline. Sepatu believed that at the tertiary level, learning was primarily the responsibility of the student and this indicated his internal locus of control: 
... it's a challenge that you've got to do the work by yourself; now I set my own goals and plan my learning whereas in secondary school ... the teachers would say what I had to do ... Besides learning in our English class, what is more important is your own learning outside the class.

(3 February, 2010)

These comments showed Sepatu was not only concerned with the initiator of learning (student or teacher), but also the location where learning happened. Sepatu kept an organizer to plan and manage his learning tasks.

Sepatu stated that he could see the improvement in his language proficiency when he managed to score a high grade for his English language paper in the secondary school national examination. His selection to represent his university in a student mobility programme in the United Kingdom indicated his success in improving his language proficiency, as applicants were selected on their ability to speak English confidently. The achievement raised his self-efficacy and belief in his ability:

I can see the improvement in myself, when I got A2 in my SPM. The latest one is I got the offer to go to United Kingdom. My confidence increased.

(3 March, 2010)

\section{Structuring learning environment}

Sepatu Chenta created a conducive learning environment for language learning or for completing the assignments for his language course. He preferred to study in a quiet place where there were no interruptions. When he could not focus on a learning task he would take actions, like asking his friends to keep quiet, using earphones or moving to a quieter place. There were also times when he would inform his friends that he wanted to focus and asked them to leave him:

Keep focused. When my friends disturb me, I said to him or her that I ... for example is practising for my information sharing assessment, she or he will understand and go away from me or I will ignore him or her and keep focused and keep practising.

(14 March, 2010) 


\section{Practising self-evaluation}

Sepatu reflected on the actions that he had taken and changed to develop better learning strategies. He learned from the comments he received from his teacher and friends to be better in future tasks. Sepatu tried to learn the strategies used by other successful students and considered whether he might need to change his strategies if they were ineffective. He would plan for new steps or actions to be taken. Sepatu Chenta pointed out the importance of students self-evaluating their progress and motivating themselves to improve their language proficiency:

When I have finished my assessment, I ask myself of my own progress, what have I achieved. If I did not get what I expect to get ... the outcome does not meet my expectation, I will not punish myself ... I'll not give up. I will recheck what is my failure ... the cause ... I'll see what's wrong and I will do better performance in my next assignment. Maybe I need to change my strategy. I tell myself to keep going and trying ... I believe I can do it!

(3 March, 2010)

\section{Seeking assistance}

Sepatu asked for assistance from more knowledgeable and successful friends. He did not mind being corrected as he felt that he could learn from mistakes and corrections:

I will also refer to the expert or people who know more ... or better students

(3 March, 2010)

However, he would only turn to a teacher who cared and showed understanding. It was important to him that his teacher showed sincere concern for their students' progress. For him a good teacher was one with whom the students felt comfortable and safe to discuss their problems, either academic or personal. Sepatu asked his language teacher's opinion on his preparation for the group presentation. The comments received from his language teacher helped his group to improve their presentation, and the materials prepared for the sketches that they planned to present.

As assignments in his business course had to be written in Bahasa Melayu and the books were in English, the students faced problems in translating certain 
business or economic terms when completing their assignments. Normally he would discuss the meaning of the business terms or phrases with his friends:

Last semester, for accounting the resource in English, when it comes to assignments, we have to write in Bahasa Melayu, I find it difficult when it comes to the terms, I don't understand the terms. I discussed with friends to understand what exactly the words, the content of the book.

(13 January, 2010)

This was another example of how he sought help from fellow students and worked collaboratively to solve problems.

Sepatu also took opportunities to learn from me during the interviews. For instance, he wanted to know the pronunciation of 'nevertheless' and 'speechless', and he asked to be shown the pronunciation guide in the dictionary. He insisted on knowing the difference in meaning of 'in spite of' and 'despite'. This showed that he could not use the dictionary unaided. After being told the meaning, he tried to form sentences by using the two phrases and asked for my comment. Sepatu showed interest in learning the pronunciation symbols and the vowels, consonants and diphthongs in English. He also tried to compare the vowels and consonants in English to those of his first language.

\section{Summary of Sepatu's self-regulated learning strategies}

Sepatu used a variety of language learning strategies to improve his language skills, like listening to English songs to improve pronunciation and using a dictionary to increase his vocabulary. He attributed success in language learning to effort rather than ability. He showed persistence in reaching his language learning goals. During the process of learning, he evaluated his learning progress. Faced with any failure, he would reflect on his past actions and he would motivate himself to keep on going in reaching his goal. He also used managing emotions strategies such as using self-talk to control his emotions and provided self-reward for his successes. Sepatu also showed awareness of time management in completing his course assignments. He sought help whenever he faced difficulty in his language learning. He not only prepared well for his individual assignments, he also acted as a leader for his group project, enabling his group to work towards a common goal in a timely way. 


\section{Behavioural}

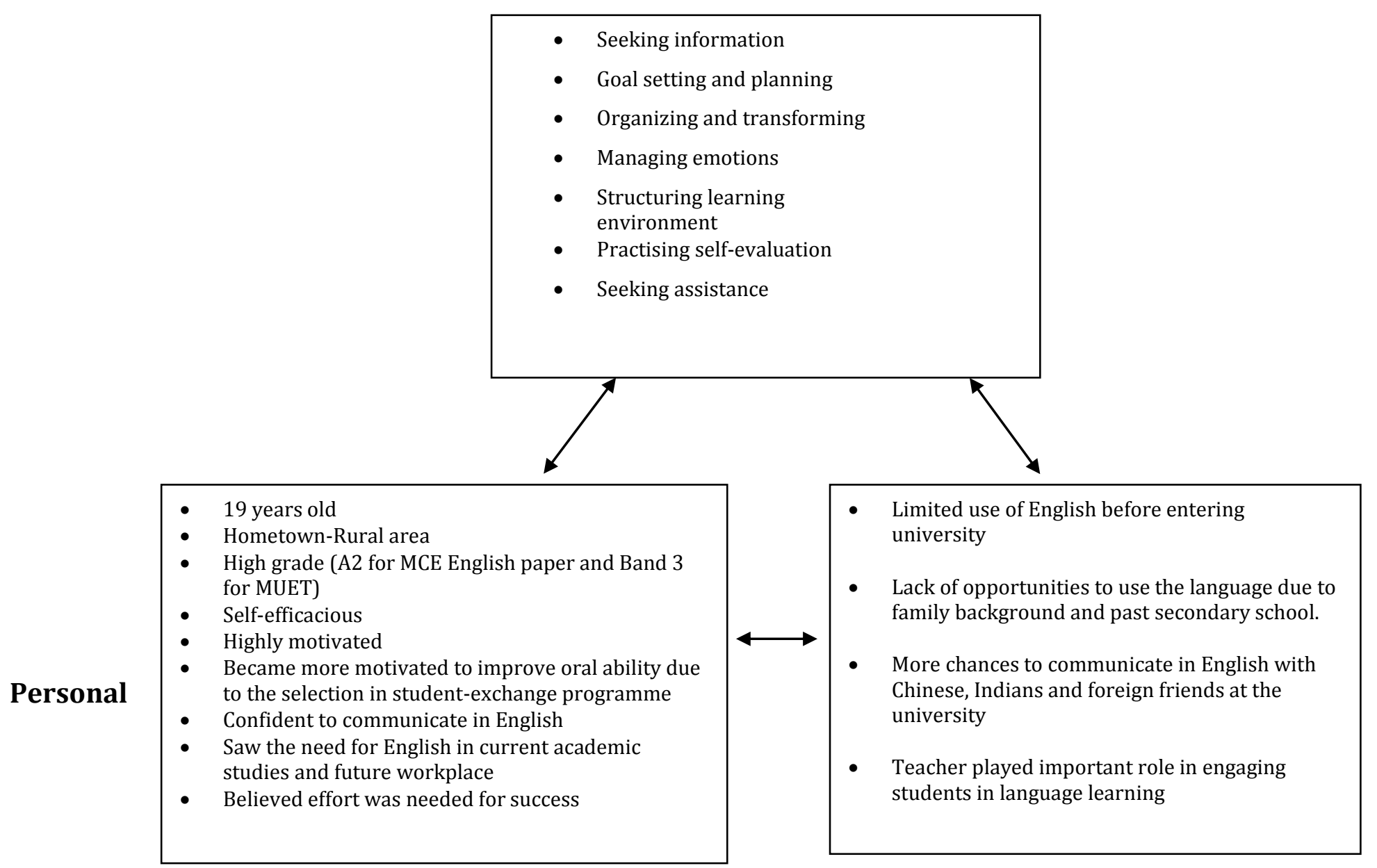

\section{Environmental}

Figure 5.2: Summary of the SRL strategies and factors influencing Sepatu Chenta's self-regulation in language learning 


\section{Learner two-Rae}

This statement that Rae made typified her attitude towards learning English:

Students should have their own motivation to learn English.

\section{Personal Factors}

Rae is a female first year Chinese student in the Business and Economic Studies Faculty, majoring in Economics. She is twenty years old. She had a high level of English language proficiency as measured by her grade for her English paper in the Malaysian Certificate of Examination and Malaysian University English Test (MUET). Due to her good MUET result, she was exempted from taking the Foundation course. Rae is an active undergraduate who joined a number of campus and residential college activities. She made friends easily with students of different races and loved reading and listening to music.

Rae attributed her English language proficiency to her previous education. She is from a rural area in the Eastern part of Peninsular Malaysia. She was educated in a Chinese school for Malaysians from primary to secondary school and studied at a matriculation college prior to university. Although it might appear that her background did not really help her acquisition of English, she had early exposure to English as she was sent to an English-medium school, which was a Catholic school, during her kindergarten years. She considered this early exposure to English language contributed to her proficiency in the language:

... from Chinese school, since primary to secondary school all Chinese school, [kindergarten] kindy... Catholic school. I [learn] touch English early... My teachers are Indians so we communicate in English

... influence of my early exposure to English... I think it is because five years old that time ... we were young and we learn faster so we can catch things very fast. I wonder why she use like this?

(27 January, 2010)

Rae perceived her English as quite proficient and saw her strength in reading and listening (receptive skills). She could readily understand what she heard. When she read, she only needed to understand what she read and did not have to worry 
about making grammatical mistakes. Rae was aware of her lack of grammatical knowledge, so she was worried about making mistakes when writing. She was conscious of inappropriate word choice when writing:

... I can understand something very fast. For reading, I guess the text is given, so I don't have to worry about my grammar mistakes, because I am quite weak in grammar. I am worried about writing and vocabulary, sometimes wrong usage.

(27 January, 2010)

Her concern for grammatical accuracy might have arisen from her previous learning experiences where grammar was one of the language aspects being frequently tested.

Rae explained that academic essay writing made her nervous because she could not express her ideas clearly:

Writing can be a slow, painful process even in our mother tongue, but when it is in a second language the problems are more ...Writing, even simple topic like 'How to stop pollution' (this was one of the topics for her class writing assignments). I hope to be perfect, but I can't coordinate the points. Writing academic essay... is a problem to me. I am really weak in writing. I feel really tensed when I need to write an essay.

(27 January, 2010)

Rae was aware of using strategies to improve her writing ability. She preferred to learn through online language learning sources and newspapers where she could see the accepted style for different types of writing:

... refer to online sources, Wikipedia, refer how to write this thing. Look at samples of good essays or report.

I also read articles in newspaper. Opinion writing by other person. So, I kind of like ... this kind of topic you have different view ... the way they write it down.

(27 January, 2010)

Rae read novels for personal interest and newspapers to improve her language proficiency. She felt that reading benefited her language proficiency, such as 
improving her vocabulary. Through reading, Rae learned ways of writing, chunks of language and correct sentence structures.

She was also concerned that her lack of vocabulary caused difficulties. When she learnt new words, she found the correct pronunciation of the words through a computer programme. The newly-learnt words were then entered in her personal vocabulary book with the English and Chinese meanings:

... sometimes I read out some words from the stories. I get new words, and ... now we have many software, just go online, type the word, how to pronounce, have my own vocabulary book. Then, I jot down the words in my vocabulary book with the English and Chinese translation.

(27 January, 2010)

By listing the newly learnt words and revising them, she endeavoured to improve her vocabulary. She revised the words and the meanings during her free time. In order to consolidate these words, Rae used them in her writing and communication like chatting and sending messages so she would not forget them. 
Figure 5.3 below shows a page of Rae's vocabulary book.

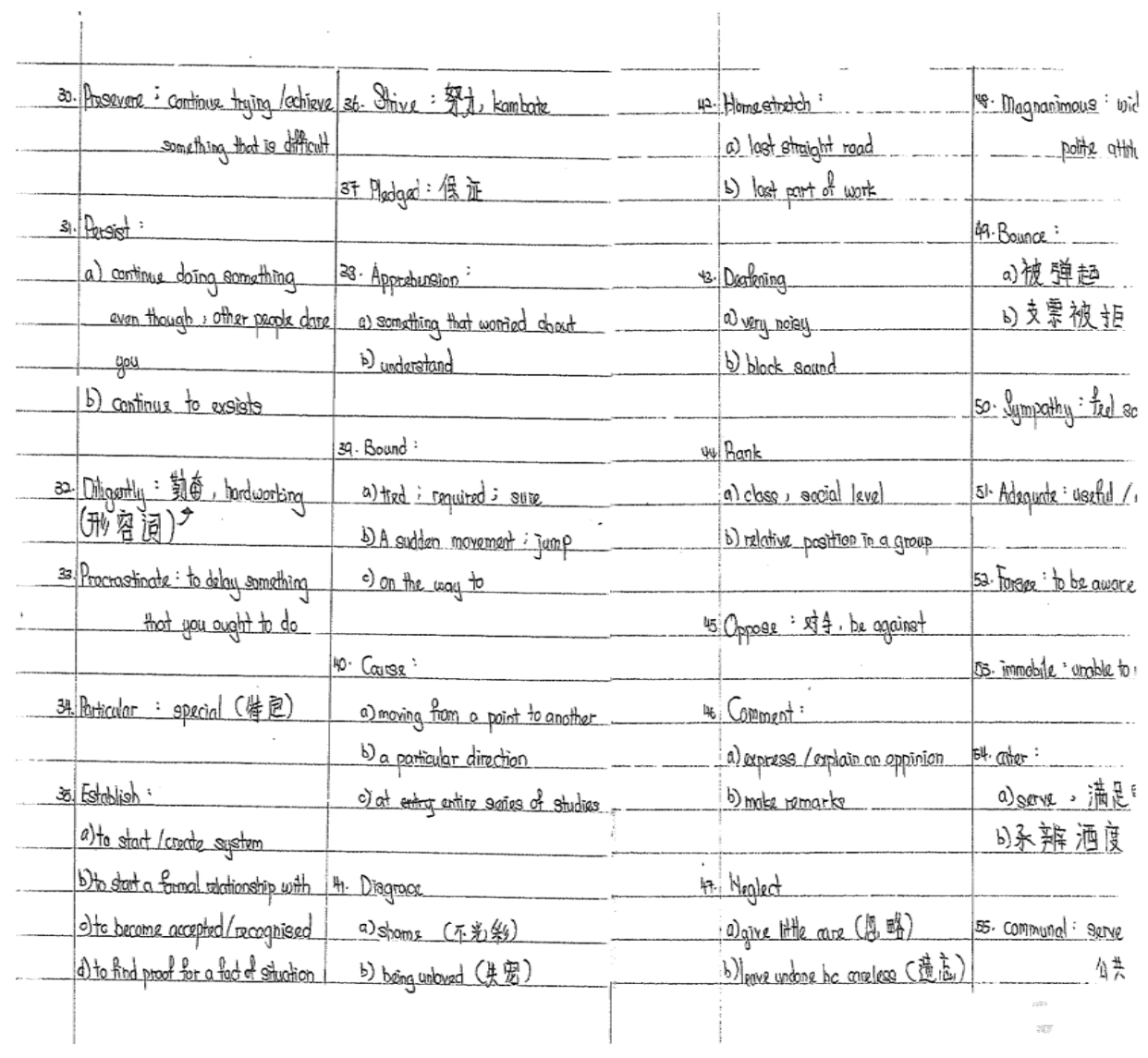

Figure 5.3: A page of Rae's vocabulary book 


\section{Self-efficacious}

Rae's efficacy to learn and improve was high. She believed that she could achieve success through effort and the use of effective learning strategies. This showed her awareness of self-regulative knowledge for her learning.

\section{Intrinsically motivated}

Chinese was the medium of instruction at Rae's primary and secondary schools and she considered that this contributed to her lack of English language proficiency. Hence, she tried to use English as much as possible at the university. Rae was intrinsically motivated to improve her language proficiency and she felt that the English language courses at university were a chance for her to improve her language skills. Rae's goal was not achieving a high score in the final English course grades but to master the language. She was aware, as a graduate of the Economics faculty, that her mastery of the language would be useful even after her university life, for example, for her future career:

... because we are in the Economics faculty, most business companies and private sectors ... they use English as the main medium of communication and interaction because everyone wants to go international. You want to have business with overseas people ... you must know English.

(27 January, 2010)

\section{Mastery goal orientation}

Rae's motivation and interest in learning language extended beyond examinations. She disagreed with some students who regarded attending the English course only as part of the university's requirement to graduate:

I do not learn English just for exam, I like to explore it, I want to know more about the language, ... exam is not my life. My life is after the university, if you study for exam, you will not be motivated to learn after the exam.

(5 February, 2010)

This mastery goal orientation was related to her intrinsic motivation. This was shown when she did not see repeating the Academic Communication I course as burdensome. She did not manage to score the required grade, above $\mathrm{C}$ grade, to continue with a higher language course. She missed the final exam which 
constituted $40 \%$ of course marks, due to a technical problem. Although she managed to score quite high marks for the on-going course assessments, the accumulated marks were not sufficient to be awarded a grade better than Grade C. Instead of seeing it as wasting her time, she regarded the repetition as a further chance for her to master English. Besides English, Rae also registered for other foreign language classes. This was due to her interest in learning languages, as she saw languages as tools for communication.

As a student of the Economics Faculty, she was aware that most of the readings in the Business field were in English. Lack of proficiency in English might cause difficulties in understanding the reading materials and completing assignments. Misinterpretations could occur and that would affect her marks for the assignments:

The problem is in doing our assignments, we have to refer to English books, so, we have to be a good translator to ... write project paper. Problems like translation and misinterpretation occur.

Sentences are ok but certain phrases or terms difficult to translate, Economics term, we never find it in the dictionary.

(27 January, 2010)

\section{Effort attribution}

Rae attributed her success in each course assessment to her efforts and this increased her self-efficacy in her language skills. Rae indicated that to be motivated in learning English as an undergraduate, students need self-discipline and they should take the initiative themselves to succeed:

... there's no pressure to perform here at university, it's all self-motivation ... I'm a pretty independent sort of person. If there's something I don't understand, I'll try and solve it out for myself ... if [I] still have problems ... I ask someone else to help me ...

(2 March, 2010) 


\section{Summary of Rae's personal factors}

Rae admitted the importance of English in her undergraduate studies and future career. Rae attributed her achievement in learning English to the early exposure to English she had when she was young and to her efforts at university. Her communication in English with other students and her reading of English reading materials also contributed to her mastery of the language. Her goal of improving her oral and writing ability was driven by her intrinsic motivation.

\section{Environmental Factors}

\section{Opportunities to use English outside university classes}

Rae experienced challenges in using oral English in her daily life as an undergraduate at the university because the Malay language was widely used as the medium of communication and instruction. Students who were not proficient in English refused to use the language. However, there were others who wanted to practise using the language, although at times they were ridiculed by those who did not use it. Rae reported that students who were not proficient in English reacted negatively to those who tried to use English by labelling them as showing off:

... they will react like showing displeasure, from their gestures, facial expressions. This person very show off. Some will suddenly be silent. It still exists but less compared to the Malay community.

(27 January, 2010)

\section{Peer influence}

She stressed that having friends who were interested in using English was important for her to improve her oral ability. Rae explained that most of her friends were reluctant to use English as they felt that they did not have sufficient vocabulary. They were also worried about making mistakes in pronunciation, grammar or sentence structure that could cause communication breakdown:

Less use of English, we prefer to use our mother tongue in our communication as it is much easier to communicate. Not all university students can use English very well. So communicate in English, might be some words cannot express, vocab ... that we cannot put it out, then the sentences be breakdown. We feel embarrassed. Another thing is because we still cannot speak properly, we cannot speak some 
words ... what she speak, friends say, I don't understand ... just use your own language. So, one of the reasons we don't use English

(27 January, 2010)

Although she faced resistance from others, Rae took action to change or regulate her less encouraging environment by asking her good friends to use English in their daily communication, which resulted in a positive response. She tried to influence her friends to talk in English by initiating communication in English:

Normally, I am the one who influence my friends. I suggest them to use English and they will be responding positively. I initiate conversation in English ...

(27 January, 2010)

Although at times there were friends who refused to use English when communicating with her, she still used English, as she believed that she must use it in her daily life to be proficient:

I want to improve my oral ability. Now, I try to use English when conversing with my good friends, although they reply in Chinese, Malays

(27 January, 2010)

Rae took the opportunity to use English with international students at university $\mathrm{X}$. There was also a practice of recruiting local undergraduates to mentor exchange students from other countries during their stay at university X. She saw that as a good opportunity to practise her spoken English.

Realising that she was facing a difficult environment at the university for practising English language socially, Rae created her own context to use English. She purposely chose online friends who used English. She used the phrases and words that she has learnt from her reading when she was chatting online with her friends. She made sure that her writing was clear in order to avoid miscommunication:

... when I master the word, I'll try to use it. Mostly by typing online, because we as students of ... we use English less, usually we only communicate in English 
online...when we are chatting on MSN because we cannot talk, we cannot make more simple to make people understand so I have to make my writing clear ...

(2 March, 2010)

She used English when she gave accountancy tuition to groups of secondary students. This enabled her to practise her oral English and improve her presentation skills. That developed her confidence in using English:

I teach Accounting to secondary school students ... part-time work, I use English, I realise my oral ability increase and I become more confident. My presentation ability also [improves] improve

(2 March, 2010)

Being an active undergraduate, Rae was involved in her residential college activities, one of which was specifically planned for the improvement of language proficiency among the undergraduates at the university. The English Speaking Zone (ESZ) at the residential colleges was a university initiative to encourage the students to use English in their communication. There were a number of benefits from participating in the activities such as information sharing opportunities, a public speaking forum, theatre, sports and a language camp:

... college's activities that had brought benefit to student, and one of it is English Speaking Zone (ESZ), where it stands for zone in college that we need to practise our English. In semester 1, first year and second year student is necessary to attend a meeting for ESZ where we had information sharing, presenting and public speaking.

(Unedited diary, 5 March, 2010)

Rae stated that by joining the ESZ activities, the undergraduates could increase the usage of English in their daily life. She further asserted that students should make full use of the opportunities to use English in the activities planned in the ESZ programme.

Rae commented on the attitude of some students who refused to take part in the organised activities. She felt that it was a waste that the undergraduates did not take the chance provided to them by the university to improve their English 
language proficiency:

... every student should has their own motivation to start learning English as they are in ESZ and not be force to attend some program to practice English. Well, for my opinion, maybe some students were force to attend the program, while others may take this as a chance to practise their English. And for those who were forced, I believe more or less they did gain benefit from attending the program. Not to mention that we can increase the usage of English in daily life, the program also helps us to built [build] confidence by speaking in public.

(Unedited diary, 5 March, 2010)

\section{Language course approach and materials}

Rae was confident she could learn the language content and materials specified in the course. As the course was at a foundational level to teach the students to function effectively in academic settings, the items included were basic grammatical items, and short reading passages. The course adopted a studentcentred approach with emphasis on reading and speaking. Rae received new language input from the course and she felt that her knowledge of English language was improving. She found the textbook interesting and reported that she found it engaging as the reading passages were relevant:

\footnotetext{
Because they are just basic concept like simple grammar, I also find that the book used for the course really helps me to learn English. The articles in the book are short and interesting, For example, the adverb 'ly'. Before this, I don't know. I learn parts of speech, noun, verb, adjectives ... I want to try to use them when I write as I become more aware of what is noun, verb ...
}

(2 March, 2010)

\section{Teacher factor that influences self-regulation}

Rae was grateful for the work of her language teacher, particularly for the twoway communication between the teacher and the students in the class. She also appreciated the teacher's work in correcting the mistakes that she and her classmates made:

is very good teacher as we communicate by talking, even the small mistakes that we have or how we pronounce a word, ... he'll correct us. (2 March, 2010) 
However, Rae was not satisfied with the class activities, and felt they weren't interesting. She found completing and discussing the exercises in the textbook a bit mundane:

Actually it is quite boring, learning just by the textbook. We don't have many activities. We just do the exercises in the textbook. It is not challenging because every class refer to text, we read we answer, cannot give us the motivation ...oh...this way... English is not fun ... every day, open textbook ... do exercises, discuss same every class... kind of know what to expect for English class ...

(2 March, 2010)

Rae wished that her language teacher would plan interesting activities, such as a treasure hunt around the campus, a trip or other activities outside of class. She suggested lessons could be held outside of class like viewing movies at the library. She had previous experience of having a creative language teacher who planned learning tasks based on movies. Rae commented that students could see the relevance of the movie viewing activity aside from just enjoyment:

Film at bilik tayangan [bilik tayangan is a special room for movie viewing at the university main library], library. Maybe the teacher can let us watch film, then ... we write a summary of the film. Not just for leisure viewing, sure there is a task after that. While we are watching the film, we have to listen. Know what is happening, we need to find the main point, we need to write, we can learn pronunciation, we can learn new words. We can learn lots of things from doing something fun.

(2 March, 2010)

Rae believed that the class could be made more challenging by incorporating a variety of interesting activities like language games, and quizzes. She thought that there were lots of ways of learning English:

Maybe we can have small games like puzzle, guessing words, debate ... something

... in between the lessons, have competition, ... there are many interesting activities related to English language.

Rae suggested language teachers should not just focus on completing the textbook and preparing students for on-going assessments and final examination. 


\section{Other contextual factors which influence self-regulation in language learning}

When asked about other contextual factors that might affect her language learning, Rae stressed the influence of her family members. She realised the need for her to be orally proficient in English as her English-educated cousins used English in their daily conversations. She did not want to feel embarrassed because she was not able to converse in English and participate in family activities:

I have cousins who are English educated and they cannot speak Chinese very well, so when we try to speak to them, we are the ones who have to speak in English. That is one of the factors that motivate me to improve my English proficiency. I will feel shy if I cannot speak in English like during family gathering... Chinese New Year, birthdays

(27 January, 2010)

\section{Summary of environmental factors that influence Rae's language learning and use}

Realizing the lack of opportunities to use English at the university, Rae made efforts to organise her environment. She created opportunities to use English with her peers, who responded positively. She also taught in English. She was actively involved in the language activities organized by her residential college. The launching of English Speaking Zone (ESZ) at the residential colleges has helped in providing environment and avenues for students to use English in their daily lives at the university. To maximize her language learning, she accessed online materials. Rae felt teachers should incorporate a variety of interesting language activities. Having English-speaking family members challenged Rae to improve her oral proficiency.

\section{Behaviour - Self-regulated learning strategies Goal setting and planning}

For her distal goal, Rae wanted to improve her mastery of the English and her level of proficiency, especially her productive language skills (writing and speaking).

Rae further clarified that she not only wanted to be able to speak English fluently, she had to speak with clear pronunciation. Thus, as her short-term goal, she tried 
to improve her pronunciation using the online pronunciation exercises. She realised the importance of conveying a clear message when communicating. She was also aware of the different ways of English use by different people:

It is important for the right mood or message to be conveyed. I want to understand the English spoken by other people and international students who have different ways of speaking English.

(27 January, 2010)

\section{Seeking information}

Rae organised her study in order to do well in the on-going class assessments. She planned and conducted research such as identifying recent issues and reading related articles to prepare for her information-sharing assessment. She felt choosing a current and controversial issue would make her presentation interesting and relevant to her audience. Rae collected information from different sources, for example, online materials and newspapers that write on the issue from different perspectives.

Rae thought that the internet facilities at university $\mathrm{X}$ had helped in her language learning process. The students could access internet easily at the residential colleges and there were internet cafes for students at the campus. Rae stated that it was the responsibility of individual students to make full use of the facilities. She indicated that she experimented with the internet and looked for ways to practise her English online. She chose online friends who used English, like those from foreign countries. She normally used online materials to tackle any difficulties that she faced while learning English. For example, she read English online materials and made use of the facilities for editing work. She used other tools such as Microsoft office for checking grammar and spelling:

Mostly online source ... I get material online ... I gather information... for example, reading materials, edit my work.

... at the university, I check my mistakes using computer, for example, by using spelling checker. ... You know where you did wrong. Before this, I did it manually

(17 February, 2010) 
Rae explored the English language learning websites like BBC World Service Learning English Website , Dave's ESL Café , English as a Second Language and English Club.com and she found out there were many interesting and challenging activities to help her to improve her language proficiency, like learning correct pronunciation:

Now at the university, we have Wi-Fi facility, I use blog, internet to learn English... now we have many softwares, just go online, type the word, how to pronounce, ... even can get different pronunciation. British or American.

(17 February, 2010)

She also tried the exercises and activities in the MyLine website which was specifically designed for Malaysian ESL learners at the tertiary level.

Rae further elaborated on the possibilities of improving her language through Facebook. She preferred using English on Facebook because it made typing much faster than typing in Chinese characters. Facebook also had a function for correcting spelling when she was writing:

I realized that the people could learn their English through face book especially the Chinese and Indians. This is because the Chinese and Indians letter are formed differently from alphabets. And for Chinese letters, we have many letters read in a same pronunciation, thus it will slow down the speed of typing as we spend the time to choose the correct word to use. For this reason, most Chinese would rather to type in English. By this reason, blogging and face booking have somehow become factors to encourage people to use and learn English.

I don't know whether has anyone realize that face book has a function that can detect wrong spelling. If we had wrongly type a word, for example type "nid" instead of "need", a red dot line will appear below the word, meaning that the word is wrongly spelled. Although it could not been automatically corrected, but at least we can check for correct spelling by highlight and right-clicking the word.

It is fun to online, but it is even fun when you discovered something new to help you learn English through online.

(Unedited diary, 12 March, 2010) 
She gave examples of learning how others wrote and used words and phrases. The new words and phrases were used later when she wrote:

For blogging, I usually read others' blog. I have this friend, she's great. She writes about love, I like the language that she uses. Big words, descriptive, show emotion. Then, I'll try to use those words or phrases when I write.

(17 February, 2010)

Rae not only learnt English online but she used online facilities like chatting to practise her newly acquired language. She stressed that there was a lack of opportunities for her to practise English orally in her daily life at university $\mathrm{X}$, so communicating in English online really helped.

Besides learning English online, Rae also took other initiatives to improve her language proficiency. She learnt by watching movies where she would listen carefully in order to understand the stories. This was because she realised that she could not rely on the subtitles, as they were very often translated inaccurately. From watching movies, she could learn pronunciation of words and phrases:

I can learn by watching movies, for example, the recent movies that I watch were Avatar and 2012. I cannot rely on the subtitles. They are wrong so I have to listen really carefully. For example, feet, the meaning given is suap (suap is a Bahasa Melayu word, which means 'feed' someone). That is also one way of learning when I know and realize that it is wrong. Most students will rely on subtitles as it is easier, but you have to be careful as mostly they are wrongly translated.

I watch movie like Ghost Whisper, I can learn English like the usage of terms, how the actors say it ... learn English informally.

(17 February, 2010)

From her response to the question on the accessibility of language learning materials at the university, she stated that it was not a problem, as the residential college provided newspapers. There were also lots of English books at the university main library. She also bought books that interested her, as she preferred to write notes while reading: 
Newspaper we got it ... There are free newspapers at the college, just read it there, books I rather buy it than borrow it at the library as I can still refer back to the things ... I can do some marking on the book.

(17 February, 2010)

However, she expressed her wish for a specific language learning centre to be set up at the university. She suggested that the centre be equipped with self-learning materials like CDs, videos, books and dictionaries for the students to use during their free time, and classes could be held there. Thus, it would make English class activities more interesting and varied.

\section{Organizing and transforming}

Rae referred to a variety of sources to prepare for her course assignments. From these different sources of information, she was able to select the relevant information for the specific task. She prepared her own notes from different sources. The steps taken in accessing information for her course assignment showed her information literacy. Figure 5.4 below shows part of Rae's notes for her preparation of the information sharing assessment. 


\begin{tabular}{|c|c|}
\hline & 莫哈末达斯里夫 - Si Petaling \\
\hline & Where do you want to throw the bomb? The price can be negotiate, \\
\hline & watch in asen attack the whole process of processing arson \\
\hline & 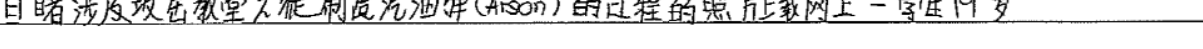 \\
\hline & $\begin{array}{l}\text { This article is related to sensitive issues that happend recently about arson attempts } \\
\text { on several churches. }\end{array}$ \\
\hline & - 118 this $a$ ind of ation that $m$ \\
\hline & religion or his attitude / main \\
\hline & - Raja Muhammod Faizal / d zham Iaja Ibrahin 24 \& 22 \\
\hline & - Azuwan Shah thmad 23 \\
\hline & - commit mischif with fire at the charch in Desa melawati, \\
\hline & - humed hand body \\
\hline 2 Feb & - illegal gatheñy. at Assumption church, sms has been passed \\
\hline & around - Ktua Palis Selogot Datur Khaliol Aby Betan. \\
\hline & \\
\hline & 9churches, 1 mosque, 1 sarou, $1 \mathrm{kml}$ Sikh \& \\
\hline & Convent shool - put up fire, disimbah cat of throw stone. \\
\hline & MCCBCHST - Buddha. Christian, Hlingu, Sith, Taibisme \\
\hline & We must remain calm and cenited at this very junture. \\
\hline & instipate \\
\hline & - social conflict er contracaliction \\
\hline & Repardless of how thee stand in the 'A' issul \\
\hline & have stood alonside $110 n$-mustims of ter the incialeut. \\
\hline & - words of comfort, flowers \& formed voluntary sguads \\
\hline & \\
\hline & cont \\
\hline & escalate tension \& prouake unrest - act of desecretion \\
\hline & \\
\hline
\end{tabular}

Figure 5.4: Rae's notes for her preparation of the information-sharing assessment

The notes above demonstrate her effort to synthesize opinions on the issue. Her effort to rewrite the points using her words made her feel comfortable and confident about presenting her speech. In the process of preparing for the presentation, she used computer tools for translation and word checking. Although she was confident in using English in informal communication, she thought that she still needed a prepared speech for the presentation. As this was an assessment, she was worried about not being able to speak spontaneously because of grammatical errors. Hence, she wrote and memorised the speech and 
rehearsed it to present it confidently:

In order to prepare for the presentation for academic communication, I had served on net to search for related article and news for my topic. To get myself more information, I had gather article and news on English, Chinese and Malay language. After going through all the articles, I choose only the related information, and I need to translate them into English language. Due to this, Google online translator and a dictionary are needs for me. I use the translator to translate the word and dictionary is use to check whether I have use it correctly. Then, I started to write my presentation speech, because I know that I could not form a whole sentence spontaneously.

(Unedited diary, 5 February, 2010)

However, when she gained more confidence from practice, she became less anxious about the assessment. Rae also rehearsed the paralinguistic features such as appropriate gestures, body movements and facial expressions that were important as presentation skills, in front of the mirror.

Rae was clear about the expectations of her language instructor for the assessment and she used strategies like predicting the questions that might be asked for her topic:

While rehearsing, I try to think and predict the questions that my friends will ask, I want to be really prepared, so I can answer the questions given to me confidently. I write down the answer to questions that might be asked.

(6 February, 2010)

She was attentive and took notes while others in the group were presenting to make sure that her assessment would proceed as planned and she could score good marks. During the presentation, Rae felt that she could answer the questions asked confidently and present her own opinion of the issue before finally summarizing the content of the presentation.

Her language instructor commented on her ability to present different points of view from different sources on a sensitive issue without being judgemental. He reported that she engaged her audience in her presentation and stimulated comments. Her language instructor commented that she was able to form a 
conclusion by sharing her personal opinion of the issue discussed and handled the question and answer session effectively. She had effective presentation skills that made her presentation clear to the listeners, and the message was conveyed effectively.

I observed that she was confident when delivering her information sharing presentation. Her choice of a topic, which was widely discussed in the media at that time, engaged the listeners:

Rae presented on one of the recent issues in Malaysia at that particular time, that was on the use of word ALLAH by the non-Muslims. Her presentation received good response from other group members as it was recent and an important issue for a multicultural and multi-religious country like Malaysia. She presented her topic with eye contact and appropriate gestures. Her voice was loud and clear.

(Teacher interview, 30 March, 2010)

Rae's choice of an interesting topic, her confidence in presenting and her delivery skills helped her in delivering an effective talk.

Rae wrote in her diary about her preparation and performance for the information-sharing assessment. She felt confident that she would be able to present well. She attributed this to her thorough preparation for the task. She took the challenge of choosing a current and sensitive issue for a multicultural nation like Malaysia for her presentation. Rae was confident about her presentation skills and ability to deliver the content of her presentation. She was aware that effective eye contact, gestures, voice control and pace of presentation were important factors for an interesting and clear presentation:

... about the presentation. I had chosen news that recently happens in Malaysia. It is quite a challenge because this can be [considered] consider new as a topic to be discussed, moreover, it is a sensitive issue. I feel [confident] confidence when I talked in group, because I know I'm fully prepared, and I believe that I had the skill to give speech. The most important is to handle the eye contact and speed to talk.

(Unedited diary, 5 February, 2010) 
Rae's fear of incorrect grammar usage did not affect her confidence for the presentation, as she was well-prepared. Rae planned the points to be presented and practised in front of a friend as well as by herself in front of the mirror. She memorised the points to be presented. After several practice sessions, Rae realised that she could present spontaneously without rigidly adhering to her prepared script.

Although Rae showed that she was well prepared and performed effectively in her first in-class assessment, information sharing, she reported that she did not have high expectations of the group project. She expected cooperation from the group members to write a good report about the issue and to prepare for the final group presentation but their lack of effort and commitment frustrated her:

I don't expect much for this group project as it does not only depend on me, it also depends on the group members.

(20 February, 2010)

Rae preferred to do individual assignments as she felt that she had more control of the process and outcome. If there were other people, it was more difficult for her, especially if there was no commitment from the group members. The group members had to allocate time for discussion, and preparation of materials for the final presentation. She further stated that working in a group required more effort and the group members should not take for granted that other group members would do the work for them.

In an initial interview, Rae believed she would not have any difficulties in collaborating with her group members, as she had chosen for her group those classmates with whom she felt she could work well. However, at the end of the semester, she stated choosing close friends as group members could lead to difficulties with being in control, as she felt uncomfortable in dictating to her friends so that they could complete their task.

Although, from the examples above, Rae showed that she planned and prepared well for her language learning task, she also reported that at times due to her involvement in many campus and residential college activities, she procrastinated. However, she still prioritized tasks, based on her perception of 
the task difficulty:

I procrastinate until a week before the due date ... but for assignments that I have more confidence, I'll do those assignments later, for assignments that are difficult, I'll give more priority. I need more time for it.

(20 February, 2010)

Rae was aware that her final grade for the course was based on cumulative marks of the in-class assessments (60\%) and the marks in the final exam (40\%) refer to the course description (Appendix F). However, she stressed that she did not see course components with the lowest percentage as being of less important. She tried her best for all the assessments:

I think every mark plays a role so it is good for sir to tell us the division of marks early of the semester but I think if he didn't tell us also, I will concentrate on the tasks and assignments as all of them are important.

(20 February, 2010)

Rae's awareness of the importance of putting effort into all the in-class assessments and also the final exam was in line with the emphasis put on them by the class teacher:

So students know what they are getting into. Students know how they are going to be evaluated, not just we do this thing, lecturer told us to do it, then we just expect for the grade, so they know they do this, they'll get this kind of marks and also how much effort they must actually put, so, knowing that for example, for exam, knowing that actually $40 \%$ are allocated for the exam, they should work for the exam. And if they know that the project presentation is allocated twenty marks, then they should work for it to present a creative and interesting presentation

(Teacher Interview, 30 March, 2010).

However, near the end of the semester, Rae's teacher reported that she missed classes a few times without valid reasons and her performance in the final assessment (project presentation) was not that good. Creativity and clarity was part of the marking criteria for the final group presentation and Rae's group 
presentation was criticised by her language instructor for lacking creativity. Each group was expected to present their work in the form of a sketch, forum, discussion or another engaging form to be awarded good marks. While her group managed to present the content, her language teacher felt that the method of presentation was not that interesting. The teacher's comments confirm my interpretation from the classroom observations:

Rae and her group members present their project presentation. At times she looks a bit hesitant and a bit unsure of what to do. I wonder whether they have prepared well. There is lack of creativity and there is nothing different. They have few sketches (just like other groups)! They seem a bit stiff and hesitant. The transition from one scene to the other in the role-play was not smooth. I wonder whether they have practised before the assessment!!!

(Observation in class-final group project presentation, 23 March, 2010)

The teacher observed that Rae and her group members changed their project topic and this could be the reason for her less effective project presentation.

\section{Managing emotions}

Although Rae was motivated to improve, there were times when she felt bored. To get rid of this boredom, she used positive self-talk to persuade herself that the learning task was fun and to ensure that her expectations and goals were realistic.

Failure motivated her to work harder. Rae saw no point in punishing herself for mistakes or being embarrassed about them. She reflected on mistakes so that she could do better in the future:

I do not want to repeat the errors that I have made. To make sure that I do not repeat the same mistake when I identify something wrong, I'll correct it and try to use it more frequently so I can remember it.

(20 February, 2010)

Frequent use of the newly learnt information (like vocabulary and grammatical items) helped her to acquire these elements. 
Rae's emphasis on correcting her own mistakes was in line with her language learning goal of being grammatically competent:

I would like to be able to:

Reduce grammatical mistakes

Able to use the right vocab in speaking and writing

(Unedited diary, 12 January, 2010)

In order to keep being persistent, Rae practised certain strategies like telling herself to keep going even when her plan did not go well. For example, Rae showed persistence when she was presenting her information-sharing presentation. When she was presenting, she received a comment from the teacher, as he felt that she should present the idea in the article before she elaborated on her own opinion about the issue. The comment did not affect her confidence and persistence to continue with the presentation. She paused for a while after the comment, then continued with the main points of the article as instructed by her teacher. In the interview conducted after the information sharing assessment, she reported that she did not regard her teacher's comment as a criticism but she took it as something constructive.

To reward herself for hard work, Rae spent time on other activities not related to studying. This also helped to prepare herself to get back to her learning task and complete it. Her active involvement in other activities like dancing helped her to overcome boredom and be energized once again for studying. When she was bored, she would take time out and do such things as listening to songs, relaxing for a while or reading novels.

\section{Structuring learning environment}

When Rae was studying or completing an assignment, she did not stop until she has finished it. She ignored any distractions, such as friends inviting her to go out. When asked about her strategies for controlling her environment to make her language learning efficient, she replied that she handled the distractions by doing things like telling her friends who were making noise that she needed to focus on her studying: 
I just say no to my friends, like when I am rehearsing for my presentation or finishing my assignments. When the learning environment becomes unsuitable, I'll sort out the problem. For example noise. Noise like music is ok but talking can disturb me, cannot concentrate. So, I will stop what I am doing. I'll inform my friend that I need to continue with my work ...

(2 March, 2010)

\section{Practising self-evaluation}

Rae expressed her concern that the lack of English language use at the university had affected her language proficiency. Rae showed that she evaluated her language learning proficiency and progress. For example, when she faced difficulty in expressing herself in English, like grappling for words, she knew that she had to use English more in order to be fluent in the language:

When I first came to the university, I realise that my English is deteriorating as I didn't speak in English much. I told myself ... I must do something or I will have problem when I graduate... For example, for speaking. When you have difficulty to talk, you know that you have to improve your speaking ability.

(27 January, 2010)

Although she was conscious of not making and repeating mistakes, normally when she was speaking in English with friends, her focus was more on the message. Rae used simple words in order to be understood by the others. However, for writing assignments, she would spend time checking for errors such as spelling and grammatical mistakes. She used computer tools such as spell check to identify mistakes:

... In speaking, I emphasise more on conveying the message. If I can't use longer words, I'll use simpler phrases as long as the message is conveyed. For writing, I have more time to check my work and edit my work using computer ...

(27 January, 2010)

\section{Seeking assistance}

Rae was willing to seek help from others if she faced difficulty in her language learning. However, she was more comfortable in getting help from peers rather than the teacher. She felt that teachers should be more friendly and show more 
concern about students' progress. That would make students feel more willing to get help from them:

... get help from more advanced students like for meaning of words

... I feel that there is a wide gap between teachers and students. I don't feel comfortable to meet teacher, unless they are approachable

I prefer to refer to internet rather than asking for help from teacher

(2 March, 2010)

Her language instructor commented that Rae asked questions in class to get clarification of learning tasks. For example, during the class, Rae asked questions about the facilities for the final group presentation. She needed this information, such as the availability Liquid Crystal Display (LCD) projector and laptop, to help plan her group presentation. She had an overview of the task that enabled her to match the mode of the presentation with the facilities provided. This hints at a need to control her environment through careful preparation for the presentation.

\section{Summary of Rae's self-regulated learning strategies}

Rae set goals to improve her written and spoken skills. She utilized motivational strategies to keep up her interest and motivation levels. She showed strong effort regulation in preparing and completing her course assignments. She requested assistance during her language learning. She was persistent in completing her language learning tasks. She expressed a preference for individual work where she could control the process and outcome through the effort she put in. Her language instructor noted Rae's lack of effort and interest when it reached the end of the semester compared to her performance early on. Rae reported efforts to control her environment to make it conducive for learning. 


\section{Behavioural}

- Goal setting and planning

- Seeking information

- $\quad$ Organizing and transforming

- Managing emotions

- $\quad$ Structuring learning environment

- Practising self-evaluation

- $\quad$ Seeking assistance

\section{Personal}

- 20 years old $/ 1^{\text {st }}$ year Economics student

- Hometown - Rural area

- $\quad$ High entry grades-MCE (A1) and MUET (Band 3)

- Had early exposure to English during early childhood education.

- $\quad$ Self-efficacious

- Saw her strength in reading and listening

- Intrinsically motivated

- Mastery goal orientation

- $\quad$ Effort attribution

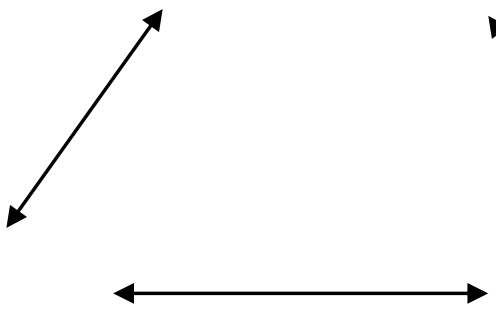

\section{Environmental}

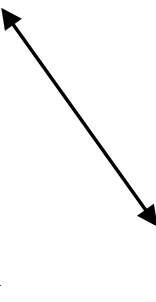

Lack of chances to practise English

- Close friends who are willing to use English

Involvement in English Speaking Zone (ESZ) activities at residential college

Availability of English materials at colleg

- Interesting course materials

- Two-way communication and feedback from teacher

- English-educated family members who use English - Feel challenged to improve spoken language

Figure 5.5: Summary of the SRL strategies and factors influencing Rae's self-regulation in language learning 


\section{Learner three-Stanza Nurmalam}

The following quote showed Stanza's self-efficacy and persistence to improve her language proficiency.

I have the confidence in myself. I won't give up!

\section{Personal Factors}

Stanza Nurmalam is a female Malay, and a first year student of the Islamic Studies Faculty majoring in Quranic and Sunnah studies. She is twenty-five years old. Previously, she gained a Diploma from a university college, and had attended a Malaysian public university. Emphasis was given to English language learning at her previous university where an ELSP (English Language Support Programme) was conducted every semester break for first year students. She stated that this has helped her to improve her language proficiency. She attributed her interest in learning English to this positive experience of studying in an environment where English was important. At her previous university, English was the medium of instruction for most subjects.

Stanza's grade for her English paper in the Malaysian Certificate of Examination was C6, and her result in the Malaysian University English Test (MUET) was Band 2. This indicated a low achievement in her past English examinations during her secondary years. However, her final course grade showed that her language proficiency had progressed. Before taking the Academic Communication 1 Course, she completed the Foundation English Course, as a requirement for students who had below Band 3.

Stanza is from a rural area from the Eastern part of Peninsular Malaysia where English is not widely used. She spoke about the importance of acquiring English at the university. Although her parents did not use English, they encouraged her to improve it in order to better her career prospects, which could heighten the family status: 
... my parents always said we are poor people, we must change our lives, my parents always said study hard and my parents support me to learn more English. Although my parents [do not understand and use] no English, my parents support me [to learn] know English.

(10 January, 2010)

The family home was near a tourist resort where her parents worked. There were lots of foreign visitors to the resort and so she saw the importance of English for communication. Encouraged by her mother, she practised English with a French neighbour who was married to a Malaysian.

\section{Intrinsically motivated}

She was highly motivated to improve her language proficiency. Stanza saw herself as self-disciplined, self-motivated and able to work independently:

You have to be more independent at the university. I believe motivation comes from an internal source rather than external source ...

(10 January, 2010)

These qualities were evident during the interviews and communication with the researcher. She believed by being motivated and believing in herself, she would be able to achieve her goal. She demonstrated a high degree of self-efficacy in her learning and improving her proficiency:

my motivation is high, although at times difficult ... even I don't understand, I think I can do it.

(10 January, 2010)

\section{Effort attribution}

She put effort into improving her oral proficiency. Although she could have used Bahasa Melayu, she chose to use English when sending messages to the researcher or responding to the researcher's e-mail. When she had difficulty, she would code switch between English and her first language. At the Islamic faculty, there were a number of foreign students and she wanted to improve her speaking skills to communicate with them. She made a considerable effort to improve spoken English. She took every opportunity to use English in her daily 
communication, like trying to communicate with the international students at the university.

Despite previous low grades in English, she felt confident with using English orally, as she was not worried about making mistakes:

even I speak not accurate, I [am] still confident even have more wrong words.

(10 January, 2010)

However, she felt that she needed to improve her pronunciation. She bought conversation books and every night before going to bed, she would read the samples of daily conversation in the books. She would also share the knowledge with her roommate at the residential college. She then tried to use the phrases learnt in her communication. She believed that regular use of English could lead to better spoken English:

If I don't understand, I will refer to dictionary, sometimes until midnight, I still refer and I buy the little book, conversation, maybe others will think it is something trivial but for me it is important because [it] is routine conversation. Sometimes I share with my roommate, before I go to sleep, I'll revise the phrases, ... just simple one, but for me [it is] important.

(22 March, 2010)

Comments made by her language teacher indicated that she was a very committed learner. Her language teacher described her as an attentive, hardworking student who regularly attended class and had the interest and motivation needed to improve her language. It was noted that Stanza always actively participated in class activities and discussions in a way that was respectful of others:

She was always interested in the lesson and participated in class activities. Although she tried to take part in the class activities, she did not dominate the discussions or activities as she also gave chances to her classmates to be equally contributing to the activities.

For example, when I ask for meaning of words in English of a word in Bahasa Melayu, I knew that she knew the answer but she didn't say the word, the 
answer, when no one could answer, then only she gave the answer. For example, once I asked for the synonymous word for the word, 'delay', she gave me the answer after making sure that no one would like to try answering.

(Teacher interview, 31 March, 2010)

During a discussion of the answers, their English teacher asked for the verb for the word application. Stanza said softly to herself, 'apply', but she did not answer the question of the teacher. When no one else answered, she said the word 'apply' loudly.

Her teacher said she requested feedback on her written drafts and she was also willing to help her classmates:

She also asks for help from me, like in the writing, in her project work, to see if there are any mistakes. Her friends also get her help in their work. She explains to them.

(Teacher interview, 31 March, 2010)

Stanza's teacher commented that she had a positive attitude, liked to try, and she gave encouragement to her classmates to try the exercises on the MyLine website.

I could see that she tries to improve herself for example when I asked about MyLINE in class, she knows how to learn from there, she tries the exercises. She even encourages her classmates to use MYLINE.

(Teacher interview, 31 March, 2010)

This indicated her motivation to improve her language proficiency as she voluntarily made use of resources outside of class:

When asked by the class teacher whether the students had tried to answer the exercises and explore the language activities in MyLine (an online lesson and activity for all university students in Malaysia), Stanza was among the students who responded and gave examples of the exercises that she had tried

(Classroom observation, 24 March, 2010) 
Stanza's perceived poor pronunciation did not stop her from using English. However, she expressed her concern over her grammatical accuracy and her ability to comprehend reading passages:

My strength at speaking, the weakness [is] in my grammar and comprehension, listening I can but I think my [confidence] confident is speaking although wrong pronounce [the pronunciation is not correct].

(10 January, 2010)

Her anxiety about her level of grammatical accuracy and her ability to comprehend reading passages might be associated with the emphasis on grammar and reading comprehension in her past language learning experiences. The main component of the final exam paper for this current language course was reading. Thus, understanding the reading passages was important to answering the comprehension questions.

Stanza also felt that she did not have problems communicating in written English as she read widely. This helped to provide her with many ideas when completing her writing tasks. However, a lack of vocabulary and her anxiety about grammar and spelling mistakes slowed her down. She wanted to improve her grammar knowledge as she felt it inhibited her ability to write:

In writing I can give more ideas, when completing my diploma, I [took] take English, my writing content, introduction, conclusion, summary is ok but ... problem is language, grammar. I received good marks for content because I have idea to give ... Usually, I received good marks for content as I had lots of ideas. I read a lot on current issues

(10 January, 2010)

Stanza tried to write her ideas down first without worrying about grammatical knowledge.

Even though she was not worried about grammatical errors in her oral communication, she believed that having a grasp of grammar was important in mastering any language. However, this belief did not seem to inhibit her language use and learning. Stanza had learnt a lot of grammar at her former 
university. She had tried the grammar exercises in the grammar book and she got help from her language teacher to check her answers. She tried the grammar exercises in the course book and tried to understand the basic grammar rules like tenses. To help her remember the rules, she pasted the notes on her hostel wall. Whenever she had free time, she would revise the notes.

The emphasis of the current language course was on reading and oral skills, so specific grammar instructions were not part of the lessons. Input on grammar was incorporated when needed. Grammar instruction in her language classes did not follow any set sequence; sometimes it was dictated by the students' communication needs. 
Figure 5.6 below shows one of her grammatical notes on the hostel wall.

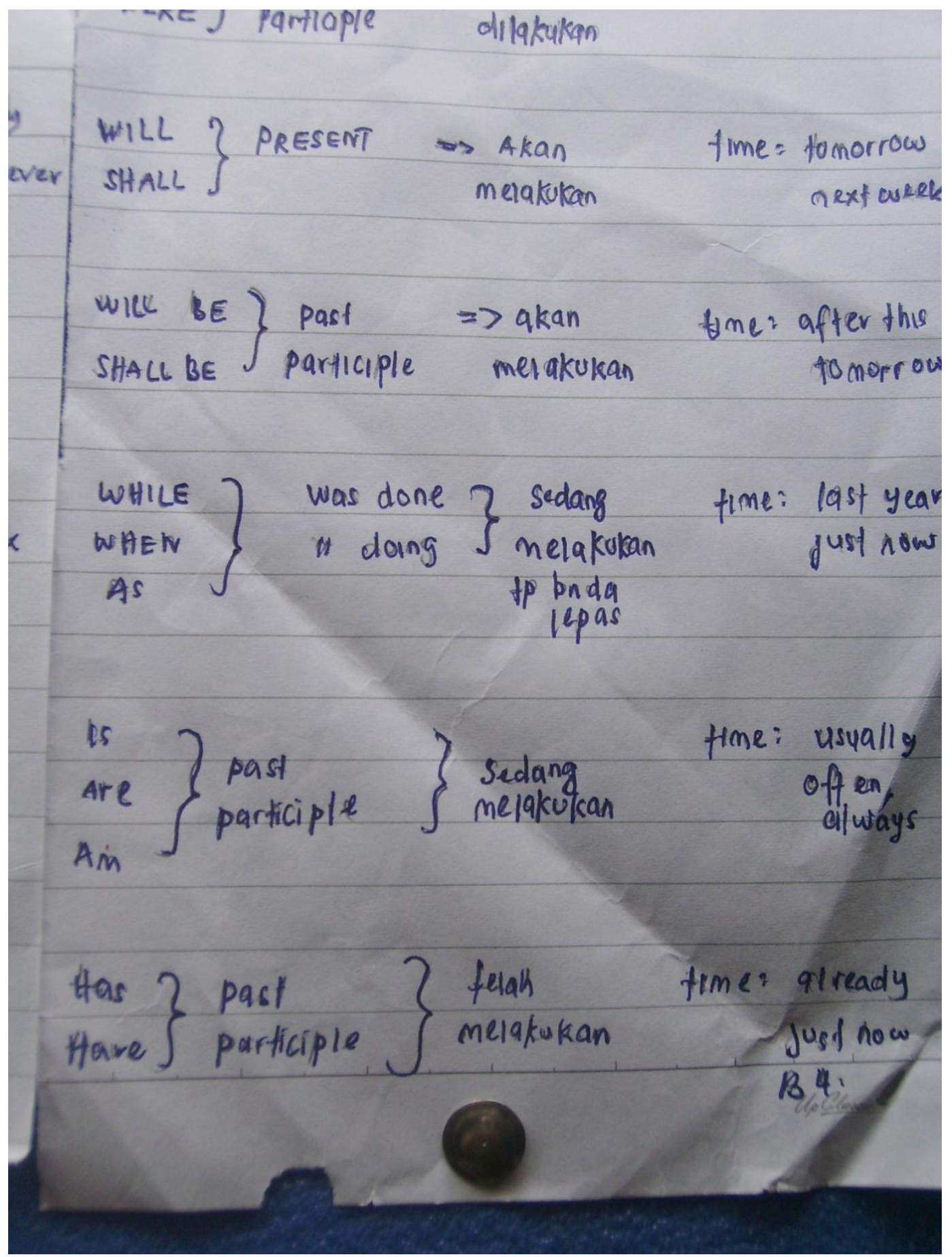

Figure 5.6: An example of Stanza's grammatical notes.

Stanza made use of her first language and other languages that she knew to understand English and she found it helpful to understand and remember the rules. For example, when she learnt English grammar, she related it to Arabic grammar, as she felt that there were similarities between the grammars of both languages. As an undergraduate of the Islamic Studies Faculty, it was important 
for her to master the Arabic language as well as English, as many of the learning materials were in Arabic. Translating the English material into her first language helped her to utilise her first language for better comprehension.

\section{Summary of personal factors that influence Stanza's language learning and use}

Despite her rural family background, where there was little opportunity to learn and use English, Stanza showed a strong motivation to achieve better English proficiency. This was because she was aware of the significant role played by English in her current studies and future workplace. Her parents encouraged her to improve her English proficiency. They believed that it could help her to secure a good job after her graduation. The experience of studying at another university where there was emphasis on English also helped in improving her language proficiency.

\section{Environmental Factors}

\section{Opportunities for interaction in English}

Stanza Nurmalam was optimistic that she could take action to improve her English language proficiency. She not only sought out additional sources of input and interaction, but in some cases, she actually created opportunities to communicate in the target language. She was not embarrassed to try communicating in English even though her oral English was not fluent. She took up opportunities to use English, such as initiating conversation in English with foreign students. She felt confident using English when she could begin with simple phrases. In the example below, she described meeting an international student at the mosque:

At the university, I make use of any chances to communicate in English. For example, last week, I had a conversation at the university mosque with a foreign student while performing ablution. She asked if I had some soap. Then I tried to know her better. I asked about her course of study and country of origin.

(2 March, 2010) 
However, if she could not understand the questions asked by her interlocutor, she would focus on the key words in the questions so that she could give appropriate responses:

I heard she said course, so I think she wants to know what am I studying.

(2 March, 2010)

Stanza asked for confirmation whether her answer was appropriate:

and I ask her... to confirm my answer is right.

(2 March, 2010)

This was a communication strategy that enabled the conversation to continue so that she could get more input in English and improve her proficiency.

To improve her oral proficiency, Stanza monitored her own speech by noting how her speech was being received by her listeners (e.g. facial expressions), and such feedback was important for her to see the effectiveness of the message conveyed. She also monitored the speech of others by noting how they pronounced and used words and phrases, as well as grammar structures.

She purposely chose online friends from foreign countries so she could use English. She told her friends that she wanted to improve her English proficiency and requested their assistance in correcting her mistakes. Normally her online friends would help by correcting her language like spelling, word choice or syntax:

When I am chatting, I find from other countries, like Singaporeans and international students at other universities in Malaysia ... who use English. I tell the persons I want to learn English and normally they give good response... When I make mistakes, they correct me.

(5 February, 2010)

Stanza said that students should make full use of the internet facilities at the university to improve their language proficiency and she thought that the English language learning website, www.MYLINE.com was useful for learning 
language through language games and learning pronunciation through interactive language activities.

Stanza compared the wide usage of the MyLine English language learning website at her previous university with the current university. At her previous university, MyLine activities had been incorporated into the teaching of English through a compulsory English laboratory session:

At my previous university, every student must register with www.MYLINE.com. We can learn lots of interesting things. There are lots of language activities and games. There is a session every week for the use of www.MYLINE.com. We have to go to the language laboratory. Learning English is more fun ... there are lots of games.

(2 March, 2010)

She thought that language teachers should incorporate activities from MyLine into their teaching.

\section{Summary of environmental factors that influence Stanza's language learning and use}

Stanza was proactive in seeking opportunities to use English orally with international students at university X. She used communicative strategies to convey her message and also to understand the meaning conveyed by others. She communicated with other language users via online interaction and requested help in correcting her language. The internet facilities at the university provided the opportunities to learn from online learning materials.

\section{Behaviour - Self-regulated learning strategies}

\section{Seeking information}

As a student at the Islamic faculty, Stanza saw the importance of English language, especially in completing assignments given by lecturers. She used books in English, and got help from students with higher levels of language proficiency. Normally, she could get the main ideas from the books, but at times she faced difficulty understanding specific terms. Then she referred to a dictionary, a strategy she had learnt at primary school: 
For words I [do] not know ... I must take dictionary and search one by one word.

As part of the class activity for the day, the students were given a reading article and they had to answer the questions. Stanza was seen using the dictionary and writing something on her paper

(Classroom observation-24 March, 2010)

When checked later of what was written, it was shown that she wrote the Bahasa Melayu (her first language) meaning below the words 'pleasure' and 'imitate'.

(Additional notes from post observation interview- 24 March, 2010)

She used both types of dictionary, a monolingual English-English version and a bilingual English-Bahasa Melayu dictionary. She primarily used the EnglishEnglish dictionary, because she wanted to know the exact meaning to choose based on the context of the word.

She prepared thoroughly for her assessments. Stanza searched for further information on the topic that she had chosen for her information sharing assessment. She referred to different types of newspapers to get different opinions on the issue and to understand the issue further. She even referred to legal documents. She compared and synthesized the points before she wrote about her topic for the presentation. This showed the high level of her information literacy skills. To get the main points of the reading materials, she translated the words that she did not understand. She clearly understood the requirement for the assessment. She listed down questions that might be asked from her friends. She presented the background of the issue before presenting her article, as she wanted the listeners to understand the issue clearly:

On the last Wednesday I was the $1^{\text {st }}$ group present for information sharing and my information is about Kartika case. Before presentation speech I was prepare to got information about my article. It is because my article is a big issue in Malaysia recently. So I need to know the background case about Kartika. I had gather article and news on English and Malay language. It is because if I refer in English article only, I think I can't understand the whole case. Beside that, I also refer to the Federal Constitution, because part of the parties related this issue 
with Federal Constitution and actually this case related with Syariah Law. If have any difficult words I will refer to dictionary and google translator. I was list down the important information to present in my group. It is because I want all members in my group understand and know about my article. That's why I tell the background case about Kartika first before I present my article.

(Unedited diary, 8 February, 2010)

Stanza's language teacher also commented on her good preparation and satisfying performance in her information sharing assessment:

She completed the task. She was well-prepared, she knows what she's doing.

(Teacher interview, 31 March, 2010)

\section{Organizing and record keeping}

The use of an online translator also helped her to find the meanings of words. When she learnt new words, she would write the words in her vocabulary book, which she reviewed in her free time. Figure 5.7 below shows a page of Stanza's vocabulary book. 


$$
\text { af ease-gelisah }
$$

at ieisure - b 11 a senang

ct full speet, selolo-10 punya

fousake, memingsalkan

forgo melepcston

outciy - menierits

outburst - milefup

underdos - y kalch

No thiough roid-jin mati

go after - menselor

for-sishted. berpendargen louh

dow neas. merghampis

onyhow, bagoimencpun

to lle ccose. bereemsunig

Figure 5.7: A page of Stanza's vocabulary book

She tried to use the words in her writing and conversation. For example, she used them in her conversation, writing or communications, like sending short messages. 
When I learn [a] new word, I will then use it when I send message to friends. When a friend uses certain words or phrases and the lecturers like them, I will jot them down and use them later in my writing or communication.

Stanza valued having a specific vocabulary book to write down the newly-learnt words to make vocabulary learning more organized. She said that it was not advisable to use a book that was also used for writing notes and doing exercises:

... before this I wrote in a book, mixed with writing, but now I change by using a specific vocabulary book. I do not mix it with other writing or information. I also have a special cover for it to differentiate it with other books.

(2 March, 2010)

Stanza related the newly learnt vocabulary to her previous knowledge to guess the meaning:

the term 'perang badar', ... Relate with previous knowledge like to the history of Islam because I have known the history before. Then I can guess the meaning.

(2 March, 2010)

During one of the classroom observations, Stanza was able to give the correct answer to her teacher's question of the function of the word, 'ground' in the phrase 'ground fibres'. This showed her ability to infer the meaning of a word from its context. Unlike some of the classmates who said that the word 'ground' means earth, and labelled it is a noun, she said that the word, 'ground' was an adjective derived from 'grind'.

\section{Goal setting and planning}

Stanza set short-term and long-term goals for her language learning. She reported:

I will repair my project report outline because my lecturer comment [on] a few information in my outline

(24 February, 2010) 
This showed her immediate goal to improve the specific course assignment. The students had to submit an outline for the project report to be approved before they wrote the report. This also signified that she took action from feedback received.

She aimed to improve her vocabulary and listening skills (immediate goal) so that she could understand the readings for her current studies (immediate goal) and future studies (long-term goal). She was aware that for postgraduate studies, she had to read lots of reading materials in English. This indicated achieving her immediate goal assisted her in reaching her long-term goal.

When Stanza listened to songs, she wanted to know the meaning of the lyrics. Thus, she printed out the lyrics and looked at them while listening to the songs. By doing this, she could learn pronunciation, word stress and guess the meaning of words or phrases by looking at the context.

Realizing her lack of vocabulary, she aimed to learn new words each day. Moreover, in order to improve her comprehension. Stanza tried to read a lot of English materials:

My lecturer [suggests] suggest to read, simple materials like Readers Digest. But in Readers Digest [there are] more difficult vocabulary but Forward magazine, we can know, understand about the word, so, I buy the book which I am confident I could understand and finish reading. It doesn't matter if the words are simple but I learn new word.

(2 March, 2010)

Stanza was determined to reach her language learning goals for that particular semester through effort and the use of effective learning strategies:

I still want to achieve my goal ... to be better. I won't give up

(24 February, 2010)

She organised her time for the completion of course assignments by keeping an organizer and reminder board. She had her own datelines for the completion of course assignments. 
She would not listen to criticism or ridicule from friends and she ignored negative remarks from friends about trying to show off by conversing in English. She would do what she believed was right regardless of what others said:

I do receive criticisms ... remarks like useless, not worth it, , but I still believe what I am doing is right and I still continue doing it.

(24 February, 2010)

Her language teacher also commented that Stanza not only planned and prepared well for her individual assessment, the information sharing presentation, but she also managed her group to make sure they complete their group project successfully and on time. As the leader of the group, she set timelines for each group member to submit work for group discussion:

... and for the project she acts as the leader of the group. There was good cooperation among the group members. Stanza cooperated well with her group members. The group was well-prepared, they know what they were doing. They completed the task.

Stanza came to see me to check whether there are any grammatical mistakes in her project draft. It seems to me that she knew what had to be done for the project.

(Teacher interview, 31 March, 2010)

During one of the class observations, I watched Stanza playing the role of group leader, assisting and guiding her group members in explaining their project to her language teacher.

In the second half of the class time, the class teacher instructed the students to sit together with their group members for their final project and check whether their script for the coming project presentation was organized. Stanza was observed to be holding the script and acted as if she was the leader of the group. She was seen explaining things to her group members and she also played the main role of explaining to the teacher of their group's plan for the final presentation. The rest of the group members just added a few things during the conferencing. Stanza seemed to know more compared to the other group 
members who seemed a bit unsure when asked by the teacher for clearer explanation of their plan.

(Classroom observation, 24 March, 2010)

Stanza used a task-structuring strategy to motivate her group members when she sensed that one of the group members felt the task of deciding the topic of the group project was difficult. She suggested they list down two topics each and then they would discuss which to select from the list:

The group members used strategies like social reinforcing in shaping their joint behaviour. When Stanza gave the above suggestion, two of the group members supported her decision. Stanza considered the group grade was important for her own achievement, as the project marks were counted in the final grade. Thus, she highly appreciated the commitment of all the group members.

Her language teacher shared her positive comments about Stanza and her group members' project work. They showed cooperation among the group members, were well-prepared, and knew what they were doing:

There was good cooperation among the group members. Stanza cooperated well with her group members.

(Teacher interview, 31 March, 2010)

Stanza was happy with the process of completing the group work as all of the group members shared similar goals of learning from the group task and enjoying the socially-shared learning experience.

In Stanza's project presentation, the teacher said that she and her group members had presented their project confidently and well. They had endeavoured to make their presentation creative and they prepared relevant visual props. Stanza self-corrected during her presentation. For example, when she realized that she had wrongly pronounced the word 'blood', she quickly corrected it.

\section{Managing emotions}

When asked how she persisted in reaching her language learning goal, Stanza 
stressed the importance of motivating herself to be interested in learning English, especially when she faced difficulties or failures in the process of achieving her goals. Besides her new dictionary and the use of an electronic dictionary, she was still using her old dictionary from her primary school days, as she felt that it gave her the motivation to strive harder and be better:

I have to keep [myself interested] interest, [motivated] motivate to learn, I'll never give up ... my inspiration is my old dictionary, since primary school until now. The cover is torn. Until now, I still bring to my hostel. When I look the dictionary, Oxford, when I look, I have the [motivation] motivated to search word. People now have technology, internet, electronic dictionary ... I also use those but my old dictionary gives me motivation.

(24 February, 2010)

Stanza also felt that role of teachers in motivating students to improve their language proficiency was vital. She believed teachers could make students interested in learning English:

When I was in primary school, I didn't realize the importance of English, But [at the secondary school] secondary, I like the teacher, the teaching method, I am motivated.

(10 January, 2010)

\section{Seeking assistance}

She got help with getting the main ideas from English materials from Singaporean students at her faculty whose language proficiency was better. However, at times, her friends could not help her in translating the exact meaning of specific Islamic terms. She also sought help in understanding assignment questions from her friends:

When I read an article and I don't understand, I ask any friends to explain to me ... but sometimes they also cannot understand about the terms because [it is] very difficult to know about the terms. I will also get help to understand the assignment questions given by lecturers.

(24 February, 2010) 
Stanza asked for help from her language teacher, like in the writing of her project work, to see if there were any mistakes. Her language teacher reported that Stanza sought help to check the draft of her group project report before they submitted it. She wanted to check the suitability of the content and correct any grammatical mistakes in their project draft and group script for the final project presentation. She also compared the completed report with the teacher's marking criteria before submitting it.

She also asks for help from me, like in the writing, in her project work, to see if there are any mistakes.

(Teacher interview, 31 March, 2010)

Stanza even got help from the researcher to check her group script for the final project presentation. She did not mind being corrected, as she felt that it was a part of the learning process. She was also willing to help her friends:

Her friends also get her help in their work. She explains to them.

(Teacher interview, 31 March, 2010)

\section{Practising self-evaluation}

Stanza Nurmalam often evaluated her own progress in her language learning. Her language teacher's comments confirmed this:

As a student, she displays commitment, motivation, hard work and positive attitude. She also evaluates her own progress in language learning

(Teacher interview, 31 March, 2010)

The evaluation of her progress determines whether her learning goals are met, and whether she needs to change her study strategies to attain better achievement.

Stanza was strategic in her approach to assessment. During her informationsharing assessment, Stanza was observed working in her group, which consisted of five students. She was observant and attentive to other students' presentation. She asked questions for clarification, for example she was the first to ask questions to the student who presented on the topic 'Bullying', "What are 
the types of bullying?" When she was asked why she asked the question, she replied that she wanted further examples and clarification as she felt that the presenter had not elaborated on some important points. The researcher observed the she also jotted down notes while others were presenting. These included questions that she had thought about while listening to her friends. These questions indicated that she was listening critically. This behaviour showed that she understood the requirements for getting a high score in the assessment, where each individual had to present his or her topic, answer questions from others in the group and also ask relevant questions of others when they were presenting. She also contributed to the discussion on 'Bullying', when she suggested, "We should have two discipline teachers in a school". She responded to the issue on how to improve relationship between parents and children (the second topic presented during the session) by suggesting that parents must have good time management. When it was her turn to present her topic on the caning of the first Muslim woman who drank alcohol, she made eye contact with the listeners and the evaluator (the class teacher). She also made use of body position (e.g. by moving forward her body to answer a question from one of the listeners) and hand gestures to emphasize her points.

Stanza used techniques to convey the message during her information sharing presentation. For example, when she had difficulty thinking of words, she used synonymous words to make sure her listeners understood the ideas.

\section{Summary of Stanza's self-regulated learning strategies}

Stanza's goal for her language learning for the semester was to improve her speaking and reading ability. She focused on increasing her grammatical knowledge and vocabulary. She employed a range of language learning strategies to help her learn English better. She continued with her effort despite the criticisms from friends about her persistence to achieve better English proficiency. She asked for help from other English language users who were better than her in understanding her reading text and completing her course assignments. Besides planning for her language learning, Stanza also evaluated the progress that she had made. She clearly understood the requirements of the course and also the teacher's expectations. She also took charge to plan her 
language learning and willingly assisted her friends. Stanza sought help from friends and her language teacher in editing her work. 


\section{Behavioural}

- Seeking information

- Organizing and record keeping

- Goal setting and planning

- Managing emotions

- Seeking assistance

- Practising self-evaluation

\section{Personal}

- Low entry grades- MCE (C6) \& MUET (Band 2)

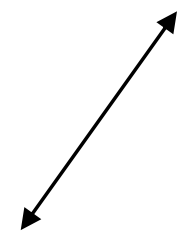

- 25 years old

- Hometown- Rural background

- Intrinsically motivated

- $\quad$ Regard good language proficiency as important for the betterment of her family status-good career prospect

- $\quad$ Positive attitude

- Effort attribution

\section{Environmental}

- Previous experience of effective language teaching and learning at another public university

- Had taken Foundation English course

- Encouragement from parents to use English

- Maximized language use via online interaction with other English users

Figure 5.8: Summary of the SRL strategies and factors influencing Stanza's self-regulation in language learning. 


\section{Learner four-Ares Mark 111}

This comment shows that Ares did not put priority into learning English despite realizing its importance.

sometimes I am a bit lazy. I don't have any specific schedule for language learning. There is no mid-term exam for English, thus I put more emphasis on Economics subjects

Ares is a twenty-year-old Malay male, and a first year student of the Economics and Business Studies Faculty majoring in Business Management. His grade for his English paper in the Malaysian Certificate of Examination was A1 and his result in the Malaysian University English Test (MUET) was band 3. These good results in previous English papers showed his high English proficiency, and he was not required to take the Foundation course. Ares felt that his English language, especially oral proficiency, was affected by not taking English for a semester.

\section{Personal Factors}

\section{Extrinsically motivated}

Ares felt more motivated to improve his language proficiency at university compared to when he was doing his matriculation because at university the English results would be counted towards his final grade point average. His motivation was spurred by the aim of getting a good final semester grade. This also signified his performance goal orientation:

It is different now. At the matriculation centre, all the subjects were in Bahasa Melayu and English language is just one of the subjects and the result is not counted in the final semester grade ... but here at the university English results can improve your grade.

(14 January, 2010)

Ares came from a middle-class family that had shifted from the Southern part of Peninsular Malaysia to the capital, where his father worked in the finance industry. He spent his free time taking photographs. He saw himself as proficient in English language and stressed that the use of English among his family members played a role in his mastery of the language. He also added that his past language learning experiences at a secondary school, where there was emphasis 
on learning English, contributed to his acquisition of the language. Reading English newspapers improved his mastery of the language.

The increasing number of foreign students at the university has helped him in practising his oral language. This experience made him realise the importance of being able to communicate in English. For example, he shared his experience of trying to help a group of Korean students who were looking for the bus stop. He had difficulty understanding their spoken English. He felt that he could communicate better than the Koreans due to exposure to English at an early age:

Last week there were a group of Korean students asking for direction, and it was bit hard for me at first. like he was asking the where's the bus stop, at first it sounded like post stop. I ask, post office? I understand it when there doing it with actions. Ha ha!! was kinda hilarious. to understand we need it to act. then, I realise that in Korea, English is not being emphasised. But like us Malaysian, English is needed for us, $y$ is it in Korea they don't take English seriously?

(Unedited diary, 31 January, 2010)

\section{Self-efficacious}

Ares Mark 111 believed he could score good marks for his English final semester results. However, he stated that he needed to make considerable effort, such as reading a range of materials, as the reading passages in the final exam could cover a wide variety of topics:

I expect to do well in this academic communication 1 course. I believe I can get good result but I have to put more effort

(14 January, 2010)

He shared his approval for the current course book, which he found helpful in his learning.

\section{Summary of personal factors that influence Ares' language learning and use}

Ares expressed an extrinsic motivation to score higher grades in English in order to receive a high end-of-semester Cumulative Grade Point Average (CGPA). English use in his family contributed to his proficiency. 


\section{Environmental Factors}

\section{Challenges in using English in the university social environment}

Ares Mark 111 highlighted the conflict that he was facing due to the medium of instruction for his studies at the university. He felt that his language proficiency was declining when he studied at the university. When he started his studies at the business faculty, he was surprised at the mix of languages used by the faculty lecturers. The lectures were conducted in English and Bahasa Melayu but the examination and thesis writing were in Bahasa Melayu. He voiced his wish for a standardization of the language used at the business faculty.

When he was at secondary school, he was in the science stream and the science and mathematics subjects were taught in English. He felt this contributed to his language proficiency. However, at the preparatory college for university entrance, all the courses were taught in Bahasa Melayu. When he entered university, he had difficulty understanding his reading materials, which were mostly in English:

During my secondary years, I learnt Mathematics and Science in English. However, at the matriculation centre, Bahasa Melayu was used. Thus, my English proficiency declined. Now at the university, lectures are in Bahasa Melayu and English. References in English but final exam and assignments are to be written in Bahasa Melayu. That leads to confusion among students.

(14 January, 2010)

\section{Course materials}

Ares stated that the textbook used for the Academic Communication 1 Course was suitable and made learning interesting, because it contained short and interesting reading passages. Grammatical items such as basic parts of speech and tenses were covered in the textbook.

\section{Teacher factor that influences self-regulation}

He felt that it was the role of the language teacher to make class interesting and motivating. If the course book was interesting but the teacher's delivery was not stimulating, the lesson would not be engaging: 
The course book is suitable and we learn a lot from it. However, the teacher is important in making the students motivated and interested. Class will have to be interesting. Course book and teacher are equally important to make us interested.

(22 March, 2010)

He had had a good relationship with his secondary school language teacher who encouraged him to improve his language proficiency:

I become more interested to learn English due to a good teacher.

(22 March, 2010)

In his diary, he communicated with his language teacher and the teacher would respond in English. The written comments helped him to improve his language use. He asserted that the concern and interest shown by his teacher made him more interested in improving his language. His teacher understood his interests and encouraged him to improve his language skills:

The teacher is like a sister. When she wrote the comments in English language, it helps me to learn. I become more interested. She asked me to read more English novels. She knows that I like adventurous things and she asked me to read Harry Potter.

(22 March, 2010)

Ares added that the feedback that teachers gave could either positively or negatively influence students' interest, attitude and motivation to learn English. He commented on an incident where he felt challenged when his language teacher praised another student who could answer questions that he could not.

Ares Mark 111 commented on the lack of writing exercises in the current language course. During his secondary years, the extensive feedback on his writing from his language teachers had been useful:

When I was at the secondary school, my teacher gave me lots of writing exercises. She would give me feedback. There would be lots of comments in red ink. I learn and improve a lot from the feedback. 
However, in the current language course the students were assigned an individual essay and one group report. He did not get any feedback from his language teacher after submitting his essay.

\section{Positive peer influence}

Ares also attributed his interest in English to his friend at secondary school who had positively encouraged him to improve his language proficiency. He regarded the girl as a role model as she was actively involved in competitions in English like debating, story-telling and poetry recitation.

\section{Summary of environmental factors for Ares}

The use of both English and the national language in his faculty has created confusion and problems among the undergraduates. He also considered studentteacher relationships, and effective teaching and feedback from teachers important in helping students to improve. In addition, positive peer influence also contributed to his language learning.

\section{Behaviour - regulated learning strategies \\ Practising self-evaluation}

Ares evaluated his progress and performance in his language learning by comparing himself to other students like his classmates. He shared an incident in his language class where he could not answer his teacher's questions and his classmate could answer it. From that incident, Ares realised that his language proficiency was still not at the level he desired. Thus, he was determined to improve his mastery of the language:

Need to have self-assessment ... evaluate my own progress. When I cannot answer my teacher's question and my friend can do it. From comparison with friends, I realise that I have to work harder.

(16 February, 2010)

Ares admitted he did not have any specific schedule to learn English, as he felt that he needed to focus more on his content courses. Moreover, as there was no mid-term exam for the language course, he felt that he did not have to do revision for the course. If he could manage his time well, maybe he could allocate time for extra language learning besides learning English in the weekly language classes: 
I must be hardworking but sometimes I am a bit lazy. I don't have any specific schedule for language learning. There is no mid-term exam for English, thus I put more emphasis on Economics subjects.

(16 February, 2010)

Ares identified his listening skills as a strength and he attributed this to his love of English songs and movies. He felt that his speaking skills were still not fluent due to a lack of vocabulary. However, he used code switching whenever he was not sure of the English words during a conversation. He worried about his grammatical proficiency. To overcome this, he focused on the lessons and took notes during the grammar lessons and tried the exercises given by his teacher. He also checked his work for mistakes.

Ares preferred to use an English-English dictionary to search for the meaning of words. However, if he could not understand the definition given, he would use the English-Bahasa Melayu dictionary. He was not sure how to check pronunciation from the dictionary. When asked whether he was interested in learning this, he gladly took the opportunity to be taught by the researcher during one of the interviews:

When I use English-English dictionary, sometimes I do not know which one is the exact meaning. Normally, I just take the first listed meaning. Our teacher does teach us pronunciation but not on how to get the correct pronunciation in the dictionary.

(16 February, 2010)

\section{Structuring learning environment}

Ares decided to change his study time for that particular semester as he had read an article about the benefits of studying early in the morning. He believed that he could study more effectively, focus more, and have better concentration in the morning. He tried to wake up early in the morning and study before preparing for the morning lectures and tutorials:

Before this, I studied during night time. However, this semester, I would want to try to change my study time to early in the morning. I read an article that your brain works better in the morning. You can study better. (16 February, 2010) 
During his language class, he thought that his teacher's loud voice helped him pay attention to the lesson taught. His teacher's effort to make all the students participate in the class activities also encouraged him to take part in the class by asking questions and contributing to discussions.

\section{Seeking assistance}

Ares did not usually ask for help from others when he faced difficulties in his language learning. He felt that he should try to solve his problems on his own first before he asked for help.

However, he posted questions on his blog to his friends to get more information on his language learning tasks. For example, when he had to write an article about endangered species, he posted questions on endangered species to his friends in his blog. The visitors to his blog would also give feedback to his post and he said that he could learn a lot from the feedback. He wrote about any information or issue to get response from his friends. Ares suggested ESL learners create a webpage on their interest in English as he found that it helped him to construct a new and confident identity of a competent English user.

\section{Managing emotions}

Ares wrote blog entries and short stories as strategies to overcome boredom or any negative feelings in the process of language learning. He listened to music and chatted online with friends to combat his boredom during his language learning tasks. Although he wrote his blog in English, Ares' main aim was just to convey a message and he was not conscious of grammar. However, his previous English teacher who occasionally visited his blog would correct his mistakes. He was glad when his teacher did that, as he could learn from the corrections.

\section{Seeking information}

Ares' strategies to improve his language proficiency included learning writing styles from reading the newspaper. He listened to songs and watched movies in order to improve his vocabulary. He preferred songs and movies in English over Bahasa Melayu as they were more interesting.

Ares collected materials from various sources to prepare for his informationsharing assessment. While reading, he highlighted the main points from the 
different sources. To keep focused on his reading, he used certain strategies like underlining the important points:

Normally, when I read for the first time, I do not focus. Thus, I read again, find the main points. I also use ruler while reading to help me focus and I underline the main ideas.

(16 February, 2010)

\section{Planning}

For his information-sharing assessment, he planned to start his presentation by asking questions of the listeners in order to attract their attention. He also listed some questions to be asked of the listeners, as he wanted his presentation to be two-way where there was interaction with other students in the group.

My article's is about food, I've planned to ask question, Maybe.. or I will ask 'who's hungry?' I've list down some questions that I'm gonna ask to make the conversation looked alive.

(Unedited diary, 31 January, 2010)

His language instructor commented that Ares presented his article quite well and he received various responses from his friends. He also managed to respond to comments given by his friends about his topic. He refuted the remark made by one of the listeners that the existence of cafes could lead to loafing problems among youths. To show his disagreement, he said, "... we cannot just simply say that cafe like this may result to social problems". Ares also gave comments on his friends' presentation on the differences between males and females, "Are you saying that women can do all the things that men can do?" and his questions led to further discussion among the group members.

At times, Ares procrastinated in completing his language learning tasks. This was because of his active involvement in other campus activities. Other aspects of his life as an undergraduate, like being involved in co-curricular campus activities, took precedence: 
For example, for the conferencing session with our teacher, I was late. Thus, I was scolded. This was because I was involved in other activities. I was busy with my photography project.

This week assignment, we were suppose [supposed] to meet our teacher ... to do a conferencing about the article that we are going to present, however only three students went ... As for me, it does not mean that I do not want to see ... but I have not printed the article. I am also busy participating in the university sports events, planning for a visit for the student bureau and being in charge of the dinner for final year students. So what I've done is, I search for old newspaper and find an interesting article to show to our teacher, on that day also. What I've learned through this is to adjust my timetable wisely, give room to do assignments rather than fulfilling the times with other stuff.

(Unedited diary, 22 January, 2010)

When he was scolded by his teacher for being late in sending his article for the information-sharing assessment, he realised that he should have better time management. Subsequently, he prepared his own timetable with a reminder of important dates and schedules on the board in his hostel room. His language teacher felt that Ares had the potential to be better if only he put more effort in his study.

\section{Summary of Ares' self-regulated learning strategies}

Ares evaluated his language learning progress by comparing himself with his friends. Although realising that he needed to put more effort into his language learning, Ares did not have any specific schedule for this. This was because he spent more time on other activities such as involvement in college activities. Ares preferred to solve his language learning problems on his own. He used study strategies to improve his competence and the most significant is his improvement due to his communication in his blog. Posting on his blog was an innovative way of using language and seeking feedback. 


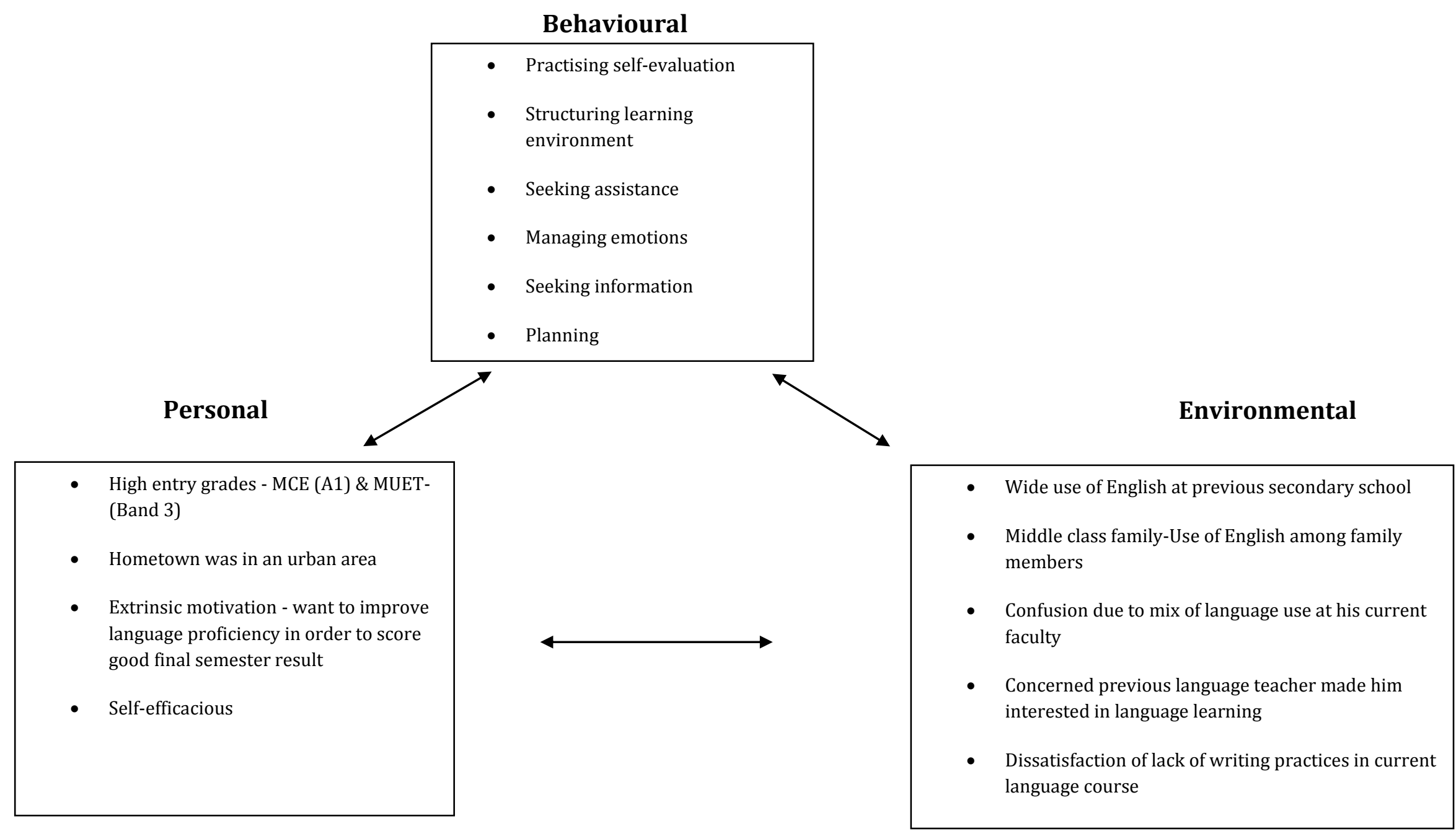

Figure 5.9: Summary of SRL strategies and factors influencing Ares' self-regulation in language learning. 


\section{Learner five-Confidence Hero}

The statement below highlights Confidence Hero's motivation and the positive influences of his peers in learning English.

I am highly motivated! I always motivate myself ... makes me keep persistent and my friends motivate me to do well in English [...] All my friends also want to improve their English language ... so I also don't want to lose to them.

\section{Personal Factors}

Confidence Hero is a twenty-year-old Malay male, and a first year student of the Economics and Business Studies Faculty majoring in Human Resource Management. His grade for his English paper in the Malaysian Certificate of Education Examination was A1 and his result in the Malaysian University English Test (MUET) was band 3. These English grades in his previous courses indicated his high level of proficiency in English language. He is from an urban area in the northern part of Peninsular Malaysia. Confidence Hero is an active person who loves adventurous outdoor activities like hiking, travelling and cycling.

\section{Highly motivated}

Confidence Hero's motivation for speaking English well was to use it in the business world:

I think English is very important for me because we do some matter with people and as a student of Economics Faculty, business today we should speak in English. We need English for future prospect.

(20 January, 2010)

Scoring a high grade in the English course was also equally important for him. This signified his performance goal orientation.

He saw himself as quite proficient in English and he felt challenged to use English with his friends, as they used English in their conversations. His lack of grammatical ability did not prevent him from using English with his close friends:

although I can't, I do not know the correct grammar, but I am still willing to speak with my friends. (20 January, 2010) 
His lack of anxiety about grammatical accuracy might be due to the encouragement for language use by his teacher and peers, where the focus was just to convey messages.

Although Confidence Hero had confidence in his speaking ability, he was worried about his writing ability:

My weaknesses ... I think writing, I don't know to write. My sentences are wrong ... grammar mistakes

(20 January, 2010)

However, he stated that he did not make any extra effort to improve his writing ability and only completed the assignments given in his language course:

I don't like to do exercise. I don't put any effort. When the task is given, I do, then that's it.

I don't have any schedule to improve my English language.

(20 January, 2010)

However, his participation in the current study made him put more effort into improving his language proficiency:

Since being chosen as a participant in this study, I become more interested in English language. I try to listen to English songs and try to understand the lyrics. I learn new vocabulary and I try to use it when I send a message to a girl.

(16 February, 2010)

He was highly confident that he could improve his language proficiency. His English teacher commented on his interest, motivation and active involvement in class, as he was always the first to volunteer. For example, during the first class assessment, which was information-sharing, he took the initiative to start the presentation and also initiated the question and answer session:

He volunteered to present first and when it comes to ask questions, he volunteered to ask his friends. He has got enthusiasm. ... He was the guy who took the 
challenge. Although at times, he's grappling for words, he still tries. He stands out among the rest.

(Teacher Interview, 31 March, 2010)

He was seen as a language learner who showed a positive attitude. His class teacher believed that Confidence Hero could achieve his goal to improve his proficiency with his positive attitude and the initiatives that he has taken in preparing for the course assessments:

... he has got the potential to improve. The communication skills. He has lots of ideas, good initiator and then he tend to ask from different aspects for the language tasks.

(Teacher interview, 31 March, 2010)

\section{Summary of personal factors that influence Confidence Hero's language learning and use}

Confidence Hero had high English language grades. He saw the need for English in his future career. He showed a positive attitude and motivation to speak in English, as he felt challenged by his peers who used English in their conversation. He also attributed his interest to his teacher's encouragement and friendliness.

\section{Environmental Factors}

\section{Positive peer influence}

Confidence Hero realised that positive peer influence was very important in supporting him in using English in his daily communication. He was fortunate as all his close friends wanted to practise their spoken language and tried to use English in their communication. He did not face any disapproval of using English due to having this peer group:

... all my friends also want to improve their English language. My friends try their best to speak English. I don't want to lose to them. I also want to prove to them that I can also use English.

(16 February, 2010) 
Competition among friends to acquiring fluency spurred his efforts:

Oh ... yes! I am trying to speak with my good friends, talk on the phone or send message, I try to use English, I [make a phone call] calling sometimes, send message to you use English ...

(16 February, 2010)

Confidence Hero's close friends also realised the importance of English and they encouraged and supported each other to improve:

I speak with my friends because this is the time to improve my English, actually in my room there are two other friends, we challenge each other. At night we speak English, we correct each other, before we correct it, we laugh and I think it is a good learning process. Although we laugh, we know, we'll not repeat the mistake. The learning process is not tensed, it is a lively learning process. Funny at times because we make lots of mistakes.

(16 February, 2010)

His close friends used the strategy of a socially shared goal orientation to motivate each other to persist in using English orally:

If we see that any of us is not motivated, we remind him of our reason of talking in English ... to reach our goal to be better in spoken English

(16 February, 2010)

They taught each other and shared their knowledge; for example, he showed them how to use the dictionary for correct pronunciation:

At times my roommate and I have arguments on how to pronounce certain words, so we open the dictionary and we use the way ... technique that you taught me how to decide the pronunciation. I teach my friend how to get correct pronunciation, the phonetic symbols like you teach me.

(16 February, 2010)

Confidence Hero stressed the importance of choosing friends who influenced someone positively, as he believed that his good friends played an important role in his motivation to improve, especially in his oral skills: 
They are positive towards the use of English. My friends motivate me to do well in English. Friends whom I mix with bring positive influence to me ... it is important to choose the correct friends.

In class, surely they use English ... but outside of class they still use English for example when we play futsal ( indoor soccer) at night, there is a rule that we must only use English. When they use English, I'll also respond in English to show that I can use the language.

I think their intention is to improve their English ... they realize the importance of English.

(16 February, 2010)

Confidence Hero disapproved of the attitudes of students who seemed not to take any initiative to improve their language proficiency, as he believed that there were lots of actions that students could take to improve their English. He urged students not to blame the university environment for their lack of language proficiency, but to take action. He commented on the lack of involvement among the undergraduates in the activities at residential colleges and campus as he saw them as a chance to improve their language proficiency. He maintained that the activities would be a waste if students themselves were not interested and did not take the initiative to join them.

He gave some examples of strategies that he had used to maximise his opportunities to learn and use English language. Besides using English with friends, watching English movies helped him to improve his vocabulary and pronunciation:

I watch movies in English, if there are any words I don't understand, I stop the movie and ... get my dictionary and check the word. I pause the story... and get the meaning.

(20 January, 2010)

He suggested ESL learners use English for sending messages, e-mails and also creating webpages. 


\section{Teacher factor that affected engagement with language learning}

Confidence Hero reported that his interest in English was partly due to his past and current language teachers' personalities and teaching techniques:

my current teacher motivates me. She motivates me to do the best in the class. Her characteristics, personality and the teaching methods used make me become motivated ... She's cool ... She is funny, she can make the class not bored and lively. I had a good teacher like her before ...they make learning English interesting and enjoyable

(21 March, 2010)

If the teacher was friendly and the class was interesting, he was very excited to participate in the class activities:

... a teacher is like a leader ... a teacher can make learning more interesting, a teacher should motivate the students, her class is lively, she's close to her students. Her lively class affects my mood. She communicates with students, she can be a friend, at times we can also share jokes, tease her ... she does not get angry. We don't feel [stressed] stress in class. But when things have to be serious, we were serious and focussed.

(21 March, 2010)

This indicated the significant role a language teacher could play in engaging students in their lessons.

Confidence Hero reported that when he was in secondary school, he was always his language teachers' favourite student. This could have resulted from his active involvement in his language class. He maintained a warm relationship with his previous secondary school teacher and asked for assistance for his language learning:

I still call or send messages to her asking for help like asking for correct word choice.

(21 March, 2010)

In his current language class, he was chosen as the class representative by his teacher, as he was always willing to help with the class chores like booking 
rooms, getting audio equipment and conveying messages about class to his classmates:

He's also kind of the informal monitor for the language class, all this time when I have got plan for my class, when I called him, he has never turned me down, he's always ever willing to do it. He has got positive attitude, as a language learner, ... he is also a responsible guy. I can rely on him for help.

(Teacher interview, 31 March, 2010)

When pressed for a reason for his active involvement, he stressed his current teacher always motivated him to do his best. This was shown in the interview with the class teacher where she herself talked about the importance of the teacher being encouraging in order for the students to feel confident. She explained that students need encouragement to improve:

When I first entered the class, he was the one who tried to speak in English but not fluent and his friends laughed at him. I backed him up and told his friends off for doing that. I told my students in my class you can try, if you are wrong, I'll correct immediately.

(Teacher interview, 31 March, 2010)

His teacher also stressed the importance of good class management and planning of activities and assessment. To ensure the effectiveness of the information sharing assessment, she changed the assessment format. She found out the students in her class could present better and participate more when she assigned each group a theme for the presentation.

... for information sharing, I assign each group a theme like new technologies, exotic food. So when their friends are presenting, my students can ask relevant questions as they know the relevant aspects.

(Teacher interview, 31 March, 2010)

She changed the assessment format as she realised that her students in the previous semester could not really ask relevant questions when their friends were presenting: 
I did trial and error for the assessment. Like last semester, when the students in the same group presented different topics, they could listen but they could not ask good questions. Questions will be just on the surface level. I told them, you have to ask intelligent questions, or there goes your mark. But to think of that, it's not fair, true enough, when you are focusing on your subject, so this semester I try, and it works, they can ask relevant questions, their responses improve, the same aspect, the same theme.

(Teacher interview, 31 March, 2010)

There was a competition among Confidence Heros's male classmates to get their teacher's attention. Each one of them wanted to be the teacher's favourite:

one of the reasons for us to be active is we want to win our teacher's attention. In a way, there's a competition who's among the Malay boys who are closer to our teacher.

When this was mentioned to the class teacher, she was aware of it and she took the opportunity to encourage the students to use English when communicating with her. She told her students she would only respond to them when they talked to her in English, and that encouraged use of English in her class:

I told them, if you want to get my attention, you have to speak in English and when you speak in English I'll listen to you and that's how you get my attention.

(Teacher interview, 31 March, 2010)

Confidence Hero believed that his current language teacher played an important role in encouraging him to improve his spoken skills. There was a lot of interaction between the teacher and the students and among the students themselves. The atmosphere was easy, friendly, and frequently humorous. He was never worried about public humiliation if he gave a wrong answer in class. His teacher encouraged them to participate in class activities and discussion without worrying about mistakes. There was also sharing of personal stories and jokes, which generated an intimate and friendly atmosphere in class. This had led to a sense of belonging in the class. The friendly atmosphere gave them the courage to ask for help in the class. 


\section{Summary of environmental factors that influence Confidence Hero's language learning and use}

Encouragement to use English from Confidence Hero's close friends helped build his confidence to converse in English. His peers positively influenced and challenged him to improve his spoken ability. He also tried to increase his opportunities to learn English through watching movies. His teacher's warm personality and motivational teaching strategies also contributed to his interest and motivation.

\section{Behaviour - Self-regulated learning strategies \\ Planning}

Confidence Hero put more effort into his project work than into other aspects of his course work. Nearly half of the course marks were allocated for the project. The group members planned and practised for their presentation. When his language teacher first explained the project work to the class, he thought he could easily score high marks, but during the process of completing the project, he realised it needed considerable commitment and cooperation among the group members:

I thought project, just do and present but ... the props, group dance, it is quite difficult, so ... it is a serious thing, this project, When she first explained to me during the first day, when I heard $40 \%$, just $40 \%$. It is ok...I thought I can get $40 \%$ easily but ... after the process, the discussions, rehearsals, all the procedures, preparation ... ahhh ... it's not easy.

... by week 11 and 12 while preparing for the project, I realize that it is not easy.

(21 March, 2010)

He thought it was really helpful when the teacher clearly explained the course requirements at the start of the semester. This gave guidance to the students in planning their study and making decisions on the effort and time for each assessment:

I think it is beneficial for my teacher to explain the course requirements so students take serious in their work, we know the priority. 
More emphasis was given to assessments that were allocated higher marks, like the group project. This signified his effort in language learning was also influenced by marks.

\section{Seeking assistance}

His language teacher pointed out Confidence Hero's initiative to learn more, such as seeking help from his teacher to improve his work.

... if he thinks that he can make anything more interesting, he'll come to me and ask, what do you think Madam, if I do it like this? Asking for my opinion. He was always enthusiastic. He was willing to ask questions from me or his friends whenever he was not sure.

(Teacher interview, 31 March, 2010)

He requested his teacher check the content and language of his project report.

\section{Managing emotions}

There were times when he felt bored or frustrated with learning English:

In the process of learning English, sometimes I feel bored, frustrated ... especially when the task is too hard such as to [write] make essay when I don't have an idea to do or I don't get words.

However, he had his own affective strategies to overcome negative feelings. He used positive self-talk to keep up motivation:

To keep being persistent ... I always motivate myself. I always say, you are great. The repetition makes me keep persistent. My friends always say, they are good language users, but I say I'm better. There's a positive competition between me and my friends. I become more motivated.

(21 March, 2010)

Besides positive self-talk, he also rewarded himself in order to continue being persistent:

Normally, in the evening, we play sports. ... like futsal (indoor soccer) ... or I just relax, hang out with my friends (21 March, 2010) 
When he was asked about the effect of his study strategy of postponing his assignments until the last minute, he responded that it worked for him, as he felt that he could work well under pressure:

I think I can work on pressure, the result is ok up to now. I did the outline for information sharing last minute.

(21 March, 2010)

He did not feel that the course was a difficult one as the final marks were an accumulation of marks from on-going course assessments and marks from the final exam paper:

it makes the course easier to score if you have done well in all the on-going assessments.

(21 March, 2010)

Thus, he felt confident about scoring good final marks, as he felt that he had completed his on-going assessments well.

\section{Summary of Confidence Hero's self-regulated learning strategies}

Although he was motivated to be better in his language proficiency, other factors like grades also played a role in his persistence in his language learning. Confidence Hero showed that he had high self-efficacy to do well in the course. The fact that the course final grade was an accumulation of the on-going class marks and a final exam made him confident he could score well. The competition between him and his friends contributed positively to his effort in language use. 


\section{Behavioural}

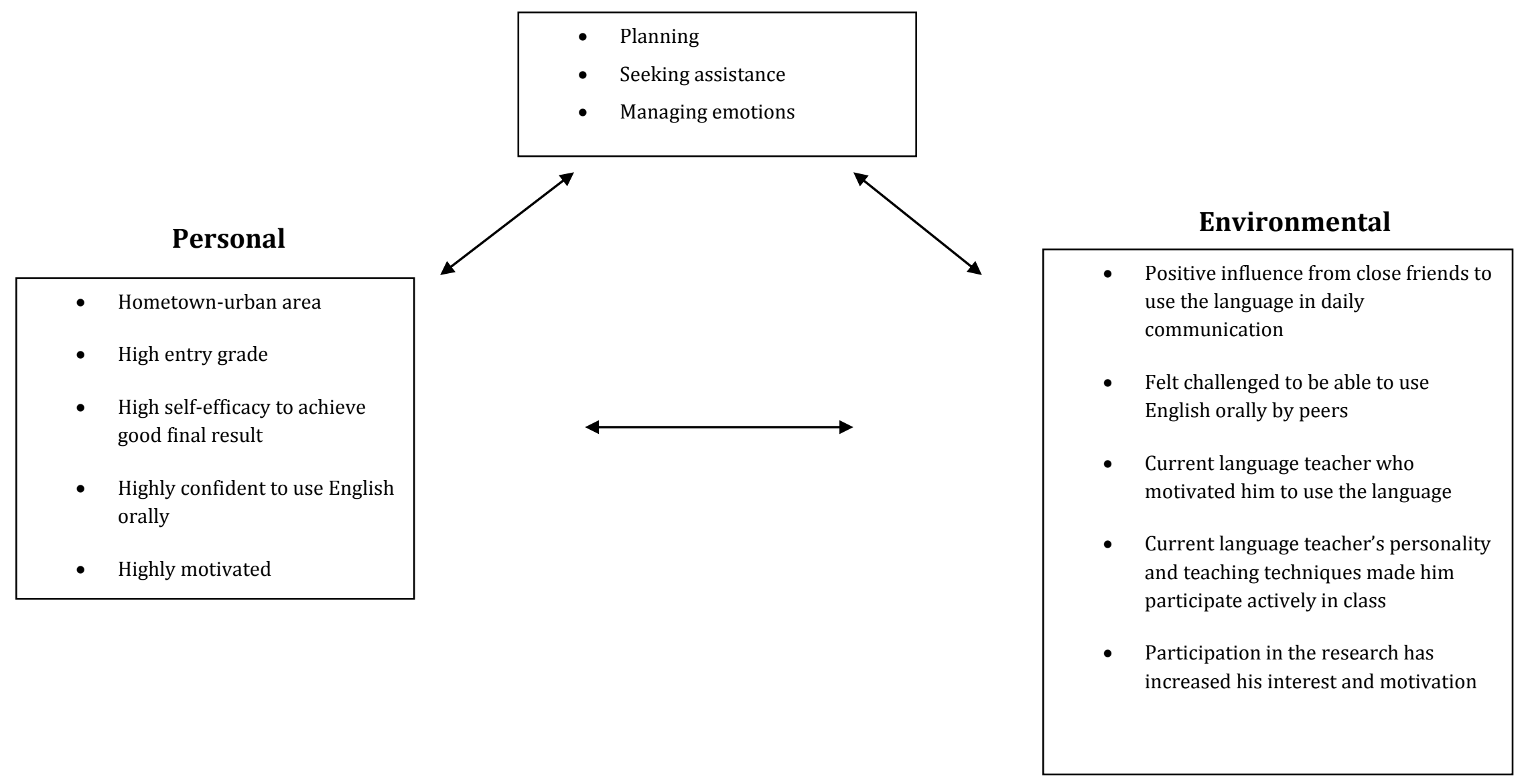

Figure 5.10: Summary of SRL strategies and factors influencing Confidence Hero's self-regulation in language learning. 


\section{Learner six-Unblocker}

The following quote showed Unblocker's perceived helplessness in achieving better English proficiency. This may be associated with his past language learning experiences and current environmental factors.

I have never managed to get A for my English paper. I have got problem in grammar. I cannot speak properly in all the national examinations, I only managed to get B. I have tried but I can't ... its demotivating when you noticed that you have learnt English for a long period, but you still can't make it.

\section{Personal Factors}

Unblocker is a twenty-year-old Malay male, and a first year student of the Economics and Business Studies Faculty, majoring in Finance and Banking. His grade for his English paper in the Malaysian Certificate of Examination was B3 and his result in the Malaysian University English Test (MUET) was band 3. This showed his mediocre language achievement. Before taking the Academic Communication I Course, he did not take any other English course.

He is from a rural area in the Southern part of Peninsular Malaysia where Bahasa Melayu was widely used, and this did not appear to help much in his acquisition of English:

I live in a remote area ... attended a rural primary school, everybody has low English language proficiency. Thus, the environment for English language learning and use is not there.

(7 January, 2010)

His motivation to learn seemed to have been affected by his rural background where the environment was not conducive for English language learning and past language learning experiences and results. This affected his effort to improve his English proficiency during his primary years. However, during his secondary school years, he sought his teacher's help to improve his writing and learnt simple grammar rules by himself through reference books:

I got help from my teacher to correct my writing. I also tried to understand the grammatical rules on my own. I used the reference books. 
However, he still did not see his marks as satisfactory. He had always wanted to score A for his national examination English papers since primary school, but he only managed to score a B:

When I was at the secondary school, I tried to do lots of writing practices. However, I still scored low marks in the exam. Thus, I stopped doing it. Then I tried to improve my vocabulary by reading newspaper but I forgot the words.

(7 January, 2010)

\section{Ability attribution}

Unblocker attributed the low achievement to a lack of grammatical skill and vocabulary. These prevented him speaking English fluently. He compared himself to others who could use a wide range of vocabulary in their communication, and he felt embarrassed about communicating in English.

Moreover, he felt less motivated to put much effort into his language learning because learning English was a long process. He felt less self-efficacious about attaining better grades. When he was asked about his study timetable, he replied that he did not have any specific schedule to learn English. He said that learning English was not something new, and he thought the focus should be on his courses in the Economics faculty:

English language is not a priority as we have learned it for a long time. It is the same thing being repeated. Even if I put more effort, the result would be the same. I prefer to focus on new courses like my Business subjects. I don't have specific schedule to learn English. I'll complete my English assignments in between study time for other subjects.

(7 January, 2010)

His language teacher felt that Unblocker had the potential to make more effort and do better:

That does not mean that he is not good but the effort put is not enough. If only he put more effort, he will be successful. He can do better.

(Teacher interview, 26 March, 2010) 
As he also learned English during his matriculation year, Unblocker thought he could score well in the final paper of the Academic Communication 1 course, as the format of the examination was similar to the previous examination during his matriculation:

I think I can get good result ... familiar with the examination ... due to the similarity of the exam format, I find it easy. Because the questions are the same from matriculation ... same format ... Objective, subjective and some essays. But the language is a bit higher.

(26 February, 2010)

He realised that he still needed to improve his language proficiency. He viewed his reading skills as adequate, as he could understand English text in his MUET exam.

Unblocker was more confident in his reading compared to his listening as he could see the words and context. The spelling and context made guessing the meaning of words much easier. Unblocker was not confident in his writing because of his limited vocabulary.

In order to improve his vocabulary, he referred to the dictionary, and he realised that in order to remember the new words and the meanings, he would need to read a lot:

Usually when I read anything, for example newspapers, I would underline and highlight the words that I don't understand. Then I refer to dictionary... must read a lot to enrich my vocabulary knowledge.

Unblocker was still not sure of the correct way of using a dictionary. He rarely used an English-English dictionary. When he was asked to show how he searched for the meaning of words from the dictionary, the researcher realised that he just took the first meaning listed without considering the context.

He did not buy the books that he needed but he said he would get them from the library. However, he seldom went to the university library as he was not sure of how to use the OPAC (Online Public Access Catalogue) system for finding books: 
When I was at the matriculation centre, I borrowed English books from the library. However, now at the university, I prefer to get materials from the internet. I am not familiar with the university library system.

(26 February, 2010)

As a student of the Economics faculty, Unblocker realised the central role that English played for international business in the era of globalization:

In the Organization Behaviour class, I realize that there is a need for proficiency in English in order to have business deals with foreign traders. Due to the globalisation era, most business are conducted internationally.

(26 February, 2010)

He wanted to improve his oral ability, as that was one of the requirements for securing a good job in the private sector in Malaysia.

I want to be able to speak fluently... Most of the private sectors require a graduate to be proficient in English. Even interviews were conducted in English. Many graduates fail to secure jobs due to inability to communicate in English.

(7 January, 2010)

To complete his assignments, he needed to read and understand the reference books, which were mostly in English. Low proficiency in English could cause difficulty in understanding reading materials. Unblocker experienced difficulty in translating certain Business terms for his assignments that were written in Bahasa Melayu:

As a student ... English is needed for lectures and tutorials. I see the crucial need for me to be proficient in English. Most references are in English. There are times when I can't translate the specific business terms to Bahasa Melayu ... special vocabulary ... Economic and Business terms ...

(26 February, 2010)

Unblocker was aware that if he decided to pursue a postgraduate degree, especially in a foreign country, he would need English. He was also keen to make more friends from other countries, and wanted to communicate well with them 
in English:

I'll need English ... maybe, when I am taking masters or PhD, or to have friends from other countries ... foreigners.

(26 February, 2010)

Unblocker saw the need to master English language to understand English songs and movies:

I collect English lyrics. There are lots of English movies on television. We will not be able to enjoy the movies if we do not know English.

(26 February, 2010)

Unblocker suggested that besides English, Malaysians needed to know other languages like Mandarin, as this was one of the requirements to secure a job at the Chinese-owned private companies in Malaysia.

\section{Summary of personal factors that influence Unblocker's language learning and use}

Although he recognized the significant role of English for his studies and future career, he did not put much effort into his language learning. Past low achievement, a rural background and a lack of chances to use English at his current university were the factors that led to Unblocker's lack of motivation and effort to improve his language proficiency. He stated that he needed language learning strategies like effective ways of using a dictionary.

\section{Environmental Factors}

Unblocker was unhappy with his competency in spoken English. He thought this was due to socialising only with Malay friends during his secondary and primary school years. Hence, their common language was Bahasa Melayu and when he tried to use English, he was called a 'show-off'. That inhibited him from using English.

However, at the university he tried to use English with his non-Malay friends, as normally they used English in their daily communication: 
With the Chinese students, I communicate in English as they use English in their daily conversation. However, I still do not communicate in English with the Malays as they will react negatively.

(7 January, 2010)

He felt that the surrounding contextual factors at the university did not help him in mastering English language. He compared the use of English at the university to other universities in Malaysia where the use of English was common, for example, as the medium of instruction, writing on signboards and for daily communication at university offices:

I did not get the chance to use English language, the environment is not there ... the main language and medium of instruction is Bahasa Melayu. It is not like other universities where English is widely used for teaching, learning and communication

(7 January, 2010)

\section{Teacher factor that influences self-regulation}

Unblocker thought teachers played an important role in motivating students to learn English. He appreciated that his current language teacher was approachable and the students felt comfortable trying to communicate in English in class:

... is a cheerful and friendly teacher. We feel safe to communicate in English

(14 March, 2010)

Unblocker had a negative past language learning experience with a teacher. That made him nervous about getting assistance from the teacher:

When I was doing my matriculation, there was a fierce and unapproachable teacher. We are afraid to talk to him.

(14 March, 2010)

Unblocker highlighted the important role of the teacher in assisting ESL learners to be motivated to improve their English language skills. He elaborated that a language teacher should be friendly and able to make language lessons 
interesting, challenging and meaningful to the students - especially at the tertiary level, as the students would not attend class if they did not like the teacher:

I think a teacher's personality is important. Now at the university, if we don't like the lecturer, we will miss the class.

(14 March, 2010)

When asked about his concentration in class, he commented that the teacher's loud voice helped him focus. His teacher's habit of calling on students' names to participate helped him to pay attention.

\section{Course materials}

He said that the new course book used for that particular semester helped him to improve his language skills, especially reading skills. He thought it was useful that the students were taught language skills like skimming and scanning for reading and also basic grammatical rules.

\section{Facilities for English language learning at the university}

Unblocker wanted the establishment of a specific language learning centre at the university for students with facilities such as a language learning laboratory with English reading materials and cassettes:

... a centre for language learning will help. We need a specific place for teaching and learning of English.

(14 March, 2010)

\section{Summary of environmental factors that influence Unblocker's language learning and use}

A lack of chances to practise English affected Unblocker's spoken English. He emphasised the teacher's role in encouraging ESL learners to improve their English language proficiency. His teacher's clear voice and efforts to involve all the students in class activities helped him to focus in his current language class. He thought the course helped him in acquiring language skills. He believed that specific language learning centre should be set up at the university to provide students with facilities and materials to learn English. 


\section{Behaviour - Self-regulated learning strategies}

\section{Seeking assistance}

Unblocker agreed on the importance of asking for assistance, as he felt that his work would be better if there were ideas from others. He would seek help from someone who had better English language proficiency, like the students who were taking a language course as their study major:

It is important to ask for help ... assistance ... when we share with others, we get more information and ideas. I get help to check my errors and mistakes.

(26 February, 2010)

However, he was a bit inhibited about requesting help in front of his classmates. This might show his weakness.

He did not mind being corrected as he felt that he needed to improve his language proficiency like grammar and pronunciation. He even requested that the researcher correct his language for the diary entry sent weekly for data collection:

Thank you for correcting my mistakes. I learn from it.

(Unedited diary, 30 January, 2010 - Unblocker's response to correction made by the researcher)

\section{Practising self-evaluation}

When he was asked whether he evaluated his language learning progress, he said that he saw himself as progressing if he achieved goals like completing his assignments on time:

I measure my own progress and achievement based on whether I have completed what I am supposed to submit.

(26 February, 2010)

Unblocker compared his language proficiency to others who were better than him in order to be more motivated to strive harder.

\section{Seeking information}

Unblocker collected additional articles for his information sharing assessment 
and group project from different sources. Unblocker prepared notes for his information sharing assessment and he reviewed the points daily for a week before the assessment day. Thus, he only needed to reread the points once on the night of the assessment. Unblocker put more effort into the information sharing assessment as he thought it was challenging. Unblocker found searching for an article and summarizing its content was easy. However, presenting it to the group was challenging, as he was worried about the oral aspects. He felt anxious during the presentation. He felt nervous being the focus of attention of his classmates:

My lack of oral ability makes me nervous and less confident to present for my information sharing assessment ... presenting in front of others scared me.

(6 February, 2010)

Unblocker was worried about the marks that he would get for his presentation. As he felt that he was not able to present himself effectively, he tried to get marks from the question and answer session by listening carefully to his friends' presentations and responding to them:

We have to listen attentively when our friends are presenting. I feel that asking questions to others is easy if we get their points.

(6 February, 2010)

Unblocker seemed alert to others' presentation. He took the effort to ask questions to his friends. He also took the initiative to ask for clarification from a presenter, "Actually I am not clear of your topic, can you please explain again?" He also showed interest to get clearer explanation of the topic presented by one of his friends on 'foot binding'.

(Classroom observation-information sharing assessment, 2 February, 2010)

He hoped that if he could ask relevant questions of his friends after they had presented, he could score better marks.

He used certain learning strategies to improve language proficiency and communicative ability. Unblocker watched English movies and referred to the English subtitles to improve his language proficiency. He learned word 
pronunciation and stress when he listened to the conversations in movies and by reading the subtitles:

From the subtitles, I can learn the correct pronunciation.

(26 February, 2010)

Unblocker used a pen as a pointer to keep focused on his reading. When reading, he would read the comprehension questions first before reading the passage as that helped him in understanding the ideas in the passage.

When he was asked how he decided on and selected materials for his language learning, he stated that he made the decision on his own but at times he would ask for suggestions from others, like his language teacher and friends.

\section{Managing emotions}

When he was asked about the strategies that he used to alleviate the negative feelings he felt while learning English language, he said that he wrote motivational quotes and put them on the hostel wall:

I have inspirational quotes on my hostel wall. That is to make me more motivated.

(26 February, 2010)

In the process of completing his language learning task, if he felt bored, he would rest for a while in order to feel motivated and energetic about continuing with the task.

\section{Structuring learning environment}

Unblocker learnt a lesson about procrastinating from doing his language learning tasks. He was late in showing the article for the information sharing assessment to his language instructor, and was not given any marks. His language instructor reprimanded him for not taking the given assignment seriously: 
Procrastination. For this semester... information sharing. We must show the article first at his office but I was late. Affect my marks. My teacher said that I still do my work based on "reward and punishment".

It is my fault. I did not take the effort to see him.

(Unedited diary, 22 January, 2010)

He admitted that he was more occupied with Facebook than his studies. However, realising the mistakes made, he had rescheduled his time to update his Facebook at night and he would focus on studies during daytime.

A conducive learning environment was important to support him to concentrate on his studies. Due to the small size of his hostel room, he could not study if it was noisy. In such a situation, he would leave the room and search for a quieter place to complete his work.

\section{Summary of Unblocker's self-regulated learning strategies}

Unblocker showed that he did take action to learn English, like asking for help when he faced difficulty in his language learning. He decided to reschedule his study time after being told off by his language teacher for not completing his assignment on time. 


\section{Behavioural}

- Seeking assistance

- Practising self-evaluation

- Seeking information

- Managing emotions

- Structuring learning environment

\section{Personal}

- $\quad$ Mediocre entry grade - B3 (MCE) and Band 3 (MUET)

- $\quad$ Past low achievement and long process of learning English led to his lack of motivation. His marks were

still not satisfying after a long process of learning English

- Ability attribution

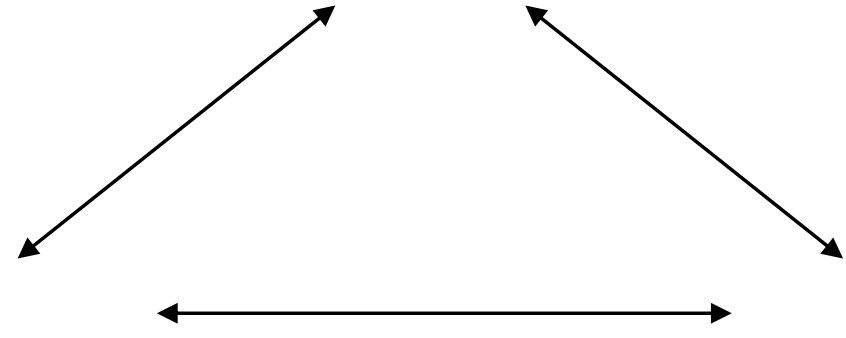

\section{Environmental}

- Hometown-Rural area

- $\quad$ Peer pressure- Ridiculed by friends for using English

- Emphasized the teacher's role to make learning more engaging and meaningful

- $\quad$ Suggested a language centre to be set up at the university

Figure 5.11: Summary of SRL strategies and factors influencing Unblocker's self-regulation in language learning. 


\section{Chapter summary}

This chapter describes the use of SRL strategies and the motivational and environmental influences on the SRL strategies used by each participant in their language learning. There were differences in each participant's use of selfregulated learning strategies, and the motivational and environmental influences on the strategies. However, there were commonalities that resulted in themes identified across cases. These differences and commonalities are reported in the following chapter. 


\section{CHAPTER SIX: \\ Cross-Case Analysis}

\section{Introduction}

The case study participants used a number of self-regulatory behaviours. In particular, they took actions to manage the learning process in general, and to cope with the particular course assignments and assessments. However, these SRL behaviours did not occur in a void; a number of contextual factors influenced the participants' use of self-regulatory strategies.

In this chapter, I will begin by discussing the participants' SRL to answer research question 1 , and then turn to a discussion of the contextual factors that influenced these strategies.

\section{Self-regulated learning strategies}

All of the participants were self-regulating their learning, even if they were doing so in different ways, to different extents, and for different tasks. This concurs with a social cognitive theoretical framework that sees self-regulation as not a general trait: students are not in general self-regulated or non-self-regulated, and self-regulation is greatly context-dependent (Schunk, 2009). Strategies the participants reported for learning English and for managing with the course assignments and assessments can be put into three categories: Cognitive and metacognitive strategies, resource management strategies, and managing emotions strategies. The three categories were related to the behavioural component of self-regulation and were sub-categories of behavioural selfregulated learning strategies. The cognitive and metacognitive strategies were goal setting and planning, seeking information, organizing and transforming, and self-evaluation. The participants employed two resource management strategies: structuring learning environment and seeking assistance strategies. For the managing emotions strategies, the participants practised positive self-talk and self-consequence to alleviate negative feelings such as boredom and frustration from language learning. 


\section{Cognitive and metacognitive}

\section{Goal-setting and planning}

SRL models of regulation assume that learners can set standards or goals to strive for in their learning, monitor their progress toward these goals, and then adapt and regulate their cognition, motivation, and behaviour in order to reach their goals (Zeidner, et al., 2000; Zimmerman, 2001). Self-regulated learning begins in a forethought phase that includes goal setting and planning (Zimmerman, 2000a). A student with self-regulation has in mind some goals to be achieved against which performance can be compared and assessed (Schunk, et al., 2008).

The participants in this study showed different degrees of goal setting and planning in their self-regulation of their language learning. Language learners' goals may determine how they use the language being learned, how grammatically accurate their utterances will be, and how much effort they will put into improving their language proficiency. The participants had both communicative and form-focused goals that were related to reasons why they were learning English. The participants' goals were task-specific.

The participants' communicative focused goal was related to improving their oral ability for communication with other English speakers, like the international students at the university, and also for future employment. For example, Rae and Sepatu prioritised achieving oral fluency. They used English as much as they could to communicate.

Sepatu pointed out that the goals he set provided him with a focus and direction for his learning. Rae, Sepatu and Stanza showed effort regulation to achieve the goals they set. They planned and prepared well for their on-going classroom assessments. They showed persistence when they faced problems and criticism in the process of their language learning. They were task focused in reaching their goals. Social cognitive theorists emphasize goal setting as a key motivational process (Bandura, 1997; Locke \& Latham, 2002). When students adopt a goal, they may experience a sense of self-efficacy and are motivated to attain it, thus resulting in meaningful learning (Alderman, 2008). Learners with a goal and a sense of self-efficacy for attaining it engage in activities they believe 
will lead to goal attainment (Schunk, 2008). As they observe their goal progresses, their sense of self-efficacy is enhanced, which strengthens motivation and leads to skill acquisition. Sepatu requested comments from his teacher on his work and he felt motivated when his language teacher was satisfied with the draft submitted and the preparation that had been done for his group final presentation. Schunk (1994) stressed that the belief that one is making progress, along with the satisfaction of goal accomplishment, enhances self-efficacy and sustains motivation.

A significant finding of this study is the contextual properties of the participants' goals, such as their specificity, difficulty level, and immediacy. Sepatu set specific goals for each course assessment. For his information sharing assessment, he aimed to deliver the presentation clearly with clear pronunciation and effective body gestures. To achieve this goal, he practised before the presentation in front of a friend, and recorded the practices to correct his pronunciation. Specificity is an important property of goals that affects performance where specific goals have clear standards for accomplishment (Alderman, 2008). On the other hand, general goals are vague, with a nonspecific outcome. Bandura (1986) proposed that specific goals increase task performance as they provide a guide for the type and amount of effort needed to accomplish the task. On the other hand, Unblocker, reported a general goal of improving his spoken skills. Because this goal was very general it seemed difficult to achieve, as there are many aspects of oral proficiency that contribute to communicative competence. Thus, he felt frustrated about his inability to achieve the goal. Locke and Latham (1990) pointed out that specific goals result in higher performance than either no goals or general goals.

A technique that helped Stanza, Rae, and Sepatu to structure their language learning involved the use of proximal (short-term) goals to assist in achieving distal (long-term) goals. The attainment of their proximal goals motivated them to persist to reach distal goals. Stanza exemplified this in her goal of learning new words and expressions every day to improve her vocabulary, which helped her stay on task to achieve her long-term goal to speak fluently, without hesitation as a result of inadequate vocabulary. The words and expressions learned were then used in her writing and conversation. To achieve her distal goal of improving her 
productive skills (writing and speaking), Rae tried to improve her pronunciation (proximal goal) as she wanted to communicate clearly. Stanza reported improving the outline of the report (proximal goal) for one of the course assessments, the group project, to produce a good report.

Social cognitive research has shown that goals that are proximal, specific, and moderately difficult offer the greatest motivational benefits (Zimmerman, 2008a). Also critical is learners' commitment to attain the goal. Motivation is enhanced when learners are enthusiastic about the goal and determined to attain it. When people do not commit to attaining a goal, they may not put in much effort and may not have self-efficacy for success (Schunk, et al., 2008). In this study, all of the participants stated that they wanted to improve their oral proficiency. However only Rae, Sepatu, Stanza and Confidence Hero showed selfregulatory behaviour, like regulating their environment to maximize their communication in English. On the other hand, Unblocker highlighted the barriers and his lack of ability, rather than actions that could be taken. Rae, Sepatu, and Stanza reported clear goal setting and using planning aids such as organizers and reminder boards to plan for the preparation and submission of on-going course assignments and to juggle various academic and personal commitments like involvement in campus activities.

Self-regulated learners identify strategies likely to accomplish their learning goals and objectives, which includes selecting and adapting strategies to match task demands. Lastly, self-regulated learners implement strategies, monitor outcomes associated with strategy use, make judgements about task performance, and adjust strategies depending on the success or failures of their efforts. This was evident in the cases of Rae, Sepatu, and Stanza. They utilized goal-setting strategies for their on-going classroom assessments. They then planned and chose the strategies to attain the goals they had set. They were also aware of their ability and performance during the process of achieving these goals. Based on this self-awareness, they observed their progress towards the goals set, the strategies they used, and managed their social and physical environments. For their course assessments, they started by analyzing task requirements, defining performance criteria, and setting learning goals. The task requirements and the performance criteria were determined from the 
information on course assessments given by their language teachers at the beginning of the semester. These steps were critical for them to make decisions about how to self-regulate their learning based on perceived task demands. During the self-regulation process, self-regulated learners "identify what the current task requires in terms of cognitive, motivational, and environmental strategies and determine if their personal resources are adequate to effectively accomplish the task" (Ertmer \& Newby, 1996, p. 18). For Stanza, goal-setting, in combination with her own self-imposed deadlines, provided her with the persistence and motivation necessary to complete the course assignments. This was consistent with Bown's (2009) findings, where the participants reported the self-imposed deadlines and goal setting created the structure for their language learning and provided the motivation to stay on task.

Sepatu and Stanza emphasised the importance of completing tasks according to timelines and not procrastinating. They not only planned for their individual assignments but also managed their group project by setting a timeline for their group members to submit their individual topic for discussion among the group. The timeline and their management of their group preparation had helped their group to complete their project successfully and on time.

Rae, on the other hand, preferred to do individual assignments as she had more control of the process and outcome. As she believed that the outcome was due to effort, she expected her group members to be as hardworking as her. However, she realised that the outcome could be out of her control when preparing and presenting a good group project unless all her group members were as committed to the project as her. In individual tasks, she could set high goals and plan successfully for the task, while with group work disagreements could detract from attaining success in reaching the goal.

In their planning strategies, the participants planned for their language learning in different ways. Rae showed a strategic approach to planning her work. The explanation of the course requirements and dates of the in-class assessments, done by her class teacher during the course briefing, helped her in planning for her language learning. She prepared for the on-going assessments based on the dates specified by her class teacher. However, she did not prioritize any of the 
assessments based on the allocation of marks for the different assessments. She regarded all of the assessments as equally important for her to learn English and improve her language proficiency.

On the other hand, Sepatu's and Confidence Hero's planning and preparation for the assessments were determined by the allocation of marks for each assessment. Scoring a high grade for their course was important for them. They put more effort and allocated more time for the assessments that were allocated more marks, such as the group project.

The context of language learning, shaped by educational values of the society in which individuals are learning the language, and combined with language learners' goals determines the learning strategies or learner behaviours (Chamot, 2004). This was so for Ares and Unblocker, who were aware of the significant role of English in their studies and future careers yet did not put much effort and planning into their language learning. Ares and Unblocker said they did not have any specific schedule to learn English as they felt that they needed to focus more on their other courses. Moreover, as there was no mid-term exam for the language course, they felt that they did not have to do revision of English. This shows that examinations had a strong influence on their learning behaviour and it may reflect the exam-oriented culture among Malaysian learners, as described in Chapter Two.

\section{Seeking information}

Successful language learners often make use of the target language input to improve their language learning (Embi \& Mohd Amin, 2010; Rivers, 2001; Rubin, 1975). Sepatu, Stanza, Rae, Unblocker and Ares reported using this strategy when searching for related articles for their individual information sharing task and group project. They collected materials from different sources (in English and their first language) and retrieved the main ideas from each source. This helped them to write and they were better equipped to argue the ideas in their information sharing assignment, as they managed to synthesize the different opinions and perspectives of different authors on a similar issue. Compared to other learners, Rae used more online resources like an online dictionary to check the meaning of words. Rae and Stanza saw dictionary use, either online or in 
hardcopy form, as an important strategy to improve their vocabulary. Rae and Stanza enjoyed learning and trying the exercises on the MyLine website. Although at the time of data collection, it was not compulsory for all language courses at the university to allocate marks for the undergraduates' use of the MyLine activities, both of these students made an effort to do the exercises during their private study. Besides learning from the MyLine website, Rae used other language learning websites. She also utilised the tools in Microsoft Word to check her spelling and grammar.

Online interaction was an important source of language learning and the learners used it in different ways. Stanza explained to her online communicators that she was trying to improve her English language. She requested that they correct her mistakes. Stanza and Rae's proficiency improved due to the use of IRC (Internet Relay Chat) as a means of practising their English. This was similar to the findings in Coniam and Wong's (2004) study of Hong Kong secondary school students, where the experimental group expressed positive attitudes towards the use of IRC in practising their English and reported that their language proficiency had improved. Rae, Ares and Stanza pointed out that the internet facilities at the university had helped them to improve their language proficiency. From their communication with their online friends, Rae and Stanza managed to practise their writing and also used the vocabulary and phrases that they learnt. Ares used his blog as the medium to express himself in English. Embi (2000) and Lamb (2002) reported that successful language learners often attribute their achievements in language learning to active engagement with the target language beyond the classroom. Besides providing extra language learning resources and opportunities, these out-of-class language learning activities also serve a variety of purposes, such as: shaping a positive learner identity and therefore sustaining motivation for learning (Lamb, 2007), providing learners with a friendly and supportive learning community and offering learners an avenue for selfexpression and for increasing their self-perception (Gao, 2009). My study demonstrates the role that the internet played in providing these opportunities to engage actively with the target language outside the classroom for some of the participants in a Malaysian university. 


\section{Organizing and transforming}

Sepatu, Rae and Stanza practised organizing and transforming strategies to manage and rearrange their instructional materials to improve learning. They used concept mapping and note taking to transform information as part of their learning processes. Zimmerman and Pons (1986, p. 618) defined organizing materials as transforming and "rearranging instructional materials to improve learning". Hofer, Yu and Pintrich (1998) stated that organizational strategies such as outlining content or relating concepts within content are cognitive learning strategies that individuals use to self-regulate, and these usually result in a deeper understanding of the material. Sepatu made a concept map to prepare for the information sharing presentation. Through concept mapping, he could understand not only the ideas in the passage, but also the relationships among those ideas, leading to a more complete understanding of the issues discussed in each of the reading materials for his individual presentation. The use of a concept map also helped him to monitor his preparation for the assessment. Concept mapping helps to promote the use of self-monitoring and knowledge acquisition strategies and to increase self-efficacy for learning (Chularut \& DeBacker, 2004). This was because "comprehension has significantly improved with the use of visual organizers such as concept maps" (Simpson \& Randall, 2000 , p. 55). Concept mapping requires students to visually represent their understanding of a text. This creates much more evidence of the quality of both the learning process and concept understanding (Chularut \& DeBacker, 2004). The use of concept mapping to organize and transform material may have facilitated a deeper understanding of the material. This may have enabled Sepatu to have a more meaningful understanding of the English language in the materials and to use it with more confidence in the assessment.

Rae, Stanza and Ares prepared notes to synthesise the information from different reading materials in preparation for their individual presentation. Stanza reported that noting down the main ideas from various sources helped her to organize the content and write her project report. This transforming strategy may have helped her to translate her reading material into a well written, coherent argument. 
Concept mapping and note making helps students attend to tasks, focus on important features, and organize material (Weinstein \& Mayer, 1986).

\section{Self-evaluation}

Self-evaluation was used in different forms for the participants. They reflected on their learning progress and quality of work and gave themselves personal feedback. Feedback is information about how a student's present state of learning and performance relates to his or her goals and standards (Nicol \& Macfarlane-Dick, 2006). If they did not feel that their progress and quality of work were on track to attain their goals, they changed their strategy. Students generate internal feedback as they monitor their engagement with learning activities and tasks, and assess progress towards goals (Nicol \& Macfarlane-Dick, 2006). However, those students who are more effective at self-regulation produce better feedback or are more able to use the feedback to achieve their desired goals (Butler and Winne, 1995). Stanza and Rae tried out their knowledge by making up new sentences, thus bringing their newly acquired competence into use. From this, they would be able to self-evaluate their understanding and competence.

Ares self-evaluated his own progress and performance by means of comparison with his classmates' progress and performance. When he could not answer a specific question in class and others in the class could answer it, he told himself to work harder in order to be on a par with his friends. Rather than aiming for a set standard, he was norming to the goals of others in class. However, for Unblocker to see others be better than him made him feel more inferior and more reluctant to use English, as he already felt embarrassed about his lack of proficiency, especially in his spoken ability.

Besides providing personal feedback, each of the learners used different ways to get feedback from others. The participants in this study played a dynamic role in feedback processes. They actively interpreted external feedback, for example, from teachers and other students, in relation to their internal goals. Sepatu, for example, rearranged his points and changed his plans for his presentation when he received feedback from his teacher. His goal was to present the summary of the article that he had read concisely to his teacher and friends. Stanza and 
Confidence Hero requested their language teacher check their project report draft. They then edited it based on the feedback received from their teacher before submitting the final report. Besides asking for comments from the teacher, Stanza also checked the quality of her report by comparing it to the criteria listed in the course description for the award of good marks for project report.

Effective students actively construct their own understanding of feedback messages derived from external sources (Ivanic, Clark, \& Rimmershaw, 2000). Nicol and Macfarlane-Dick's (2006) conceptual model of feedback places students in a central and active role in all feedback processes. They are always actively involved in monitoring and regulating their own performance, both in relation to desired goals and in terms of the strategies used to reach these goals. In this study, Sepatu, Stanza and Confidence Hero played a dynamic role in feedback processes.

\section{Resource management}

\section{Structuring learning environment}

Bandura's (1986) social cognitive theory states that self-regulated learners understand the impact of the environment on them and know how to improve the environment through the use of various strategies. The participants in this study took actions to regulate their learning environment in order to achieve their language learning goals. Rae, Sepatu, Ares and Unblocker reported such a strategy when they took action to make their environment conducive for learning.

For example, both Rae and Sepatu did not allow their friends to distract them. The environmental regulation strategy used by Rae and Sepatu supported previous findings that self-regulated learners' used strategies to structure an effective learning environment, arranging elements in an instructional environment so that learning goals successfully compete with other goals for attention and other cognitive resources. Ares and Unblocker also reported developing similar strategies of getting away from distractions like noise. They decided to reschedule their study time so they could focus better. Before learners can pay attention, they must have an environment that allows, if not encourages them to focus attention on the learning task at hand. 
Self-regulated learning perspective has shifted the focus from student learning abilities and environments as "fixed entities" (Zimmerman, 2001, p. 2) to students' personally initiated strategies to improve learning outcomes and environments. Structuring the environment relates to a learner's ability to cope effectively with disturbances and is a crucial part of SRL (Corno, 1994).

Expert learners have knowledge about the "optimal study conditions for meeting the demands of the task" (Ertmer \& Newby, 1996, p. 8). The findings from Ares and Unblocker supported previous findings on environmental structuring among self-regulated learners. Ertmer and Newby (1996, p. 20) stated that selfregulated learners ask themselves, "When and where do I study best?" and "How supportive is the learning environment?"

All of the participants complained of the lack of opportunities to use English in their daily lives at the university, as Bahasa Melayu was widely used as the medium of instruction and communication. In Malaysia, most people see English as having a "higher social status" (Renganathan \& Chong, 2007, p. 13) for the reason that being proficient in English, especially in speaking, makes others respect them. Hence, all the participants in this study had the aspiration to become proficient English speakers.

Good language learners take and create the opportunities to practise what they have learned (Embi \& Mohd Amin, 2010). To compensate for the lack of opportunities for oral practice, the participants in this study created experiences for communication in English. This demonstrates effort as well as an understanding that communication is essential to language learning (Ellis, 2003). Rae, Stanza and Ares used strategies such as influencing close friends to use English, choosing online friends among English users and using blogs for selfexpression in English. In addition to providing an avenue for English use, Stanza's online communication provided linguistic benefits as her friends corrected her mistakes as requested. Rae and Stanza managed to practise their writing and also used the vocabulary and phrases that they learnt in online communication. Seeking interaction also provided important social and affective benefits. Stanza reported that the ability to communicate with other English speakers increased her self-efficacy. 
Rae's active involvement in the English Speaking Zone (ESZ) at her residential college also contributed to her language proficiency. Sepatu took the initiative to apply for the study-exchange programme to get more exposure to English and to interact in a native speech community where he expected to improve his oral language ability (Segalowitz \& Barbara, 2004). His attributed his gains in oral performance to opportunities to use English in real life communication in the study abroad context.

Sepatu, Confidence Hero and Stanza also regarded their participation in the research as a chance for them to use English. This shows what becomes a possibility depends on the learner's goals and behaviours. In this study, the learning environment offered diverse opportunities to learners, depending on the learners' awareness of their roles in the learning process, and their perceptions of the environment as fixed or changeable. The factors that positively influenced Confidence Hero's proficiency were his own actions to maximise the use of English in his daily communication with close friends and also his effort to communicate in English for his teacher's approval. Confidence Hero's use of English with close friends showed that influential third parties such as peers, teachers and parents also influenced the participants' self-regulation in language learning. Confidence Hero received support in using English from his close friends. They even challenged each other to be better in spoken English, taught and corrected each other.

\section{Seeking assistance}

Rae, Sepatu and Stanza sought help whenever they faced difficulties in their language learning. From a motivational perspective, help seeking is an adaptive cognitive strategy that indicates a striving for mastery and achievement (Karabenick, 1998), social self-regulation (Karabenick \& Dembo, 2011) and a general problem solving strategy (Newman, 2008). Students who attributed success to effort are more likely to ask for help (Newman, 2008).

The participants in this study reported that they practised help seeking whenever they had problems in their language learning. However, all of them preferred to ask for assistance from their friends rather than their language teacher. Sepatu asked for assistance from friends who were better than him. He 
tried to use the strategies used by those advanced students to improve his performance. Stanza also took the opportunities to learn from the Singaporeans at her faculty who were more proficient in English, such as how to write effective academic writing. Confidence Hero studied with his friends and they shared and discussed their knowledge, taught each other and exchanged corrections. Rae and Sepatu only sought their teachers' assistance when they could not get help from their friends, as they thought that only the teachers could give accurate advice and information. They sought help to clarify expectations on assignments and assessments. This was task information rather than help with language.

However, Stanza and Confidence Hero felt comfortable in requesting help from their teachers because of their teachers' approachable way of working with students. Stanza consulted her teacher to make sure that her assignments were grammatically correct. Confidence Hero's language teacher reported that he consulted her on the content and language of the group project report. He also asked for his teacher's opinion of his work and progress in order to fulfil the teacher's expectations and receive a good mark. Stanza's final draft of group project report had improved due to the feedback received during conferencing with her language instructor.

Unblocker reported that he was reluctant to ask for help especially in the classroom and from the language teacher. He felt that by requesting help or asking questions in class, he would reveal his weaknesses in front of his peers and the teacher. Alderman (2008) states that help seeking may be seen as threatening if a student thinks it is a sign of low ability. Many students in higher education are reluctant to seek academic help for reasons that include low selfefficacy and threat to self-esteem, a competitive classroom climate, and teachers who appear to be unresponsive or inflexible (Kozanitis, Desbiens, \& Chouinard, 2008). Unblocker preferred to get help from close friends compared to the teacher. This was because he felt more comfortable with peers, as peers could provide him with feedback that was easily understood and did not pose a threat to his ego.

Learners' adaptive help seeking is an important skill (Newman, 2002). However, poor learners are reluctant to seek help in a dependent manner because it can 
expose their limitations, as shown by Unblocker. Students with favourable motivational beliefs, such as a mastery goal orientation, are willing to seek assistance because they are confident that it will lead to more adaptive cycles of learning (Newman, 2002). Help seeking strategies used by Rae, Stanza, Sepatu and Confidence Hero portrayed this. Not all sources of assistance were human, as Rae sought Web-based assistance.

\section{Managing emotion}

The participants in this study had their own managing emotion strategies to cope with the negative emotions like the frustration and discouragement resulting from their language learning. The strategies enable them to be motivated and persistent in completing their language learning tasks and achieving their goals. Managing emotion strategies which "serve to regulate emotions, attitude and motivation" (Richards \& Renandya, 2002, p. 121) are important for regulating language learning outcomes. Positive self-talk and practising self-consequences were examples of this kind of strategy used by participants in this study.

\section{Practising self-talk}

Positive self-talk was the strategy used by the participants to help them maintain perspective on their language learning that, in turn, alleviated feelings of frustration. The participants in this study used positive self-talk to remind themselves of their own purpose and motivation for learning English and to encourage themselves when they felt that they were not making sufficient progress. Trying to master the language and improve their oral proficiency was in itself the cause of feelings of frustration and doubt. As they have learned English since their primary years, their inability to communicate well in the language made them feel frustrated. Thus, they tried to think positively and to have conviction in their ability to improve. Rae's positive self-talk helped her to see learning as fun. It also helped her to keep her expectations of her success in language learning realistic. As she accepted that making mistakes is part of learning, she told herself not to be embarrassed about making mistakes and to learn from them. Sepatu's positive self-talk led to his positive thinking and belief in his own ability to put more effort in achieving his learning goals.

A learner like Unblocker, who reported self-efficacy in his ability to achieve 
better, reduced the effort he put into English language learning when he felt that he had not been making much progress. Avoiding studying English and focusing more on other university courses due to the belief that he could not do better in English, represented a passive technique that might undermine Unblocker's efforts to learn and to manage his language learning process effectively. Although he reported writing motivational quotes to motivate himself, this activity did not foster more effort.

\section{Practising self-consequence}

On the other hand, in an effort to regulate both their learning and emotions, the more successful learners used strategies to help them be persistent. One such strategy was a self-consequence strategy practiced by Rae, Sepatu and Confidence Hero. Self-regulated learners reward themselves "self-administered stimuli or consequences" (Zimmerman, 2001, p. 21) for task completion or success. Sepatu self-rewarded himself by taking a break or going on an outing with his peers after achieving success in his language learning. Social cognitive theory proposes that the anticipation of consequences may enhance students' motivation (Schunk, 2009). Rae stressed the importance of extra-curricular activities at the campus in allowing her to take a break from studying. Confidence Hero's active involvement in rugby and futsal (indoor soccer) made him more energetic and improve his concentration while studying.

The awareness of the strategies in coping with negative emotions is associated with how successful language learners are in encouraging and motivating themselves (Bown, 2006).

The next section answers Research Question Two and Three on the motivational and environmental influences on the self-regulated learning strategies used by the participants.

The ESL learners in this study exhibited a number of self-regulatory behaviours to manage the learning process. However, these self-regulatory strategies did not function in a vacuum, as a number of motivational and environmental factors influenced the learners' self-regulatory behaviours. The themes that emerged for the motivational influences on the participants' self-regulatory behaviours were motivation, goal-orientation, self-efficacy, beliefs about language learning, and 
attribution. The environmental influences on the participants' self-regulatory behaviours were related to the chances to use English in university social environments, teacher-related factors that affected engagement in language learning, peer influence, and the language course.

\section{Motivational influences}

\section{Motivation}

There were differences in the participants' motivation in learning English. Their motivation was related to the reasons as to why they learnt English, and what they meant by learning English. Their motivation influenced their effort regulation to learn English. There were differences in the extent to which they were doing additional work that contributed to their language proficiency. The participants' strategies and behaviours such as choice of activities, level and quality of task engagement, persistence, and performance indicate levels of motivation and self-regulation.

The participants in this study, except for Rae, were extrinsically motivated by factors such as the desire to get good grades. They saw English as an academic subject to be studied for examination success. They aimed for good marks in the course as it contributed to their overall grade average. However, they also had other reasons for learning English, like the need for English in their current studies, further studies and future employment.

They saw that English proficiency could contribute to their overall academic programme. They highlighted problems with understanding course content materials that were in English, especially those from the Business Faculty. Proficiency in English language is a major contributing factor to gaining access to relevant business related materials and journals. English proficiency was also regarded as important for future employment. The participants stated that they had to master English, as they would have to use English at their future workplaces, especially if they work at the private companies. Thus, all of the participants aimed for better communicative ability in English.

In addition to these reasons, Rae learned English out of her general interest in languages. She showed intrinsic motivation to learn English. She also learnt other 
foreign languages. Rae related her intrinsic motivation to early exposure to English.

Sepatu seemed to have both intrinsic and extrinsic motivation. He had a love for languages as he learnt Mandarin in addition to English. However, he was persistent in improving his English language proficiency in order to get a good final semester result. He stressed the importance of doing his best in whatever he did as he believed that an inability to perform would lead to others forming a negative impression of him. This could be related to his performance goal.

Confidence Hero seemed to have the extrinsic motivation of demonstrating his ability, especially to his language teacher. He tried his best to outperform his friends. Unblocker seemed to be less motivated to take action to be better and he had low self-efficacy that he could achieve good marks for his language course. He regarded passing the language course as being sufficient for him. This attitude was associated with his mediocre past results despite a long process of learning English. Unblocker's lack of motivation might also be caused by his lack of awareness of what was involved in learning a language and of language learning processes.

Stanza was highly motivated despite being from a socio-economic background which had been associated with low motivation in another study (Tiang, 2003). Her motivation to learn English helped Stanza in her learning, as she was willing to frequently practise all the four skills, use all the facilities to learn English and make use of any chances to communicate in the language. She employed relevant SRL strategies and specific language learning strategies to assist her in learning English. Students who have self-regulation use both motivation and learning strategies (Zimmerman, 2000a). Students who have strong motivation normally will succeed as they have adaptive attitudes and strategies, such as maintaining intrinsic interest, goal setting, and self-monitoring (Alderman, 2008). Positively motivated students engage in self-regulatory activities that help them achieve their goals. Such activities in turn promote learning and self-competence (Schunk, 2001).

Stanza was motivated to improve due to her filial piety towards her parents who encouraged her to master English to improve her future prospects and improve 
her family's social status. Her motivation included factors like social contexts that influence her language learning and use. Her experience of being an undergraduate at another public university where there was emphasis on English contributed to her motivation towards learning English language. Although Rae and Sepatu showed motivation towards learning English, they still voiced their dissatisfaction with the teaching and learning activities. They expected more interesting and varied teaching and learning activities. This variety can foster more interest in learning and a mastery achievement goal in students (Matos, Lens, \& Vansteenkiste, 2009).

Motivation in language learning is associated with resources and activities in the classroom. "Classroom L2 learning motivation is not a static construct as often measured in a quantitative manner, but a compound and relative phenomenon situated in various resources and tools in a dynamic classroom context" (Kimura, 2003, p. 78). Nikolov's study (2001) shows the significance of situation specific factors in students' language learning motivation. She found that the unsuccessful Hungarian language learners typically shared positive attitudes toward knowing foreign languages. Thus, they could be said to be integratively motivated. However, the main reasons given for their lack of success in the L2 were their negative perceptions of the classroom practices. For these learners, situation specific motives overrode the positive attitudes toward the L2. Nikolov (2001) highlights that "the most problematic areas relate to classroom methodology in general, and assessment, focus on form, and rote-learning in particular" (p. 149). This may apply to Malaysian learners. The Malaysian education system is exam-oriented (Ali, 2003), and although a communicative syllabus is prescribed by the Ministry of Education for the teaching and learning of English, in reality there is still emphasis on preparing students for public examinations. Although the teaching and learning of English at the tertiary level is not governed by standardized public examination, studies (see Abdul Razak, 2000) have shown that undergraduates report a lack of motivation to learn due to classroom factors such as a lack of stimulating teaching materials and methods and irrelevant courses.

An interesting finding from this study arises from the change of motivation for Rae. At the end of the semester, her language teacher reported that she missed 
classes and her group project presentation was not satisfying. Motivational measures, such as goals and self-efficacy beliefs, not only change during the course of learning, but these "altered measures remain predictive of further attempts to learn" (Zimmerman \& Schunk, 2001a, p. 295). Rae's active involvement in other campus activities at the end of the semester had affected the effort she put into her studies and thus her performance. Moreover, she felt frustrated with the lack of commitment from her group members for the final project. They did not have the same goals as those that she set for herself. They were not willing to put extra effort for the final presentation and written report. Compared to Sepatu and Stanza, who were successful in managing their group members, Rae felt helpless, as she did not want to jeopardize the friendship she had with other group members.

\section{Goal orientation}

The participants' self-regulation was also influenced by their learning goal orientation. Participants in this study showed that they had different goal orientations, depending on the language learning tasks. Sepatu showed a performance goal for his course assessments. He wanted to score good grades for his language course as it would affect his semester CGPA. He put effort into the preparation of his individual presentation to enable him to deliver it effectively and score good marks. While this was consistent with findings in Thang, Gobel, Mohd Nor and Suppiah (2011), which show getting a good grade is one of the most endorsed attributes for success among English as a second language learners in six public universities in Malaysia, Sepatu also wanted to improve his competence (mastery goal). His acceptance of being corrected by others showed his mastery goal. Second language students with mastery goals take more risks and see making mistakes as a natural part of language learning (Embi \& Mohd Amin, 2010). Sepatu did not mind being corrected to improve. He recognized that errors are part of the learning process itself and he looked upon them as a potential source of information, as well as a way of improving his language skills. Mastery-oriented students assume they are still good even when their work has errors, and they believe they could improve through effort (Pintrich, 2000b).

Harackiewicz, et al. (2002, p. 638) point out that researchers should focus on multiple goal perspectives to enrich understanding of motivation and 
achievement, and move beyond the "dichotomous mastery versus performance goal comparisons". Harackiewicz, et al. (2002) conclude that both mastery and performance-approach goals can have positive effects. They stated that different goals may be adaptive in different situations, and students who can selectively shift between goals may be particularly advantaged. For example, Sepatu pursued mastery goals to increase his competence when he learned English, especially new topics and language skills. However, he adopted performanceapproach goals when he prepared for his language course assessments. Harackiewicz, and colleagues' (2002) proposition that students who adopt both kinds of goals might have the highest overall level of performance held true for Sepatu, who scored high final marks in the course. Both performance and mastery goals can improve both accomplishment and continuing interest in a topic (Harackiewicz, et al., 2000). Harackiewicz, Barron and Elliot (1998) and Celine, Benoit, Florian, Caroline, and Fabrizio (2009) argue that a performance approach goal coupled with a mastery goal is adaptive for learning at the university level.

In this study, Confidence Hero may have exhibited performance goal orientation when he reported being highly competitive with his peers. He focused on being able to develop his oral proficiency to a higher level than his close friends and performed his best in the classroom in order to win his teacher's attention. Performance goal orientation is evident when a student is focused on demonstrating his or her abilities and performances in relation to other students. Students with performance goal orientation perceived that normative performance is important and constantly want to demonstrate that they have academic abilities in order to protect their ego (Midgley, Kaplan, \& Middleton, 2001). Confidence Hero tried to maximise his use of English language as he responded to a sense of competition with his peers' oral ability. This performance goal contributed to improving his oral proficiency. Midgley, et al.'s (2001) study proposed that performance-approach goals may have adaptive outcomes. Confidence Hero has shown in this study that he sought help from his language instructor and friends, showed persistence and cooperated well with his group members for his group project. Confidence Hero's achievement could be due to his ability to fulfil course requirements for the award of good marks. He 
tried his best in the completion of his course assessments.

\section{Language learning beliefs}

The participants' beliefs about the nature of language and language learning influenced their use of self-regulated learning strategies. This indicated a major tension between form focused learning and communicative language learning. All of the participants indicated that they wanted to improve their oral ability. However, there was also emphasis on getting their language grammatically correct. This may be due to the emphasis on grammatical items in their previous language learning experiences. Though grammatical accuracy was important for them, Stanza, Sepatu and Rae regarded making mistakes as a natural part of language learning and they were not afraid of making mistakes. They noted their errors, and tried to understand why they made them and how to avoid making them again in the future. This is in contrast to Unblocker, who was so afraid of making mistakes that he said nothing until he was sure that he could say it absolutely correctly.

Even though the teacher did not prioritise form in the criteria used to mark the course assignments, the participants were still concerned about being grammatically correct. However, the participants' emphasis on grammar varied according to the tasks. Sepatu was not concerned about grammar in informal conversation, but was when he was evaluated during his presentation. For the writing task, Stanza just wrote the ideas without worrying about the grammar. She only checked the grammar during editing. Similarly, when Ares wrote on his blog, he just focused on conveying the message and did not worry about grammar.

The participants' beliefs about the factors determining success or failure also had an influence on their self-regulation. These factors relate to the construct of locus of control. Locus of control is the orientation of an individual towards what determines their success or failure. Internal locus of control is an individual's belief in his ability to shape events, while external locus of control is an individual's belief that external factors control performance (White, 1999). The participants' locus of control may be one of the factors for the differential success among them. The varying motivation, self-efficacy and effort put in by the 
participants indicated that their locus of control might be a medial somewhere between internal and external.

The more successful participants (based on the final course marks) showed more internal locus of control; they believed they were primarily responsible for the learning process and outcomes. Although they also stated that external factors such as the teacher, course materials, and cooperation from peers were important in the learning process, they expressed that they themselves should take more action in their learning process. Rae, Sepatu and Stanza had internal locus of control and believed that they had the ability to improve and their persistence could lead to success. They believed that they should show more personal responsibility in their language learning, and not just rely on the teachers. Although they reported internal locus of learning, they also attributed the learning process to external factors such as materials and cooperation from peers. This was also in varying degrees. Though Sepatu regarded teachers' teaching methodology and materials as being important for interesting lessons, he saw that it was his responsibility to ask questions and be active in class.

Similarly, Confidence Hero's locus of control could be categorized along a range from internal to external. Despite emphasising his own roles in improving his spoken skills, his teacher's teaching methodology and class interactions had a major influence in his learning.

Better performances for Rae, Sepatu and Stanza, who reported more internal locus of control, could also be due to the effort they took to learn outside of the classroom. Locus of control influenced participants' views of the teachers; participants with internal locus of control regarded themselves as the initiators of their own learning. They took the initiative to learn more from other sources, and employed strategies such as seeking help to improve understanding.

Unblocker, who demonstrated more external locus of control, focused more on learning within the classroom settings. He saw that it was the teacher's responsibility to transmit knowledge and ensure students' understanding. He saw the lack of opportunity to use English language as a barrier to competency. Bown's (2006) study shows that language learners who perceive the process of learning as external to them may be less willing to engage in self-regulation. 


\section{Self-efficacy}

Rae, Stanza and Sepatu had a high level of self-efficacy in improving their language proficiency, as they believed that they would be able to achieve their goal through their own efforts. They reported that they would persist more whenever they realised that they were having problems with their English assignments. Compared to other learners, they used more language learning strategies to make their language learning more effective.

Social cognitive theorists propose that students' self-efficacy is the underlying premise to self-regulated learning (Zimmerman, 2000b). In other words, it is the key personal factor affecting self-regulated learning. According to social cognitive theory (Bandura, 1997; Schunk, 1989), people's feelings of self-efficacy affect several aspects of their behaviour, including their choice of activities, their effort and persistence, and ultimately, their learning and achievement. Students who believed they were capable of performing tasks used more learning strategies and persisted longer at those tasks than those who did not (Zimmerman \& Martinez-Pons, 1990).

Social cognitive theory highlights efficacy beliefs as the foundation of human agency (Bandura, 2001). Bandura (1993) states that strong personal efficacy beliefs enhance motivation and performance. Conversely, low efficacy beliefs are characterized by low aspiration and weak commitment to goals. Unblocker displayed a lack of belief in his ability which resulting in low effort, performance and achievement. He had set his mind against English and pursued other subjects. He believed that he might not be able to achieve good results, and only aimed to just pass the language course. This showed his low self-efficacy about his ability to improve his language proficiency. This might be due to his mediocre past results despite the long process of learning English. Self-efficacy is a student's judgement of their capabilities to accomplish a task in a specific situation and has been linked to a number of positive performance and achievement outcomes (Bandura, 1986). When a learner has low self-efficacy, it is less likely that the learner will engage in behaviours necessary to meet the goal (Bandura, 1986). 
Bandura (1986) states that a student may not put in effort if he or she views a model as more able than him or herself. Unblocker lamented that he might not be able to do as well as his friends, who were more proficient in English. He felt that they had a better grasp of grammatical skills and more confidence to communicate in English. Bandura (1997), Schunk (1984), and Zimmerman (2000b) reviewed extensive research indicating that students' self-efficacy measures were related to their choice of tasks, persistence, effort expenditure, and skills acquisition. Compared to other participants, Unblocker preferred to solve his language problems on his own without seeking help from others. An example was using the dictionary. He reported that he lacked information literacy skills as he was not sure how to search for materials at the library. Despite being aware of all of these inadequacies, he was reluctant to seek help from others. Alternatively, his awareness of his own inadequacies inhibited him from seeking help from others as he did not want to expose them.

He did not practise English with his peers, and thus he had less opportunity for feedback or self-evaluation of his English skills, which may contribute to his lack of self-efficacy (Schunk, 2001). On the contrary, other participants like Rae, Sepatu, Stanza and Confidence Hero were more willing to get help from those around them. They regarded their more able peers as their models. Observing models according to Pajares, Johnson and Usher (2007), can positively influence students' self-efficacy. Their comparatively high self-efficacy may be the result of their frequent opportunities to speak English with their peers and the international students at the university. Stanza's confidence in her oral ability could be due to her experience studying at her previous university where English was used as the medium of instruction, and also her persistence in using English with others. The success she had like being able to convey her message and taking part in numerous discussions and presentations in English at her previous university increased her self-efficacy. Pajares, and colleagues (2007, p. 106) state that "... [students] interpret the results of their effort, use the interpretations to develop beliefs about their capability to engage in subsequent tasks, and act in concert with the beliefs created". Stanza's efforts were interpreted as successful and this raised her self-efficacy.

Another interesting finding in this study was the male ESL learners, Sepatu and 
Confidence Hero, reported high self-efficacy in their English language proficiency, particularly in their speaking ability. Sepatu and Confidence Hero's self-efficacy in their oral skills could be due to their frequent use of English in daily conversation. Sepatu's involvement in the student-exchange programme to the United Kingdom could also bolster his self-efficacy.

The findings showed that the participants' self-efficacy was task-specific. For example, Unblocker felt efficacious about completing tasks related to reading, as he had high self-efficacy in this area. When reading texts, the spelling and context made guessing the meaning of words much easier. However, he felt less efficacious in his oral ability. This might be due to the emphasis on reading skills over other aspects in his past language learning. He was also not confident in his writing because of his limited vocabulary. This was consistent with findings in other studies (Wang, 2004; Wong, 2005) that self-efficacy is task specific.

Findings in this study showed that the participants who consistently used SRL strategies had high self-efficacy and believed that their effort would lead to success. This fits with social cognitive models of SRL, which suggest that an individual's SRL behaviours in all phases of the learning process depend largely on one's self-efficacy beliefs (Zimmerman, 2000b). Wang's (2004) study of school children's self-efficacy beliefs and their use of self-regulated learning (SRL) strategies in the process of learning English as a second language showed that the children's self-efficacy influenced their use of language learning strategies. The participants in his study were more persistent when they felt efficacious about accomplishing the learning task, whereas they were likely to withdraw or give up when they felt less so.

\section{Attribution}

The participants in this study who showed high self-regulation - Rae, Sepatu, and Stanza - attributed effort as being key to their success. Attribution theory considers a person's beliefs about causes of outcomes and how those beliefs influence expectations and behaviour (Alderman, 2008). Hidi and Harackiewicz (2000) stated that there are two explanations for unsatisfactory academic performance of student. They are effort and ability. Ability and effort have been found to be the most frequent reasons given for success and failure in 
achievement contexts (Weiner, 1992).

Sepatu attributed his previous mediocre English marks to his lack of effort when he was in secondary school. However, he emphasised that at university he was more persistent and put more effort into his language learning, and he attributed his progress and achievement to the effort put in. Sepatu, whom the language instructor viewed as the most hardworking, attributed effort as the primary reason for his success. He was convinced that his strategies of time management and planning prevented him from procrastinating and contributed to his success in doing his best for the course assessments. The findings from Sepatu's case align with previous research that found effort attributions relate to a positive motivational style, higher success expectations, lower level of helplessness, and ongoing improvement in performance (Linnenbrink \& Pintrich, 2002; Liu, Cheng, Chen, \& Wu, 2009; McClure et al., 2011).

On the other hand, Unblocker was convinced that ability was the primary element for achieving success and a lack of ability was the main reason for his failure to achieve English language proficiency. Alderman (2008) points out that the attribution a student makes for failure acts as a bridge between a student's willingness to try again and the student's tendency to give up. Unblocker's past history of failure in language learning may have made him believe that he would not be able to improve his language proficiency.

\section{Environmental influences}

Besides the motivational influences, the findings showed that there were environmental influences on the participants' self-regulation in language learning. The environmental influences were opportunities to use English in the university social environment, teacher-related factors that affected engagement in language learning, and the language course.

\section{The university environment}

The status of English in comparison to the national language and the connection between languages and the ethnic identity of the participants in a multicultural country influenced the opportunities that the participants had to use English in the environment of this university. The lack of opportunities to use English to 
communicate orally emerged as the main issue in this study. Ares and Unblocker only used English with non-Malays, as Malays faced resistance from their ethnic peers when they tried to communicate in English. The fear of being laughed at by his Malay friends and communication breakdown made Unblocker avoid using English. The negative response from some Malays towards the use of English could be due to the fact that despite the official status of English in Malaysia, the quality of the English language spoken by Malays is often relatively poor, and often poorer than among Malaysian Chinese and Indians. Malays feel more comfortable using their mother tongue, which is the official medium of communication and instruction in Malaysia. Thus, they do not find it necessary to acquire another language. "Although English is officially a second language, to most of them (the Malays) it just means that it is compulsory as a subject, and it is not something that one should acquire as an added asset" (Asmah, 1992, p. 17). Low proficiency may also be a barrier for Malay friends of the participants in this study refusing to communicate in English. Lee (2003) reported that there still exists resentment towards use of English within interpersonal contexts, particularly among Malays who are not proficient in English. The resistance that Unblocker and Ares faced towards the use of English in daily communication among some Malay students might also be due to the status that Malay students give their mother tongue language, since they strongly identify with it as ethnic Malays (Renganathan, 2005; Tamam, 2011).

Tamam (2011, p. 134) pointed out that race remains an important dimension of identity in Malaysia, despite governmental policies and efforts to "promote national integration via common identification by super-ordinate identity and language use". Wodak, de Cillia, Reisigl, and Liebhart (2000) and Norton (1997) contend that a person's language is an important part of his or her identity and learning a language always takes place within a cultural and political context. However, none of the participants in this study reported learning and mastering English language as a threat to their ethnic identity. This contradicts Abdullah \& Eng's (2011) study, where Malay ESL learners felt strongly that English was a threat to their ethnic and national identity. Sepatu and Stanza even emphasized that they did not feel less Malay when they were communicating in English. They thought that learning a second language did not mean disregarding their first 
language. Rather, it involved adding a new language to one's repertoire.

While Mohd Adnan's (2005) study reported that Malay students did not use as much English as they were asked to because of negative attitudes towards English, the people who use it and the culture connected to the language, the participants in this study reported a preference for English songs and movies compared to Malay ones. A lack of English use by Unblocker was not caused by negative attitude towards English, but was more influenced by peer pressure and his lack of competence and self-efficacy. In a collectivist society like Malaysia, others like peers influence one's behaviour. Tan's (2005) findings showed that compared to Chinese learners, Malay adult learners tend to submit more to pressure from others and this influences how they perceive the importance of learning and motivation in learning. The fear of embarrassing oneself by making mistakes stops some language learners from using the target language (Liu, 2005). However, Confidence Hero collaborated with peers who share a similar goal to be better in their oral English, and as a result he did not seem to experience this embarrassment.

Confidence Hero recommended mixing with like-minded peers to improve language proficiency as peer relationships are significant influences on behaviour (Schunk, et al., 2008). He did not fear being judged for his ability to use English within this safe environment. The positive attitude, competition, and encouragement by his close friends and classmates had provided to be a supportive learning environment to self-regulate his learning. The abilities of good language learners are not only due to their individual differences but also to the possibilities their various communities offer to them (Norton \& Toohey, 2001). Goodenow (1992) argued that peer influence plays a major role in the extent to which the peer group values or devalues academic effort and achievement. Peers may influence each other to work hard and achieve or not (Berndt \& Keefe, 1992).

Successful language learners try to use the language at every opportunity available, practise what they have learnt as soon as possible, and use friends to get feedback (Embi \& Mohd Amin, 2010). Stanza believed that the strategy of talking to someone else helped her to better remember and understand the new 
information she learnt, and helped her to clarify her own doubts through discussion. Rather than avoiding the subject, if they did not know the correct word or phrase for what they wanted to get across, Rae, Sepatu and Stanza were willing to try out different ways to communicate such as using gestures, rephrasing and even drawing.

Rubin $(1975$, p. 43) stressed that the good language learner seems to have a "high motivation to communicate, no matter where he is". Good language learners also show an awareness of language for different audience and purposes. Rae, Sepatu, Stanza and Confidence Hero saw language learning as a tool for communication rather than just classroom exercises.

\section{Teacher factors}

All of the participants mentioned the significant role played by language teachers in supporting students to self-regulate their language learning. The participants felt that language teachers could influence students' self-regulation through engaging teaching methodology and positive student-teacher interactions.

\section{Engaging teaching methodology}

The participants emphasised the need for language teachers to create conducive and stimulating classroom environments to make learning English more fun and relevant.

Rae and Sepatu spoke about their dissatisfaction with the teaching and learning activities. They expected more interesting and varied activities to avoid student boredom. Rae and Sepatu said that language teachers at the tertiary level should be creative in planning for class activities. Littlewood (2000, p. 33) points out that:

... if Asian students do indeed adopt the passive classroom attitudes that are often claimed, this is more likely to be a consequence of the educational contexts that have been or are not provided for them, than of any inherent disposition of the students themselves

A variety of teaching and learning tasks can foster more interest in learning and a mastery achievement goal in students (Matos, et al., 2009). 
Besides the need for a variety of teaching and learning activities, Ares and Unblocker pointed out that the teacher's planning and time management for inclass assessments were important. For the individual assessment, they did not have enough time to present properly, as it was nearly the end of the class. It affected their performance and marks as they were rushing to finish and they could not ask further questions of their friends.

The participants valued opportunities to understand assessment requirements. All of the participants found that the clear explanation of course requirements and assessments at the start of the semester really guided them to plan their language learning. They commented that from the course briefing, they knew how they were going to be evaluated. All of them, except for Rae, explained that they determined the effort they would put in for each assignment based on the allocation of marks. Confidence Hero elaborated that the information on the percentage of marks for course assignments would help students to know which one was the priority. He planned and managed each assignment based on the marks allocated. Rae, on the other hand, argued that all of the assignments were equally important to her, as she saw them as chances for her to improve her language proficiency.

The participants in this study viewed the role of teacher in planning and carrying out engaging class activities, managing assessments and clarifying the course requirements as vital in the self-regulation of their language learning.

\section{Student-teacher interactions}

Student-teacher interaction emerged as another contextual factor affecting the participants' efforts to regulate their behaviour. Social interaction between students and teachers can influence self-regulated learning (Zeidner, et al., 2000). This interaction occurs most frequently during the teaching and learning processes.

Positive teacher-learner interaction was regarded as important by all of the participants. All of them thought that their current language teacher was approachable. Unblocker and Ares commented that their language teacher's loud voice and effort to involve all students in the class activities helped in them focusing on their English lessons. Ares also commented that the feedback given 
by teachers, especially in public, could have either positive or negative effects on students. He pointed out that teachers should not embarrass students. He noted that praise could influence positively not only the students being praised but also other students in the class who would feel challenged and motivated to be better. Social cognitive theory highlights the influence on motivation of social comparison, where seeing other students act in a particular way and receiving praise or recognition may motivate students to act similarly (Schunk, et al., 2008). Sepatu commented that he would only feel comfortable to consult a teacher who was understanding, non-judgemental and showed empathy to the students.

Findings from this study showed the ESL learners preferred an encouraging classroom environment where they would not be worried about public humiliation if they gave a wrong answer. A positive classroom climate is beneficial for language learning, particularly in classrooms where student participation in communicative tasks is required (Senior, 2009). Confidence Hero reported he felt confident about talking in his class. His teacher discouraged actions that prevented students from using English and encouraged them to put in lots of effort.

He perceived that his teacher valued the role of effort and believed that her students could be better. She encouraged them to take risks with their learning and to try using English. When he had a problem understanding a lesson, his teacher or a fellow student would provide another way of explaining it.

All of the participants in this study reported that they had the freedom to choose any topic of their interest for their individual information sharing assignment and also for the group project. They were allowed to decide the group members in their group project. They had the freedom to decide on the mode of their final group presentation. In encouraging creativity, the learners were told during the course briefing that higher marks would be awarded for interesting, wellplanned and well-presented group project presentation. They felt that learning English at university was more interesting as they were allowed to make their own decisions in course assessments. Boekaerts (2005) and Boekaerts (1997) address the role of the teacher in fostering self-regulation and argue that for self- 
regulated learning to develop, teachers must provide chances for students to make decisions about their learning.

Teachers who give more autonomy to students, provide opportunities to the students to have more responsibility for their own learning (Deci \& Ryan, 2002). According to Ryan and Deci (2000), teachers who valued students' autonomy are more likely to promote confidence and intrinsic motivation in learning on the part of their students. McCombs (1989) believed that teachers who give autonomy to students by practising student-centred learning may be providing more opportunity for students to learn actively and independently or becoming self-regulated learners. Teachers can enhance students' opportunities to become self-regulated learners by allowing them to choose tasks, strategies, and manage time for learning (Boekaerts, 1997). The participants in this study reported that the freedom and flexibility allowed by their language teacher in the selection of group members made the group task more enjoyable for them. Vansteenkiste, Zhou, Lens and Soenens (2005) maintained that people have a universal need for autonomy which, when it is supported, leads to optimal learning and increased well-being.

Feedback provided by teachers during the teaching and learning processes was an important part of the student-teacher interaction in this study. Feedback from teachers is a source of much information about ability, and helps to refine and improve students' self-regulated learning skills (Alderman, 2008). The constructive and encouraging feedback from her language teacher helped Stanza to monitor her engagement with the learning tasks, and assess her progress and performance towards her language learning goals. The findings show that by providing positive interpersonal support and appropriate feedback, the teacher can support learners' efforts to reflect constructively on their learning experience and to redirect their efforts in productive ways.

All of the participants mentioned the important role played by the language teacher in motivating students to learn English. Thang, Gobel, Mohd Nor, and Suppiah's (2011) study showed that language learners at Malaysian public universities perceive their teachers as having a tremendous impact on their learning abilities. Ares and Confidence Hero liked learning English because of a 
previous language teacher they had had. The teachers encouraged their students to use English orally regardless of the level of grammatical accuracy. This made them feel more confident about speaking English. If a teacher considers mistakes as part of the learning process and emphasizes effort, mastery goals will be fostered (Matos, et. al, 2009). Besides attributing her interest and motivation to improve to her current friendly language teacher, Stanza also acknowledged her language teacher at secondary school. This teacher's teaching methods and personality had changed Stanza's attitude from being uninterested about learning English during her primary school years to being really motivated at university. In North-East Asia language learners think teachers' friendliness is equally as important as their knowledge (Life, 2011). All of the participants thought that their current language teachers were approachable and had pleasant personalities.

\section{Course design}

Elements in the design of the course seemed to encourage the participants to use specific SRL strategies. Rae and Sepatu reported that the course briefing by their language instructors early in the semester made planning and time management easier. From the course briefing, they knew how they were going to be evaluated and that helped in planning. The briefing on the requirements for each course assessment and submission date of assignments assisted in regular selfmonitoring of progress. Rae commented that the course briefing early in the semester helped her to evaluate her work in terms of her teacher's expectation. Furthermore, Rae, Sepatu, and Stanza said that the conferencing session held by their language instructors before the final submission of the course assignment and the feedback received in this helped them to evaluate their progress and to decide on further actions to be taken to improve their work. Stanza elaborated that the constructive comments on content, language and word choice by her language instructor helped her to plan, edit her work and produce better scripts for her final group presentation and also final group report.

Compared with the teaching and learning of English at a secondary school level, which focused on preparation for examination, Rae found that the teaching and learning of English at the university was more interesting, as there were on-going class assessments like individual and group presentations. All of the participants 
in this study mentioned that the final course grade was an accumulation of ongoing marks and this made it easier for them to do well. Compared to their primary and secondary years where the marks were from one exam, the grading system for this course makes it easier for them to plan their learning. The marks of earlier assessments helped them to gauge effort to put in to coming assessments. They also found the different assessment techniques interesting even though they were challenging.

The group work also allowed for socially constructed regulation, where the participants were observed using social regulation strategies such as social reinforcing, socially shared goal oriented talk and task structuring. For example, Stanza's group project members used a social reinforcing strategy in the group work discussion. Other group members supported her decision when Stanza suggested for listing of possible project topics before making the decision for a suitable one. This is elaborated in the 'goal setting and planning' in Stanza's case description in Chapter Five. Confidence Hero's peers also showed socially constructed self-regulated learning when they communicated in English outside of the classroom. Confidence Hero's peers used the strategy of a socially shared goal to motivate each other to persist in communicating in English, as elaborated in his case description.

Stanza and Confidence Hero considered the role of the group to be important in achieving their personal goals. In collaborative work, both individual (selfregulation) and group (social regulation) interrelate (Volet, Vauras, \& Salonen, 2009). For example, group goals can have a positive effect on personal goals and group members may help a reluctant member become engaged in the learning task through encouragement (Schunk, et al., 2008). This socially shared regulation is illustrated in figure 6.1 below. Järvelä, Järvenoja, and Veermans (2008) define socially shared regulation as the processes whereby people regulate their collective activity. It also includes individual regulatory processes. The findings in this present study suggest that although prior research has found that learning is more effective through students' own initiative and strategies, group regulation also plays role in collaborative tasks. Figure 6.1 below conceptualizes the role of both individual and group regulatory processes in socially shared regulation for the success of group work. This signifies that the 
collaborative learning tasks like group work may facilitate both individuals' selfregulation and group regulation. This might lead to students putting effort into completing their socially shared group-learning task. However, as reported by Rae, this did not happen among her group members.

This implies that in Malaysia's collectivist society, cooperative or collective learning may be an alternative instructional method to give the chance for students to help one another learn academic materials or accomplish a learning goal. Self-regulated learning in this study is seen as not restricted to asocial forms of learning, but takes into account social forms of learning.

However, Rae expressed the importance of cooperation and active involvement from all the group members for the completion of group task. Student-centred work was more valued by learners and effective if all of the group members actively contributed, showed interest and were united (Garret \& Shortall, 2002). This cooperation, sense of a common goal and individual responsibility contributes to positive motivation (Schunk, et al., 2008). Rae felt frustrated, as her group members did not contribute much to their project. Conflicting personal goals and perceived unfairness resulting from imbalance in participation could contribute to negative experiences with collaborative tasks (Volet, et al., 2009).

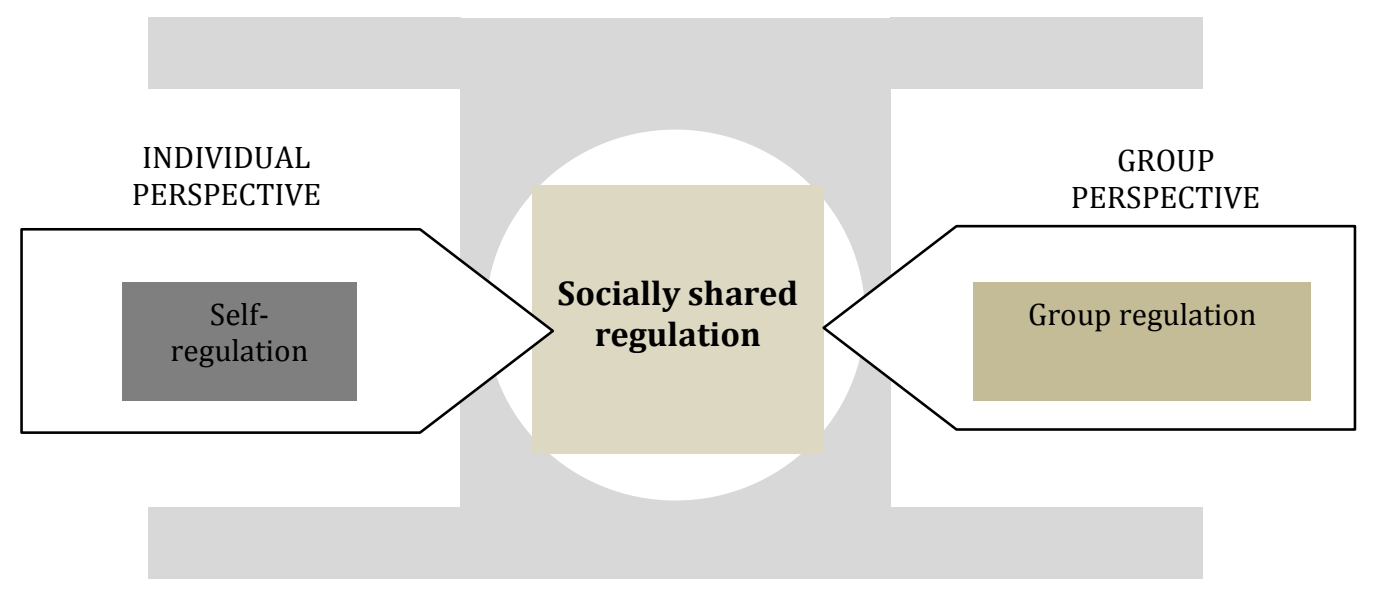

Figure 6.1: Self and group regulation in socially shared learning. Adapted from Järvelä, et al. (2008, p. 123)

Situational factors such as the relevance of course specific materials also influenced the participants' self-regulation. All of the participants in this study 
considered that it was important for language course designers and teachers to select an interesting textbook or course materials. They further indicated that the current course textbook was helpful and interesting as the reading passages were not too long and there was explicit explanation of grammatical items. They learnt language skills including reading skills like skimming, scanning, paraphrasing and summarizing.

\section{The nature of self -regulation}

The ESL learners in this study exhibited a number of self-regulatory behaviours to manage the learning process. These self-regulatory strategies were influenced by a number of motivational and environmental factors. The motivational influences on the participants' self-regulatory behaviours were the type of motivation, goal-orientation, self-efficacy, beliefs about language learning, and attributions. The environmental influences on the participants' self-regulatory behaviours were related to the opportunities to use English in the university social environment, teacher-related factors that affected engagement in language learning, and the language course.

\section{The reciprocal relationship of the interdependent factors in self-regulation}

Self-regulated learning involves reciprocal interactions between behaviours, environmental variables, and personal factors (Bandura, 1986). These three components of self-regulated learning interact with and influence each other.

Behavioural self-regulated learning strategies may increase self-efficacy (a personal factor), which is related to goal attainment and achievement. Reciprocally, self-efficacy and motivation (personal factors) may have an effect on the behavioural component of self-regulation where self-efficacious students may use more self-regulatory strategies such as goal-setting and planning, and self-evaluation. The interaction between self-efficacy (a personal factor) and environmental factors can be demonstrated when positive teacher feedback can raise self-efficacy. Another example of the influence of social and environmental factors in the students' self-regulation of their learning is when the social climate provides components (such as teacher feedback and peer support) from whom students can seek for help. Each self-regulatory behaviour can be learned from instruction and modelling by teachers and peers. Motivational processes such as 
motivation (personal factors) may be influenced by features of learning tasks, and the classroom (environmental factors). For example, when students are given choices such as in determining classroom learning activities, they might be more motivated to self-regulate their learning. Students' behaviours and classroom environments influence one another. For example, when a teacher delivers information, students direct their attention to the teaching. Students' behaviours may influence the instructional environment. When students ask questions or give incorrect answers, teachers may explain the lesson again.

The reciprocal relationship of the factors can be exemplified from the findings of Sepatu whose personal factors showed that he was self-efficacious and highly motivated. His attribution for success to effort led to behaviours related to SRL such as seeking information and structuring his learning environment. The environmental factors such as chances for language use in the university environment affected his motivation and language learning behaviours. Better chances to communicate in English with other undergraduates of different ethnicities and the internationl students made him more motivated to improve his proficiency through SRL behaviours such as goal-setting and planning. The explanation of the reciprocal relationship of the interdependent factors in selfregulation shows that when learners self-regulate, there are some external and internal interrelated processes that occur.

The findings suggest the contribution of both self and social regulation in collaborative learning tasks.

\section{Categorisation of the participants' self-regulation}

The participants in this study self-regulated their language learning to varying degrees and in different ways. Based on Che Musa, Koo Yew, and Azman's (2012) proposed framework for the theorizing of English literacy learning in Malaysian classrooms, I categorised the participants' self-regulated learning into two categories: Self-regulated as a language learner, and self-regulated as a language user in social situations. The participants' self-regulation as language users in social situations was related to their participation in meaningful communication, for example when they structured their environment by creating opportunities to use English. The participants were self-regulated as communicators where they 
also employed strategies for effective communication.

For the participants' self-regulation as language learners, their SRL behaviours were categorized as the use of learning strategies to improve their language skills, and complete the tasks in the language course when, for example, they sought information for their assignments. This is shown in Figure 6.2 below.

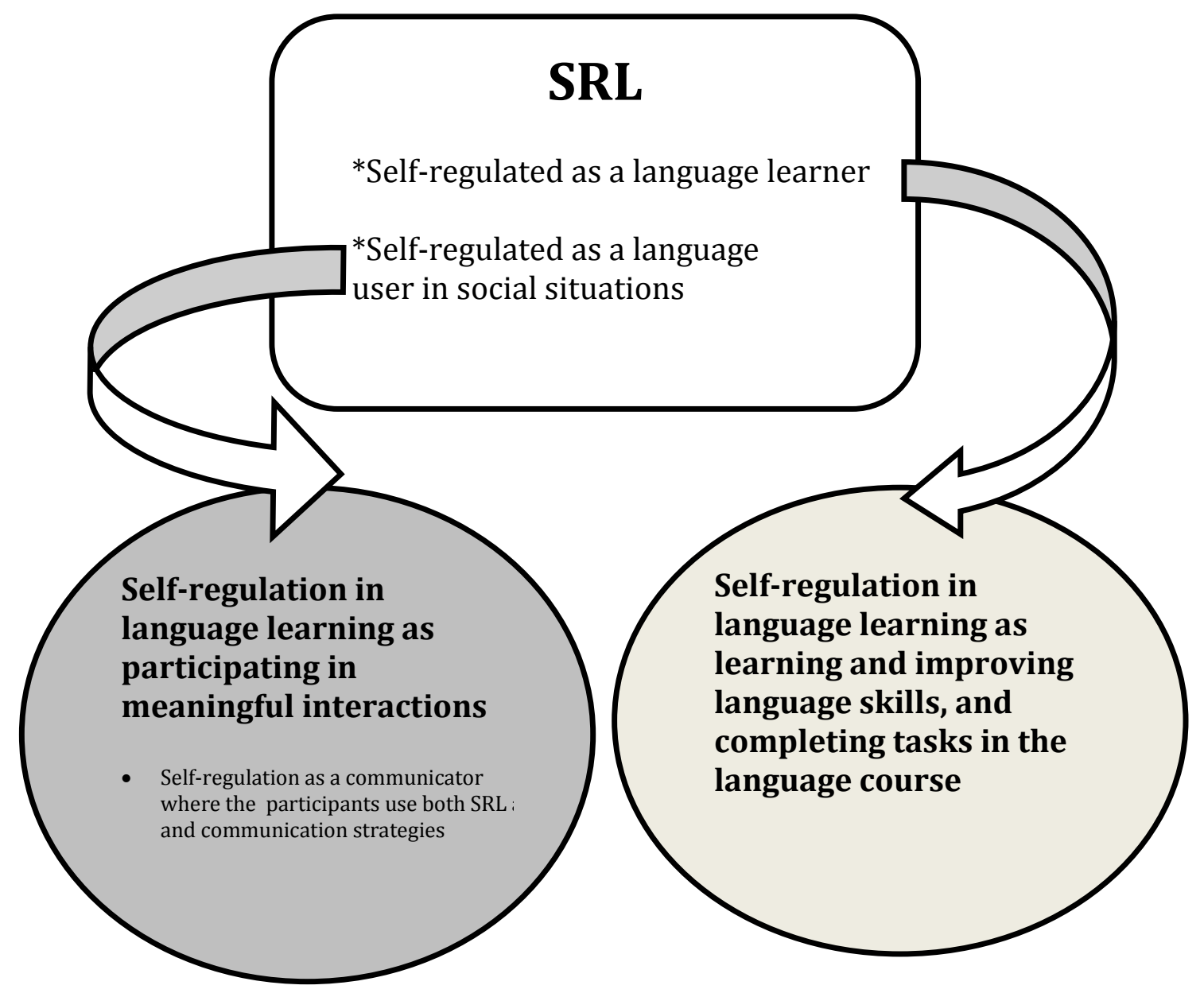

Figure 6.2: Categorisation of the participants' self-regulation. Adapted from Che Musa, et al. (2012, p. 46)

\section{Self-regulation and course grades}

The participants in this study attempted to regulate their language learning, though they did so with varying levels of success. The comparison of the case study participants' past and current achievement in language learning showed 
that characteristics of students who effectively self-regulate their learning coincide with those attributed to high performance, as opposed to those with low performance. They also coincided with one of the characteristics of successful language learners in the ground breaking study of Naiman, et al. (1978) where the successful learners showed an active task approach.

Rae, Ares and Confidence Hero had previously scored well in the national examination at the end of secondary school. Only Rae could be considered as a competent user of English (based on her MUET score - refer to Appendix A on the description and band scale of MUET). Rae received good marks for her on-going class assessments. However she missed the final exam. Thus, it affected her overall final course score. Based on their MUET result, Ares, Confidence Hero, Sepatu Chenta and Unblocker were considered as having fair command of English. In the final result of the Academic Communication 1 course, only Confidence Hero and Sepatu scored high marks. Confidence Hero scored consistent good on-going marks and Sepatu scored very well in his final paper. Comparing his previous modest results to his final result in the current course, Sepatu has shown good progress. Stanza's past result for her English language paper signified her as a limited user of English. However, she showed tremendous improvement in her final result in the course.

The cross case analysis showed that the participants who showed improvement (Sepatu and Stanza) in their results used more SRL strategies than those who had less improvement (Ares and Unblocker). Sepatu and Stanza also self-regulated their learning more effectively. Generally, the learners who showed improvement were independent learners who took ownership of their learning activities and managed them efficiently. They acted autonomously by constructing the conditions they thought necessary for their language learning. They also developed a sense of personal competence and the belief that they were responsible for their own achievements. The attributes of the good language learner - "a personal learning style, a tolerant and outgoing approach to the target language, technical know-how about how to tackle a language, willingness to use the language in real communication, and strategies for testing and revision of hypotheses about the Target Language" (Rubin, 1975, pp. 44-48) - are characteristics of the more effective self-regulated learners in this study. 


\section{Differences in SRL strategy use}

Although all the participants reported SRL behaviours, the cross case analysis highlighted that there were differences in use and effectiveness of the information seeking, assistance seeking, goal setting, planning, self-evaluating, organizing and transforming strategies employed by the participants. These differences were elaborated in this chapter. Sepatu and Stanza showed behaviours that supported the metacognitive perspective of self-regulated learners where they were capable of setting goals and planning their own learning (Zimmerman, 1986; Zimmerman, 2000a). Zimmerman and Pons (1986) reported that high-achieving students have been found to employ cognitive and metacognitive strategies more voluntarily and spontaneously to understand learning material when compared to low achieving students. Sepatu and Stanza's improvement was partly due to SRL strategies used at the university like using online learning and communication, seeking help and structuring the learning environment to maximise language use through actions like communication with international students On the other hand, Unblocker and Ares seemed not to have clear and specific goals and only changed strategies after receiving comments from their language instructor on their less than satisfying progress and performance for on-going course assessments.

Unblocker aimed just to pass even though he admitted to the importance of English for his current studies and future workplace. Ares, although he had the capability to do better, did not put much effort into taking charge of his own language learning. Both Unblocker and Ares admitted that their interest and time were directed to their core subjects also other non-academic campus activities.

There were motivational influences on the participants' self-regulation. Those who showed improvement were motivated, mastery-oriented or a combination of mastery and performance-oriented, self-regulated, and made use of effective study strategies. They believed that success depended on the effort put in, and monitored learning progress against their own performance. Learners who showed less improvement lacked motivation, adopted the goal of doing just sufficient work to pass the language course, and generally lacked self-regulation. 


\section{Chapter summary}

These findings extend research on self-regulated learning among learners of English as a second language. These findings on self-regulated learning of tertiary level learners at a Malaysian public university support the models of selfregulated learning that share some general assumptions: active participation by learners in setting goals and planning, seeking information, seeking social assistance, self-evaluating, and mediating between their beliefs, behaviours, and the environment (Zimmerman, 2001). The findings showed that a self-regulating student is an active participant in learning from the metacognitive, motivational, and behavioural point of view.

Learners who showed improvement had a strong self-regulatory repertoire that assisted them in staying focused and completing tasks (Zeidner, et al., 2000; Zimmerman, 2002b). The findings of this study extended the findings in research on self-regulated learning in language learning, where similar findings showed that students who performed were better self-regulators. In conclusion, the accurate use of cognitive and metacognitive, resource management, and managing emotion strategies to manage the language learning process and the learning environment is the hallmark of self-regulated language learning in a Malaysian tertiary level context. In collaborative work, both individual regulatory processes and group regulation are important. This may be related to Malaysia's cultural values where collective and interdependent behaviour is valued, in comparison to Western cultural values, which puts emphasis on the individual over the group. Although there is cultural diversity in Malaysian society, all Malaysian ethnic groups share some common values. One of them is being relationship oriented (Abdullah, 1996), where "mutual and reciprocal obligations are clearly understood and acted upon" (Merriam \& Mohamad, 2000, p. 49). 


\section{CHAPTER SEVEN: \\ Conclusion}

\section{Introduction}

This chapter presents a summary of the research by revisiting the research questions. There are pedagogical and research implications from this study. After presenting these contributions, I discuss the limitations of the study and recommend directions for future research. The chapter ends with my concluding statement of the research as well as the self-regulation of language learners in a Malaysian tertiary level context.

\section{Summary of the research}

Malaysia is endeavouring to enhance the English language proficiency of its graduates. Students are taught English from an early age and yet many lack the level of language proficiency required for academic English and the work place. The combination of chalk and drill methods of teaching and the emphasis on examinations has created a reliance on the teacher and reluctance among students to take responsibility for their own learning. This has highlighted a need for an in-depth study of self-regulation at tertiary level.

This research aimed to explore six Malaysian tertiary level ESL learners' selfregulatory strategies in the process of learning English. The literature review positions my study as a qualitative investigation of language learners' SRL strategies and the factors influencing them in the learning of English. To address this, three research questions were formed:

1. How do the English language learners in a Malaysian university use SRL strategies?

2. What motivational influences on SRL strategy use are reported by the participants?

3. What environmental influences on the SRL strategy use are evident among the participants? 
Qualitative case studies were used to investigate SRL strategies of Malaysian tertiary ESL learners. This study adds to existing research in the field of selfregulation by complementing studies that use self-report instruments such as questionnaires to measure students' perceived self-regulatory engagement.

Six Malaysian tertiary level ESL learners' self-regulatory strategies and the factors influencing their use of the strategies were explored. Primary data sources were interviews with the learners extending over one semester and interviews with three language instructors; course documents and assignments; and students' reflective journals. The researcher's notes on classroom observations were secondary data sources. Each participant's SRL behaviours and the personal and contextual influences were interpreted through social cognitive theory. Bandura's (1986) triadic reciprocality which sees a person's performance as a series of mutual interactions involving behavioural, environmental, and personal variables was used to analyse the data. The conclusions for the present study arose from the analysis of the individual cases and cross-case analysis.

\section{Summary of research findings}

The participants in this study exhibited a number of self-regulatory behaviours to manage the learning process. Analysis of the data indicated that the six ESL learners used SRL strategies to varying degrees, and in ways that were unique to the Academic Communication 1 language course and using English in a university context. The findings show that the participants varied in their self-regulatory competence and the use of strategies.

The cross-case analyses brought the individual factors that the cases had in common and the differences between cases to the fore. The self-regulatory strategies did not function in a void. A number of personal and contextual factors influenced the participants' choice of self-regulatory strategies. In keeping with social cognitive theory, the importance of the influence of personal factors (such as intrinsic motivation) and environmental influences (such as teacher factors) on students' self-regulated learning behaviour (such as strategy use) has been borne out in the present study. Understanding these factors is essential for language educators to assist language learners to be self-regulated in their 
language learning within a context.

Figure 7.1 below summarises the participants' motivational, environmental and SRL behaviours which have been examined by the research questions. 
Behaviour

\section{Research Question One}

SRL strategies

- Cognitive and metacognitive strategies

- Goal setting and planning

- Seeking information

- Organizing and transforming

- Practising self-evaluation

- Resource management strategies

- Structuring learning environment

- Seeking assistance

- Managing emotion strategies

- Practising positive self-talk

- Practising self-consequence

Person

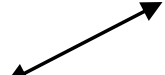

\section{Research Question Two \\ Motivational beliefs that influence the participants' SRL \\ strategy use}

- Motivation

- Goal orientation

- Beliefs about language learning

- Self-efficacy

- Attribution

\section{Research Question Three}

Environmental influences on the participants' SRL strategy use

- English use in a Malaysian university social environment

- Teacher factor that influences students' selfregulation

- Language course design

Figure 7.1: The participants' SRL strategies, and motivational and environmental influences on the SRL strategies use. 
Pintrich (2004, p. 388) states that self-regulatory activities are "mediators between personal and contextual characteristics and actual achievement or performance". That is, it is not just individuals' demographic profile or personality characteristics that influence achievement and learning directly, nor just the contextual characteristics of the classroom environment that shape achievement, but the individuals' self-regulation of their cognition, motivation, and behaviour that mediate the relations between the person, context, and eventual achievement. The personal and contextual factors can facilitate or hinder an individual's self-regulatory behaviours. This is conceptualized in figure 7.2 below.

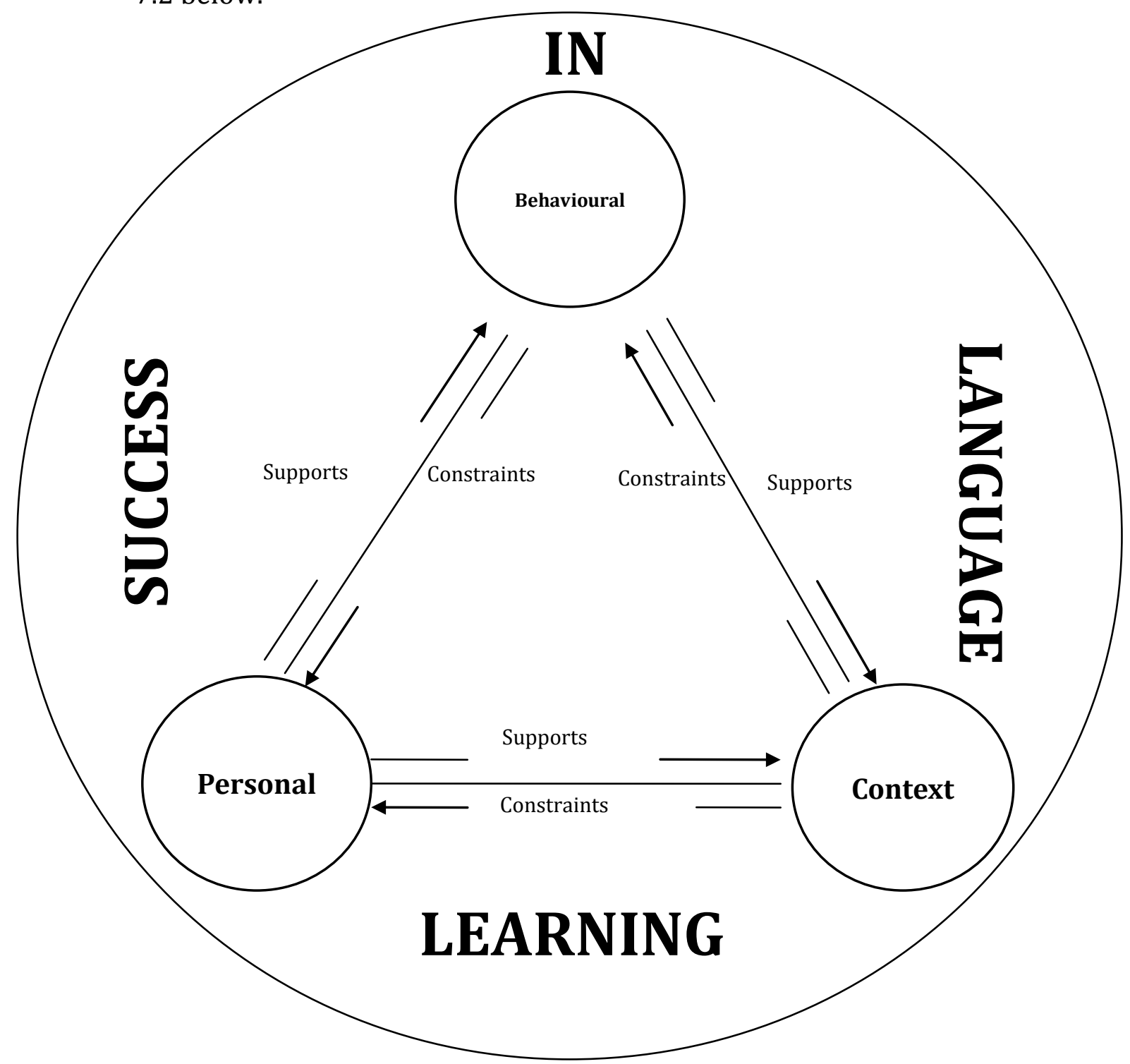

Figure 7.2: Conceptualization of self-regulation that mediate the relations between the person, context, and eventual achievement in language learning 
To overcome the social constraints experienced as learners and users of English, Rae, Stanza, Sepatu and Confidence Hero created their own opportunities to learn and use English. These are essential for the learning and acquisition of English language in the context of a public university, where English language is not widely used in daily communication. Similar to learners in the Individualized Instruction in Bown's (2009) study, to compensate for the lack of opportunities for oral practice in English, the more successful learners in this study created acquisition-rich experiences for themselves. The SRL strategy of structuring the learning environment mediates their motivation (personal factor), opportunities to use English (context) and the achievement (improvement in oral proficiency). Peers who share a similar goal of improving their oral abilities facilitated Rae's and Confidence Hero's SRL behaviour. This research indicates that achievement in language learning, like other forms of academic achievement, depends on expertise in self-regulatory processes, and motivational beliefs and environmental factors. This investigation of a language learning experience aligns with social-cognitive theory which is based on the principle that people are not entirely self-directed, nor do environmental forces primarily control them; rather there is a reciprocal relationship between person, environment and behaviour (Bandura, 1986).

In line with social cognitive theory, the findings show that all the participants attempt to self-regulate their language learning in some way. What differentiates the effective forms of self-regulation from the less effective ones is the quality and quantity of each participant's self-regulatory processes. For example, the learning goals of Sepatu, a highly self-regulated learner, are organized hierarchically, where the process goals function as proximal regulators of distal goals.

From this research, these students' ability to self-regulate their language learning may contribute positively to their final English course grades. Thus, the findings suggest that self-regulated learning is applicable to Malaysian language learners in a tertiary institution and may be positively associated with achievement in language learning. 
These six students' self-regulation appeared to be influenced by their primary and secondary educational experiences, which emphasised effort to obtain good grades in the national examinations. For the more effective self-regulated students, Rae, Stanza and Sepatu, their belief in effort bringing success may have been a more significant predictor of their success than self-efficacy as suggested in the social cognitive theory (Bandura, 2001). This attribution of effort leading to success may have developed self-efficacy, as they believed that they could do something about their learning rather than just attributing success to ability, which cannot be changed.

Ares, on the other hand, although he reported a high degree of self-efficacy to achieve a good grade, did not score well as he did not put effort in his language learning. The finding that effort is a more significant predictor of success in this study supports Paris, et al.'s (2001) suggestion that the educational contexts and social norms in a culture denote which aspects of self-regulated learning are important for students. In the Malaysian exam-oriented educational context, effort is valued for academic achievement. In many Asian countries, students are encouraged to persevere for academic success. In contrast, in a Western context, the belief is that students who have high ability will succeed, and that effort is a less important determinant (Salili, et al., 2001). Highly competitive access to tertiary education and highly structured tertiary curriculum may contribute to a greater emphasis on persistence and effort in tertiary education in Asian countries, including Malaysia (Komarraju, Karau, \& Ramayah, 2007). The values of obligation to family to do well academically in Malaysia's collectivistic culture may also influence students' effort (Komarraju, et al., 2007). This was shown in this study by Stanza, who emphasised improving language proficiency for better job prospects in order to bring higher status to her family. However, the findings also show that self-efficacy does have relevance in the participants' selfregulation, as shown by Rae, Stanza and Sepatu. They had high level of selfefficacy in improving their language proficiency, and they believed that they would be able to achieve their goal through their own efforts. Thus for them, high self-efficacy may have aided their language learning success. It may be concluded that both effort and self-efficacy are relevant in attaining success in Malaysian context. This is conceptualized in Figure 7.3 below. 


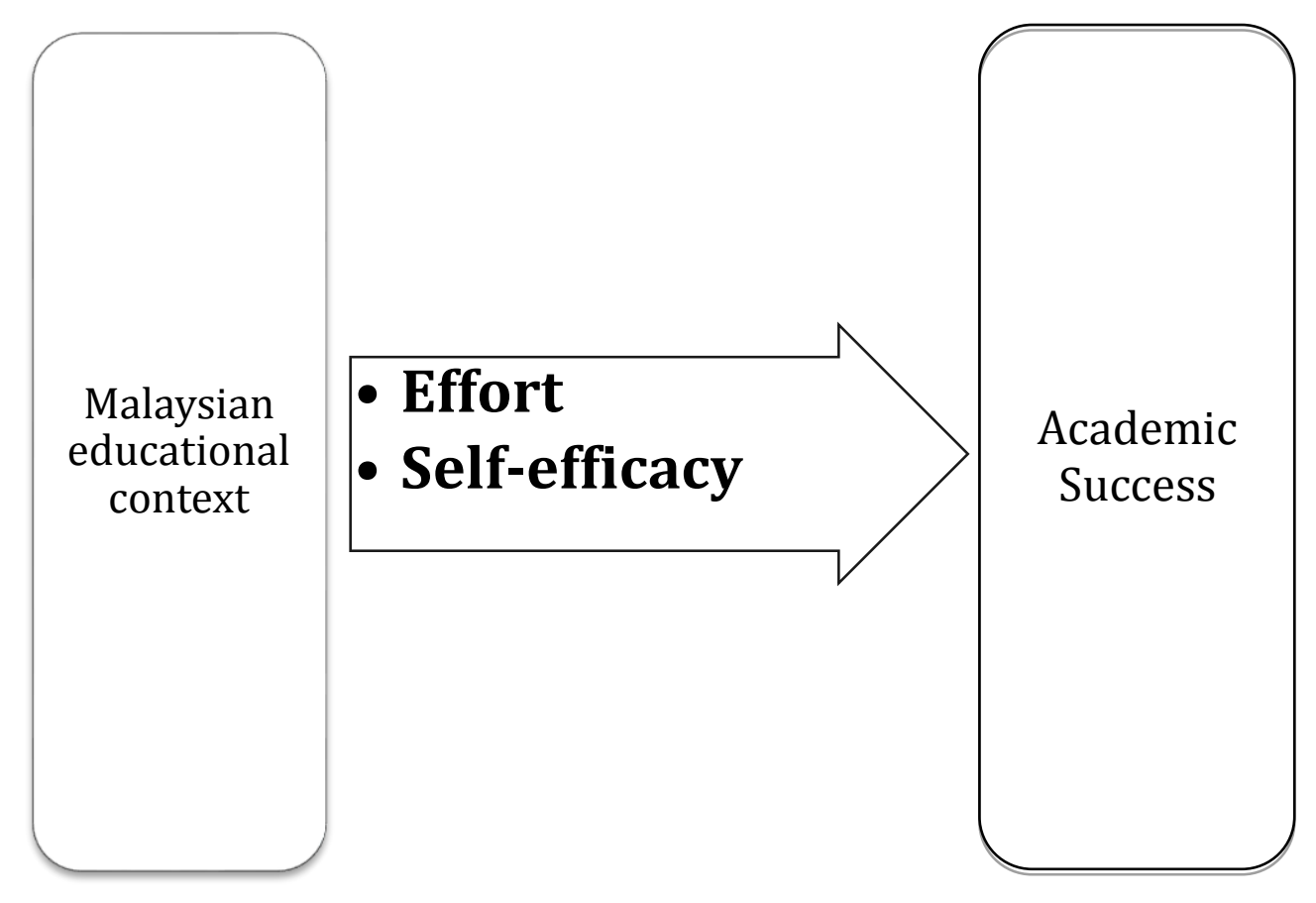

Figure 7.3: Contribution of both effort and self-efficacy in academic success in Malaysian educational context

This study extends the literature on cross-cultural perspectives of self-regulation in various educational contexts. Even though a considerable amount of literature has been published on the positive significance of self-regulation in learning, much of the research focused on general academic achievement and little is known about how ESL learners self-regulate their language learning. The findings in this study emphasise the importance of social support. The participants' efforts to regulate their learning were supported by the teachers and peers. These findings call attention to the significance of positive student-teacher interactions in promoting self-regulation. This implies a need for language teachers to plan and organize classes in a way that facilitates learners to develop self-regulation. Teachers can help learners to reflect on and evaluate their learning experience and progress.

The findings provide evidence for self-regulation in cooperation with others. The findings also suggest that approaches to learning that consider both collective and individual initiative are important for self-regulation of language learning in a collectivist Malaysian context. However, collaborative work may not succeed if 
there is no individual accountability where each group member puts forth his or her best effort (Schunk, et al., 2008).

These conclusions have important implications in the fields of self-regulation study, social cognitive theory and tertiary level ESL classroom teaching. The discussion of the implications in each of these fields follows.

\section{Contributions to the self-regulation field}

This thesis provides an insight into self-regulation for language learners in the context of tertiary study in one university in Malaysia. This insight contributes to addressing the problem of low levels of English proficiency among many Malaysian university students by highlighting the nature of self-regulation. Relatively, there are few studies of self-regulation in Malaysian tertiary contexts, and even fewer in Malaysian tertiary language learning contexts. Thus, this study contributes to knowledge and understanding of self-regulation in Malaysian tertiary language learning contexts.

This study adds to the emerging use of qualitative methods to investigate selfregulation. In the Malaysian context, most self-regulation research has been conducted using a quantitative design. This study contributed to the field of selfregulation by focusing on the process rather than the product of the participants' learning. The use of a qualitative research design in this study provides insights into the participants' learning process and self-regulation in real-life contexts over a semester. The duration of the case study over the whole semester of the Academic Communication 1 Course gave me the opportunities to investigate the participants' SRL behaviours in a series of learning situations.

Methodologically this study makes a contribution to the self-regulation literature by demonstrating the feasibility and usefulness of using Bandura's (1986) theory of reciprocal causation within a qualitative case study design as a framework to structure the research design, and as an analytical lens. This provided a sound basis for consideration of the findings within what is a largely quantitatively grounded research literature. The case studies illustrate the diverse ways in which the interdependence between the person, their environment and behaviour play out. 
This study provides insights into the ways in which the cultural context including prior educational experiences influences current self-regulation. Motivational and contextual factors influenced the participants' use of self-regulatory strategies.

These provide a basis for identifying potential for pedagogical interventions to foster students' ability to take responsibility for their own learning.

\section{Pedagogical implications}

Results of the current study provide some instructional implications to help ESL learners at the tertiary level to regulate their language learning. These instructional implications may help language learners develop the knowledge and skills necessary to become independent and self-regulated language learners.

\section{SRL intervention}

An implication of this study is the role of teachers in scaffolding the implementation of self-regulatory practices. For instance, the teacher needs to promote, model and practise a range of possible strategies students can practise in order to become self-regulated learners. A simple example is one related to seeking information strategies such as using a dictionary effectively, which most of the case study participants did not know how to do.

Ley and Young (2001) suggested four main principles for embedding SRL support in instruction to facilitate regulation in less expert learners. For effective self-regulated learning support, teachers would have to guide learners to prepare and structure an effective learning environment, organize instruction and activities to facilitate cognitive and metacognitive processes, use instructional goals and feedback to present student monitoring opportunities, provide learners with continuous evaluation information and occasions to self-evaluate. Relating these to the findings in this study, language teachers may encourage students to maximize language input and use, set goals and plan for their language learning, and provide effective feedback on students' progress. 


\section{ESL learners' self-efficacy strengthening}

The findings of this study showed that the lack of English used by one of the learners, Unblocker, was not caused by the perception that English was a threat to ethnic identity and negative attitudes towards learning English, but was due to lack of self-efficacy.

A positive classroom environment can enhance students' sense of competence that they will be able to do their work and achieve well. Thus, language teachers could help learners who have low self-efficacy. Teachers can facilitate socially shared learning by building social supports within classrooms such as creating opportunities for collaboration among students on tasks like pair and project group work or discussion.

\section{Motivating the learners}

The role of the language teacher is important in motivating students in a university context in Malaysia. In an effort to make the language learning experience as successful as possible, language practitioners at universities should find ways to empower students to take responsibility and to manage their own learning (Lee, 2002). This will produce more successful language learners who have acquired the skills necessary to enhance learning and to develop autonomy and a sense of personal agency (Embi \& Mohd Amin, 2010). However, before the learners take responsibility for their language learning, they must have the motivation to improve their English proficiency and feel that learning English is relevant in their lives

It is necessary to consider the socio-psychological factors in motivating ESL learners. Methods and techniques recommended in books on second language teaching and learning will not work if the stigma associated with the use of English, as faced by Unblocker in this study, is not resolved. Thus, language teachers play an important role in motivating the students to acquire and use the language given that for the majority of the students, the English class is the only place where they can use the language. For certain contexts, English language environment and input is limited and non-conducive to learning and acquisition. In the study, the strategy used by one of the language instructors who 
reprimanded other students who laughed at their friends' mistakes was an effective one. This created a non-threatening environment on English use in the class.

The importance of oral communication skills in mastering a second language is emphasized by Ellis (1985) when he points out that second and foreign language acquisition involves the ability to use the sound and grammar systems to communicate meaning. An important implication from this study is instruction needs to ensure that learners focus predominantly on meaning and language instructors should highlight communication strategies in teaching. In teaching communication strategies, language teachers should raise students' awareness of communication strategies, to foster acquisition in oral communication. Communication strategies are not new to students; in fact most of them probably use the strategies frequently, as reported by Sepatu and Stanza in this study, where they simplified, used shorter phrases, or paraphrased in conveying their message. They kept the original communicative goal and attempted to compensate for insufficient means to achieve it. Some of the strategies reported by Sepatu and Stanza were approximation, paraphrase, use of L1, asking for assistance and mime.

Another interesting finding from this study relates to teacher feedback. In many English classes at the tertiary level, students must do oral presentations. Teachers could videotape the presentations and when giving feedback to the students on their presentations, the teacher could show the video and highlight the communication strategies that the students have employed while delivering their presentations. Then the teacher could ask the student or the rest of the class to find other examples of the use of this particular strategy and discuss its effectiveness. This may make the students aware of possible strategies to use to improve their communicative ability.

Another technique to motivate the students is the use of goal setting. Teachers can assist students to set proximal goals by designing a language learning contract with them that specifies a series of sub-goals that progress to greater distal goals. Then, teachers can provide feedback on performance that increases students' self-efficacy for attaining the goals. 


\section{Attribution retraining}

In this study, Confidence Hero's teacher encouraged her students to perform their best in her class. This resulted in effort put in by his classmates to achieve competence. If language teachers are conscious of the attributional messages they send their students, then they can effect attributional changes in their students and in this way bring about successful learning (Thang, et al, 2011). Dornyei (2001) states that teachers can encourage internal attributions and downplay external ones and that by emphasizing the link between effort and outcomes, they will have a positive impact on students' perceptions that attributions towards success can indeed be controlled. Teachers can exploit this to promote learning by focusing on effort as the factor critical for success as done by Confidence Hero's teacher in this study.

Alderman (2008) suggests that knowledge of how students use attributions to account for success and failure can help teachers predict students' expectations and plan intervention strategies when needed. The findings in my study concur with Alderman's suggestion that students' attribution information can be obtained through the use of learning logs, in which students keep records and write about their goals, successes, and failures. The key strategies for teacher intervention are to focus the students' attributions on (a) unstable, controllable factors of effort and strategy use, and (b) ability as knowledge or skills that can be learned.

\section{Library orientation programme}

The learners need library user education or library orientation programs as reported by Unblocker, who was not confident searching for materials at the university library. He found he still had problems with how to use the library catalogue and search for books. Research found that knowledge of library services and usage affected academic achievement among students (Rosch, 2003). There are courses on searching for information organized for students at the university library. At the beginning of each new academic year, all first year students are taken round the library and the intricacies of author/title and subject card catalogues are briefly explained to them. The undergraduates are also introduced to the online public access catalogue (OPAC). However, as they are not compulsory, some students like Unblocker did not take them seriously, 
even although they were important. Chan (2003, p. 330) highlighted the reasons for the poor attendance and impact of library user education at a Malaysian public university: the programmes "were not accorded any official status and thus did not receive the support of students or academic staff"; they were short in duration, and thus they were ineffective; and they lacked chances for hands-on experience for the undergraduates, therefore resulting in no formal assessment of programme effectiveness. Another factor of the lack of success of such a programme was the undergraduates had no or very limited experience and exposure to library use and resource-based learning during their primary and secondary years. Thus, when they entered the university, they did not see the benefit of a library user education programme.

Efforts to improve students' library skills could change the concept of teacher talk and writing on the board towards a more self-instructional learning concept through reading a wide range of both paper based and electronic materials in libraries (Adikata \& Anwar, 2006). The group project and information sharing assessments in the participants' language course in the current study may facilitate the effort to improve their library skills. For the assessments, they had to get materials from different sources, including materials from the library such as magazines, books and journals.

\section{Limitations of the study}

The study was aimed at providing an understanding of the extent of selfregulation among ESL learners at a Malaysian public university. This research was not designed to be generalised among undergraduates at Malaysian public universities. There are public universities in Malaysia where English is the medium of instruction and communication on campus. Thus, the students there may have more exposure to and use of English. The findings may be applicable to other undergraduates taking similar language courses. The participants for this study were from one public university in the middle region of Peninsular Malaysia. A number of limitations need to be noted. While this case study provided a detailed examination of the students' perspective on their selfregulation, it was only for the process of completing the tasks in the Academic Communication 1 Course. Much of the data were self-reported. There were also 
effects of the study itself on the learners' self-regulation. These effects were elaborated in the Researcher's role section in the methodology chapter.

Moreover, as the study was grounded in the interpretive approach, total objectivity and neutrality in the data analysis process cannot be claimed. My own understanding and definition of learning English language will have influenced how I approached the participants' value-laden data to some extent. I acknowledged my own subjectivity, which I endeavoured to manage by respecting the worlds and sensitivities of the participants in the research context (Denzin \& Lincoln, 2005).

This study did not explore whether there are differences in self-regulation in the three major ethnic groups in Malaysia, the Malays, Chinese, and Indians. Although there are certain Asian values shared by the three ethnic groups, each group still retains its own cultural identity and values.

\section{Implications for future research}

Much recent research on self-regulated learning has been directed at developing and improving self-regulated learning (Arsal, 2010). In order to carry out effective interventions to promote self-regulated learning, factors that are related to it must be taken into consideration. Thus, more exploratory qualitative study should be carried out in various contexts. For the effectiveness of teaching and learning of English for tertiary level learners, this study could be replicated with ESL students attending Malaysian private universities or other public universities where English is used as the medium of instruction and communication. For such universities, there are also higher chances for English language use in daily communication, as the number of international students is higher and English is widely used as medium of communication by university administrators and staff. In a context where enabling factors for language learning and use exist, the findings might be different. The findings from these studies could then provide justifications for educational changes and improvement in the teaching and learning of English at the tertiary level.

A similar study following the students through their different language courses may be conducted. In a similar vein, doing a study which compared the learners' 
self-regulation in a language class with that in the university courses for which they were required to use English may be beneficial.

Further studies to investigate whether there are differences in self-regulation in the three major ethnic groups in Malaysia may provide valuable insights into cross-cultural differences in self-regulation in language learning. Further studies on gender differences in self-regulation may also be conducted.

The findings in this study underscore the importance of student-teacher interactions in fostering self-regulation. Further research on classroom practices like the influence of teacher and student interaction in self-regulated learning could also be conducted. In relation to the influence of teacher and student interaction in learners' self-regulation, Archer's study (2001) indicated that university lecturers could generate interest in the subject matter by bringing it to life with personal anecdotes, and involving students in discussions about it. As most research on situational interest has focused on texts, more work needs to be done on the way in which interest is generated in social situations. Further exploratory studies to investigate the interactions that might assist or hinder the development of learners' self-regulation may be carried out.

Research has shown that language learners can be taught how to enhance their language learning through undergoing strategy training or learning-to-learn programme (Chularut \& DeBacker, 2004; Hawthorne, 2008; Lee, 2002). However, not much work has been done on the development of self-regulation strategy instruction, especially in the teaching of English language. An exception is Hawthorne (2008), who investigated the effect of a self-regulation strategy training programme on the engagement and writing performance of reluctant writers in secondary school English, and Lee (2002) who found that strategy and self-regulation instruction has equipped students with the knowledge on how to plan and revise their essays. Most of the strategy instruction intervention focused on writing skills, thus further research on strategy intervention could look into the development of an intervention model and also effects of strategy training to assist students to improve other language skills like listening, speaking, and reading. Studies looking at the effectiveness of an intervention programme on self-efficacy and attribution may also be conducted. 


\section{Concluding statement}

This study has presented a contextualized view of self-regulation and has afforded voice to learners. The data collected in this study, primarily grounded in the stories of the learners themselves, provides evidence of the ways in which the processes of language learning and self-regulation are linked with social relationships such as peers or the need for teacher affirmation. It contributes to research that endeavours to consider the roles of the individual and social contexts in the regulation of learning. Self-regulation in language learning in this study is not only seen as individual capability but an interdependent process of personal, behavioural, and environmental events. This concurs with Bandura's (1986) triadic view of self-regulation. It contributes to research that endeavours to consider roles of individual and social context in the regulation of learning. Taken together, the importance of strategy use to self-regulated learning and language learning achievement has been underscored in the present study. The role of the educational context in influencing self-regulated learning has also been evidenced. The findings show that all learners use self-regulatory strategies in some ways, but there are differences in the effectiveness of the strategies and the motivational beliefs among learners. The findings also show that selfregulation is not an innate ability. It changes and can be improved. One implication for educational practices arising out of these findings suggests that, in order to optimise language learners' achievement, language teachers play a significant role in teaching students self-regulatory skills. In addition, there is potential for language teachers to foster positive motivational beliefs in their students, and create a stimulating and positive language learning environment. The findings in this study show that interactions with teachers are important to the development of the participants' self-regulation. The findings also suggest a role for peers in the process of self-regulation. This indicates the value of peer learning tasks in language classrooms. This also suggests that learners' development to regulate their language learning may be mediated through process of social support and social regulation. 
This thesis provides an insight into self-regulation for language learners in the context of tertiary study in a public university in Malaysia. This insight contributes to addressing the problem of low levels of English proficiency among many Malaysian undergraduates by underlining the nature of self-regulation. 


\section{References}

Abdul Majid, S. Z., Hashim, M. Y., Ghazali, A. Z., Lee, K. H., Basri, A. F., \& Wahid, Z. A. (1999). Sejarah Malaysia Tingkatan 5. Kuala Lumpur: Dewan Bahasa dan Pustaka.

Abdul Razak, N. Z. (2000). Motivational factors and learners' strategies in the English as a Second Language classroom at Universiti Teknologi Malaysia with special reference to computer assisted language learning. (Unpublished doctoral dissertation), University of Stirling, Scotland, UK.

Abdullah, A. (1996). Going global: Cultural dimensions in Malaysian management. Kuala Lumpur: Malaysian Institute of Management.

Abdullah, M. H., \& Eng, W. B. (2011). Listening to the ethnic voice in ESL learning. The English Teacher, $x x x v, 15-26$.

Academic Department. (2009). Bandar Baru Bangi, Selangor: National University of Malaysia.

Adikata, A. A., \& Anwar, M. A. (2006). Student library use: A study of faculty perceptions in a Malaysian university. Library Review, 55(2), 106-119. doi: 10.1108/00242530610649602

Adnan, A. H. M. (2005). The English language dilemma in Malaysia: Vision, reality and ethnicity-religion-language tapestry of the Malay majority. In K. Ariffin, M. R. Ismail, R. Abdul Aziz, M. Z. Abdul Latif \& N. K. Leng (Eds.), English in education: Issues and challenges. Shah Alam: Pusat Penerbitan Universiti.

Alderman, M. K. (2008). Motivation for achievement: Possibilities for teaching and learning (3 ed.). New York: Routledge.

Ali, M. S. (2003). English language teaching in primary schools: Policy and implementation concerns. IPBA E-Journal, 1-14.

Ali, M. S. (2008). A case for a case: A qualitative research experience. Kuala Lumpur: Penerbit Universiti Malaya.

Ali, N. L., Hamid, M. O., \& Moni, K. (2011). English in primary education in Malaysia: policies, outcomes and stakeholders' lived experiences. Current Issues in Language Planning, 12(2), 147-166. doi: 10.1080/14664208.2011.584371

Allodi, M. W. (2010). The meaning of social climate of learning environments: Some reasons why we do not care enough about it. Learning Environments Research, 13, 89-104.

Archer, J. (2001). From motivation to self-regulation: Clustering students' motivational and cognitive characteristics, and exploring the impact of social interaction on learning. In C.-y. Chiu, F. Salili \& Y.-y. Hong (Eds.), Multiple competencies and self-regulated learning: Implications for multicultural education. Greenwich, Connecticut: Information Age

Arsal, Z. (2010). The effects of diaries on self-regulation strategies of preservice science teachers. International Journal of Environmental and Science Education, 5(1), 85-103.

Asmah, H. O. (1992). The linguistic scenery in Malaysia. Kuala Lumpur: Dewan Bahasa dan Pustaka.

Azevedo, R. (2009). Theoretical, conceptual, methodological, and instructional issues in research on metacognition and self-regulated learning: A discussion. Metacognition and Learning, 4(1), 87-95. doi: 10.1007/s11409-009-9035-7

Azevedo, R., Guthrie, J. T., \& Seibert, D. (2004). The role of self-regulated learning 
in fostering students' conceptual understanding of complex systems with hypermedia. Journal of Educational Computing Research, 30(1/2), 87-111.

Azman, H. (2009). English in 1Malaysia: A paradox in rural pluri-literacy practices. Akademika, 76, 27-41.

Bailey, K. M. (1991). Diary studies of classroom language teaching: The doubting game and the believing game. In E. Sadtono (Ed.), Language acquisition and the second/foreign language classroom (pp. 60-102). Singapore: SEAMEO Regional Language Center.

Bailey, K. M., \& Nunan, D. (Eds.). (1996). Voices from the language classroom. Cambridge: Cambridge University Press.

Bailey, K. M., \& Ochsner, R. (1983). A methodological review of the diary studies: Windmill tilting or social science? In K. M. Bailey, M. H. Long \& S. Peck (Eds.), Second language acquisition studies (pp. 188-198). Rowley, M. A.: Newbury House.

Bandura, A. (1977). Self-efficacy: Toward a unifying theory of behaviour change. Psychological Review, 84, 191-215.

Bandura, A. (1986). Social foundations of thought and action: A social cognitive theory. Englewood Cliffs, NJ: Prentice-Hall.

Bandura, A. (1990). Conclusion: Reflections on notability determinants of competence In R. J. Sternberg \& J. Kolligian (Eds.), Competence considered (pp. 315-362). New Haven and London: Yale University Press.

Bandura, A. (1993). Perceived self-efficacy in cognitive development and functioning. Educational Psychologist, 28(2), 117-148.

Bandura, A. (1995). Self-efficacy and educational development. In A. Bandura (Ed.), Self-efficacy in changing societies. New Jersey: Cambridge University Press.

Bandura, A. (1997). Self-efficacy: The exercise of control. New York: Freeman

Bandura, A. (2001). Social cognitive theory: An agentic perspective. Annual Review of Psychology, 52, 1-26. doi: 10.1146/annurev.psych.52.1.1

Bandura, A. (2006). Guide for constructing self-efficacy scales. In F. Pajares \& T. Urdan (Eds.), Self-efficay beliefs of adolescents (pp. 307-337). Greenwich, CT: Information Age

Barron, K. E., \& Harackiewicz, J. M. (2001). Achievement goals and optimal motivation: Testing multiple goal models. Journal of Personality and Social Psychology, 80(5), 706-722.

Baumeister, R. F., \& Vohs, K. D. (Eds.). (2004). Handbook of self-regulation: Research, theory and applications. New York: Guilford Press.

Bazeley, P., \& Richards, L. (2000). The Nvivo qualitative project book. Retrieved from http://srmo.sagepub.com/view/the-nvivo-qualitative-project$\underline{\text { book} / \mathrm{n} 1 . x m l}$.

Berndt, T. J., \& Keefe, K. (1992). Friends' influence on adolescents' perceptions of themselves at school. In D. H. Schunk \& J. L. Meece (Eds.), Student perceptions in the classroom. Hillsdale, NJ: Lawrence Erlbaum.

Birbili, M. (2000). Translating from one language to another. Social Research Update, 31, 1-6.

Boeakaerts, M., Pintrich, P. R., \& Zeidner, M. (2000). Handbook of self-regulation. San Diego, CA: Elsevier Academic Press.

Boekaerts, M. (1997). Self-regulated learning: A new concept embraced by researchers, policy makers, educators, teachers, and students. Learning and Instruction, 7(2), 161-186.

Boekaerts, M. L. (2005). Self-Regulation in the classroom: A perspective on 
assessment and intervention. Applied Psychology: An International Review, 54(2), 199-231. doi: 10.1111/j.1464-0597.2005.00205.x

Bogdan, R. C., \& Biklen, S. K. (1992). Qualitative research for education: An introduction to theory and methods. Boston: Allyn \& Bacon.

Bogdan, R. C., \& Biklen, S. K. (2007). Qualitative research for education: An introduction to theories and methods. Boston: Pearson.

Bonney, C. R., Kempler, T. M., Zusho, A., Coppola, B. P., \& Pintrich, P. R. (2005). Student learning in science classrooms: What role does motivation play? In S. Alsop (Ed.), Beyond Cartesian Dualism: Encountering affect in the teaching and learning of science (Vol. 29, pp. 83-97). Dordrecht, Netherlands: Springer.

Bown, J. (2006). Locus of learning and affective strategy use: Two factors affecting success in self-instructed learning. Foreign Language Annals, 39, 640-659.

Bown, J. (2009). Self-regulatory strategies and agency in self-instructed language learning: A situated view. [Article]. Modern Language Journal, 93(4), 570583. doi: 10.1111/j.1540-4781.2009.00965.x

Braine, G. (2003). From a teacher-centered to a student-centered approach: A study of peer feedback in Hong Kong writing classes. Journal of Asian Pacific Communication, 13(2), 269-288. doi: 10.1075/japc.13.2.05bra

Breen, M. P. (2001). Introduction: Conceptualization, affect and action in context. In M. P. Breen (Ed.), Learner contributions to language learning: New directions in research. Essex: Pearson Education.

Bryman, A. (1988). Quantity and quality in social research. London: Routledge.

Butler, D. L. (2002). Qualitative approaches to investigating self-regulated learning: Contributions and challenges. Educational Psychologist, 37(1), 59-63. doi: 10.1207/00461520252828564

Butler, D. L., \& Winne, P. H. (1995). Feedback and self-regulated learning: A theoretical synthesis. Review of Educational Research, 65(3), 245-281.

Celine, D., Benoit, D., Florian, D., Caroline, P., \& Fabrizio, B. (2009). Achievement goal promotion at university: Social desirability and social utility of mastery and performance goals. Journal of Personality and Social Psychology, 96(1), 119-134.

Centre for Teaching and Learning. (2007). Johor Baharu: Technology University of Malaysia.

Centre of General Studies. (2010). ZZZE1012 Academic Communication [Course description]. National University of Malaysia. Bandar Baru Bangi, Selangor.

Chamot, A. U. (2004). Issues in language learning strategy research and teaching. Electronic Journal of Foreign Language Teaching, 1(1), 14-26.

Chan, S. N. (2003). Making information literacy a compulsory subject for undergraduates: The experience of the University of Malaya. IFLA Journal, 29(4), 328-335.

Che Musa, N., Koo Yew, L., \& Azman, H. (2012). Exploring English Language learning and teaching in Malaysia. GEMA Online Journal of Language Studies, 12(1), 35-51.

Chen, C. S. (2002). Self-regulated learning strategies and achievement in an introduction to Information Systems course. Information Technology, Learning, and Performance, 20(1), 11-25.

Ching, L. C. (2002). Strategy and self-regulation instruction as contributors to improving students' cognitive model in an ESL program. English for 
Specific Purposes, 21(3), 261- 289.

Chiu, C.-y., Salili, F., \& Hong, Y.-y. (Eds.). (2001). Multiple competencies and selfregulated learning: Implications for multicultural education (Vol. 2). Connecticut, United States of America: Information Age.

Chong, W. H. (2007). The role of personal agency beliefs in academic selfregulation: An Asian perspective. School Psychology International, 28(1), 63-76. doi: $10.1177 / 0143034307075681$

Chong, W. H., Smith, I. D., \& M, L. K. (2001). Motivational and self-regulatory processes on academic and social functioning of secondary school students in Singapore. Paper presented at the Australian Association for Research in Education-Joint International Education Research Conference Fremantle, Australia.

Choy, S. C., \& Troudi, S. (2006). An investigation into the changes in perceptions of and attitudes towards learning English in a Malaysian college. International Journal of Teaching and Learning in Higher Education, 18(2), 120-130.

Chularut, P., \& DeBacker, T. K. (2004). The influence of concept mapping on achievement, self-regulation, and self-efficacy in students of English as a second language. Contemporary Educational Psychology, 29, 248-263.

Clearly, T. J. (2006). The development and validation of the self-regulation strategy inventory - Self-report. Journal of School Psychology, 44, 307-322.

Cohen, A., \& Macaro, E. (2007). Language learning strategies: 30 years of research and practice. Oxford: Oxford University Press.

Cohen, L., Manion, L., \& Morrison, K. (2000). Research methods in education (5 ed.). New York: Routledge-Falmer.

Cohen, L., Manion, L., \& Morrison, K. (2007). Research methods in education (6 ed.). New York, NY: Routledge-Falmer.

Coniam, D., \& Wong, R. (2004). Internet Relay Chat as a tool in the autonomous development of ESL learners' English language ability: An exploratory study. System, 32, 321-335.

Conrad, C. F., Haworth, J. G., \& Lattuca, L. R. (Eds.). (2001). Qualitative researh in higher education: Expanding perspectives (2 ed.). Boston, MA: Pearson.

Corno, L. (1994). Student volition and education: Outcomes, influences, and practices. In D. H. Schunk \& B. J. Zimmerman (Eds.), Self-regulation of learning and performance: Issues and educational applications (pp. 229254). Hillsdale, NJ: Lawrence Erlbaum.

Corno, L. (2001). Volitional aspects of self-regulated learning. In B. J. Zimmerman \& D. H. Schunk (Eds.), Self-regulated learning and academic achievement: Theoretical perspectives (pp. 191-225). Hillsdale, NJ: Erlbaum.

Corno, L., \& Mandinach, E. B. (1983). The role of cognitive engagement in classroom learning and motivation. Educational Psychologist, 18, 88-108.

Creswell, J. W. (2003). Research design: Qualitative, quantitative, and mixed methods approaches (2 ed.). Thousand Oaks, California: Sage

Creswell, J. W. (2008). Educational research: Planning, conducting, and evaluating quantitative and qualitative research (3 ed.). New Jersey: Pearson Prentice Hall.

Creswell, J. W. (2009). Research design: Qualitative, quantitative and mixed methods approaches (3rd ed.). Thousand Oaks, California: Sage

Darus, S. (2010). The current situation and issues of the teaching of English in Malaysia. Ritsumeikan Studies in Language and Culture, 22 (1), 19-28.

Davidson, C., \& Tolich, M. (Eds.). (2003). Social science research in New Zealand: 
Many paths to understanding Auckland: Pearson Education.

De Groot, E. V. (2002). Learning through interviewing: Students and teachers talk about learning and schooling. Educational Psychologist, 37(1), 41-52.

Deci, E. L., \& Ryan, R. M. (2002). Handbook of self-determination research. Rochester, NY: University of Rochester.

Denzin, N. (2001). Strategies of multiple triangulation. In C. F. Conrad, J. G. Haworth \& L. L. R (Eds.), Qualitative research in higher education: Expanding perspectives (2 ed., pp. 317-327). Boston, MA: Pearson.

Denzin, N. K., \& Lincoln, Y. S. (2000). Handbook of qualitative research (2nd ed.). Thousand Oaks: Sage.

Denzin, N. K., \& Lincoln, Y. S. (2005). Introduction: The discipline and practice of qualitative research. In N. K. Denzin \& Y. S. Lincoln (Eds.), The SAGE handbook of qualitative research (3 ed., pp. 1-32). Thousand Oaks: Sage.

Denzin, N. K., \& Lincoln, Y. S. (2008). The landscape of qualitative research. London: Sage

Dörnyei, Z. (2001). Motivational strategies in language classroom. Cambridge: Cambridge University Press.

Dörnyei, Z. (2005). The psychology of the language learner: Individual differences in second language acquisition. New Jersey: Lawrence Erlbaum

Dörnyei, Z. (2006). Individual differences in second language acquisition. In K. Bardovi-Harlig \& Z. Dornyei (Eds.), Themes in SLA research (Vol. 19, pp. 42-68). Philadelphia: John Benjamins.

Dörnyei, Z. (2007). Research methods in applied linguistics. Oxford: Oxford University Press.

Dörnyei, Z. (2009). The psychology of second language acquisition. Oxford: Oxford University Press.

Dornyei, Z., \& Skehan, P. (2003). Individual differences in second language learning. In C. J. Doughty \& M. H. Long (Eds.), The handbook of second language acquisition. Malden, MA: Blackwell Publishing.

Eekelen, I. M. V., Boshuizen, H. P. A., \& Vermunt, J. D. (2005). Self-regulation in higher education teacher learning. Higher Education, 50, 447-471.

Ellis, R. (1985). Understanding second language acquisition. Oxford: Oxford University Press.

Ellis, R. (2003). The study of second language acquisition. Oxford: Oxford University Press.

Ellis, R. (2008). Learner beliefs and language learning. Asian EFL Journal, 10(4), 725.

Embi, M. A. (2000). Language learning strategies: A Malaysian context. Bangi: Penerbit Universiti Kebangsaan Malaysia.

Embi, M. A., \& Mohd Amin, M. Z. (2010). Strategies for successful English Language learning. Shah Alam: Karisma

Ertmer, P. A., \& Newby, T. J. (1996). The expert learner: Strategic, self-regulated, and reflective. Instructional Science, 24, 1-24.

Esposito, N. (2001). From meaning to meaning: The influence of translation techniques on non-English focus group research. Qualitative Health Research, 11(4), 568-579. doi: 10.1177/104973201129119217

Finkbeiner, C. (2008). Culture and good language learners. In C. Griffiths (Ed.), Lessons from good language learners. New York: Cambridge University.

Gahungu, 0. N. (2007). The relationships among strategy use, self-efficacy, and language ability in foreign language learners. Doctoral dissertation, Northern Arizona University, Northern Arizona. Retrieved from http://ci- 
doc.coe.nau.edu/13-Dissertations/supporting files/Dissertation-Olive.pdf

Gan, Z. (2003). Self-directed language learning among university EFL students in Mainland China and Hong Kong: A study of attitudes, strategies and motivation. Unpublished doctoral dissertation, Hong Kong Polytechnic University.

Gan, Z., Humphreys, G., \& Hamp-Lyons, L. (2004). Understanding successful and unsuccessful EFL students in Chinese universities. The Modern Language Journal, 88(2), 229-244. doi: 10.1111/j.0026-7902.2004.00227.x

Gao, X. (2010). Strategic language learning: The roles of agency and context Salisbury, UK: Multilingual Matters.

Gao, X. S. (2009). The 'English corner' as an out-of-class learning activity. ELT Journal, 63, 60-67.

Garret, P., \& Shortall, T. (2002). Learners' evaluations of teacher-fronted and student-centred classroom activities. Language Teaching Research, 6(1), 25-57.

Gass, S. M., \& Mackey, A. (2000). Stimulated recall methodology in second language research. Mahwah, New Jersey: Lawrence Erlbaum.

Geertz, C. (2001). Thick description: Toward an interpretive theory of culture In C. Geertz (Ed.), Contemporary field research: Perspectives and formulations (pp. 55-75). Prosect Heights, IL: Waveland Press.

Glesne, C., \& Peshkin, A. (1992). Becoming qualitative researchers: An introduction. White Plains, New York: Longman.

Goodenow, C. (1992). Strengthening the links between educational psychology and the study of social contexts. Educational Psychologist, 27(2), 177-196.

Graham, S. (1997). Effective language learner. Clevedon: Multilingual Matters

Guba, E. G. (1990). The alternative paradigm dialog. In E. G. Guba (Ed.), The paradigm dialog (pp. 17-30). Newbury Park: Sage.

Hadwin, A., \& Oshige, M. (2011). Self-regulation, coregulation, and socially shared regulation: Exploring perspectives of social in self-regulated learning theory. Teachers College Record, 113(2), 240-264.

Hammersley, M. (2002). The relationship between qualitative and quantitative research: Paradigm loyalty versus methodological eclecticism. In J. T. E. Richardson (Ed.), Handbook of qualitative research methods for psychology and the social sciences (pp. 159-174). Oxford: BPS Blackwell.

Hancock, D. R., \& Algozzine, B. (2006). Doing case study research: A practical guide for beginning researchers. New York: Teachers College

Hang, P. T. T. (2009). Impacts of Vietnam's social context on learners' attitudes towards foreign languages and English language learning: Implications for teaching and learning. Asian EFL Journal, 11(4), 169-188.

Harackiewicz, J. M., Barron, K. E., \& Elliot, A. E. (1998). Rethinking achievement goals: When are they adaptive for college students and why? Educational Psychologist, 33, 1-21.

Harackiewicz, J. M., Barron, K. E., Pintrich, P. R., Elliot, A. J., \& Thrash, T. (2002). Revision of achievement goal theory: Necessary and illuminating. Journal of Educational Psychology, 94(3), 638-645.

Harackiewicz, J. M., Barron, K. E., Tauer, J. M., Carter, S. M., \& Elliot, A. E. (2000). Short-term and long-term consequences of achievement goals in the college classroom: Maintaining interest and making the grade. Journal of Educational Psychology, 92, 316-330.

Hardie, J. C. (2009). New opportunities or difficult challenges? Self-regulation of learning of Chinese students in a Western setting. Unpublished doctoral 
dissertation, University of Canterbury, Canterbury, New Zealand. Retrieved from http://www.ir.canterbury.ac.nz/bitstream/10092/3392/1/thesis fulltext . $\mathrm{pdf}$

Hashim, A. (2009). Not plain sailing: Malaysia's language choice in policy and education. AILA Review, 22(1), 36-51. doi: 10.1075/aila.22.04has

Hassan, F., \& Fauzee, S. N. (2002). Why aren't students proficient in ESL: The teachers' perspective. The English Teacher, 31, 107-123.

Hawthorne, S. (2008). Engaging reluctant writers: The nature of reluctance to write and the effect of a self-regulation strategy training programme on the engagement and writing performance of reluctant writers in secondary school English. Unpublished doctor of education thesis, University of Auckland, Auckland.

Hidi, S., \& Harackiewicz, J. M. (2000). Motivating the academically unmotivated: A critical issue for the 21st century. Review of Educational Research, 70(2), 151-179.

Hiemstra, R. (2004). Self-directed learning lexicon. International Journal of SelfDirected Learning, 1(2), 1-6.

Hirata, A. (2010). An exploratory study of motivation and self-regulated learning in second language acquisition: Kanji learning as a task focused approach. (Unpublished master's thesis), Massey University, Manawatu, New Zealand.

Ho, J., \& Crookal, D. (1995). Breaking with Chinese cultural traditions: Learner autonomy in English language teaching. System, 23(2), 235-243.

Hoban, S., \& Hoban, G. (2004). Self-esteem, self-efficacy and self-directed learning: Attempting to undo the confusion. International Journal of SelfDirected Learning, 1(2), 7-25.

Hofer, B. K., Yu, S. L., \& Pintrich, P. R. (1998). Teaching college students to be selfregulated learners. In D. H. Schunk \& B. J. Zimmerman (Eds.), Selfregulated learning: From teaching to self-reflective practice. New York: The Guilford Press.

Hornberger, N. H. (1994). Ethnography. In A. Cumming (Ed.), In alternatives in TESOL research: Descriptive, interpretive, and ideological orientations (pp. 688-690).

Hsiao, T. Y., \& Oxford, R. L. (2002). Comparing theories of language learning strategies: A confirmatory factor analysis. Modern Language Journal, 86(3), 368-383.

Huang, J. (2006). Learner autonomy in the Chinese university classroom: An insider perspective on teacher-learner role relationships. In P. Benson (Ed.), Learner autonomy 8: Insider perspectives on autonomy in language teaching and learning. Dublin: Authentik.

Huberman, A. M., \& Miles, M. B. (2002). The qualitative researcher's companion. Thousand Oaks, CA: Sage.

Idrus, H., \& Salleh, R. (2008). Perceived self-efficacy of Malaysian ESL engineering and technology students on their speaking ability and its pedagogical implications. The English Teacher, XXXVII, 61-75.

Idrus, H., \& Sivapalan, S. (2007). Perceived self-efficacy of ESL students with regard to their oral communication ability. Paper presented at the International Conference on Social Sciences and Humanities. Retrieved from http://eprints.utp.edu.my/6290/1/perceived selfefficacy in oral comm.pdf 
Inpornvijit, K. (2008). Effects of feedback on self-regulated learning strategy use and academic performance. (Doctoral dissertation, University of Souh Alabama). Retrieved from http://gateway.proquest.com/openurl\%3furl ver=Z39.882004\%26res dat=xri:pqdiss\%26rft val fmt=info:ofi/fmt:kev:mtx:disserta tion\%26rft dat=xri:pqdiss:3338078

Ismail, R. (2008). Factors affecting less proficient ESL learners' use of strategies for language and content area learning. Unpublished doctoral dissertation, Universiti Putra Malaysia, Serdang.

Ivanic, Clark, R., \& Rimmershaw, R. (2000). What am I suppposed to make of this? The messages conveyed to students by tutors' written comments. In M. R. Lea \& B. Stierer (Eds.), Student writing in higher education: New contexts. Buckingham: Open University Press.

Järvelä, S., Järvenoja, H., \& Veermans, M. (2008). Understanding the dynamics of motivation in socially shared learning. International Journal of Educational Research, 47(2), 122-135. doi: 10.1016/j.ijer.2007.11.012

Johnson, B., \& Christensen, L. (2008). Educational research: Quantitative, qualitative and mixed approaches (3rd ed.). Thousand Oaks, California: Sage.

Johnson, K. (2005). Introduction. In K. Johnson (Ed.), Expertise in second language learning and teaching. New York: Palgrave Macmillan.

Joo, Y., Bong, M., \& Choi, H. (2000). Self-efficacy for self-regulated learning, academic self-efficacy, and internet self-efficacy in web-based instruction. Educational Technology Research and Development, 48(2), 5-17.

Kaplan, A., \& Lichtinger, E. (2009). Achievement goal orientations and selfregulation in writing: An integrative perspective. Journal of Educational Psychology, 101(1), 51-69.

Kaplan, A., Middleton, M. J., Urdan, T., \& Midgley, C. (2002). Achievement goals and goal structures. In C. Midgley (Ed.), Goals, Goal structures, and patterns of adaptive learning. Hillsdale, NJ: Lawrence Erlbaum.

Karabenick, S. A. (1998). Help seeking as a strategic resource. In S. A. Karabenick (Ed.), Strategic help seeking: Implications for learning and teaching (pp. 111). Mahwah, NJ: Lawrence Erlbaum.

Karabenick, S. A., \& Dembo, M. H. (2011). Understanding and facilitating selfregulated help seeking. New Directions for Teaching and Learning, 2011(126), 33-43. Retrieved from http://onlinelibrary.wiley.com/doi/10.1002/tl.442/abstract doi:10.1002/tl.442

Kaur, S., \& Peng, C. H. (2000, December). A few controversies mar an otherwise good year, The Star Education Supplement., p. 2.

Kember, D. (2000). Misconceptions about the learning approaches, motivation and study practices of Asian students. Higher Education, 40(1), 99-121.

Kimura, Y. (2003). English language learning motivation: Interpreting qualitative data situated in a classroom task. Annual Review of English Language Education in Japan, 14, 71-80.

Komarraju, M., Karau, S. J., \& Ramayah, T. (2007). Cross-cultural differences in the academic motivation of university students in Malaysia and the United States. North American Journal of Psychology, 9(2), 275-292. doi: 10.1006/ceps.1996.0013

Koo, Y. L. (2008). Language, culture and literacy: Meaning-meaking in global contexts. Bangi: Penerbit Universiti Kebangsaan Malaysia. 
Kozanitis, A., Desbiens, J., \& Chouinard, R. (2008). Perception of teacher support and reaction toward questioning: Its relation to instrumental help-seeking and motivation to learn. International Journal of Teaching and Learning in Higher Education, 19(3), 238-250.

Kvale, S. (1996). Interviews: An introduction to qualitative research interviewing. Thousand Oaks, California: Sage.

Lai, C., \& Gu, M. (2011). Self-regulated out-of-class language learning with technology. Computer Assisted Language Learning, 24(4), 317-335. doi: 10.1080/09588221.2011.568417

Lamb, M. (2002). Explaining successful language learning in difficult circumstances. Prospect: An Australian Journal of TESOL, 17, 35-52.

Lamb, M. (2007). The impact of school on EFL learning motivation: An Indonesian case study. TESOL Quarterly, 41, 757-780.

Leaver, B. L. (2009). Self-regulation and learner autonomy. In M. Ehrman \& B. Shekhtman (Eds.), Achieving success in second language acquisition. Cambridge: Cambridge University Press.

Lee, C. C. (2002). Strategy and self-regulation instruction as contributors to improving students' cognitive model in an ESL program. English for Specific Purposes, 21(3), 261-289. doi: 10.1016/s0889-4906(01)00008-4

Lee, I. (2008). Student reactions to teacher feedback in two Hong Kong secondary classrooms. Journal of second language writing, 17(3), 144-164.

Lee, S. K. (2003). Multiple Identities in a Multicultural World: A Malaysian Perspective. Journal of Language, Identity \& Education, 2(3), 137-158. doi: 10.1207/s15327701jlie0203_1

Lemos, M. S. (1999). Students' goals and self-regulation in the classroom. International Journal of Educational Research, 31, 471-485.

Ley, K., \& Young, D. B. (2001). Instructional principles for self-regulation. Educational Technology Research and Development, 49(2), 93-103.

Life, J. (2011). Motivation and EFL university students in North-East Asia. Asian EFL Journal, 13(3), 11-41.

Lincoln, Y. S., \& Guba, E. G. (1985). Naturalistic inquiry. Newbury Park, CA: Sage.

Linnenbrink, E. A. (2005). The dilemma of performance-approach goals: The use of multiple goal contexts to promote students' motivation and learning. Journal of Educational Psychology, 97(2), 197-213.

Linnenbrink, E. A., \& Pintrich, P. R. (2002). Motivation as an enabler for academic success. School Psychology Review, 31(3), 313.

Little, D. (2007). Language learner autonomy: Some fundamental considerations revisited. Innovation in Language Learning and Teaching, 1(1), 14-29. doi: $10.2167 /$ illt040.0

Littlewood, W. (2000). Do Asian students really want to listen and obey? ELT Journal, 54(1), 31-36.

Liu, G. (2005). The trend and challenge for teaching EFL at Taiwanese uinversities. RELC Journal, 36, 211-221.

Liu, K.-S., Cheng, Y.-Y., Chen, Y.-L., \& Wu, Y.-Y. (2009). Longitudinal effects of educational expectations and achievement attributions on adolescents' academic achievements. Adolescence, 44(176), 911-924. doi: 10.1146/annurev.psych.53.100901.135153

Locke, E. A., \& Latham, G. P. (1990). A theory of goal setting and task performance. Englewood Cliffs, NJ: Prentice-Hall.

Locke, E. A., \& Latham, G. P. (2002). Building a practically useful theory of goal setting and task motivation: A 35-year odyssey. American Psychologist, 
57(9), 705-717.

Mackay, A., \& Gass, M. (2008). Second language research (2 ed.). New York: Routledge.

Malaysian Examination Council. (2008). Putrajaya: Malaysian Ministry of Education.

Mason, J. (2002). Qualitative researching (2 ed.). Thousand Oaks, CA: Sage.

Masui, C., \& De Corte, E. (2005). Learning to reflect and to attribute constructively as basic components of self-regulated learning. British Journal of Educational Psychology, 75, 351-372.

Matos, L., Lens, W., \& Vansteenkiste, M. (2009). School culture matters for teachers' and students' achievement goals. In A. Kaplan, S. Karabenick \& E. V. De Groot (Eds.), Culture, self, and motivation United States of America: Information Age.

Mattern, R. A. (2005). College students' goal orientations and achievement. International Journal of Teaching and Learning in Higher Education, 17(1), 27-32.

McClure, J., Meyer, L. H., Garisch, J., Fischer, R., Weir, K. F., \& Walkey, F. H. (2011). Students' attributions for their best and worst marks: Do they relate to achievement? Contemporary Educational Psychology, 36(2), 71-81. doi: 10.1016/j.cedpsych.2010.11.001

McCombs, B. L. (1989). Self-regulated learning and achievement : A phenomenological view. In B. J. Zimmerman \& D. H. Schunk (Eds.), Selfregulated learning and academic achievement: Theory, research, and practice. New York: Springer-Verlag.

McCombs, B. L. (2001). Self-regulated learning and academic achievement: A phenomenological view. In B. J. Zimmerman \& D. H. Schunk (Eds.), Self regulated learning and academic achievement. Mahwah, NJ: Lawrence Erlbaum.

McInerney, D. M. (2008). The motivational roles of cultural differences and cultural identity in self-regulated learning. In D. H. Schunk \& B. J. Zimmerman (Eds.), Motivation and self-regulated learning: Theory, research and applications. New York: Lawrence Erlbaum.

Mckay, S. L. (2006). Researching second language classrooms. New Jersey: Lawrence Erlbaum.

Merriam, S. B. (1988). Case study research in eduation: A qualitative approach. California Jossey-Bass

Merriam, S. B. (1998). Qualitative research and case study applications in education. San Francisco: Jossey-Bass

Merriam, S. B. (2001). Qualitative research and case study applications in education: Revised and expended from case study research in education. San Francisco: Jossey-Bass.

Merriam, S. B., \& Mohamad, M. (2000). How cultural values shape learning in older adulthood: The case of Malaysia. Adult Education Quarterly, 51(1), 45-63. doi: 10.1177/074171360005100104

Mezei, G. (2008). Motivation and self regulated learning : A case study of a preintermediate and an upper-intermediate adult student. WoPaLP, 2, 79104.

Midgley, C., Kaplan, A., \& Middleton, M. (2001). Performance-approach goals: Good for what, for whom, under what circumstances, and at what cost? Journal of Educational Psychology, 93(1), 77-86.

Mikulecky, L., Lloyd, P., \& Huang, S. C. (1996). Adult and ESL literacy learning self- 
efficacy

questionnaire.

Retrieved

from http://eric.ed.gov/PDFS/ED394022.pdf

Miles, M. B., \& Huberman, A. M. (1994). Qualitative data analysis (2 ed.). Thousand Oaks, California: Sage.

Moeller, A. J., Theiler, J. M., \& Wu, C. (2011). Goal Setting and Student Achievement: A Longitudinal Study. The Modern Language Journal, 1-17. doi: 10.1111/j.1540-4781.2011.01231.x

Mohamed, A. R., Morad, S., Mohamed Ismail, S. M., Omar, H., \& Abdul Rahman, W. (2006). Reluctant teachers, rustic students and the remoteness of English. Jurnal Pendidik dan Pendidikan, 21, 47-60.

Mohd Adnan, A. H. (2005). The 'English Language Dilemma' in Malaysia: Vision, Reality and the Ethnicity-Religion-Language Tapestry of the Malay Majority. In K. Ariffin, M. R. Ismail, R. Abdul Aziz, M. Z. Abdul Latif \& K. L. Ngo (Eds.), English in Education: Issues and Challenges in the Malaysian Classroom. Shah Alam: Pusat Penerbitan Universiti.

Mohd Kosnin, A. (2007). Self-regulated learning and academic achievement in Malaysian undergraduates. International Education Journal 8(1), 221-228.

Mohd Noor, N. (2006). Reading academic text: awareness and experiences among university ESL learners. GEMA: Online Journal of Language Studies, 6(2), 65-78.

Mohd Shah, P. (2002). Attitude, motivation, and individual characteristics as variables of L2 acquisition. In M. Jayakaran, A. S. Arshad \& S. Teh (Eds.), Readings in English Language teaching (pp. 116-123). Serdang: Penerbit University Putra Malaysia.

Montalvo, F. T., \& Torres, M. C. G. (2004). Self-regulated learning: Current and future directions Electronic Journal of Research in Educational Psychology, 2(1), 1-34.

Murayama, K., Elliot, A. J., \& Yamagata, S. (2011). Separation of performanceapproach and performance-avoidance achievement goals: A broader analysis. Journal of Educational Psychology, 103(1), 238-256.

Murphey, T., Jin, C., \& Li-Chi, C. (2005). Learners' constructions of identities and imagined communities. In P. Benson \& D. Nunan (Eds.), Learners' stories: Difference and diversity in language learning. Cambridge: Cambridge University Press.

Mustaffa, R. (2006). The effects of culture on students' learning styles. $3 \mathrm{~L}$ The Southeast Asian Journal of English Language Studies, 12, 83-94.

Naiman, N., Frohlich, M., Stern, H. H., \& Todesco, A. (1978). The good language learner. Clevedon, UK: Multilingual Matters.

Nakata, Y. (2006). Motivation and experience in foreign language learning. Switzerland: International Academic.

Nelson, G. (1995). Cultural differences in learning styles. In J. Reid (Ed.), Learning styles in the ESL/EFL classroom (pp. 3-18). Boston, MA: Heinle \& Heinle.

Newman, R. S. (2002). How self-regulated learner cope with academic difficulty: The role of adaptive help seeking. Theory into Practice, 41(2), 132-138.

Newman, R. S. (2008). The motivational role of adaptive help seeking in selfregulated learning. In D. H. Schunk \& B. J. Zimmerman (Eds.), Motivation and self-regulated learning: Theory, research, and applications. New York: Lawrence Erlbaum.

Nicol, D. J., \& Macfarlane-Dick, D. (2006). Formative assessment and selfregulated learning: A model and seven principles of good feedback practice. Studies in Higher Education, 31(2), 199-218. 
Nikolov, M. (2001). A study of unsuccessful language learners. In Z. Dornyei \& R. Schmidt (Eds.), Motivation and second language learning (pp. 147-172). Honolulu: University of Hawaii Press.

Noels, K. A. (2005). Orientations to learning German: Heritage language learning and motivational substrates. The Canadian Modern Language Review, 62(2), 285-312.

Norton, B. (1997). Language, identity, and the ownership of English. TESOL Quarterly, 31(3), 409-429.

Norton, B., \& Toohey, K. (2001). Changing perspectives on good language learners. TESOL Quarterly, 35(2), 307-322.

Nota, L., Soresi, S., \& Zimmerman, B. J. (2004). Self-regulation and academic achievement and resilience: A longitudinal study. International Journal of Educational Research, 41(3), 198-215. doi: 10.1016/j.ijer.2005.07.001

Osman, Z., Chan, S. N., \& Chall, D. K. (1998). Developing IT skills through information skills (IS) programmes. Paper presented at the PPM/LAS, Kota Kinabalu.

Oxford, R. L., \& Schramm, K. (2007). Bridging the gap between psychological and sociocultural perspectives on language learning strategies. In A. D. Cohen \& E. Macaro (Eds.), Language learning strategies: 30 years of research and practice Oxford: Oxford University Press.

Pajares, F. (2002). Overview of social cognitive theory and self-efficacy Retrieved May, 8, 2011, from http://www.des.emory.edu/mfp/eff.html

Pajares, F., Johnson, M. J., \& Usher, E. L. (2007). Sources of writing self-efficacy beliefs of elementary, middle, and high school students. Research in the Teaching of English, 42(1), 104-120.

Pajares, F., \& Urdan, T. C. (Eds.). (2005). Self-efficacy beliefs of adolescents. Greenwich, Conn: Information Age

Pandian, A. (2002). English language teaching in Malaysia today. Asia Pacific Journal of Education, 22(2), 35-52. doi: 10.1080/0218879020220205

Pandian, A. (2006). What works in the classroom? Promoting literacy practices in English. 3L The Southesat Asian Journal of English Language Studies, 11, 15-39.

Pape, S. J., \& Wang, C. (2003). Middle school children's strategic behaviour: Classification and relation to academic achievement and mathematical problem solving. Instructional Science, 31, 419-449.

Paris, S. G., Byrnes, J. P., \& Paris, A. H. (2001). Constructing theories, identities, and actions of self-regulated learners. In B. J. Zimmerman \& D. H. Schunk (Eds.), Self-regulated learning and academic achievement: Theoretical perspectives (2 ed., pp. 253-287). Mahwah, NJ: Lawrence Erlbaum.

Park, C. C. (2000). Learning style preferences of Southeast Asian students. Urban Education, 35, 245-268.

Patrick, H., Kaplan, A., \& Ryan, A. M. (2011). Positive classroom motivational environments: Convergence between mastery goal structure and the classroom social climate. Journal of Educational Psychology, 103(2), 367382.

Patrick, H., \& Middleton, M. J. (2002). Turning the kaleidoscope: What we see when self-regulated learning is viewed with a qualitative lens. Educational Psychologist, 37(1), 27-39.

Patton, M. Q. (1990). Qualitative evaluation and research methods (2 ed.). Newbury Park, CA: Sage.

Perry, N. E. (2002). Introduction: Using qualitative methods to enrich 
understandings of self-regulated learning. Educational Psychologist, 37(1), 1-3. doi: $10.1207 / 00461520252828500$

Perry, N. E., VandeKamp, K. O., Mercer, L. K., \& Nordby, C. J. (2002). Investigating teacher-student interactions that foster self-regulated learning. Educational Psychologist, 37, 15-25.

Peshkin, A. (1993). The goodness of qualitative research. Educational Researcher, 22(2), 23-29.

Pierson, H. D. (1996). Learner culture and learner autonomy in the Hong Kong Chinese context. In R. Pemberton, E. S. L. Li, W. Or \& H. D. Pierson (Eds.), Taking control: Autonomy in language learning. Hong Kong: Hong Kong University Press.

Pillay, H., Purdie, N., \& Boulton-Lewis, G. (2000). Investigating cross-cultural variation in conceptions of learning and the use of self-regulated strategies Education Journal 28(1), 65-84.

Pintrich, P. R. (1999). The role of motivation in promoting and sustaining selfregulated learning. International Journal of Educational Research, 31(6), 459-470. doi: 10.1016/s0883-0355(99)00015-4

Pintrich, P. R. (2000a). Multiple goals, multiple pathway: The role of goal orientation in learning and achievement. Journal of Educational Psychology, 92(3), 544-555.

Pintrich, P. R. (2000b). The role of goal orientation in self-regulated learning. In M. Boekaerts, P. R. Pintrich \& M. Zeidner (Eds.), Handbook of selfregulation (pp. 451-502). San Diego, CA: Elsevier Academic Press.

Pintrich, P. R. (2004). A conceptual framework for assessing motivation and selfregulated learning in college students. Educational Psychology Review, 16(4), 385-407.

Pintrich, P. R., \& De Groot, E. V. (1990). Motivational and self regulated learning components of classroom academic performance. Journal of Educational Psychology, 82, 33-40.

Pintrich, P. R., \& Schunk, D. H. (2002). Motivation in education: Theory, research, and applications (2 ed.). Upper Saddle River, NJ: Merrill Prentice-Hall.

Purdie, N., \& Hattie, J. (1996). Cultural differences in the use of strategies for selfregulated learning. American Educational Research Journal, 33(4), 845871. doi: 10.3102/00028312033004845

Purdie, N., Hattie, J., \& Douglas, G. (1996). Student conceptions of learning and their use of self-regulated learning strategies: A cross-cultural comparison. Journal of Educational Psychology, 88(1), 87-100. doi: 10.1037/0022-3514.41.3.586.

Puustinen, M., \& Pulkkinen, L. (2001). Models of self-regulated learning: A review. Scandinavian Journal of Educational Research, 45(3), 269-286. doi: $10.1080 / 00313830120074206$

Quek, A.-H. (2005). Learning for the workplace: A case study in graduate employees' generic competencies. Journal of Workplace Learning, 17(4), 231-242. doi: 10.1108/13665620510597185

Rahman, S., \& Phillips, J. A. (2006). Hubungan antara kesedaran metakognisi, motivasi dan pencapaian akademik pelajar universiti. Jurnal Pendidikan, 31, 21-39.

Rajadurai, J. (2010). Speaking English and the Malay community. Indonesia and the Malay World, 38(111), 289-301. doi: 10.1080/13639811.2010.489371

Randi, J., \& Corno, L. (2000). Teacher innovations in self-regulated learning. In M. Boekaerts, P. R. Pintrich \& M. Zeidner (Eds.), Handbook of self-regulation. 
San Diego: Academic Press.

Renganathan, S. (2005). The use of English as a social practice: A study of Malaysian ESL students. Paper presented at the Language and Global Communication (LGC 2005) Conference, Cardiff University. Retrieved from http://eprints.utp.edu.my/3480/

Renganathan, S., \& Chong, S. L. (2007). The use of English as a social practice in a multilingual and multi-ethnic community. Paper presented at the International Conference on Social Sciences and Humanities, Bangi, Malaysia.

Richards, J. C., \& Renandya, W. A. (2002). Methodology in language teaching: An anthology of current practice. Cambridge: Cambridge University Press.

Richards, L. (2009). Handling qualitative data: A practical guide (2nd ed.). London: Sage.

Richardson, L. (2000). Writing: A method of inquiry. In N. Denzin \& Y. S. Lincoln (Eds.), Handbook of qualitative research (2nd ed., pp. 923-948). Thousand Oaks, CA: Sage.

Ridge, B. (2004). Bangsa Malaysia and recent Malaysian English Language policies. Current Issues in Language Planning, 5(4), 407-423. doi: 10.1080/14664200408668266

Rivers, W. P. (2001). Autonomy at all costs: An ethnography of metacognitive self-assessment and self-management among experienced language learners. Modern Language Journal, 85(2), 279-290.

Rosch, H. (2003). Dissemination of information. In Feather \& Sturges (Eds.), International encyclopedia of information and library science (pp. 141142). London: Routledge.

Roslan, S. (2000). Relationship between self-regulated learning, self-efficacy and academic achivement among higher institution students. Unpublished doctoral dissertation, Universiti Putra Malaysia, Serdang.

Rubin, J. (1975). What the "good language learner" can teach us. TESOL Quarterly, 9(1), 41-51.

Rubin, J., \& Thompson, I. (1982). How to be a more successful language learner. Boston: Heinle \& Heinle.

Ryan, R. M., \& Deci, E. L. (2000). Intrinsic and extrinsic motivations: Classic definitions and new directions. Contemporary Educational Psychology, 25, 54-67.

Salili, F., Chiu, C.-y., \& Lai, S. (2001). The influence of culture and context on students' motivational orientation and performance student motivation. In F. Salili, C.-y. Chiu \& Y. Y. Hong (Eds.), (pp. 221-247): Springer US.

Salili, F., Fu, H.-y., Tong, Y.-y., \& Tabatabai, D. (2001). Motivation and selfregulation: A cross-cultural comparison of the effect of culture and context of learning on student motivation and self-regulation. In C.-y. Chiu, F. Salili \& Y.-y. Hong (Eds.), Multiple competencies and self-regulated learning: Implications for multicultural education Greenwich, CT: Information Age.

Salili, F., \& Hoosain, R. (2007). Culture, motivation, and learning: A multicultural perspective. Charlotte, NC: Information Age.

Sawyer, R. J., Graham, S., \& Harris, K. R. (1992). Direct teaching, strategy instruction, and strategy instruction with explicit self-regulation: Effects on the composition skills and self-efficacy of students with learning disabilities. Journal of Educational Psychology, 84(3).

Schunk, D. H. (1984). Self-efficacy perspectives on achievement behaviour. Educational Psychologist, 19, 48-58. 
Schunk, D. H. (1989). Self-efficacy and achiement behaviours Educational Psychology Review, 1, 173-208.

Schunk, D. H. (1994). Self-regulation of self-efficacy and attributions in academic settings. In D. H. Schunk \& B. J. Zimmerman (Eds.), Self-regulation of learning and performance: Issues and educational applications (pp. 75-99). Hillsdale, New Jersey: Erlbaum.

Schunk, D. H. (2001). Self-regulation through goal setting. Retrieved from http://www.schoolbehavior.com/Files/Schunk.pdf

Schunk, D. H. (2001). Social cognitive theory and self-regulated learning. In B. J. Zimmerman \& D. H. Schunk (Eds.), Self-regulated learning and academic achievement: Theoretical perspectives (2nd ed., pp. 125-151). Mahwah, NJ: Lawrence Erlbaum

Schunk, D. H. (2003). Self-efficacy for reading and writing: Influence of modeling, goal setting, and self-evaluation. Reading and Writing Quarterly, 19(2), 159-172.

Schunk, D. H. (2009). Social cognitive theory and self-regulated learning. In B. J. Zimmerman \& D. H. Schunk (Eds.), Self-regulated learning and academic achievement: Theoretical perspectives. New York, NY: Routledge.

Schunk, D. H., \& Pajares, F. (2001). The development of academic self-efficacy. In A. Wiggield \& J. Eccles (Eds.), Development of achievement motivation. San Diego: Academic Press.

Schunk, D. H., Pintrich, P., \& Meece, J. L. (2008). Motivation in education: Theory, research and applications. New Jersey: Pearson Prentice Hall.

Schunk, D. H., \& Zimmerman, B. J. (Eds.). (2008). Motivation and self-regulated learning: Theory, research, and applications. New York: Lawrence Erlbaum

Seale, C. (1999). The quality of qualitative research. London Sage.

Segalowitz, N., \& Freed, B. F. (2004). Context, contact, and cognition in oral fluency acquisition: Learning Spanish in at home and study abroad contexts. Studies in Second Language Acquisition, 26(02), 173-199. doi: doi:10.1017/S0272263104262027

Senior, R. (2009). Class-centred teaching. ELT Journal, 63(4), 393-396.

Shakir, R. (2009). Soft skills at the Malaysian institutes of higher learning. Asia Pacific Education Review, 10(3), 309-315. doi: 10.1007/s12564-009-90388

Shankar, S. (2003). Local grads still not proficient in English, New Sunday Times.

Shute, V. J. (2008). Focus on Formative Feedback. Review of Educational Research, $78(1), 153-189$.

Siegel, J. (2003). Social context. In C. J. Doughty \& M. H. Long (Eds.), The handbook of second language acquisition. Malden, MA: Blackwell Publishing.

Silverman, D. (2006). Interpreting qualitative data: Methods for analyzing talk, text and interaction (3rd ed.). London: Sage.

Simon, S. (1996). Gender in translation: Cultural identity and the politics of transmission. London: Routledge.

Simpson, M., \& Randall, M. (2000). Vocabulary development at the college level. In R. F. Flippo \& D. C. Caverly (Eds.), Handbook of college reading and study strategies. Mahwah, NJ: Lawrence Erlbaum.

Smith, L. (2008). Ethical principles in practice: Evidence from participatory action research. Weaving Educational Practice, 9, 16-21.

Smith, R. C. (2003). Pedagogy for autonomy as (becoming-) appropriate methodology. In D. Palfreyman \& R. C. Smith (Eds.), Learner autonomy across cultures: Language education perspectives. Basingstoke: Palgrave 
Macmillan.

Stake, R. E. (1995). The art of case study research. Thousand Oaks: Sage

Stake, R. E. (2000). The case study method in social inquiry. In R. Gomm, M. Hammersely \& P. Foster (Eds.), Case study method: Key issues, key texts (pp. 19-26). London: Sage.

Tamam, E. (2011). National pride, race, language use in interracial communications with peers: A case of Malaysian youths of 20-25 years old. Human Communication, 13(3), 127-136.

Tan, P. L. (2005). Approaches to learning and learning values: An investigation of adult learners in Malaysia. Unpublished doctoral dissertation, Queensland University of Technology, Queensland, Australia. Retrieved from http://eprints.qut.edu.au/16295/1/Po Li Tan Thesis.pdf

Thang, S. M. (2001). Malaysian learners' conceptions of their learning processes and their perceptions of their English as a second language course in a tertiary distance learning context. Unpublished doctoral dissertation, University of Nottingham, Nottingham.

Thang, S. M. (2003). How ready are Malaysian learners for online learning? An investigation into learner characteristics. Paper presented at the ASIACALL International Conference on Information Technology and Language Education, Bangkok, Thailand.

Thang, S. M. (2004). Learning English in multicultural Malaysia: Are learners motivated? Journal of Language and Learning, 2(2), 142-153.

Thang, S. M. (2005). Investigating Malaysian distance learners' perceptions of their English proficiency courses. Open Learning, 20(3), 243-256.

Thang, S. M., \& Alias, A. (2007). Investigating readiness for autonomy: A comparison of Malaysian ESL undergraduates of three public universities. Reflections on English Languge Teaching, 6(1), 1-18.

Thang, S. M., Gobel, P., Mohd Nor, N. F., \& Suppiah, V. (2011). Students' attributions for success and failure in the learning of English as a second language: A comparison of undergraduates from six public universities in Malaysia. Pertanika Journal Social Sciences and Humanities, 19(2), 459474.

Tiang, L. M. (2003). Factors affecting the learning of English among Malay learners. Unpublished masters's thesis, Kuala Lumpur.

Tseng, W., Dornyei, Z., \& Schmitt, N. (2006). A new approach to assessing strategic learning: The case of self-regulation in vocabulary acquisition. Applied Linguistics, 27, 78-102.

Turner, J. E., \& Waugh, R. M. (2007). A dynamic systems perspective regarding students' learning processes: Shame reactions and emergent selforganizations. In P. A. Schutz \& R. Pekrun (Eds.), Emotion in education (pp. 125-145). Burlington: Elsevier.

Van Den Hurk, M. (2006). The relation between self-regulated strategies and individual study time, prepared participation and achievement in a problem-based curriculum. Active Learning in Higher Education, 7(2), 155169.

Vansteenkiste, M., Simons, J., Lens, W., Sheldon, K. M., \& Deci, E. L. (2004). Motivating learning, performance, and persistence: The synergistic effects of intrinsic goal contents and autonomy-supportive contexts. Journal of Personality and Social Psychology, 87, 246-260.

Vansteenkiste, M., Zhou, M., Lens, W., \& Soenens, B. (2005). Experiences of autonomy and control among Chinese learners: Vitalizing or 
immobilizing? Journal of Educational Psychology, 97(3), 468-483.

Volet, S., \& Mansfield, C. (2006). Group work at university: significance of personal goals in the regulation strategies of students with positive and negative appraisals. Higher Education Research \& Development, 25(4), 341-356. doi: 10.1080/07294360600947301

Volet, S., Vauras, M., \& Salonen, P. (2009). Self- and social regulation in learning contexts: An integrative perspective. Educational Psychologist, 44(4), 215226. doi: 10.1080/00461520903213584

Wang, C. (2004). Self regulated learning strategies and self efficacy beliefs of children learning English as a second language. Doctoral dissertation, Ohio State University, Ohio. Retrieved from http://etd.ohiolink.edu/sendpdf.cgi/Wang\%20Chuang.pdf?acc num $=$ osu 1091546670

Wang, C., \& Pape, S. J. (2004). Self-efficacy beliefs and self-regulated learning strategies in learning English as a second language: Four case studies. The CATESOL Journal, 16(1), 1-19.

Wang, C., Quach, L. H., \& Rolston, J. (2009). Understanding English language learners' self-regulated learning strategies. In C. C. Park, R. Endo \& X. L. Rong (Eds.), New perspectives on Asian American parents, students, and teacher recruitment. United States of America: Information Age

Weiner, B. (1986). Attribution, emotion and action. In R. M. Sorrentino \& E. T. Higgins (Eds.), Handbook of motivation and cognition: Foundations of social behaviour. New York: The Guilford Press.

Weiner, B. (1992). Human motivation: Metaphors, theories and research. Newbury Park, CA: Sage.

Weinstein, C. E., \& Mayer, R. E. (1986). The teaching of learning strategies. In M. Wittrock (Ed.), The handbook of research on teaching. New York: Macmillan.

Weistein, C. E., Husman, J., \& Dierking, D. R. (2000). Self-regulation intervention with a focus on learning strategies. In M. Boekaerts, P. R. Pintrich \& M. Zeidner (Eds.), Handbook of self-regulation. San Diego: Academic Press.

Wentzel, K. R. (2000). What is it that I'm trying to achieve? Classroom goals from a content perspective. Contemporary Educational Psychology, 25, 105-115.

Whipp, J. L., \& Chiarelli, S. (2004). Self-regulation in a web-based course: A case study. Educational Technology Research and Development, 52(4), 5-22.

White, C. (1999). Expectations and emergent beliefs of self-instructed language learners. System, 27(4), 443-457. doi: 10.1016/s0346-251x(99)00044-5

Winne, P. H., \& Perry, N. E. (2000). Measuring self-regulated learning. In M. Boekaerts, P. R. Pintrich \& M. Zeidner (Eds.), Handbook of self-regulation San Diego, CA: Academic Press.

Wodak, R., de Cillia, R., Reisigl, M., \& Liebhart, K. (2000). The discursive construction of national identity. Edinburgh: Edinburgh University Press.

Wolters, C. (2004). Advancing achievement goal theory: Using goal structures and goal orientations to predict students' motivation, cognition, and achievement. Journal of Educational Psychology, 96, 236-250.

Wolters, C. A. (1999). The relation between high school students' motivational regulation and their use of learning strategies, effort, and classroom performance. Learning and Individual Differences, 11(3), 281-299.

Wong, M. S. L. (2005). Language learning strategies and language self-efficacy: Investigating the relationship in Malaysia. RELC Journal, 36(3), 245-269.

$\mathrm{Wu}, \mathrm{P} . \mathrm{C}$. (2006). The effects of goal orientation, self-efficacy, and cognitive/metacognitive self-regulatory strategy use on EFL college 
students' course achievement. Doctoral dissertation, University of Southern California, Southern California. Retrieved from http://gradworks.umi.com/32/38/3238324.html

Yin, R. K. (2009). Case study research: Design and methods (4 ed.). California: Sage. Young, M. R. (2005). The motivational effects of the classroom environment in facilitating self-regulated learning. Journal of Marketing Education 27(25), 25-40.

Zamel, V. (1983). The composing processes of advanced ESL students: Six case studies. TESOL Quaterly, 17(2), 165-187.

Zeidner, M., Boekaerts, M., \& Pintrich, P. R. (2000). Self-regulation: Directions and challenges for future research In M. Boekaerts, P. R. Pintrich \& M. Zeidner (Eds.), Handbook of self-regulation (pp. 749-768). San Diego: Academic Press.

Zimmerman, B. (1990). Self-regulating academic learning and achievement: The emergence of a social cognitive perspective. Educational Psychology Review, 2(2), 173-201. doi: 10.1007/bf01322178

Zimmerman, B. J. (1983). Social learning theory: A contextualist account of cognitive functioning. In C. J. Brainerd (Ed.), Recent advances in cognitive development theory. New York: Springer.

Zimmerman, B. J. (1986). Becoming a self-regulated learner: What are the key subprocesses? Contemporary Educational Psychology, 16, 307-313.

Zimmerman, B. J. (1989a). Models of self-regulated learning and academic achievement. In B. J. Zimmerman \& D. H. Schunk (Eds.), Self-regulated learning and academic achievement: Theory, research, and practice (pp. 126). New York: Springer-Verlag.

Zimmerman, B. J. (1989b). A social cognitive view of self-regulated academic learning. Journal of Educational Psychology, 81(3), 329-339. doi: 10.1037/0003-066x.37.2.122

Zimmerman, B. J. (1990). Self-regulated learning and academic achievement: An overview. Educational Psychologist, 25(1), 3-17. doi: 10.1207/s15326985ep2501_2

Zimmerman, B. J. (1998). Developing self-fulfilling cycles of academic regulation: An analysis of exemplary instructional models. In H. Schunk \& B. J. Zimmerman (Eds.), Self-regulated learning: From teaching to self-reflective practice. New York: Guilford Press.

Zimmerman, B. J. (2000a). Attaining self-regulation: A social cognitive perspective. In M. Boekaerts, P. R. Pintrich \& M. Zeidner (Eds.), Handbook of self-regulation (pp. 13-39). New York: Academic Press.

Zimmerman, B. J. (2000b). Self-efficacy: An essential motive to learn. Contemporary Educational Psychology, 25, 82-91.

Zimmerman, B. J. (2001). Theories of self-regulated learning and academic achievement: An overview and analysis. In B. J. Zimmerman \& D. H. Schunk (Eds.), Self-regulated learning and academic achievement: Theoretical perspectives. Mahwah, NJ: Lawrence Erlbaum

Zimmerman, B. J. (2002a). Achieving academic excellence: A self-regulatory perspective. In M. Ferrari (Ed.), The pursuit of excellence through education (pp. 85-110). Mahwah, NJ: Erlbaum.

Zimmerman, B. J. (2002b). Becoming a self-regulated learner: An overview. Theory into Practice, 41(2), 64-70.

Zimmerman, B. J. (2008a). Goal setting: A key proactive source of academic selfregulation. In D. H. Schunk \& B. J. Zimmerman (Eds.), Motivation and self- 
regulated learning: Theory, research, and applications. New York: Lawrence Erlbaum

Zimmerman, B. J. (2008b). Investigating self-regulation and motivation: Historical background, methodological developments, and future prospects. American Educational Research Journal, 45(1), 166-183. doi: 10.3102/0002831207312909

Zimmerman, B. J., Bonner, S., \& Kovach, R. (1996). Developing self-regulated learners: Beyond achievement to self-efficacy. Washington, D. C: American Psychological Association.

Zimmerman, B. J., Bonner, S., \& Kovach, R. (2006). Developing self-regulated learners: Beyond achievement to self-efficacy. Washington, D.C.: American Psychological Association.

Zimmerman, B. J., \& Campillo, M. (2003). Phases and subproceses of selfregulation. In J. E. Davidson \& R. J. Sternberg (Eds.), The nature of problem solving (pp. 239). New York Cambridge University Press.

Zimmerman, B. J., \& Campilo, M. (2003). Motivating self-regulated problem solvers. In J. E. Davidson \& R. J. Stenberg (Eds.), The nature of problem solving (pp. 239). New York: Cambridge University.

Zimmerman, B. J., \& Martinez-Pons, M. (1986). Development of a structured interview for assessing students' use of self-regulated learning strategies. American Eduational Research Journal, 23(4), 614-628.

Zimmerman, B. J., \& Martinez-Pons, M. (1990). Student differences in selfregulated learning: Relating grade, sex, and gifttedness to self-efficacy and strategy use. Journal of Educational Psychology, 82(1), 51-59.

Zimmerman, B. J., \& Risemberg, R. (1997). Self-regulatory dimensions of academic learning and motivation. In G. D. Phye (Ed.), Handbook of academic learning: Construction of knowledge (pp. 105-125). New York: Academic Press.

Zimmerman, B. J., \& Schunk, D. H. (2001a). Reflections on theories of selfregulated learning and academic achievement. In B. J. Zimmerman \& D. H. Schunk (Eds.), Self-regulated learning and academic achievement: Theoretical perspectives. Mahwah, NJ: Lawrence Erlbaum

Zimmerman, B. J., \& Schunk, D. H. (2001b). Self-regulated learning and academic achievement: Theoretical perspectives. Mahwah, NJ: Lawrence Erlbaum

Zimmerman, B. J., \& Schunk, D. H. (2004). Self-regulating intellectual processes and outcomes: A social cognitive perspective. In D. Y. Dai \& R. J. Sternberg (Eds.), Motivation, emotion, and cognition: Integrative perspectives on intellectual functioning and development (pp. 323-349). Mahwah, NJ: Erlbaum 


\section{Appendices}

\section{Appendix A: MUET results}

Graph 1: MUET Score for $2007 / 2008$ student intake at a public university in Malaysia

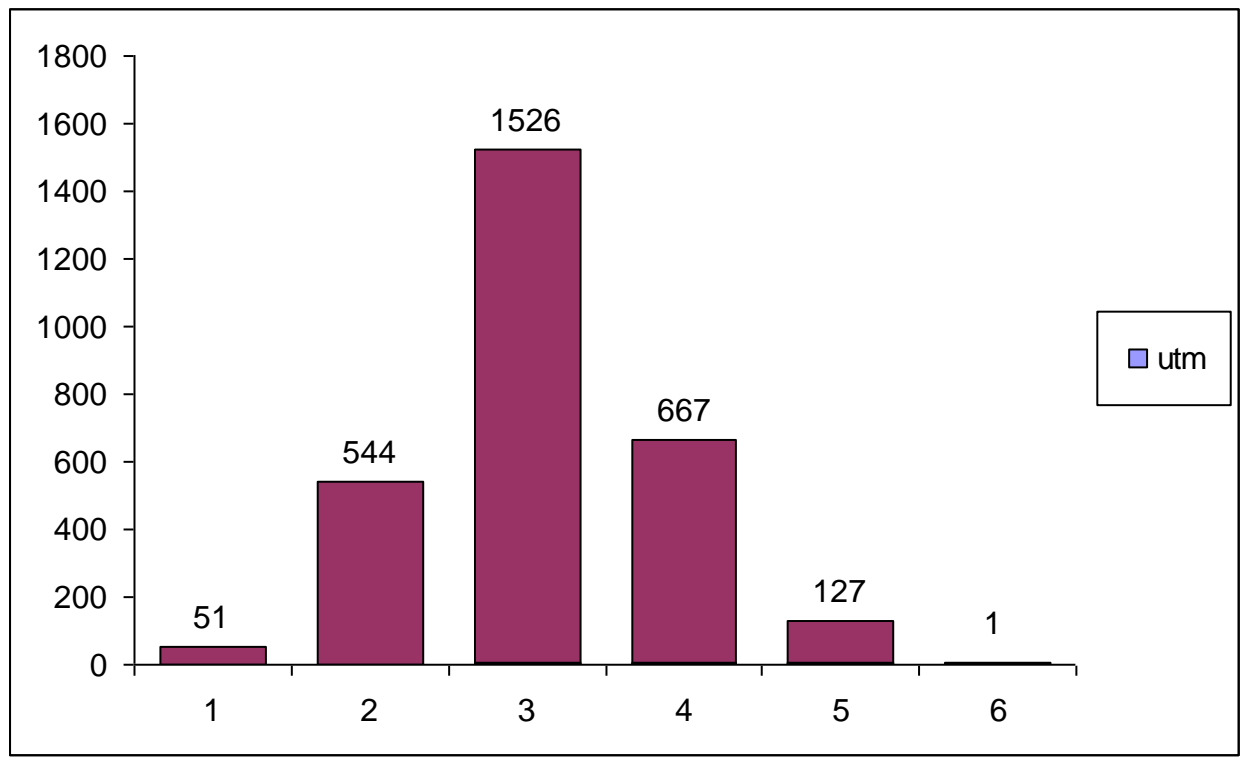

Source: Centre for Teaching \& Learning (2007)

Malaysian secondary school students are required to take a compulsory MUET (Malaysian Undergraduate English Test) for entrance into a public university. Graph 1 shows the MUET results for new entry students for 2007/8 intake at one public university (Technology University of Malaysia), which can be considered a typical sample for other public universities, including my research site. The result shows that most of the students scored below the satisfactory level in English competency. From the population of 2916 new student's intake, about $72.7 \%$ has a score of band 1,2 and 3 . 
Graph 2: Analysis of MUET result for 2008/2009 student intake at National University of Malaysia

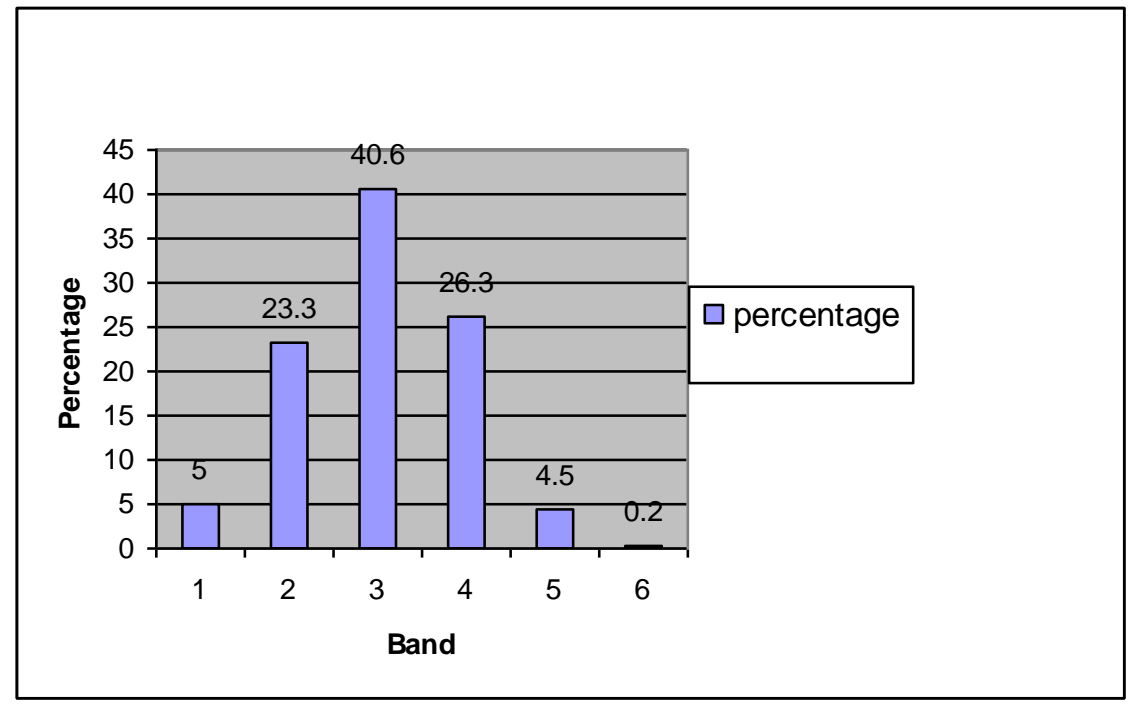

Source: Academic Department (2009)

For a description of Band 1-6, refer to MUET scores on a six-band scale below:

MUET Components, Scoring and Grading

\section{Description of MUET}

The MUET was developed in 1999 in response to requests for a standardized test of English language proficiency for students applying to enter university. The MUET is now a requirement for admission to local universities. In order to be admitted, applicants must obtain the minimum band set by the faculties of each university. The test is used to determine whether candidates have an adequate level of English ability to follow undergraduate courses in the chosen field of study. It should also provide some diagnostic information for remedial English language courses for those candidates whose English ability is not considered adequate for a particular undergraduate programme.

The body which is responsible for the conduct of the Malaysian University English Test is the Malaysian Examinations Council, a statutory body established under the Malaysian Council Act 1989. The MUET can only be taken by those who have already sat for any of the following examinations: Sijil Pelajaran Malaysia (SPM), SPM (Vocational), Malaysian Certificate of Education (MCE), Cambridge School Certificate or those who have gone through a 10 -year formal education, that is equivalent to 0-level. 


\section{Structure of the MUET}

There are four sections: listening, reading, writing and speaking and each section counts towards the score. The following diagram shows the structure of the MUET.

\begin{tabular}{|c|c|c|c|c|}
\hline Component & Time & Questions & $\begin{array}{l}\text { Weight } \\
(\%)\end{array}$ & $\begin{array}{l}\text { Maximum } \\
\text { Score }\end{array}$ \\
\hline Listening & $\begin{array}{l}30 \\
\text { minutes }\end{array}$ & $\begin{array}{l}15 \text { multiple choice reading comprehension } \\
\text { questions }\end{array}$ & $15 \%$ & 45 \\
\hline Reading & 2 hours & $\begin{array}{l}50 \text { multiple choice questions: } \\
8^{\text {th }} \text { word cloze }-15 \text { blanks } \\
\text { Information transfer tasks- } 7 \text { items } \\
\text { Reading comprehension }-28 \text { items }\end{array}$ & $45 \%$ & 135 \\
\hline Writing & $\begin{array}{l}1 \text { hour } 30 \\
\text { minutes }\end{array}$ & 2 writing tasks: summary and essay writing & $25 \%$ & 75 \\
\hline \multirow[t]{2}{*}{ Speaking } & $\begin{array}{l}30 \\
\text { minutes }\end{array}$ & $\begin{array}{l}2 \text { guided tasks: an individual presentation and a } \\
\text { group discussion }\end{array}$ & $15 \%$ & 45 \\
\hline & $\begin{array}{l}4 \text { hours } \\
30 \\
\text { Minutes }\end{array}$ & & $100 \%$ & 300 \\
\hline
\end{tabular}


MUET scores on a six-band scale

\begin{tabular}{|c|c|c|c|c|c|c|}
\hline $\begin{array}{l}\text { Aggregated } \\
\text { Band Score }\end{array}$ & Band & User & $\begin{array}{l}\text { Command of } \\
\text { language }\end{array}$ & $\begin{array}{l}\text { Communicative } \\
\text { Ability }\end{array}$ & Understanding & $\begin{array}{l}\text { Task } \\
\text { Performance }\end{array}$ \\
\hline $260-300$ & 6 & $\begin{array}{l}\text { Very good } \\
\text { user }\end{array}$ & $\begin{array}{l}\text { Very good } \\
\text { command of } \\
\text { the language }\end{array}$ & $\begin{array}{l}\text { Very fluent, } \\
\text { accurate and } \\
\text { appropriate; } \\
\text { hardly any } \\
\text { inaccuracies }\end{array}$ & $\begin{array}{l}\text { High level of } \\
\text { understanding of } \\
\text { the language }\end{array}$ & $\begin{array}{l}\text { Functions } \\
\text { extremely } \\
\text { well in the } \\
\text { language }\end{array}$ \\
\hline $220-259$ & 5 & Good user & $\begin{array}{l}\text { Good } \\
\text { command of } \\
\text { the language }\end{array}$ & $\begin{array}{l}\text { Fluent, } \\
\text { appropriate, but } \\
\text { with occasional } \\
\text { inaccuracies }\end{array}$ & $\begin{array}{l}\text { Good level of } \\
\text { understanding of } \\
\text { the language }\end{array}$ & $\begin{array}{l}\text { Functions } \\
\text { well in the } \\
\text { language }\end{array}$ \\
\hline $180-219$ & 4 & $\begin{array}{l}\text { Competent } \\
\text { user }\end{array}$ & $\begin{array}{l}\text { Satisfactory } \\
\text { command of } \\
\text { the language }\end{array}$ & $\begin{array}{l}\text { Generally } \\
\text { fluent, } \\
\text { appropriate but } \\
\text { with occasional } \\
\text { inaccuracies }\end{array}$ & $\begin{array}{l}\text { Satisfactory level } \\
\text { of understanding } \\
\text { of the language }\end{array}$ & $\begin{array}{l}\text { Functions } \\
\text { reasonably } \\
\text { well in the } \\
\text { language }\end{array}$ \\
\hline $140-179$ & 3 & $\begin{array}{l}\text { Modest } \\
\text { user }\end{array}$ & $\begin{array}{l}\text { Fair } \\
\text { command of } \\
\text { the language }\end{array}$ & $\begin{array}{l}\text { Fairly fluent, } \\
\text { usually } \\
\text { appropriate, but } \\
\text { with noticeable } \\
\text { inaccuracies }\end{array}$ & $\begin{array}{l}\text { Able to } \\
\text { understand but } \\
\text { with some } \\
\text { misinterpretation }\end{array}$ & $\begin{array}{l}\text { Able to } \\
\text { function, but } \\
\text { with some } \\
\text { effort }\end{array}$ \\
\hline $100-139$ & 2 & $\begin{array}{l}\text { Limited } \\
\text { user }\end{array}$ & $\begin{array}{l}\text { Limited } \\
\text { command of } \\
\text { the language }\end{array}$ & $\begin{array}{l}\text { Lacks fluency } \\
\text { and } \\
\text { appropriacy, } \\
\text { inaccurate use } \\
\text { of the language } \\
\text { resulting in } \\
\text { frequent } \\
\text { breakdowns in } \\
\text { communication }\end{array}$ & $\begin{array}{l}\text { Limited } \\
\text { understanding of } \\
\text { the language }\end{array}$ & $\begin{array}{l}\text { Limited } \\
\text { ability to } \\
\text { function in } \\
\text { the language }\end{array}$ \\
\hline $0-99$ & 1 & $\begin{array}{l}\text { Extremely } \\
\text { limited } \\
\text { user }\end{array}$ & $\begin{array}{l}\text { Poor } \\
\text { command of } \\
\text { the language }\end{array}$ & $\begin{array}{l}\text { Inappropriate } \\
\text { and inaccurate } \\
\text { use of the } \\
\text { language; } \\
\text { frequent } \\
\text { breakdowns in } \\
\text { communication }\end{array}$ & $\begin{array}{l}\text { Poor } \\
\text { understanding of } \\
\text { the language }\end{array}$ & $\begin{array}{l}\text { Hardly able } \\
\text { to function in } \\
\text { the language }\end{array}$ \\
\hline
\end{tabular}

Source: Malaysian Examination Council (2008) 


\section{Appendix B (1): Categories of SRL strategies}

\begin{tabular}{|c|c|}
\hline Category definitions & $\begin{array}{l}\text { Examples within the English language learners } \\
\text { sample }\end{array}$ \\
\hline $\begin{array}{l}\text { 1. Self-evaluation: Self-initiated evaluations of the } \\
\text { quality or progress of students' work. }\end{array}$ & $\begin{array}{l}\text { Check the writing before returning it in to the } \\
\text { teacher. }\end{array}$ \\
\hline $\begin{array}{l}\text { 2. Organizing and transforming: Self-initiated overt } \\
\text { or covert rearrangement of instructional materials } \\
\text { to improve learning. }\end{array}$ & $\begin{array}{l}\text { Translate English into their native language to help } \\
\text { memorize the word. }\end{array}$ \\
\hline $\begin{array}{l}\text { 3. Goal setting and planning: Setting educational } \\
\text { goals or sub goals and planning for sequencing, } \\
\text { timing, and completing activities related to the } \\
\text { self-set goals. }\end{array}$ & $\begin{array}{l}\text { Adjust what to write in a journal entry by checking } \\
\text { how much time is left. }\end{array}$ \\
\hline $\begin{array}{l}\text { 4. Seeking information: Self-initiated efforts to } \\
\text { secure further task information from non-social } \\
\text { sources. }\end{array}$ & Look for the meaning of a word in a dictionary. \\
\hline $\begin{array}{l}\text { 5. Keeping records and monitoring: Self-initiated } \\
\text { efforts to record events or results. }\end{array}$ & Take down an unknown word to ask for help later. \\
\hline $\begin{array}{l}\text { 6. Environmental structuring: Self-initiated efforts to } \\
\text { select or arrange the physical setting to make } \\
\text { learning easier. }\end{array}$ & Study in one's own room. \\
\hline $\begin{array}{l}\text { 7. Self-consequences: Student arrangement or } \\
\text { imagination of rewards or punishment for success } \\
\text { or failure. }\end{array}$ & $\begin{array}{l}\text { Jump up and down when one gets good results of } \\
\text { study. }\end{array}$ \\
\hline $\begin{array}{l}\text { 8. Attentional control: Self-initiated performance of a } \\
\text { particular personal behaviour to improve learning. }\end{array}$ & Listen carefully in class. \\
\hline $\begin{array}{l}\text { 9. Rehearsing and memorizing: Self-initiated efforts } \\
\text { to memorize learning materials by overt or covert } \\
\text { practice. }\end{array}$ & $\begin{array}{l}\text { Write the word many times on paper in order to } \\
\text { memorise it. }\end{array}$ \\
\hline $\begin{array}{l}\text { 10. Seeking assistance: Self-initiated efforts to solicit } \\
\text { help from adults, teachers, or peers. }\end{array}$ & Ask the teacher for help. \\
\hline $\begin{array}{l}\text { 11. Reviewing records: Self-initiated efforts to reread } \\
\text { notes, tests, or textbooks. }\end{array}$ & Reread the textbook before a test. \\
\hline
\end{tabular}

Source: Wang (2004) 


\section{Appendix B (2): Categories of SRL strategies of Malaysian tertiary level ESL learners}

\begin{tabular}{|c|c|}
\hline Category definitions & $\begin{array}{c}\text { Examples within the tertiary level English } \\
\text { language learners }\end{array}$ \\
\hline $\begin{array}{l}\text { COGNITIVE \& METACOGNITIVE STRATEGIES } \\
\text { 1. Goal setting and planning: Setting educational } \\
\text { goals or sub goals and planning for sequencing, } \\
\text { timing, and completing activities related to the } \\
\text { self-set goals. }\end{array}$ & $\begin{array}{l}\text { Planning for the completion of course assignments } \\
\text { based on the date of presentation and submission, } \\
\text { and allocation of marks for each assignments }\end{array}$ \\
\hline $\begin{array}{l}\text { 2. Seeking information: Self-initiated efforts to } \\
\text { secure further task information from non-social } \\
\text { sources. }\end{array}$ & Using online resources like an online dictionary \\
\hline $\begin{array}{l}\text { 3. Organizing and transforming: Self-initiated overt } \\
\text { or covert rearrangement of instructional } \\
\text { materials to improve learning. }\end{array}$ & $\begin{array}{l}\text { Translating English into one's first language; and } \\
\text { preparing a mind-map of points for individual } \\
\text { presentation }\end{array}$ \\
\hline $\begin{array}{l}\text { 4. Self-evaluation: Self-initiated evaluations of the } \\
\text { quality or progress of students' work. }\end{array}$ & $\begin{array}{l}\text { Using checklists and referring to course descriptions } \\
\text { on criteria listed by the language teacher for the } \\
\text { award of assignment marks; rewriting and editing } \\
\text { drafts for course assignments based on feedback } \\
\text { from the language teacher and more advanced } \\
\text { students; referring to examples of good course } \\
\text { assignments like a project report }\end{array}$ \\
\hline $\begin{array}{l}\text { RESOURCE MANAGEMENT STRATEGIES } \\
\text { 5. Environmental structuring: Self-initiated efforts } \\
\text { to select or arrange the physical setting to make } \\
\text { learning easier. }\end{array}$ & $\begin{array}{l}\text { Telling friends that they are trying to finish their } \\
\text { assignments; move to a quieter place for studying }\end{array}$ \\
\hline $\begin{array}{l}\text { 6. Seeking assistance: Self-initiated efforts to solicit } \\
\text { help from teachers, or peers. }\end{array}$ & $\begin{array}{l}\text { Getting assistance from students with better } \\
\text { language proficiency; asking their language teacher } \\
\text { to check their drafts of a group project report; } \\
\text { asking online friends to correct grammatical } \\
\text { mistakes during online conversations and doing } \\
\text { self-correction via online facilities like spelling and } \\
\text { grammar check }\end{array}$ \\
\hline $\begin{array}{l}\text { MANAGING EMOTION STRATEGIES } \\
\text { 7. Positive self-talk }\end{array}$ & $\begin{array}{l}\text { Telling themselves not to be embarrassed over } \\
\text { language mistakes made }\end{array}$ \\
\hline $\begin{array}{l}\text { 8. Self-consequences: Student arrangement or } \\
\text { imagination of rewards or punishment for } \\
\text { success or failure. }\end{array}$ & $\begin{array}{l}\text { Taking a break or going for an outing with peers } \\
\text { after achieving success in language learning }\end{array}$ \\
\hline
\end{tabular}


3. I would like to draw your attention to the undertaking signed by you that you will submit without cost to the Economic Planning Unit the following documents:

a)

A brief summary of your research findings on completion of your research and before you leave Malaysia; and

b) Three (3) copies of your final dissertation/publication.

4. Lastly, please submit a copy of your preliminary and final report directly to the State Government where you carried out your research. Thank you.

Yours sincerely,

Nherame

MUNIRAH ABD. MANAN

For Directo

Economic Planning Unit.

E-mail: munirah@epu.gov.my

Tel: $88725281 / 88725272$

Fax: 88883961

\section{ATTENTION}

This letter is only to inform you the status of your application and cannot be used as a research pass. 


\section{Appendix D: Research information sheets and consent forms}

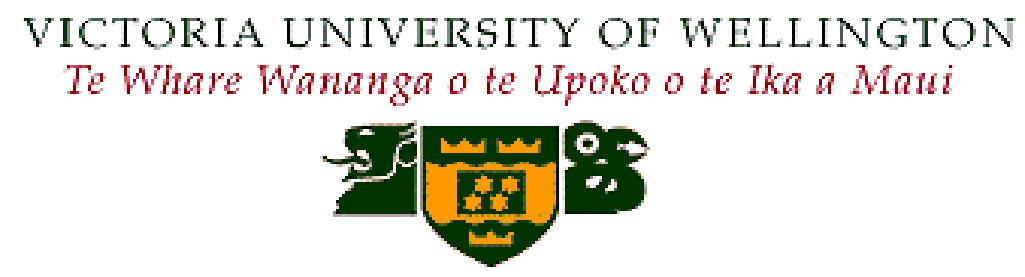

Azizah Binti Mohd Zahidi

PhD candidate

c/o Postgraduate Office

Faculty of Education

Victoria University of Wellington

Date

Title of project: Self-regulation of Malaysian English language learners at the tertiary level.

Researcher: Azizah Binti Mohd Zahidi, School of Educational Psychology and Pedagogy, Faculty of Education, Victoria University of Wellington.

\section{RESEARCH INFORMATION SHEET: STUDENTS}

I am a PhD student at the School of Educational Psychology and Pedagogy, Faculty of Education, Victoria University of Wellington. I am undertaking research in Self-regulation of Malaysian English language learners at the tertiary level for my PhD dissertation. This research is supervised by Dr Stephanie Doyle and Carolyn Tait.

I would like to invite you to participate in my research. Your participation is voluntary and you will not be identified in the research report or in any other presentation or publication. Your participation in this research will not affect your English language course grade. The knowledge of self-regulation among English language learners from this research aims to contribute to the development of future language learning programmes.

\section{What happens if you agree to participate?}

If you agree to participate in this research, you are invited to take part in the case study. You will take part in three interviews of varying lengths. The length of the initial interview will be 40 - 60 minutes for each participant. The follow up interviews will take 30 minutes, and the final interview will be in about $40-60$ minutes.

These interviews will be taped to provide a record of what was said for later analysis. Weekly observations of language classrooms will be conducted. You will also be required to write a detailed record and reflection on your language learning experiences for three months. You will have to print and send the diary entries on a weekly basis to the researcher. The researcher will respond to the 
diary by asking for clarification of the diary content in relation to self-regulation via e mail with the individual participant. Your permission will be sought to access your notes, course works and assignments (writing and project drafts) and assessments (quizzes). These will be analysed for any evidence of selfregulatory strategies.

\section{How will I ensure that your privacy, rights and confidentiality are protected?}

All participants involved in this research have the right to decline participation and withdraw themselves (or any information provided) from the research at any time before data collection and analysis is complete. The participants can ask questions about the study at any time throughout their participation and have the questions answered to their satisfaction. They can also refuse to answer any particular questions. Participants will receive feedback or a summary of the research findings when it is concluded.

The names of student-participants and language classes will remain confidential to the researcher and her supervisors. Participants will be allowed to choose their own pseudonyms. Language classes will also be given a pseudonym in this research project or in any other presentation or publication. All audio and transcript files will be kept on password protected systems. All hardcopy written materials will be kept in a locked filing cabinet and will be destroyed five years after the research is completed. All interviews which are audio-taped will be transcribed by the researcher herself and codes will be used for participants. Transcription of data from interviews will be given to participants for checking before it is being used in the analysis.

\section{What happens to the information provided by participants?}

- Initially your coded data will be used in writing my doctoral dissertation. The PhD dissertation will be submitted to the university and deposited in the university library (student research).

- Papers will be written to be presented at conferences and articles submitted to academic journals.

- Copies of the final PhD thesis will also be submitted to the Malaysian Ministry of Higher Education, Malaysian Economic Planning Unit and National University of Malaysia library.

This research has been reviewed and approved by Victoria University Faculty of Education Ethics Committee. The University requires that ethics approval be obtained for research involving human participants. If you require any further information or clarifications about this research, please do not hesitate to contact me or my supervisors at Victoria University of Wellington (details below). 
Supervisors contact details:

\begin{tabular}{|c|c|}
\hline $\begin{array}{l}\text { Dr Stephanie Doyle } \\
\text { Faculty of Education } \\
\text { Victoria University of Wellington } \\
\text { P0 Box 17-310 } \\
\text { Karori, Wellington } 6147 \text { New Zealand } \\
\text { Email: Stephanie.doyle@vuw.ac.nz } \\
\text { Ph: }+6444636657\end{array}$ & $\begin{array}{l}\text { Carolyn Tait } \\
\text { Faculty of Education } \\
\text { Victoria University of Wellington } \\
\text { PO Box 17-310 } \\
\text { Karori, Wellington } 6147 \text { New Zealand } \\
\text { Email: carolyn.tait@vuw.ac.nz } \\
\text { Ph: }+6444639590\end{array}$ \\
\hline \multicolumn{2}{|l|}{$\begin{array}{l}\text { Azizah Binti Mohd Zahidi } \\
\text { No 9, Jalan 23/E, Pandamaran Jaya, } \\
42000 \text { Pelabuhan Kelang, Selangor, } \\
\text { Malaysia }\end{array}$} \\
\hline $\begin{array}{l}\text { Email: azizah.zahidi@vuw.ac.nz } \\
\text { Ph: +603 } 31672367 \text { (home) +603 } 01\end{array}$ & 53 \\
\hline
\end{tabular}

Thank you for taking the time to read this information sheet and thinking about your participation in this research. The information gained from you for this research will help the researcher to gain insights of English language learners' self-regulation strategies. The findings of this study may later prove to be valuable to language teachers in developing intervention program for language learners to equip them with self-regulation strategies for them to be strategic and effective learners.

I am looking forward to your reply.

Yours Sincerely,

Azizah Binti Mohd Zahidi 
Title of project:

Self-regulation of Malaysian English language learners at the tertiary level.

\section{STUDENT'S CONSENT TO PARTICIPATE IN RESEARCH}

\section{Please tick (/) each box}

I agree to take part in this research under the conditions set out in the information sheet.

I have been provided with sufficient information regarding the nature and objectives of this research.

I have understood the information and have been given the chance to obtain further clarification.

I am clear that I may withdraw from this study at any time until the final analysis of data, without having to give reasons and without any penalty of any sort. My data would also be withdrawn and destroyed.

I understand that any information or opinion I provide will be kept confidential. No information which identifies me individually will be used and no opinions will be attributed to me in any way that will identify me.

I understand that the information I have provided will be used only for this research project, publications and presentations arising from this research.

I understand that when this research is completed the information obtained will be destroyed.

Signature:

Name:

Date:

I would like to receive a summary of the research findings: YES / NO

Please send the summary to the following address: 
Azizah Binti Mohd Zahidi

$\mathrm{PhD}$ candidate

c/o Postgraduate Office

Faculty of Education

Victoria University of Wellington

Date

Title of project: Self-regulation of Malaysian English language learners at the tertiary level.

Researcher: Azizah Binti Mohd Zahidi, School of Educational Psychology and Pedagogy, Faculty of Education, Victoria University of Wellington.

\section{RESEARCH INFORMATION SHEET: TEACHER}

I am a PhD student at the School of Educational Psychology and Pedagogy, Faculty of Education, Victoria University of Wellington. I am undertaking research in Self-regulation of Malaysian English language learners at the tertiary level for my PhD dissertation. This research is supervised by Dr Stephanie Doyle and Carolyn Tait.

I would like to invite four students from your language class to be the participants in case studies. I need your consent for me to conduct classroom observation, conduct interview with the participants, collect entries of learner diary (from class blog), collect student work (such as writing drafts, project) and refer to relevant course documentation (such as course outlines and assessments).

Your voluntary participation in this research will contribute to knowledge of English language learners' self-regulation and may provide valuable information to language teachers for the development of intervention program in order to empower language learners to become more self-directed, strategic and resourceful in their learning through the application of appropriate and effective self-regulation strategies.

What happens if you give your consent for me to conduct the research?

- Since the main purpose of this study is to identify SRL strategies used by each participant, the primary focus of classroom observation is on individual students.

- Other students in the class who do not wish to be part of the observation (such as in pair work and group work) can inform you. You will then arrange for other students to be partner or group members of the research participants. 


\section{How will I ensure that the participants' privacy, rights and confidentiality are protected?}

All participants involved in this research have the right to decline participation and withdraw themselves (or any information provided) from the research at any time before data collection and analysis is complete. The participants can ask questions about the study at any time throughout their participation and have the questions answered to their satisfaction. They can also refuse to answer any particular questions. Participants will receive feedback or a summary of the research findings when it is concluded.

The names of student-participants, language classes, classroom teachers and language department will remain confidential to the researcher and her supervisors. Participants will be allowed to choose their own pseudonyms. Language classes will also be given a pseudonym in this research project or in any other presentation or publication. All audio and transcript files will be kept on password protected systems to safeguard against unauthorised access and misuse of data. All hardcopy written materials will be kept in a locked filing cabinet and will be destroyed five years after the research is completed. All interviews which are audio-taped will be transcribed by the researcher herself and codes will be used for participants. Transcription of data from interviews will be given to participants for checking before it is being used in the analysis.

\section{What happens to the information provided by participants?}

Initially the coded data will be used in writing my doctoral dissertation. The PhD dissertation will be submitted to the university and deposited in the university library (student research).

- Papers will be written to be presented at conferences and articles submitted to academic journals.

- Copies of the final PhD thesis will also be submitted to the Malaysian Ministry of Higher Education, Malaysian Economic Planning Unit and National University of Malaysia library.

This research has been reviewed and approved by Victoria University Faculty of Education Ethics Committee. The University requires that ethics approval be obtained for research involving human participants. If you require any further information or clarifications about this research, please do not hesitate to contact me or my supervisors at Victoria University of Wellington (details below). 
Supervisors contact details:

\begin{tabular}{|c|c|}
\hline $\begin{array}{l}\text { Dr Stephanie Doyle } \\
\text { Faculty of Education } \\
\text { Victoria University of Wellington } \\
\text { P0 Box 17-310 } \\
\text { Karori, Wellington } 6147 \text { New Zealand } \\
\text { Email: Stephanie.doyle@vuw.ac.nz } \\
\text { Ph: +644 4636657 }\end{array}$ & $\begin{array}{l}\text { Carolyn Tait } \\
\text { Faculty of Education } \\
\text { Victoria University of Wellington } \\
\text { PO Box 17-310 } \\
\text { Karori, Wellington } 6147 \text { New Zealand } \\
\text { Email: carolyn.tait@vuw.ac.nz } \\
\text { Ph: }+6444639590\end{array}$ \\
\hline \multicolumn{2}{|l|}{$\begin{array}{l}\text { Azizah Binti Mohd Zahidi } \\
\text { No 9, Jalan 23/E, Pandamaran Jaya, } \\
42000 \text { Pelabuhan Kelang, Selangor, } \\
\text { Malaysia }\end{array}$} \\
\hline $\begin{array}{l}\text { Email: azizah.zahidi@vuw.ac.nz } \\
\text { Ph: +603 31672367(home) +603 } 0122\end{array}$ & 523 (cell-phone) \\
\hline
\end{tabular}

Thank you for taking the time to read this information sheet and thinking about the participation of your students in this research. The information gained from this research may provide information to language teachers in developing intervention program for language learners to equip them with self-regulation strategies for them to be strategic and effective learners. If you agree for me to conduct this research at the language classrooms, please complete and return the attached consent form using the enclosed envelope.

I am looking forward to your reply.

Yours Sincerely,

Azizah Binti Mohd Zahidi 
Title of project:

Self-regulation of Malaysian English language learners at the tertiary level.

\section{TEACHER'S CONSENT TO PARTICIPATE IN RESEARCH}

Please tick (/) each box

I give consent for Azizah Binti Mohd Zahidi, PhD student at Victoria University of Wellington, to orally inform the students in my class of the research purpose and invite students to participate in her research, and for her to conduct classroom observations of (language course).

I agree to the participation of my language students in this research under the conditions set out in the information sheet.

I have been given the information about this project and I understand the explanation of this research project.

I have had the opportunity to ask questions and have them answered to my satisfaction.

I understand that I can withdraw my consent (or any information I have provided) at any time prior to the end of the data collection period without having to give reasons and I will not be penalised for it.

I understand that any information provided will be confidential. No information will identify the language course and the participants in particular.

I understand that all information will be used only for this research, publications and presentations arising from this research project.

All field notes taken during observation, transcriptions of interviews, copies of participants' diary and documents will be destroyed five years after the research is completed.

Signature:

Name:

Date:

I would like to receive a summary of the research findings carried out with the learners of my language class: YES / NO

Please send the summary to the following address (please write address below). 


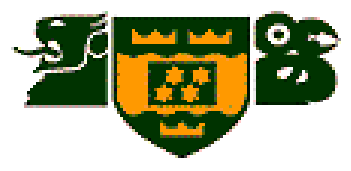

Azizah Binti Mohd Zahidi

$\mathrm{PhD}$ candidate

c/o Postgraduate Office

Faculty of Education

Victoria University of Wellington

Date

Title of project: Self-regulation of Malaysian English language learners at the tertiary level.

Researcher: Azizah Binti Mohd Zahidi, School of Educational Psychology and

Pedagogy, Faculty of Education, Victoria University of Wellington.

\section{RESEARCH INFORMATION SHEET: HEAD OF ENGLISH LANGUAGE DEPARTMENT}

I am a PhD student at the School of Educational Psychology and Pedagogy, Faculty of Education, Victoria University of Wellington. I am undertaking research in Self-regulation of Malaysian English language learners at the tertiary level for my PhD dissertation. This research is supervised by Dr Stephanie Doyle and Carolyn Tait.

I would like to invite the students of the language courses to be the participants for the case studies in this research. I need your consent for me to contact language teachers in your department in order to select participants. I also need your consent to allow me to conduct classroom observations, collect student work samples (such as writing drafts, project and learning diaries), conduct interviews, and refer to relevant course documentation (such as course outlines and assessments).

\section{What happens if you give your consent for me to conduct the research?}

- All participants in this study will be required to give written informed consent.

- The students' participation in this research will provide valuable information to language teachers for the development of intervention program in order to empower language learners to become more self-directed, strategic and resourceful in their learning through the application of appropriate and effective self-regulation strategies. 


\section{How will I ensure that the participants' privacy, rights and confidentiality are protected?}

All participants involved in this research have the right to decline participation and withdraw themselves (or any information provided) from the research at any time before data collection and analysis is complete. The participants can ask questions about the study at any time throughout their participation and have the questions answered to their satisfaction. They can also refuse to answer any particular questions. Participants will receive feedback or a summary of the research findings when it is concluded.

The names of student-participants, language classes, classroom teachers and language department will remain confidential to the researcher and her supervisors. Participants will be allowed to choose their own pseudonyms. Language classes and the department will also be given a pseudonym in this research project or in any other presentation or publication. All audio and transcript files will be kept on password protected systems to safeguard against unauthorised access and misuse of data. All hardcopy written materials will be kept in a locked filing cabinet and will be destroyed five years after the research is completed. All interviews which are audio-taped will be transcribed by the researcher herself and codes will be used for participants. Transcription of data from interviews will be given to participants for checking before it is being used in the analysis.

\section{What happens to the information provided by participants?}

- Initially the coded data will be used in writing my doctoral dissertation. The $\mathrm{PhD}$ dissertation will be submitted to the university and deposited in the university library (student research).

- Papers will be written to be presented at conferences and articles submitted to academic journals.

- Copies of the final PhD thesis will also be submitted to the Malaysian Ministry of Higher Education, Malaysian Economic Planning Unit and National University of Malaysia library.

This research has been reviewed and approved by Victoria University Faculty of Education Ethics Committee. The University requires that ethics approval be obtained for research involving human participants. If you require any further information or clarifications about this research, please do not hesitate to contact me or my supervisors at Victoria University of Wellington (details below). 
Supervisors contact details:

\begin{tabular}{|c|c|}
\hline $\begin{array}{l}\text { Dr Stephanie Doyle } \\
\text { Faculty of Education } \\
\text { Victoria University of Wellington } \\
\text { P0 Box 17-310 } \\
\text { Karori, Wellington } 6147 \text { New Zealand } \\
\text { Email: Stephanie.doyle@vuw.ac.nz } \\
\text { Ph: }+6444636657\end{array}$ & $\begin{array}{l}\text { Carolyn Tait } \\
\text { Faculty of Education } \\
\text { Victoria University of Wellington } \\
\text { PO Box 17-310 } \\
\text { Karori, Wellington } 6147 \text { New Zealand } \\
\text { Email: carolyn.tait@vuw.ac.nz } \\
\text { Ph: }+6444639590\end{array}$ \\
\hline \multicolumn{2}{|l|}{$\begin{array}{l}\text { Azizah Binti Mohd Zahidi } \\
\text { No 9, Jalan23/E, Pandamaran Jaya, } \\
4200 \text { Pelabuhan Kelang, Selangor, } \\
\text { Malaysia }\end{array}$} \\
\hline $\begin{array}{l}\text { Email: azizah.zahidi@vuw.ac.nz } \\
\text { Ph: +603 31672367(home) +603 } 01\end{array}$ & 23 \\
\hline
\end{tabular}

Thank you for taking the time to read this information sheet and thinking about the participation of students and teachers of the language courses offered by your department in this research. The information gained from this research may provide information to language teachers in developing intervention program for language learners to equip them with self-regulation strategies for them to be strategic and effective learners. If you agree for me to conduct this research at the language classrooms, please complete and return the attached consent form using the enclosed envelope.

I am looking forward to your reply.

Yours Sincerely,

Azizah Binti Mohd Zahidi 
Title of project:

Self-regulation of Malaysian English language learners at the tertiary level.

\section{HEAD OF DEPARTMENT'S CONSENT}

Please tick (/) each box

I give consent for Azizah Binti Mohd Zahidi, PhD student at Victoria University of Wellington, to invite students and teachers at

in her research project. (name of language department) to participate

I have been given the information about this project and I understand the explanation of this research project.

I understand that students and teachers will be individually approached for their informed consent.

I agree to the participation of the teachers and language learners in this research under the conditions set out in the information sheet.

I have had the opportunity to ask questions and have them answered to my satisfaction.

I understand that information will not be used for any purpose other than what consent is given for.

I am assured that any information given will be treated with respect and confidentiality, and that the university, the course and the participants will not be identified in reports or publications

Signature:

Name:

Name of Department:

Date:

I would like to receive a summary of the research findings: YES / NO Please send the summary to the following address (please write address below). 


\section{Appendix E: Description of language course}

\section{ZZZE1012 Academic Communication}

\section{Course Synopsis}

The course is designed for students who have passed MUET with either Band 3 or 4 as well as students who have completed the ZZZE1002 Foundation English course. It equips students with the language skills necessary to function effectively in academic settings. The course adopts a student-centered approach with emphasis on reading and speaking.

\section{Course Outcomes}

At the end of the course, students should be able to:

- Apply basic reading skills in academic environment

- Participate effectively in group discussions

- Give an effective presentation

- Write a short paper

\section{Course materials}

Textbook

Philpot, S and Curnick, L. 2007. Academic Skills: Reading, Writing and Study Skills Level 3. New York: Oxford

\section{Course Evaluation}

\begin{tabular}{|c|l|c|c|}
\hline No. & Evaluation Component & Weighting (\%) & Week \\
\hline 1. & Information sharing & $\mathbf{1 5}$ & $\mathbf{7}$ \\
\hline 2. & $\quad$ Project & $\mathbf{4 0}$ & \\
& $\bullet \quad$ Conferencing & 5 & \\
& $\bullet \quad$ Outline & 5 & \\
& $\bullet \quad$ Project paper & 10 & 14 \\
\hline 3. & Class participation & 20 & $1-14$ \\
\hline 4. & Final examination & $\mathbf{4 0}$ & $\mathbf{1 5 / 1 6}$ \\
\hline
\end{tabular}




\section{Description of Evaluation Components}

\section{Information Sharing (15\%)}

\section{Goal}

To share and exchange views on information and issues related to general or academic topics.

\section{Objectives}

Students will able to:

Read widely on current issues related to general and academic topics

Expand their vocabulary and general knowledge

Recognize main ideas and important details

Express opinions on general or academic topics

\section{Procedure}

1. Each student finds an article of between $600-800$ words on current issues from newspaper, magazines or internet.

2. Students show the article to the instructor for approval. The instructor will check in terms of content and length of the article. The article should contain an issue which can be discussed and not factual information which have been generally accepted.

3. During presentation, in groups of 4 or 5 students, each student identifies and presents main ideas and important details of the article. Students also give his/her own comments or reaction on the article. Instructor determines the members of each group on the evaluation day.

4. After a student has presented his/her article (in about 3 minutes), other students in the group give their reaction to the article presented by giving their views and/or asking questions (in about 4 minutes).

5. The Information Sharing session should consist of 3 parts-Opening (greeting, topic preview), Discussion (overview of article, questions and comments) and Ending (summary of discussion).

6. Step 4 is repeated until all the group members have presented their articles and their opinions.

7. Marks will be awarded at the end of the group's presentation based on the student's overall participation. Each person's presentation should end in 
about 7 minutes. Students should be reminded about this as they may get carried away during the discussion especially is they are discussing a hot issue.

\section{Project (40\%)}

\section{Goal}

To do a comparative study on general or academic topics

\section{Objectives}

Student will be able to:

Read general articles as well as academic texts

Expand their vocabulary and knowledge

Use the language of comparison

Produce a short project paper

Present their study in the form of a sketch

\section{Procedure}

1. In groups of 4, students select two 'things' (methods/techniques /ways/types/brands) to be compared.

2. Students should get instructor's approval (during Conference 1) before they can proceed with their project. They need to study and compare both of them, and then choose which one they prefer by giving their justification. The comparison made should be put in context (i.e. the comparison is made in order to achieve a purpose).

3. Students should have at least 4 criteria for comparison. The criteria can be as follows: cost, equipment used, convenience, effectiveness, etc.

4. For information regarding their project, students should find at least 3 articles from 3 different sources-newspaper, magazine, journal, book, encyclopaedia, and online sources, as well as expert interview.

5. Students prepare an outline which includes notes, and a table of comparison made, together with at least three articles during Conference 2. Instructor checks the outline and gives comments. 
6. Based on the outline, students write a project paper of about 1000 words. The paper should follow the following format:

Introduction- A brief introduction to the topic i.e. background information about the topic including the purpose of comparing the two 'things'.

Discussion/Body-Elaboration/Details of each of the criteria of comparison. Proper headings and sub-headings should be used. Diagrams can also be included to aid explanation.

Conclusion - The summary of the comparison which include the justification of their choice.

7. Students present the findings of their study in a form of a sketch. The sketch to be held in Week 14, should be about 20 minutes long. Students discuss their ideas for sketch with instructor in Conference 3.

\section{Class Participation (5\%)}

\section{Goal}

To ensure students' participation in class activities and regular class attendance

\section{Procedure}

1. Instructor makes sure that students sign the attendance sheet every time they come to class. Failure to attend classes regularly $(<70 \%)$ will result in students being barred from sitting for the Final Exam.

2. Students should also be encouraged to actively participate in class activities as marks will be awarded for participation.

\section{Final Exam (40\%)}

The exam, scheduled in week 15 or 16, is 2 hours long. The format of the exam is as follows:

Section A; Vocabulary

Section B; Reference

Section C: Comprehension 


\section{Appendix F: Description of research instruments}

\section{1) Learner's diary}

The impact of the research on the participants' use of SRL is discussed within the thesis.

\section{Guidelines and suggestions for diary entry}

Here are some suggestions on how to approach the writing of your diary:

- There is no stipulated length for each entry, but aim to make each one at least five sentences long. Write anything and everything you feel about your language learning.

- Make entries on a regular basis. Spend about five minutes each day to record anything related to your classroom (an activity which you participate in, a understanding of a rule, etc.) or out of class (college activity, language camp, a reaction to a news item, film, song) language learning.

- Support your insights with examples.

- Start by doing your autobiography as a language learner-your first exposure to English language, your learning experience, teachers, etc.

- If you are unable to write something each day, try to write at least twice a week.

- Write in English or in Bahasa Melayu (the national language), whichever language feels more comfortable to express your thoughts at the time.

- Do not worry about the mechanics of your writing, punctuation etc.

- If you feel at a loss about what to write at anytime, here are some areas that you might explore:

1. Teaching or learning activities in the classroom and your feelings about these activities.

2. Your own English learning activities after class, and your purposes and feelings about the activities:

3. You may also answer the questions listed below:

- Do you feel that English is a difficult language to learn?

- How can you describe yourself as a good language learner?

- How English language is best learned?

- How do successful English language learners become masters of their own learning process?

- How do learner characteristics such as motivation and learner behaviour such as self-regulation, strategy use, metacognition, or autonomy relate to effective language learning?

- How do you use self-regulation to manage aspects of the learning situation such as teaching and learning method, error correction, or task, in order to effectively reach learning goals such as expanding grammatical knowledge and functional competence, and developing your listening, speaking, reading, and writing skills?

4. Reflections on the problems and progress in your learning process. 


\section{2) Interview protocol (Student)}

Participant Code:

Date:

Time In:
Location:

Time Out:

\section{Questions \\ Initial Interview \\ 1. Questions on background information (age, faculty, year of study, past language learning experiences, and opinion of language learning experiences at the university for the previous and current semester)? \\ Possible probe questions for past language learning experiences: \\ - When you were in secondary school, how were you taught the English language? Explain some of the methods that your teachers used to teach you? \\ - How did you like the manner in which English was taught to you when you were in secondary school? \\ - What did you like? What did you not like?}

Comments

2. Why is learning English important to you?

Probe: current studies? Future workplace, entertainment?

- How much do you like using English?

- Explain how do you feel about using English in your everyday conversation?

3. Tell me about your strengths and weaknesses in learning and using English language.

4. How do you view your responsibilities in the learning process?

5. Indicate what you like to be able to do when you complete your language course this semester and how long you think it will take you to reach these goals?

Probe: What is/are your goal/s in language learning? Why did you set this/these goals? Do you believe that you will be able to learn the materials in the course? Specific steps that you will take to accomplish this goal/Possible blocks, both external and personal, to accomplishing this goal? How will you overcome them? Do you expect to do well in this language course?

\section{Follow-up Interview}

\section{Questions on SRL}

What initiatives do you take to help yourself in your language learning?

\section{Monitoring}

- When someone corrects you (such as your pronunciation, grammar, sentence structure, vocabulary usage), do you attempt to understand why you made a mistake?

- Do you keep track of errors that you usually make, look for a pattern, and decide how to correct the ones that form a pattern?

- In learning English language, do you note when something is unclear, ambiguous, or not known to you, and then do you formulate a plan for resolving these problems?

\section{Seeking information}

- How do you get additional information to complete your language learning tasks?

Apart from the English lessons, what sources do you draw on to learn English? 


\author{
Seeking assistance \\ - Do you ask your teacher, more advanced students or others for help when you do not \\ understand?
}

\title{
Evaluating
}

- Do you think it is important to evaluate your own progress in learning English? How do you evaluate your progress?

- $\quad$ Do you keep track of the way you have learned something and whether it is helpful? If you find it is not, do you look for other ways to learn the material?

\section{Goal setting and planning}

- Do you clearly determine how you are going to organize your studying?

- Do you learn best when you have control of your learning, such as determining what, when, and how you will learn? Do you monitor your progress?

- Do you set specific goals for yourself each time you sit down to study? How confident are you that you will accomplish the goal?

- How do you prepare for the course assessments?

\section{Self-consequences}

- Do you reward yourself for any goal achievement in language learning? How?

\section{Environmental structuring}

- Do you think learning environment matters? How do you manage your learning environment?

\section{Questions on Strategies to Learn Specific Language Skills}

\section{Grammar}

- When you learn grammar, do you look for a pattern or rule to what you already know about this particular structure?

- In learning grammar, do you use your knowledge of your own and other foreign languages to try to make sense of English language?

\section{Vocabulary}

- Do you try to remember words by using them in context, such as in a conversation or in writing?

- Do you associate new words with those you already know?

- Do you review vocabulary you studied earlier?

\section{Speaking}

- When you don't know how to say something in English language, do you try to say it another way?

- When you don't know how to say something in English language, do you ask your conversation partner for help?

- Do you take every opportunity to practise speaking with other speakers of English language?

\section{Listening}

- Do you try to guess if you don't fully understand what is being said?

- When you don't understand, do you pinpoint for your conversation partner what exactly you did not understand?

\section{Reading}

- Do you rely on words that look similar to words in your native or any other language you know to figure out the meaning of unfamiliar words in the text?

- Do you consider the context when you look up unfamiliar words in a dictionary?

- Do you ask yourself questions in order to monitor your understanding of the text?

- Do you use contextual clues (title, illustrations, layout, etc.) in order to figure out what the text is about?

\section{Writing}

- Do you develop an outline before you start writing?

- Do you write a draft first and review it before turning in the final version? 


\section{Final Interview}

Participant Code:

Location:

Date:

Time In:

Time Out:

1. In what way do you feel that the English course you are attending is helping you improve in learning English? Explain. In what way could your English classes be improved? What sort of relationship do you have with your course mates and language teacher? Describe a lesson you have enjoyed. Describe a lesson you have not enjoyed.

2. Think back to a challenging/difficult English lesson/learning task you have completed. Could you describe this lesson/ learning task and why was it challenging/difficult? How did you feel in this situation? How did you tackle/address this challenge? What were the strategies that you used to facilitate your language learning?

3. Tell me about your language learning goals. How did you go about achieving them? What difficulties or barriers have you met as you work towards your goals? How have you addressed them? How satisfied are you with your goal accomplishment? Reasons for accomplishing or not accomplishing the goal?

4. How did you prepare for an assessment (test, quiz, final exam, project presentation)? Comment on your performance and progress in the on-going class assessments.

5. When you were in the process of completing a learning task, how did you keep focused?

6. You are toward the end of your English course. What do you feel about your performance in the course as a whole? 


\section{3) Observation instrument}

Participant Code:

Observation Date:

Beginning Time:
Location/Class:

Activity:

Ending Time:

\begin{tabular}{|l|l|}
\hline \multicolumn{2}{|l|}{ Setting of the Observation site/classroom setting : } \\
\hline $\begin{array}{l}\text { Purpose: To observe the participant's behaviour that might be related to self-regulated learning } \\
\text { to perform language learning tasks. }\end{array}$ & \\
\hline $\begin{array}{l}\text { DESCRIPTION OF ACTIVITIES } \\
\text { AND OBSERVATION NOTES }\end{array}$ & \\
\hline FOR FOLLOW UP INTERVIEWS \\
\hline
\end{tabular}




\section{Appendix G: Summary of Participants' Personal Background}

\begin{tabular}{|c|c|c|c|c|c|c|c|}
\hline $\begin{array}{c}\text { Name/ } \\
\text { Language } \\
\text { performance }\end{array}$ & $\begin{array}{c}\text { Sex/Age/ } \\
\text { Race } \\
\text { /First } \\
\text { language }\end{array}$ & Faculty/Major & $\begin{array}{l}\text { SPM/MCE } \\
\text { English } \\
\text { grade }\end{array}$ & $\begin{array}{c}\text { English } \\
\text { band } \\
\text { for } \\
\text { MUET }\end{array}$ & $\begin{array}{c}\text { English } \\
\text { Foundation } \\
\text { Course/Final } \\
\text { course grade }\end{array}$ & Hometown & Hobbies \\
\hline $\begin{array}{l}\text { Sepatu } \\
\text { Chenta/ }\end{array}$ & $\begin{array}{l}\text { Male/19/ } \\
\text { Malay/ } \\
\text { Bahasa } \\
\text { Melayu }\end{array}$ & $\begin{array}{l}\text { Economics and } \\
\text { Business/ } \\
\text { International } \\
\text { Business } \\
\text { Studies }\end{array}$ & $\mathrm{A} 2$ & 3 & $\begin{array}{c}\mathrm{X} \\
\mathrm{B}+\end{array}$ & RURAL & $\begin{array}{l}\text { Surfing } \\
\text { internet and } \\
\text { playing } \\
\text { football }\end{array}$ \\
\hline Unblocker/ & $\begin{array}{l}\text { Male/20/ } \\
\text { Malay/ } \\
\text { Bahasa } \\
\text { Melayu }\end{array}$ & $\begin{array}{l}\text { Economics and } \\
\text { Business/ } \\
\text { Finance and } \\
\text { Banking }\end{array}$ & B3 & 3 & $\begin{array}{l}\mathrm{X} \\
\mathrm{B}-\end{array}$ & RURAL & $\begin{array}{l}\text { Drawing and } \\
\text { reading }\end{array}$ \\
\hline $\begin{array}{l}\text { Ares Mark } \\
\text { III/ }\end{array}$ & $\begin{array}{l}\text { Male/20/ } \\
\text { Malay/ } \\
\text { Bahasa } \\
\text { Melayu }\end{array}$ & $\begin{array}{l}\text { Economics and } \\
\text { Business/ } \\
\text { Business } \\
\text { Management }\end{array}$ & A1 & 3 & $\begin{array}{l}\mathrm{X} \\
\mathrm{B}\end{array}$ & URBAN & $\begin{array}{l}\text { Photography } \\
\text { and } \\
\text { blogging }\end{array}$ \\
\hline Rae/ & $\begin{array}{l}\text { Female/ } \\
\text { Chinese/ } \\
\text { Mandarin }\end{array}$ & $\begin{array}{l}\text { Economics and } \\
\text { Business/ } \\
\text { Economic } \\
\text { Monetary \& } \\
\text { Fiscal }\end{array}$ & A1 & 4 & $\begin{array}{l}\mathrm{X} \\
\mathrm{C}\end{array}$ & RURAL & $\begin{array}{l}\text { Reading and } \\
\text { listening to } \\
\text { music }\end{array}$ \\
\hline $\begin{array}{l}\text { Stanza } \\
\text { Nurmalam/ }\end{array}$ & $\begin{array}{l}\text { Female/25 } \\
\text { Malay/ } \\
\text { Bahasa } \\
\text { Melayu }\end{array}$ & $\begin{array}{l}\text { Islamic } \\
\text { Studies/ } \\
\text { Department of } \\
\text { Al-Quran and } \\
\text { Sunnah }\end{array}$ & C6 & 2 & $\begin{array}{l}\sqrt{ } \\
B\end{array}$ & RURAL & $\begin{array}{l}\text { Reading } \\
\text { novel }\end{array}$ \\
\hline $\begin{array}{l}\text { Confidence } \\
\text { Hero/ }\end{array}$ & $\begin{array}{l}\text { Male/20/ } \\
\text { Malay/ } \\
\text { Bahasa } \\
\text { Melayu }\end{array}$ & $\begin{array}{l}\text { Economics and } \\
\text { Business/ } \\
\text { Human } \\
\text { Resource } \\
\text { Management }\end{array}$ & A1 & 3 & $\begin{array}{l}\mathrm{X} \\
\mathrm{A}-\end{array}$ & URBAN & Travelling \\
\hline
\end{tabular}

